\title{
PERSPECTIVES FOR FOREST AND CONSERVATION MANAGEMENT IN RIPARIAN FORESTS
}

1,1 

PERSPECTIVES

FOR FOREST AND

CONSERVATION

MANAGEMENT IN

RIPARIAN FORESTS

Ljubljana, 2021 


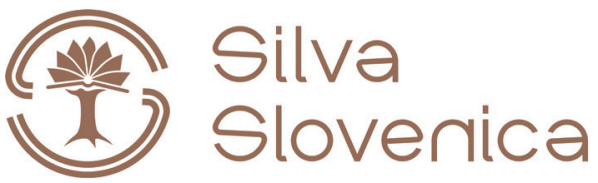

Studia Forestalia Slovenica, 169

ISSN 0353-6025

ISBN 978-961-6993-62-3

Publisher: Slovenian Forestry Institute, Silva Slovenica publishing centre, Ljubljana 2021

Title: Perspectives for forest and conservation management in riparian forests

Editors: Markus Sallmannshofer, Silvio Schüler, Marjana Westergren

Technical editors: Silvija Krajter Ostoić, Peter Železnik

Language editor: Ad Litteram, Croatia

Design and print: Klinger d.o.o.

Edition: $1^{\text {st }}$ edition

Price: Free

Circulation: 300

Electronic issue: http://dx.doi.org/10.20315/SFS.169

Funding: Resilient riparian forests as ecological corridors in the Mura-Drava-Danube Biosphere Reserve (DTP2-044-2.3 - REFOCuS). The project was co-funded by European Union funds (ERDF, IPA).

Acknowledgement: We would like to acknowledge the project Celebrating Biodiversity Governance (BIOGOV PGI04824) for guidance on participatory approaches used to draft this book.

Disclaimer: The contents and views presented in this handbook are the sole responsibility of the authors and not of the Interreg Danube Transnational Programme or European Commission.

\section{(ㅇ) (1) $(8)$}

Perspectives for forest and conservation management in riparian forests is licensed under a Creative Commons Attribution 4.0 International License.

CIP - Kataložni zapis o publikaciji

Narodna in univerzitetna knjižnica, Ljubljana

$630 * 26(035)$

PERSPECTIVES for forest and conservation management in riparian forests / [editors Marcus Sallmannshofer, Silvio Schüler, Marjana Westergren]. - 1st ed. - Ljubljana: Slovenian Forestry Institute, Silva Slovenica Publishing Centre, 2021. - (Studia Forestalia Slovenica, ISSN 0353-6025; 169)

ISBN 978-961-6993-62-3

COBISS.SI-ID 55651843 


\section{AUTHORS}

\section{Kerstin Böck ${ }^{9}$}

Gregor Božič ${ }^{2}$

Thomas L. Cech ${ }^{1}$

Debojyoti Chakraborty ${ }^{1}$

György Csóka ${ }^{7}$

Maarten de Groot ${ }^{2}$

László Demeter ${ }^{8}$

Andreas Fera ${ }^{4}$

Thomas Geburek ${ }^{1}$

Gernot Hoch $^{1}$

Thomas Kirisits ${ }^{4}$

Alen Kiš ${ }^{6}$

András Koltay ${ }^{1}$

Heino Konrad ${ }^{1}$

Marko Kovač

Gyula Kovács $^{7}$

Silvija Krajter Ostoić ${ }^{3}$

Katharina Lapin ${ }^{1}$

Aleksander Marinšek ${ }^{2}$

László Nagy $^{7}$

Janine Oettel $^{1}$

Nikica Ogris ${ }^{2}$

Predrag Pap ${ }^{5}$

Werner Ruhm ${ }^{1}$

Markus Sallmannshofer ${ }^{1}$

Hannes Schönauer ${ }^{1}$

Silvio Schüler ${ }^{1}$

Katharina Schwanda ${ }^{1}$

Srdjan Stojnićs

Imola Tenorio-Baigorria ${ }^{7}$

Gregor M. Unger ${ }^{1}$

Viktoria Valenta ${ }^{1}$

Marjana Westergren ${ }^{2}$

Mirjana Zavodja ${ }^{5}$

Milica Zlatkovićs

${ }^{1}$ Austrian Research Centre for Forests BFW, Austria

${ }^{2}$ Slovenian Forestry Institute, Slovenia

${ }^{3}$ Croatian Forest Research Institute, Croatia

${ }^{4}$ Institute of Forest Entomology, Forest Pathology and Forest Protection, Department of Forest- and Soil Sciences, University of Natural Resources and Life Sciences, Austria

${ }^{5}$ Institute of Lowland Forestry and Environment, University of Novi Sad, Serbia

${ }^{6}$ Institute for Nature Conservation of Vojvodina Province, Srbija

${ }^{7}$ University of Sopron, Forest Research Institute, Hungary

${ }^{8}$ Institute of Ecology and Botany, Centre for Ecological Research, Hungary

${ }^{9}$ WWF Austria, Austria 


\section{CONTRIBUTORS}

\section{Lajos Gyergyák ${ }^{1}$}

Zoltán Puskás ${ }^{2}$

Herbert Tiefenbacher ${ }^{3}$

${ }^{1}$ Zalaerdő PLtd., Hungary

${ }^{2}$ SEFAG Forest Management and Wood Industry Share Co., Hungary

${ }^{3}$ Forest Estate Grafenegg, Austria

\section{GRAPHIC MATERIAL}

Markus Sallmannshofer, all figures except:

Gregor Božič (Figures 3.1.1-1, 3.1.1-3 a, b, 3.1.3-2, Coverpage 3.3.2)

Thomas Cech (Figures 3.3.1-3, 3.3.3-2, 3.3.3-3, 3.3.6-1, 3.3.6-2)

Jim Connel (Figure 3.3.3-1)

György Csóka (Figure 3.3.1-1)

László Demeter (Figure 3.2.5-2)

Andreja Ferreira (Figure 2.2-1)

Zoran Galić, (Figure 1.3-1)

Gernot Hoch (Figure 3.3.1-1)

Dušan Jurc (Figure 3.3.2-3)

András Koltay (Figures 3.3.2-1, 3.3.2-5, 3.3.2-7)

Aleksander Marinšek (Figures 3.1.1-2, 3.1.1-3 c)

Predrag Pap (Figure 3.3.2-4)

Janine Oettel (Figures 3.2.7-1, 3.2.7-2)

Leopold Poljaković-Pajnik (Coverpage 2.5, Figure 3.3.1-2)

Werner Ruhm (Figures 3.2.2-3, 3.2.6-2)

Gerald Schnabel (Figures 2.3-1, 2.3-2, 3.1.5-1, 3.1.5-2, 3.2.2.-4)

Katharina Schwanda (Figures 3.2.5-7, 3.3.4-1, 3.3.4-2)

Thomas Thalmayr (Figure 3.3.5-1)

Gregor M. Unger (Figures 3.3.5-2, 3.3.5-3)

Viktoria Valenta (Infographics in chapter 4)

Mirjana Zavodja (Figure 1.3-2)

Milica Zlatković (Figures 3.3.2-2, 3.3.2-6, 3.3.2-7) 


\section{CONTENTS}

1. INTRODUCTION . . . . . . . . . . . . . . . .7

1.1 Scope of the handbook, target groups and preparation process . . . . . . . . . . . 7

1.2 About the REFOCuS project and the

Mura-Drava-Danube Biosphere Reserve . . . . . . . . . .8

1.3 Case study: Stakeholder perspectives on riparian forest management and conservation in the Mura-Drava-Danube Biosphere Reserve . . . . . . . . . . . . . . . 10

2. RIPARIAN FORESTS. . . . . . . . . . . . . . . . . 17

2.1 Importance of and threats to riparian forests . . . . . . 17

2.2 Managing riparian forest ecosystems . . . . . . . . . . 22

2.3 Structure and ecology of a riverine floodplain

landscape . . . . . . . . . . . . . . . . 26 . . . . . . . . . .

2.4 Forest habitat types. . . . . . . . . . . . . . . 31

2.5 Common forest management forms in riparian forests 36

\section{MANAGEMENT GUIDELINES FOR RIPARIAN}

FORESTS . . . . . . . . . . . . . . . . . . . . 39

3.1 Forest regeneration and genetics . . . . . . . . . . 39

3.1.1 Choosing natural or artificial regeneration. . . . . 39

3.1.2 Supporting adaptation of forests by selecting

suitable forest reproductive material . . . . . . . . . . 49

3.1.3 Genetic conservation for practitioners . . . . . . 55

3.1.4 Regeneration of pedunculate oak stands:

natural and with direct sowing. . . . . . . . . . . 60

3.1.5 Supplemental enrichment, restoration and

establishment of oak stands via artificial regeneration .66

3.2 Forest and conservation management . . . . . . . 71

3.2.1 Biodiversity and Conservation management goals. . . . . . . . . . . . . . 71

3.2.2 Optimization of the production of high-quality logs in hardwood stands . . . . . . . . . . . .80

3.2.3 Challenges of climate change . . . . . . . . . 86

3.2.4 How to manage game and protect forests

from damage. . . . . . . . . . . . . . . . .990 
3.2.5 Management of non-native plants . . . . . . . .997

3.2.6 Integrating biodiversity enrichment in

poplar forest management . . . . . . . . . . . 106

3.2.7 Integration of deadwood portions into regular management . . . . . . . . . . . 111

3.3 Forest health . . . . . . . . . . . . . . . . 116

3.3.1 Forest pests and diseases in a changing world:

the importance of early detection. . . . . . . . . . 116

3.3.2 Diseases of poplars and their hybrids with an emphasis on disease management recommendations 126 3.3.3 Oak decline - an example for a disease phenomenon characterized by various interacting causal agents. . . . . . . . . . . . . . . . 134 3.3.4 Ash dieback as a major threat to riparian forest biodiversity . . . . . . . . . . . . . . . . . 139 3.3.5 Ash in distress: conservation and resistance breeding programme for Fraxinus excelsior in Austria. . . . . . . . . . . . . . . . . . . 146 3.3.6 Measures against the spread of Phytophthora in riparian forests . . . . . . . . . . . . 152

4. APPENDIX . . . . . . . . . . . . . . . 157

4.1 Tree species occurrence and seed transfer . . . . . . 157 4.1.1 Species occurrence probability under climate change . . . . . . . . . . . 157 4.1.2. Seed transfer zones and their predicted spatial change over time . . . . . . . . 157

4.2 Tree species portraits . . . . . . . . . . . . . . . . . . . . . . . . . . . . . . . .

4.2.1 Autochthonous tree species. . . . . . . . . . . 159

4.2.2 Alternative tree species and clones. . . . . . . . 170 4.3 Glossary . . . . . . . . . . . . . . . . . . . 173

4.4 References by chapters . . . . . . . . . . . . 175 


\section{INTRODUCTION}

Markus Sallmannshofer, Silvio Schüler, Marjana Westergren

\subsection{Scope of the handbook, target groups and preparation process}

Riparian forests are among the most threatened terrestrial ecosystems. However, they are rich in biodiversity and have the potential to contribute to the development of local communities. They provide multiple ecosystem services, including habitat for wildlife and unique animal and plant communities, wood and non-wood forest products, recreational areas for residents and a growing number of tourists, carbon sequestration, and more. Due to their extension along major rivers, many riparian forests are valuable ecological corridors for endangered fauna. With so many interests associated with the same area, developing forest management and biodiversity conservation options is necessary for riparian forest sustainability.

The purpose of this handbook is to provide forest and conservation managers at Mura-Drava-Danube Biosphere Reserve and beyond with a guide to manage riparian forests. The handbook covers topics such as a general description of riparian forests and their habitat types, best practices for forest regeneration, genetics, forest and conservation management, and forest health. It is aimed at foresters and conservation practitioners, but also includes sections that may be of interest to non-governmental organisations, citizen initiatives, nurseries and policy makers.

The participatory process to produce the handbook was initiated in 2018 with a workshop in Slovenia. Here, the different perspectives of foresters, conservation managers, forest nurseries and hunters were discussed. The workshop was attended by 37 stakeholders from public administration, small and medium enterprises, non-governmental organisations and research institutions from Austria, Croatia, Hungary, Serbia and Slovenia. The discussion resulted in a common list of relevant topics on riparian forests, which served as a template for the further development of this handbook. Throughout the REFOCuS project, solutions to the issues posed by these topics were found through various activities and deliverables. These solutions were compiled into a handbook outline and discussed again with stakeholders in an online workshop in 2020. Finally, the chapters of the handbook were finalised jointly by project 
partners, stakeholders, public administration, small and medium enterprises, and non-governmental organisations. The outcome of the process is a handbook on perspectives for forest and conservation management of riparian forests, available in six languages (English, Croatian, German, Hungarian, Serbian and Slovenian). The handbook was developed with Mura-DravaDanube Biosphere Reserve in mind, but the topics covered in the handbook are universal to today's riparian forests, giving the handbook a much wider geographical scope.

\subsection{About the REFOCuS project and the Mura-Drava- Danube Biosphere Reserve}

The project 'Resilient riparian forests as ecological corridors in the Mura-Drava-Danube Biosphere Reserve - REFOCuS' is part of the Interreg Danube Transnational Programme under the priority 'Environment and culture responsible Danube region'. The project is dedicated to measures that promote the conservation and management of riparian forests in the biosphere reserve and beyond. Academic, forestry and nature conservation organisations and national authorities from five countries: Austria, Croatia, Hungary, Serbia and Slovenia, which share parts of the Mura-Drava-Danube Biosphere Reserve, have joined forces to address issues of sustainable forest management, conservation and use of forest genetic resources and the health of increasingly threatened riparian forests. Learn more about the REFOCuS project and its results at http://www.interreg-danube.eu/refocus.

The partners of the project are: Slovenian Forestry Institute, which coordinates the project, the Austrian Research Centre for Forests BFW, the Croatian Forest Research Institute, the University of Sopron from Hungary and the University of Novi Sad, Institute of Lowland Forestry and Environment from Serbia. Five associated partners support the core project team in its work: the Ministry of Agriculture, Forestry and Food and the Slovenian State Forests d.o.o., Unit Murska Sobota from Slovenia, Amt der Steiermärkischen Landesregierung, Baubezirksleitung Südoststeiermark from Austria, Public Institution for Management of Protected Natural Areas in the Koprivnica Križevci County from Croatia, the Ministry of Agriculture and Environmental Protection, Directorate of Forests from Serbia and Mecsek Forestry Co. Ltd. from Hungary. 


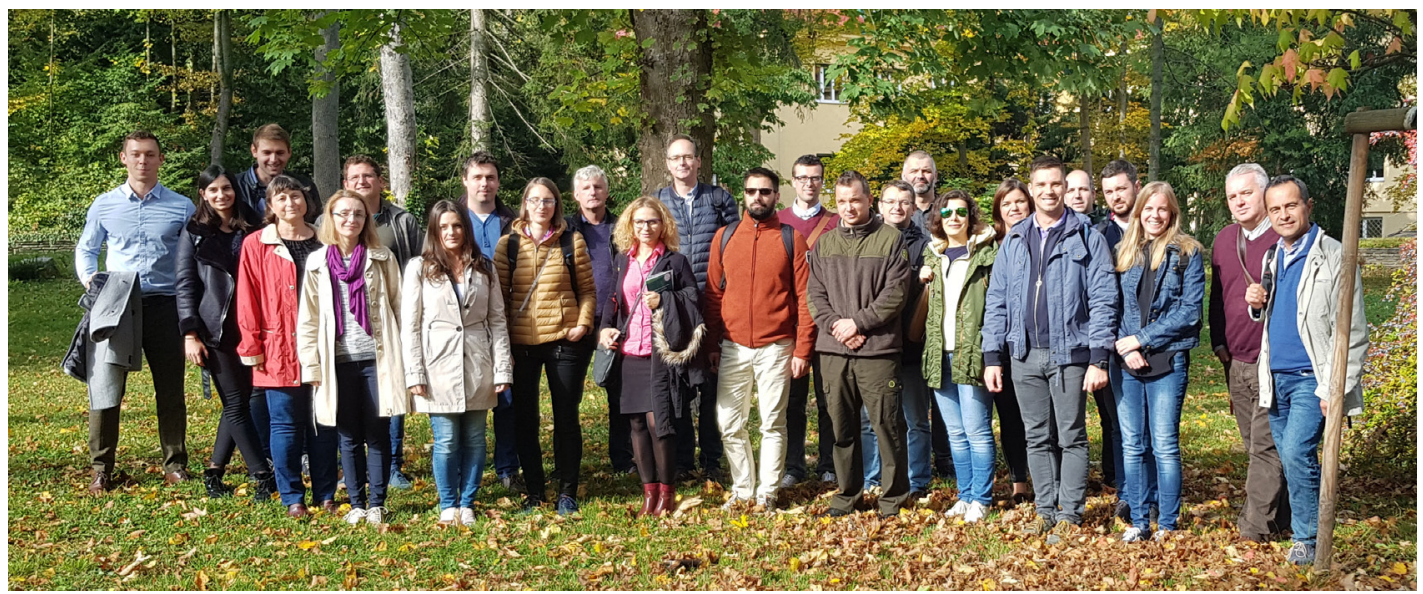

Figure 1.2-1: The project team, with many of the authors of the chapters included in this handbook

The future Mura-Drava-Danube Biosphere Reserve covers an area of about $8,300 \mathrm{~km}^{2}$, being the largest protected river basin in Europe. Within the coming years it will become the first five-country (Austria, Slovenia, Hungary, Croatia, and Serbia) UNESCO-Biosphere reserve in the world. The new biosphere reserve is rich in biodiversity and harbours high ecological and cultural diversity and heritage. Therefore, it attracts the interests of manifold stakeholders and interest groups. Forests cover an area of $2,250 \mathrm{~km}^{2}$, which is $27 \%$ of the total reserve area and $61 \%$ of its core zone. They provide multiple ecosystem services including habitats for wildlife and a unique biodiversity, wood and non-wood forest products, recreation areas for residents and a growing number of tourists, carbon sequestration and many more.

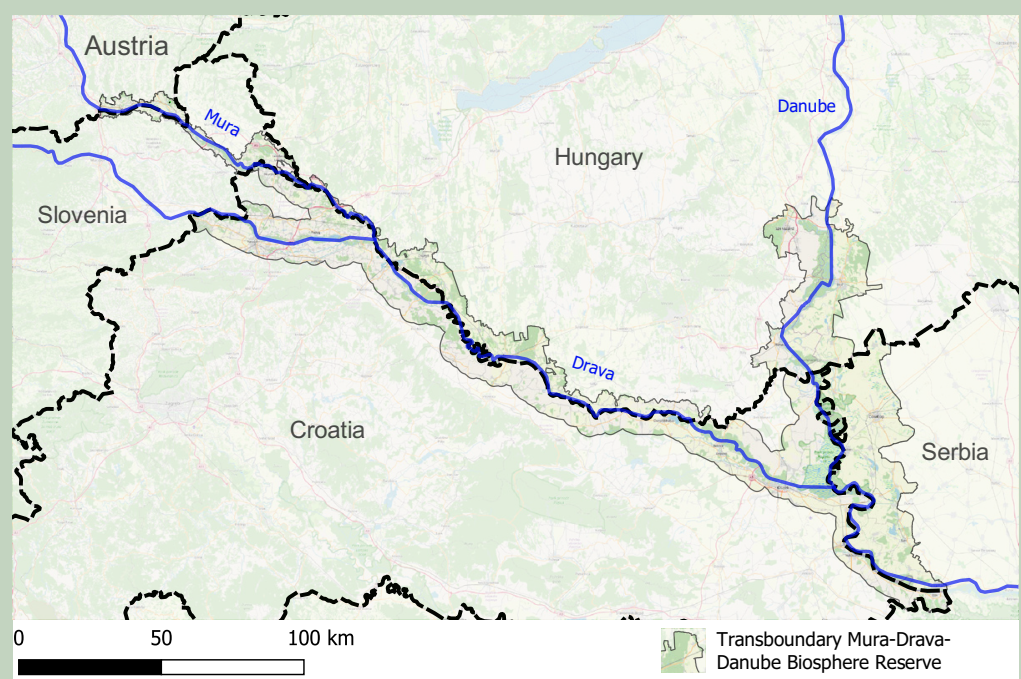

Figure 1.2-2: Map of the Mura-Drava-Danube Biosphere Reserve 
1.3 Case study: Stakeholder perspectives on riparian forest management and conservation in the Mura-DravaDanube Biosphere Reserve

Srdjan Stojnić, Silvija Krajter Ostoić, Mirjana Zavodja

The REFOCUS project involved stakeholders from the beginning and facilitated the exchange between science and practice through stakeholder workshops. The outcomes from two of these stakeholder workshops are summarized in this chapter. Both workshops involved participants from across the Mura-Drava-Danube Biosphere Reserve and included the groups of conservationists, forest managers, (forest owners), forest scientists, residents and farmers, hereafter referred to simply as the stakeholders.

\section{Forest-related policies}

The UNESCO Biosphere Reserves, including the MuraDrava-Danube Biosphere Reserve, should evolve as models of sustainability that incorporate land use and conservation. National Biosphere Reserve management organisations should further develop national management plans to advance this goal. Existing forest-related policies provide a framework for riparian forest conservation and management activities. This mosaic of often difficult policies usually creates confusion in interpretation and implementation. As a result, conflicts can arise among stakeholders. Nevertheless, forests are recognised in their importance by all stakeholders involved (Table 1.3-1).

Table 1.3-1: Common features of the Mura-Drava-Danube Biosphere Reserve (MDD BR) observed through the prism of policies, legal acts and regulations

\begin{tabular}{|c|c|c|c|}
\hline Country & $\begin{array}{c}\text { Absence } \\
\text { of specific } \\
\text { regulation } \\
\text { related to } \\
\text { (forests of }) \\
\text { MDD BR }\end{array}$ & $\begin{array}{c}\text { Marginal role } \\
\text { of MDD BR } \\
\text { (forests) }\end{array}$ & $\begin{array}{c}\text { MDD BR } \\
\text { forests } \\
\text { reserve as an } \\
\text { inter-sectoral } \\
\text { spot }\end{array}$ \\
\hline Austria & ++ & ++ & ++ \\
\hline Croatia & ++ & ++ & ++ \\
\hline Hungary & ++ & + & ++ \\
\hline Slovenia & ++ & + & ++ \\
\hline Serbia & ++ & ++ \\
\hline
\end{tabular}




\section{Conflicting interests of stakeholders}

When discussing the priority objectives of forest management, stakeholders in different sectors have different attitudes. For example, for the forestry sector, wood production (market orientation) was perceived as the priority objective, which often conflicts with the conservation sectors' priority, which is oriented towards nature conservation. This is particularly true in densely populated agricultural landscapes adjacent to areas of high biodiversity, such as riparian forests in the Mura-DravaDanube Biosphere Reserve. We will illustrate this conflict with the example of Koviljsko-Petrovaradinski Rit, which is located in the province of Vojvodina in Serbia (Fig. 1.3-1).

Forest users in the area are categorized as forest owners (state/ province and private), forestry employees, companies/ institutions and citizens. The analysis of stakeholders' (forest users') interests showed two conflicting zones (Fig. 3.4-2). The first conflicting interest zone is identified between very strong forest users' interests in forest utilization, expressed by forest owners and forest management companies, whose main goal is profitable wood harvesting, and the interest field consisting of very strong and strong user interests in nature conservation, represented by companies / institutions and citizens. The second conflicting interest zone reveals an internal conflict of the public enterprise Vojvodinašume, as a state-owned forest management company in charge of managing forests in Vojvodina province, having a very strong interest in profitable wood production on the one hand and in nature conservation on the other. To harmonise these conflicting interests, as required by the legal framework, the enterprise is having an advantage of being in the position to look for a solution internally. The current shares of protection zones (strict protection 6\%, active protection $29 \%$ and profitable use of wood $65 \%$ ) reflect the actual compromise package between the owners and the interests of remaining users. That solution will last as long as the province is in the position to "defend" it with available political means. Potential changes could trigger conflicts, for instance with the wood industry if the share of strict and active protection zones would be increased or with nature protection if logging would be intensified (Fig. 1.3-2).

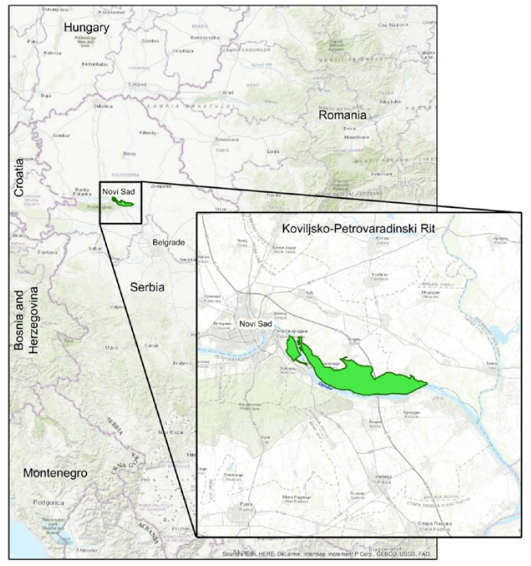

Figure 1.3-1: Nature reserve KoviljskoPetrovaradinski Rit in Serbia 


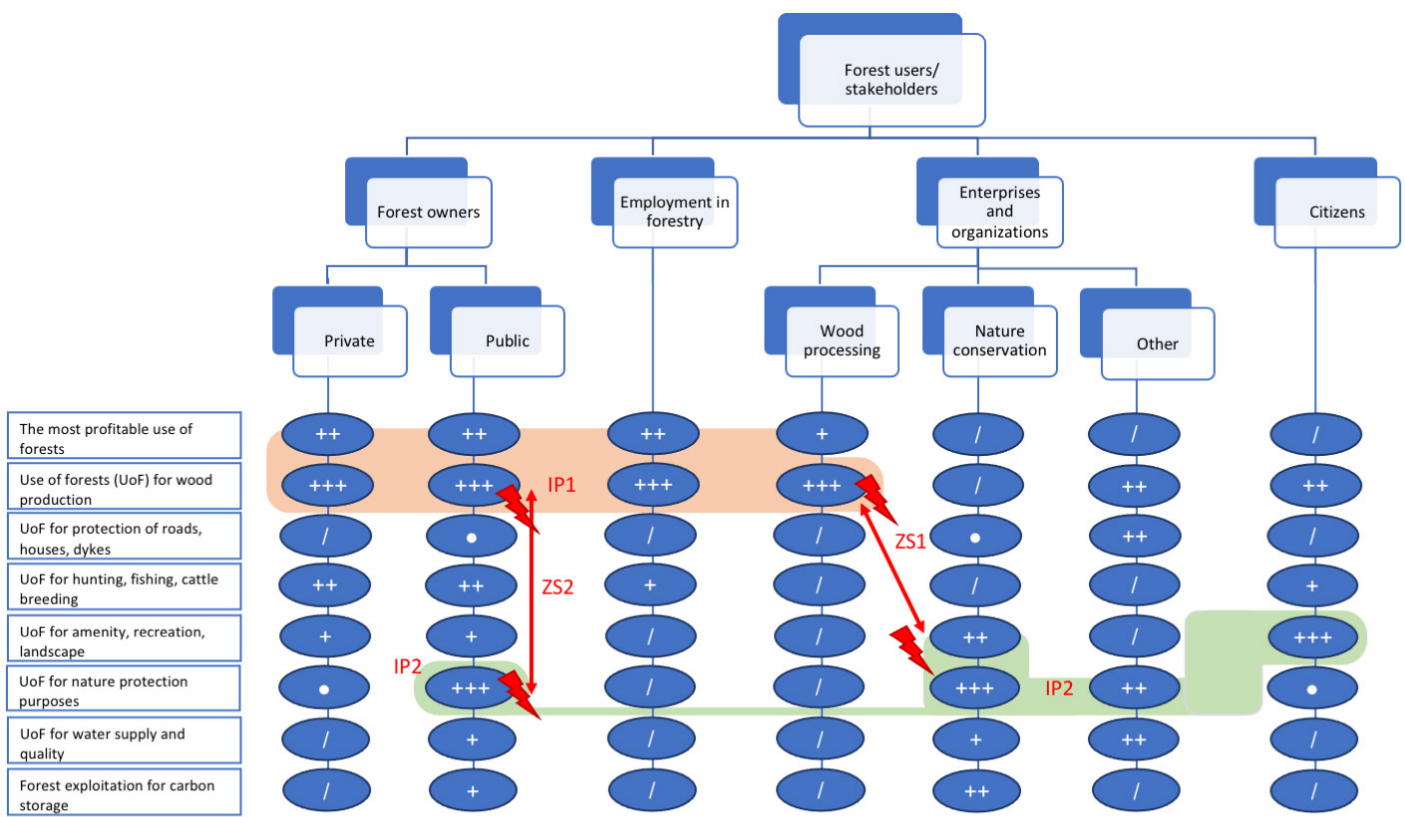

Legend: horizontal - forest users, vertical - user interests, on their intersection (round fields) estimated intensity of user interests: very strong $(+++)$, strong $(++)$, moderate $(+)$, existing $(\bullet)$, non-existing $(/)$; ZS - zone of conflicts; IP - interest field

Figure 1.3-2: Schematic synthesis - forest users, interests, fields of interest and zones of conflicting interest, presented on the example of the Nature Reserve "Koviljsko-Petrovaradinski Rit"

An analytical approach such as the one presented in the example provides a good basis for more active communication between forestry and nature conservation in order to find a balance between conflicting interests and objectives.

Stakeholder insights into key issues in riparian forest management and conservation and recommendations for addressing these issues

Stakeholder workshops provided important insights into the five "hot issues" within the Mura-Drava-Danube Biosphere Reserve. These are decline of underground water, pests and diseases, natural regeneration, forest management planning and availability of forest reproductive material:

- Decline of underground water has been a widely present problem in the project partner countries, especially in the case of pedunculate oak. The dieback of oak trees is common across the Mura-Drava-Danube Biosphere Reserve, not only in mature stands, but also at regeneration sites, causing reforestation failures. Furthermore, climate change is identified as an additional problem, as it is predicted 
to negatively influence pedunculate oak ecosystems and sustainable wood production in them.

- Considering pests and diseases, besides commonly presented problems in the Mura-Drava-Danube Biosphere Reserve, such as ash dieback, Phytophthora sp., wind throws and wind breaks, the Serbian representative highlighted the raising issue of oak lace bug (Corythucha arcuata), as well as presence of complex disease in hybrid poplar plantations (i.e. bacterial canker disease caused by Lonsdalea populi).

- The availability of native forest reproductive material is generally not a limiting factor for reforestation in MuraDrava-Danube Biosphere Reserve. In Slovenia, for example, three nurseries meet the demand for forest reproductive material for the national part of the Mura-Drava-Danube Biosphere Reserve. However, most countries stressed that irregular mast years of pedunculate oak can sometimes be a problem. In addition, stakeholders from Austria stressed the importance of establishing new trade relations with the countries of in Southeast Europe, as seeds imported from Western Europe do not seem to be well adapted to local conditions. In this sense, stakeholders from Slovenia suggested that nursery producers should be more oriented towards international trade in order to expand the market beyond the borders of their own country, for example by establishing a regional market. Regarding forest reproductive material of non-native tree species, Juglans nigra and hybrid poplars are considered to have the potential to be used for reforestation purposes in the Mura-Drava-Danube Biosphere Reserve, although their use is limited in certain countries. However, some inconsistencies in the treatment of non-native tree species have been observed between different countries. In Serbia and Hungary, for example, nurseries produce large quantities of hybrid poplar seedlings annually for plantation establishment, while in Slovenia no new plantations are established except for experimental purposes.

- All the countries have forest management plans that consider forest conservation, water management and other goals to varying degrees. The stakeholders in Slovenia are of the opinion that poplar and willow plantations should be established on abandoned lands, rather than letting private owners establish them on small forest areas, potentially causing greater problems, such as hybridization with autochthonous tree species. As a key characteristic in Austria, 
according to the stakeholders, is a large number of small forest properties, and, therefore, very diverse management, frequently targeting only fuelwood production. The stakeholders from Serbia, both from forest conservation and forest management sectors pointed out the non-existence of climate-smart adaptive forest management since wood production for commercial purposes is still dominant in the Mura-Drava-Danube Biosphere Reserve. They stated that the majority of forests are even-aged, characterized with low resilience to disturbances. Therefore, future management planning in forestry should consider all aspects of forest science. The representatives of the forest conservation sector highlighted that legislative changes are required to mitigate negative effects of climate change on forest ecosystems.

- Natural regeneration in general has been considered extremely difficult to achieve due to dense ground vegetation and therefore requires human intervention. Ground vegetation is recognized as one of the most limiting factors to successful regeneration. In cases where ground vegetation is not too dense, management interventions are proposed to support natural regeneration.

There is a great concern whether native tree species would be able to cope with rapid climatic changes. Several species have been suggested to be potentially promoted for reforestation, including sessile oak and the non-native black walnut and black locust, although there is concern for potential invasiveness. Furthermore, insurance strategies for forests should be considered in the light of climatic changes due to natural conditions and risks that have become more severe in the past decades.

The lack of natural regeneration is perceived to be very severe in Hungary and Serbia, although it has been documented that certain species successfully regenerate spontaneously even on marginal sites (such as pedunculate oak growing on sandy dunes or salty soils). Therefore, despite the problems with natural regeneration, the possibility of natural regeneration should not be neglected. Large areas under extensive plantations of hybrid poplars and willows in the mentioned countries, as well as the pressure of game, are also an obstacle to natural regeneration in the Mura-DravaDanube Biosphere Reserve. 
Table 1.3-2: Main issues regarding riparian forest management and conservation in the Mura-Drava-Danube Biosphere Reserve, as estimated during workshop in Novi Sad (April 2019) and refined by country representatives during an online workshop in October 2020

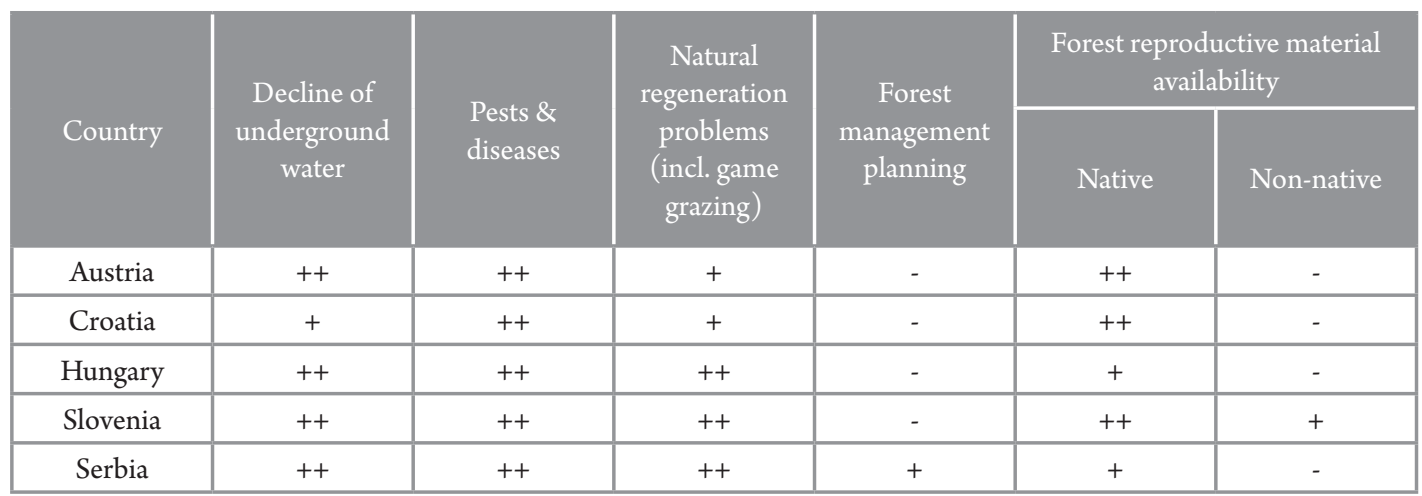

Legend: $(++)$ strongly present, $(+)$ partly present, (-) not present 


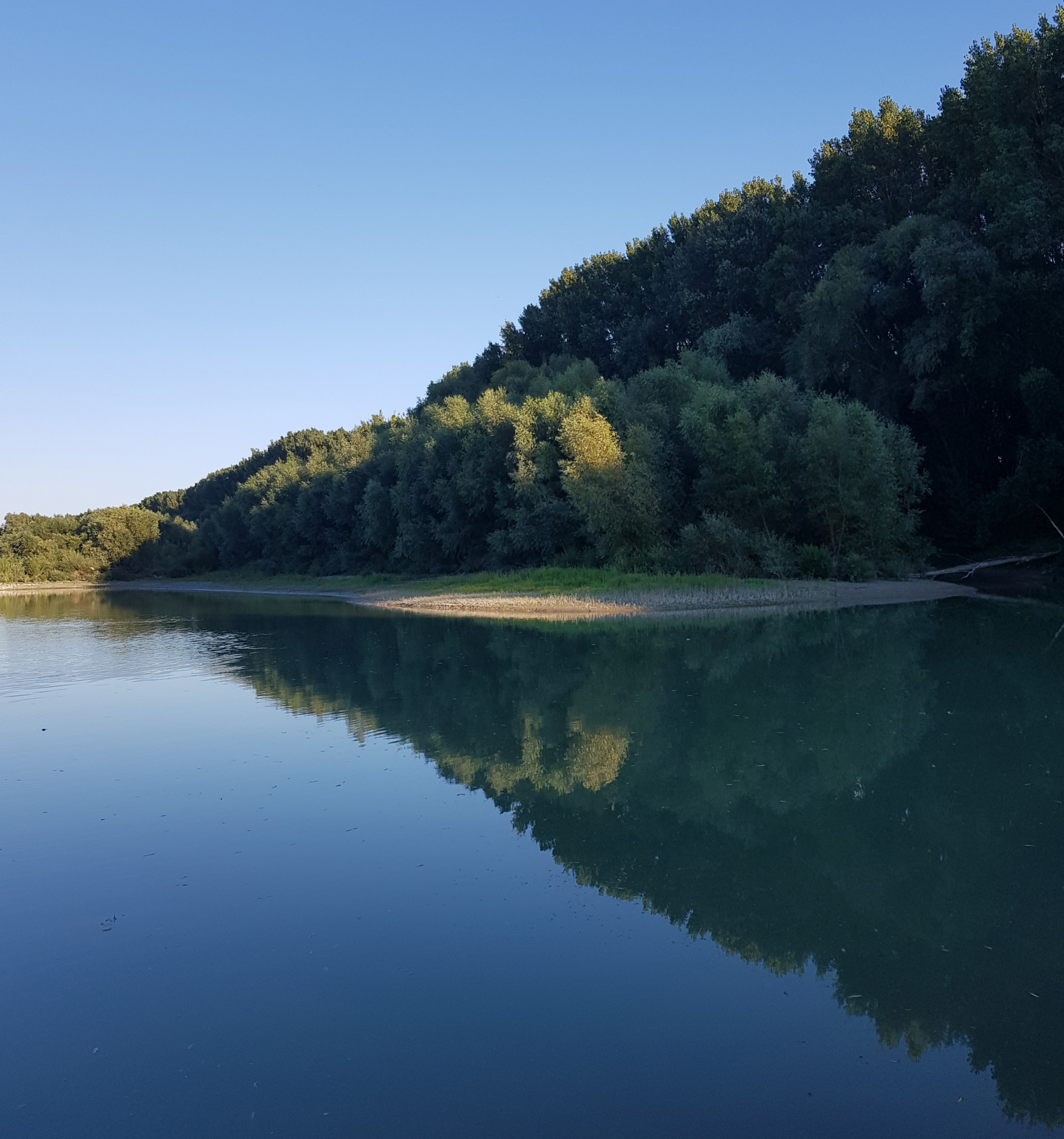




\section{RIPARIAN FORESTS}

Marko Kovač, Markus Sallmannshofer

\subsection{Importance of and threats to riparian forests}

Lowland floodplain forest ecosystems provide important ecosystem services; they act as natural buffers along rivers and provide protection against flood hazards in addition to physical, chemical and biological protection of the soil. They are characterized by high biodiversity and productivity and play an important role in maintaining species diversity. Their recreational and aesthetic value has been increasingly recognized during the last decades. Nevertheless, the floodplain forests are under pressure by historical and current unsuitable management, largescale environmental changes, and globalisation. Simultaneously, the need for healthy floodplain forests is increasing as, for instance, climate related risks such as storm-generated river flow peaks are expected more frequently while highly productive forests can substantially contribute to climate change mitigation.

\section{Historical transformations of riparian forests}

Man's presence and his influence on the Central European rivers and their floodplains can be traced far back in history. This long-lasting coexistence led to gradual transformations of these landscapes as society evolved. The first, and perhaps the most significant, encroachments on riparian forests occurred no earlier than the $7^{\text {th }}$ century $\mathrm{AD}$, when progressive colonization dictated the clearing and controlled burning of large areas of forest to secure sufficient arable land for food and pasture. By the $17^{\text {th }}$ century, these forests were used only moderately for house construction, firewood and hunting. The next wave of changes at the turn of the $17^{\text {th }}$ and $18^{\text {th }}$ centuries introduced extensive drainage and watercourse regulation into riverine floodplain landscapes. Both of these activities, exhibited through diverted and deepened river bottoms and altered hydroperiod regimes (the groundwater table may have declined for several meters), significantly impaired the long-lasting ecological conditions of riparian forests, at times bringing them to the brink of extinction. In parallel with extensive land use activities, forest management introduced necessary construction activities (e.g. construction of forest roads and railways, channelization of stream-flows, bridging of watercourses) and large-scale clear-cutting into these previously only moderately used forests (Fig. 2.1-1). Next in a series of forest 


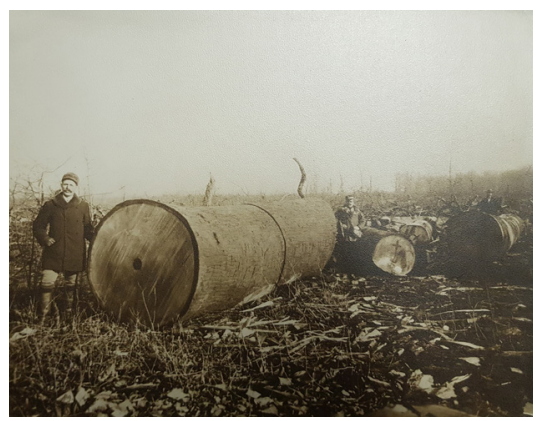

Figure 2.1-1: Large-scale clear cuts changed forest landscape and even-aged forest management units were created management measures was the gradual replacement of native tree species with alien ones. Fast-growing tree species such as poplars, walnuts, oaks, ash and pines and cypresses were particularly popular. In an effort to produce quality timber, plantation forests were created that were planted with fast-growing species and well-formed and robust clones. Since all of these species required similar ecological conditions, the plantations were often intermixed with managed semi-natural riparian forests. To date, agricultural cultivation has destroyed $90 \%$ of Europe's floodplain forests over the last century. Globally, deforestation, fragmentation and conservation of natural floodplain forests are still major problems.

At the turn of the $17^{\text {th }}$ and $18^{\text {th }}$ centuries extensive drainage and initial watercourse regulation in riverine floodplain landscapes was initiated (Fig. 2.1-2). To date, river systems have been extensively altered to support navigation and to enable hydropower generation. These alterations regulated river flows, and hand-in-hand with floodplain drainage, serious downstream impacts such as increased flood risk occurred. Upstream, the consequences of the changed water dynamics were mainly of ecological nature. Protective dikes were built as a countermeasure to the flood hazard and again altered ecosystems through severe ecological fragmentation and disconnection of water-dependent floodplain forests from flooding. River regulation impedes natural floodplain dynamics with periodic flooding and interrupts lateral nutrient supply. This had significantly impaired ecological conditions, led to the loss of softwood forests and drastically reduced the natural regeneration of typical forest species such as willows or black poplar (Fig. 2.1-3). Hydroelectric power plants, in combination with increased flow velocity and truncation of sediment transport, caused a rapid riverbed incision and lowering of water levels. In addition, groundwater extraction further lowered the groundwater tables. This change in water availability makes riparian tree species vulnerable to drought, which is expected to occur more frequently in a changing climate.

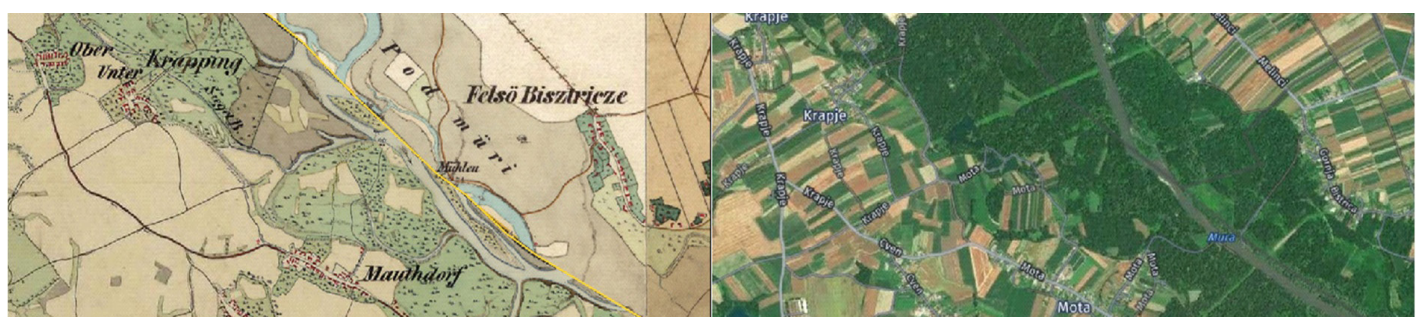

Figure 2.1-2: Watercourse and land use changes along the Mura River between 1829 and 2020 (near Bistrica, Prekmurje, Slovenia) 


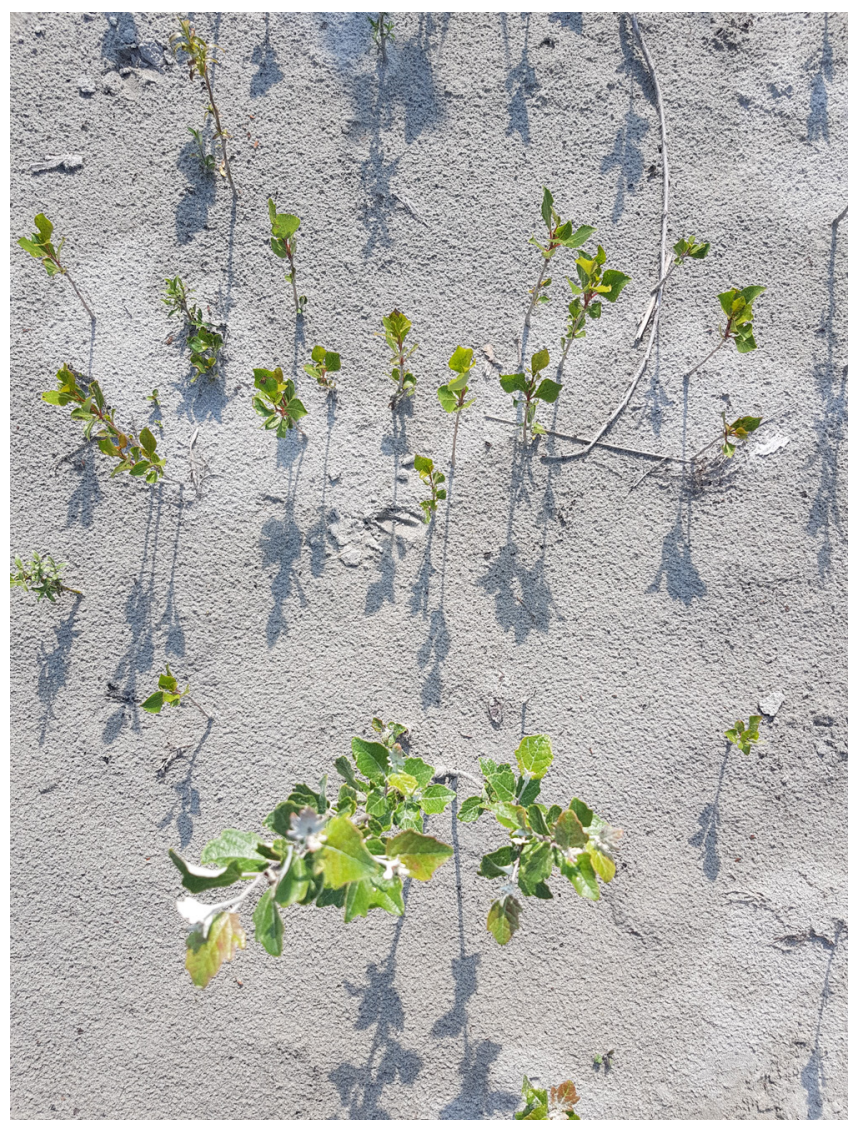

Figure 2.1-3: River regulations have led to loss of suitable habitats for softwood species and have drastically reduced the natural regeneration of typical riparian species such as willows (Salix sp.) or black poplar (Populus nigra)

\section{Climate change}

Forest disturbances are an integral part of forest ecosystems, especially in riparian forests where periodic flooding is important to maintain specialised species composition. Climate change, the interplay of warming, changing precipitation, and the changing pattern, frequency, and magnitude of extreme events interacting with forest disturbances, will have yet unknown consequences for riparian forests. Already, habitat suitability and vulnerability are changing within the current distribution area of local riparian forest communities. Biotic disturbances are also expected to alter pest and pathogen habitat ranges, leading to new risky overlaps. In addition, the adaptability of pests and diseases is expected to be higher than that of host species due to the shorter life cycles 
of the former. As a result, interactions between abiotic and biotic stressors are likely to become the main drivers of pest and disease outbreaks. Similar to pests and diseases, the spread of non-native plants may increase, leading to higher competitive pressure on native plant communities.

\section{Globalisation}

Since prehistory, the intentional transfer of plants and animals has taken place and is still common in forestry, agriculture, and horticulture. Additionally, globalisation with international trade and travel today strongly contributes to the unintentional spread of non-native species. This can lead to increased occurrence of non-native pests and diseases and non-native plant species in forests. Floodplain forests in particular are highly susceptible to invasion by non-native plant species due to their high nutrient availability, recurring disturbances that result in favourable light conditions, and the nature of rivers that act as transport vectors for seeds and vegetative material.

Alien pests and pathogens are much more likely to spread through unintended transfer than plant material due to their small size and/or active movement. Since native trees have not coevolved with alien pests and pathogens, they are usually more susceptible to their attack than tree species in the native range of these pests and pathogens. Through their pathogenicity, alien pests and pathogens have a high potential to alter forest stand composition and structure.

Invasive non-native plants, pests or pathogens may alter forest species composition and structure, which may have a strong ecological effect that alters the provision of ecosystem services of floodplain forests.

\section{Recent recognition}

Because of their importance and unfavourable conservation status (Fig. 2.1-4), floodplain forests have recently received national and international recognition and have been consequently addressed in a number of processes and legal documents. Worth mentioning are the Ramsar Convention, the Forest Europe process, the EU Biodiversity Strategy and the Habitats Directive. All these processes and documents consider riparian forests as tangible assets and call on responsible national authorities, services and managers to manage them in a sustainable way, balancing their long-term forest development and the provision of their ecosystem services. 


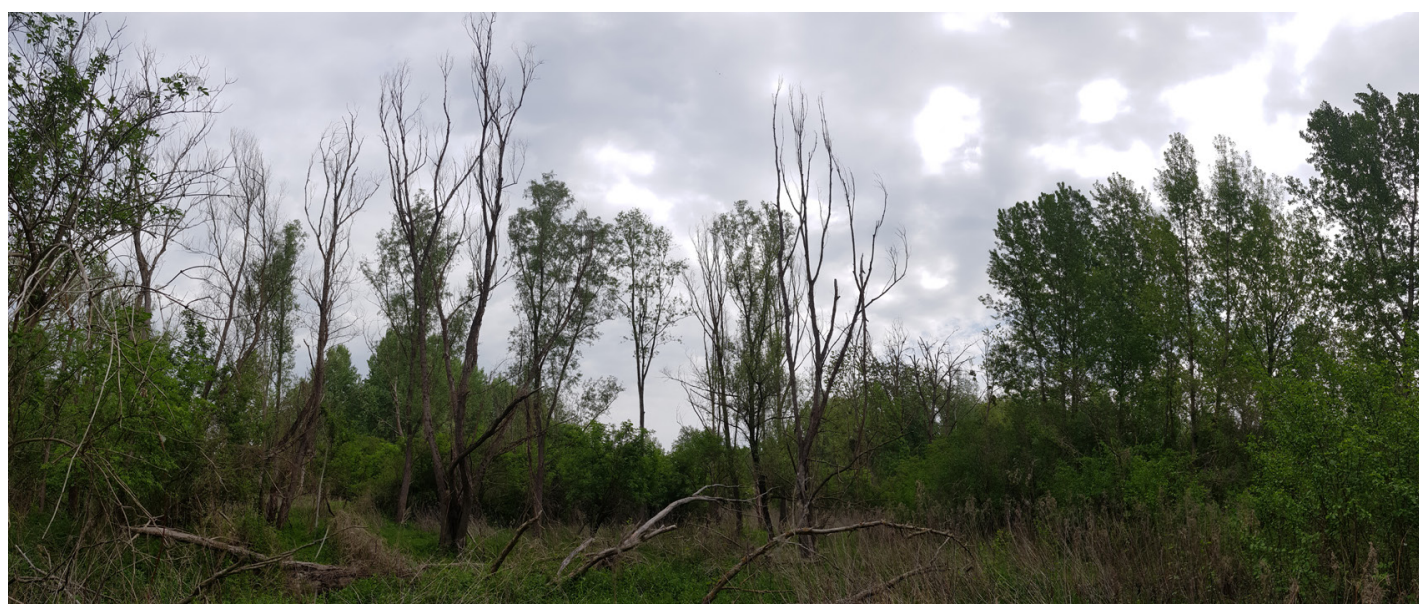

Figure 2.1-4: Dieback of trees in riparian forests at the Drava River, Croatia 


\subsection{Managing riparian forest ecosystems}

Balancing riparian forest development with various ecosystem services requires incorporating new approaches into the paradigm of sustainable forest management and its practices. Two appropriate approaches are the landscape perspective (essential in ecosystem management) and the concept of ecological integrity. The former approach should be understood as integrated, holistic forest management at the landscape level. The second approach should be understood as the ability of a riparian forest to support and maintain its areal, structural, compositional, and functional components.

From a landscape perspective, a riparian forest can be viewed as a forest matrix composed of differently shaped forest patches (complexes) and corridors. In most cases, bothlandscape elements are heterogeneous in terms of structure, since they house a variety of forest habitat types and subtypes, with core and buffer areas of different sizes. By considering some of the isolation effects, such as, that 1 ) a forest habitat type that is widely distributed across its original range is more persistent than one that is restricted to small parts, that 2) a larger forest habitat type with larger core areas is superior to a smaller one, and that 3 ) a contiguous forest habitat type is more robust to external impacts than a fragmented one, it becomes clear that the ecological integrity of forest habitat types increases with the size and compactness of forest habitat type complexes.

Such an understanding of a riparian forest has several advantages over current forest management practices; it views a riparian forest as a whole rather than as a sum of land pieces (compartments), introduces new forest management alternatives (e.g. promotion of expanding-gap system over the shelterwood system, coppicing, clearcutting), and makes management for conservation more efficient by contributing to greater integrity of forest habitat types. The current distributions of riparian forests (Fig. 2.2-1) show that the establishment of larger complexes can be shaped by better forest spatial planning and by placing more effort in distribution of age classes or development phases. This is not true for the riparian habitat subtypes along streams, whose longitudinal geometries (Fig. 2.3-1) often cannot sustain their own core areas. Consequently, these habitat subtypes should be effectively monitored and managed (e.g. individual and group selection, structural thinning) to prevent them from disintegration. Management with complexes also suggests moving tree plantations and similar land uses (e.g. nurseries, 
seed orchards) away from core and buffer habitat types to avoid potential invasion by invasive species and undesirable effects (e.g. hybridisation, nutrient flows).

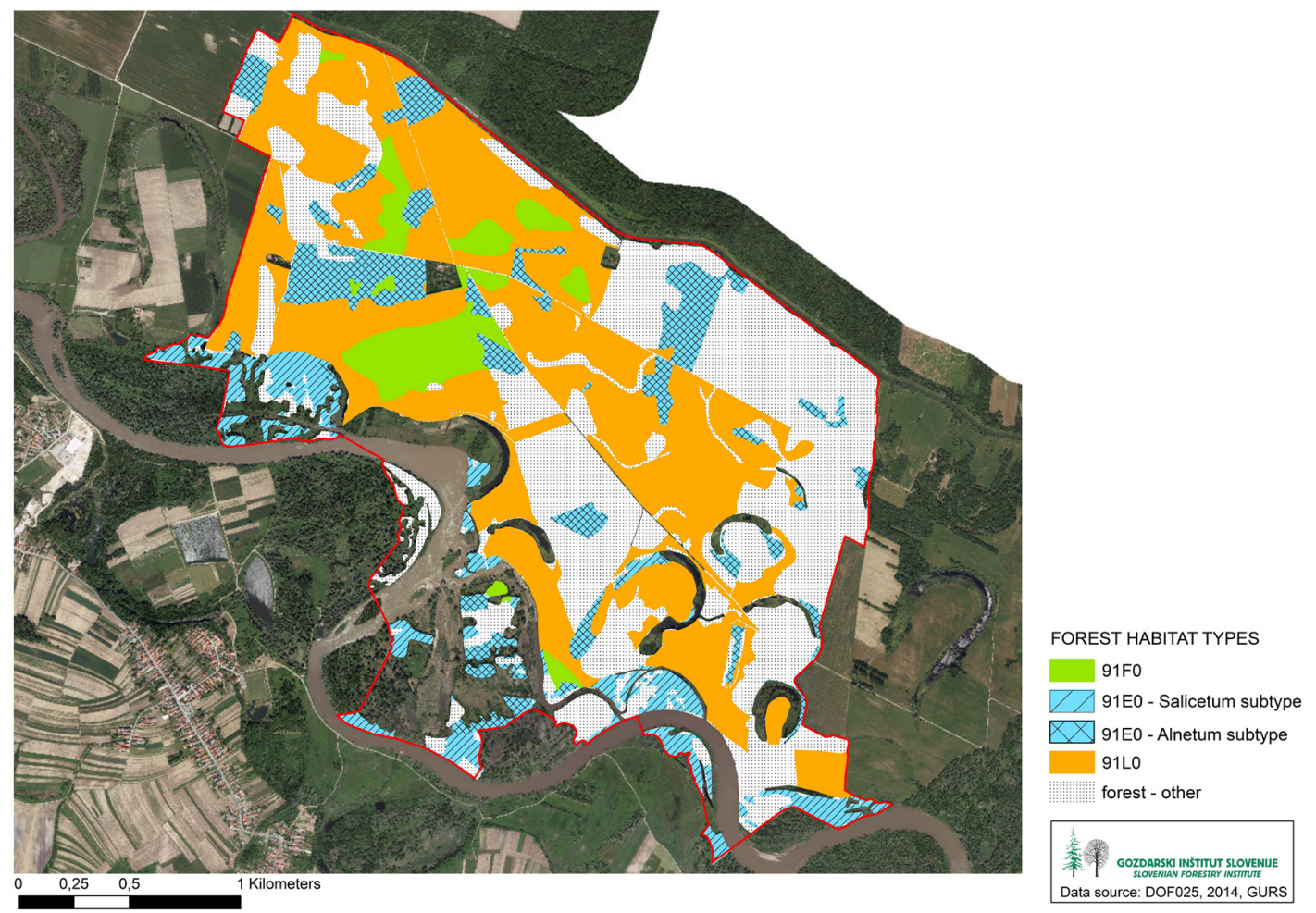

Figure 2.2-1: Compartment-based management suggested for managing Natura 2000 habitat types of Murska Šuma

In addition to both approaches, further efforts are needed to better understand biodiversity, disturbance, and their effects on forest management practices. The intermediate disturbance hypothesis states that biodiversity is highest in environments exposed to disturbances of intermediate intensity and frequency. This hypothesis works well in many forests, including riparian forests. Its result can be easily demonstrated along a transect that extends between the watercourse and the outer boundary of the floodplain (see 2.3 Structure and ecology of a riverine floodplain landscape). In this transect, the pioneer successional stages are found near the watercourse where disturbance is most frequent and severe. In contrast, the most evolved floodplain successional stages, the pedunculate oak forests, are generally located further from the watercourse, in the centres of the floodplains. As such, they remain dependent on the water regime 
but are safe from frequent disturbance.

The insurance hypothesis is concerned with existing tree species compositions and their functioning. It states that species that are currently redundant for forest habitat functioning, may at some point, possibly after disturbance, take over some functions previously performed by declining or extirpated species. This fact is important for understanding forest habitat types and tree species compositions, which should not be understood as permanent and fixed, but as temporary and evolving in time and space. The insurance hypothesis may play a notable role in future riparian forests. This is because many of the dominant tree species of current forest communities suffer from a variety of diseases and environmental stresses that may lead to their local extinction (see 3.1.2 Supporting adaptation of forests by selecting suitable Forest Reproductive Material and 3.3 Forest health).

Riparian forests are complex ecological systems that are exposed to and dependent on a variety of natural and human-induced disturbances. Because of their fragility and the likelihood that the damaging actions will affect larger parts of the riverine floodplain landscape, these forests should be managed at different spatial scales and in accordance with good practice, taking into account ecological knowledge gained. Riparian forest managers need to be encouraged to implement appropriate forest management approaches, including appropriate spatial arrangement of riparian forest habitat types and subtypes (spatial planning), in recognition of the risks posed by changing river dynamics, climate change, pests and diseases, and invasive species, in order to maintain the economic potential and ecological value of these forests for future generations. 


\section{As \\ ate}

A.

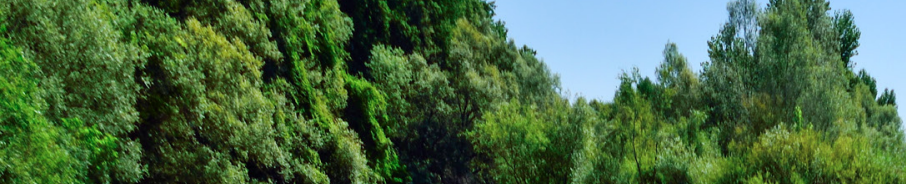

casur 100.

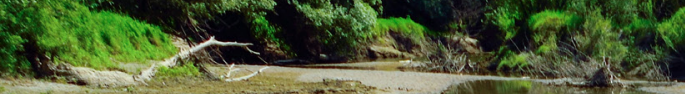

*.

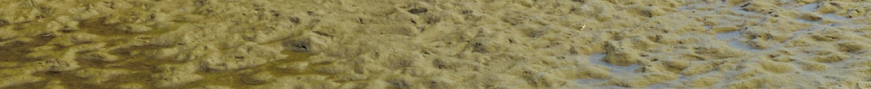

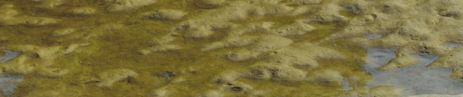

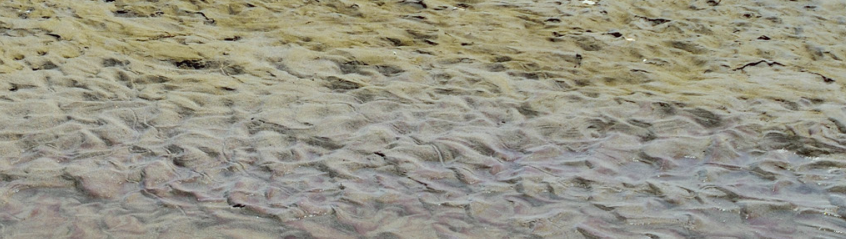

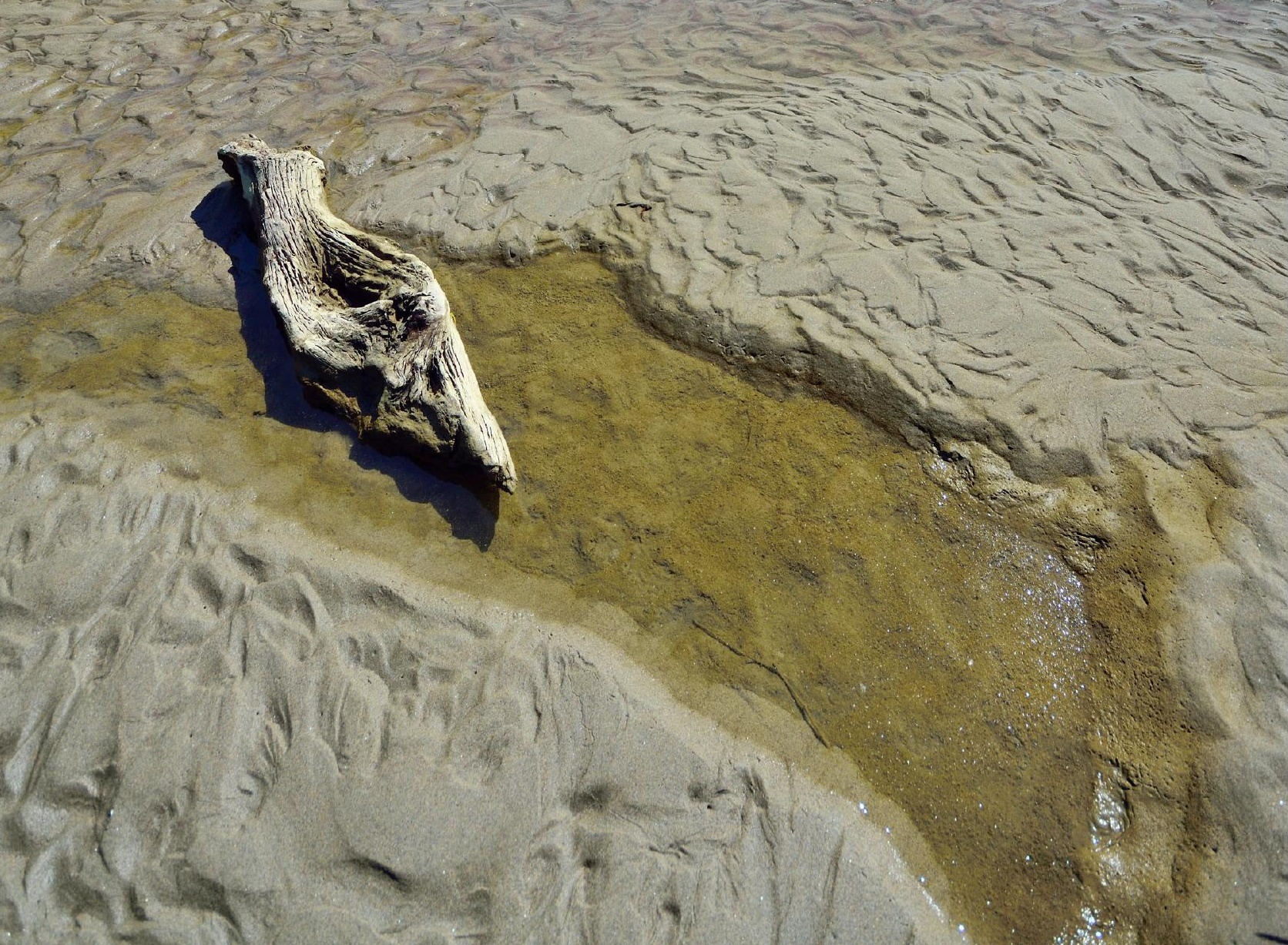




\subsection{Structure and ecology of a riverine floodplain landscape}

A dynamic interplay between water and land is the principal process that produces and sustains different types of riverine* floodplain landscapes and creates a variety of habitats, which biotas colonize, adapt to, and reside therein.

Types of riverine floodplain landscapes are:

Disequilibrium floodplain: in the upper stream, where water has a torrent-character and, channels through narrow gorges

Equilibrium floodplain: mid and down steam, where water meanders through non-cohesive sedimentary material, landscape changes do occur

Low-gradient floodplain: down steam, where water meanders through cohesive sedimentary material, landscape changes are negligible

A riverine floodplain landscape consists of four distinct landscape element groups, which are further subdivided into ecotopes and ecoelements. The first and most significant group includes standing and running waters. Connected by a network of channels, water bodies facilitate riparian plants (many of which are considered nurse plants as they prepare sites for the arrival of pioneer forest species) to colonise various habitats, survive in them, and thrive. The water bodies support plants with flows of coarse- and fine-grained materials, soils, and nutrients.

The second group is represented by groundwater, which is part of a more complex system named subterranean water aquifers. In addition to running water, groundwater is the second source of moisture for riparian forests and becomes a critical factor during dry periods. A pulsating groundwater table also creates and maintains its own habitats called swamp forests.

The third group consists of geomorphological features. The interconnectedness of watercourses in a riverine floodplain landscape creates meandering, branching, and anastomosing channels that form cutbanks, oxbows, islands, levees and undulating flood-prone plains, rich with swales and ridges, all of which are potential habitats for individual forest plants as well as small and large patches of forest communities (Fig. 2.3-1).

\footnotetext{
*In this chapter, we associate the expression riverine with landscape and vegetation (as a forest type) and the term riparian with vegetation. However, scientific literature does not draw a strict line between the two, but rather uses them interchangeably.
} 


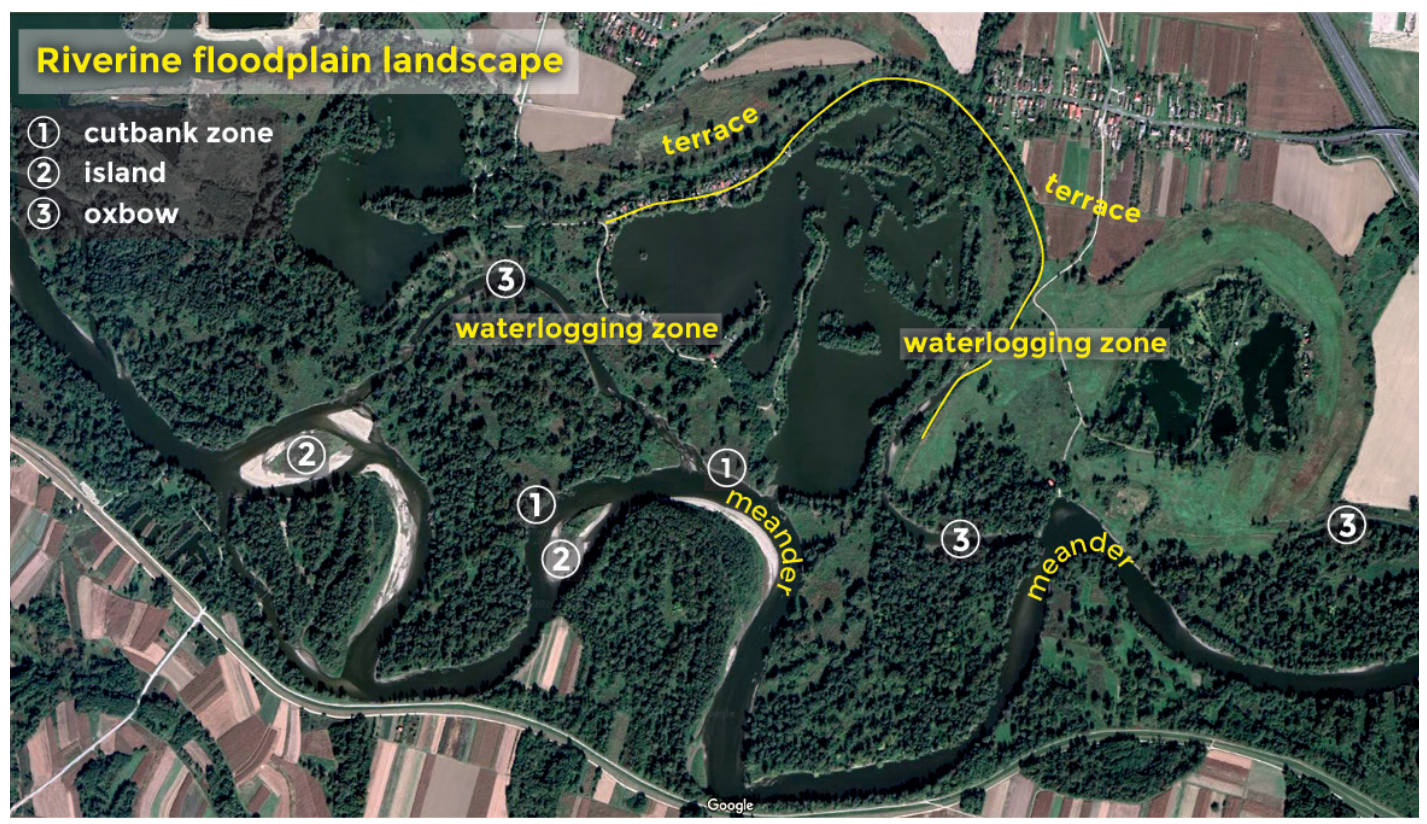

Figure 2.3-1: Scheme of potential riverine habitats with cutbanks, islands, terrace and oxbows

The final riverine floodplain landscape element group is vegetation cover, in our case riparian forest plant communities. Although the ecological factors that determine forest plant communities in riverine floodplain landscapes are not always as obvious as in landscapes with much sharper ecological gradients (e.g. mountain landscapes, high karst landscapes), riparian forest communities depend heavily on them. Most critical to their existence are site hydroperiods, macro- and micromorphological gradients (e.g. relative elevation), precipitation, and soil types.

The factors presented allow the distinction of three main riparian forest communities along the lateral transect connecting the water channel to the outer boundary of the floodplain, namely riverine, floodplain and swamp forests (Fig. 2.3-2). 


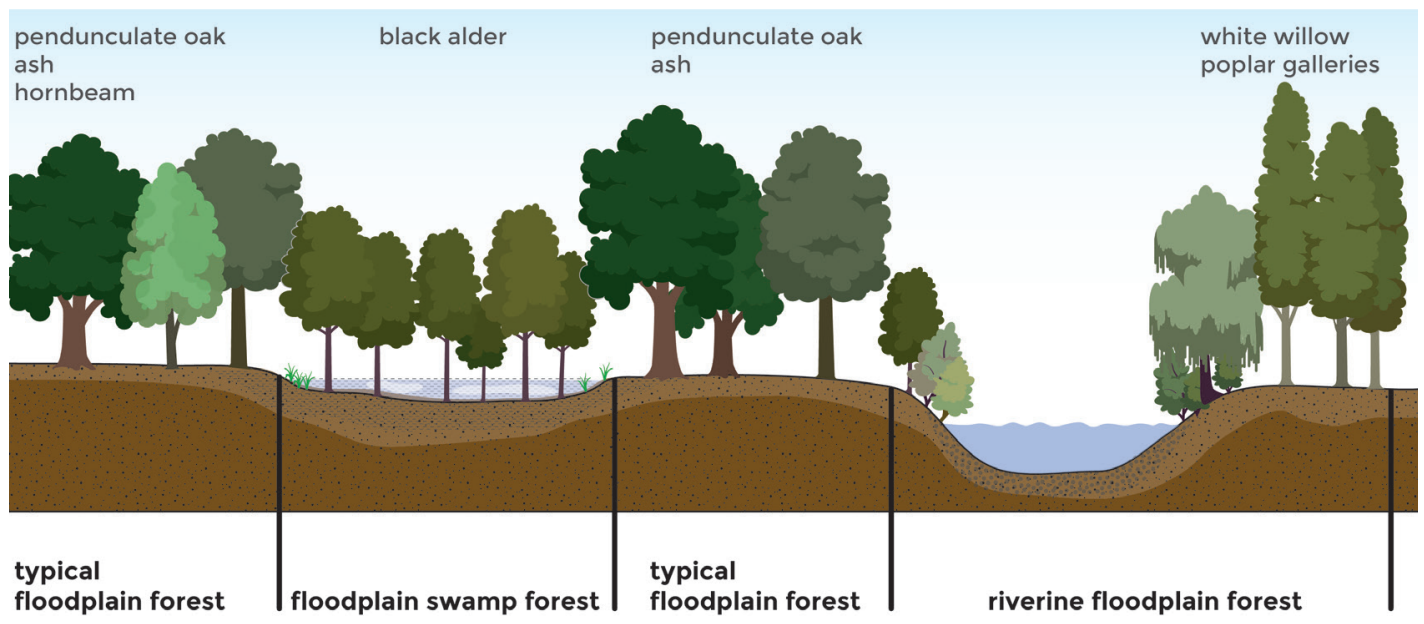

Figure 2.3-2: Lateral transect with typical riparian forest types

The lowest and most adjacent habitats to a watercourse, such as cutbanks and islands, and banks, levees, and terraces affected by changes in water flow, are inhabited by riverine forests. Although these habitats are capable of withstanding constant water level changes, prolonged waterlogging, and water currents, those directly adjacent to streams are often unstable. The instability is due to strong currents that erode unfortified natural and seminatural riverbanks, transport alluvial material into riverbeds, wash away resident plant communities, and facilitate the colonization of new habitats. Soil fertility of these sites is poor due to prolonged saturation with water and significantly underdeveloped soils. Poplar (Populus sp.), ash (Fraxinus sp.), willow (Salix sp.) and elm (Ulmus sp.) reside on well drained, stabilized sites. By contrast, pioneer species such as bitter, red, goat, grey and white willow (Salix eleagnos, S. purpurea, S. caprea, S. cinerea, S. alba) and grey and black alder (Alnus incana, A. glutinosa) occur on sites adjacent to water (i.e. banks, islands).
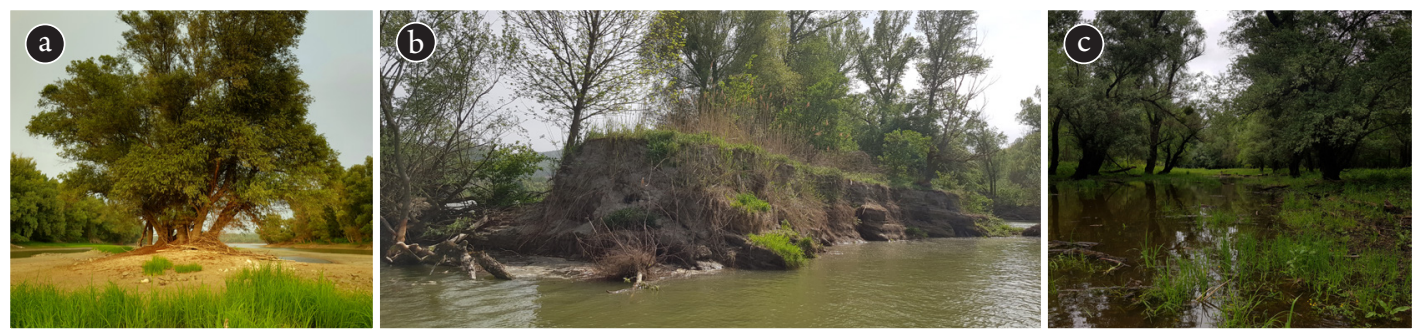

Figure 2.3-3: a) Colonization of new habitats on river islands; b) Stabilized sites are capable of withstanding constant water level changes, but also erosion of riverbanks is an essential component of the system; c) Flooded area colonized by Salix species 
The second type of sites are higher floodplains that are beyond the reach of river flow alterations, but still within the boundaries of regularly flooded areas. These sites are mostly inhabited with typical floodplain forests with tree species such as elm (Ulmus laevis), pedunculate oak (Quercus robur), white hornbeam (Carpinus betulus) and ash (Fraxinus excelsior, F. angustifolia) and occasionally sycamore and field maple (Acer pseudoplatanus, A. campestre), both of which demand well-drained soils and very short-lasting waterlogging. Apart from maple and accompanying species, such as linden tree and cherry (Acer sp., Tilia sp., Prunus avium), the rest of the species inhabit regularly flooded sites with sometimes poorly drained soils. Yet, unlike riverine forests, which are very tolerant to moisture and long-lasting waterlogging, floodplain forests prefer regular seasonal flooding. As these forests also inhabit sites away from watercourses, where flooding periods are significantly shorter, they are more dependent on groundwater and precipitation. Precipitation is especially important in dryer periods before leaf flushing as some species, such as pedunculate oak, need enough water to produce vessels to conduct water and dissolved nutrients between leaves and roots.

The last type of riparian forests are swamp forests. These forests inhabit small and large-sized depressions in floodplains, in which hydric soils (gleysols) are poorly drained due to high groundwater tables and long-lasting waterlogging. Unlike riverine and typical floodplain forests, these forests are capable of surviving on sites with frequent anaerobic conditions caused by stagnant waters. The main tree species of these forests is black alder (Alnus glutinosa). However, because of undulating terrains (often within the range of one meter), less flooded sites are often inhabited by elm, pedunculate oak and ash.

Looking at the riverine floodplain landscape as a whole, the flood-prone areas are where the greatest amount of nutrients are produced, stored, and decomposed and transported to other, less fertile, locations when floods arrive.

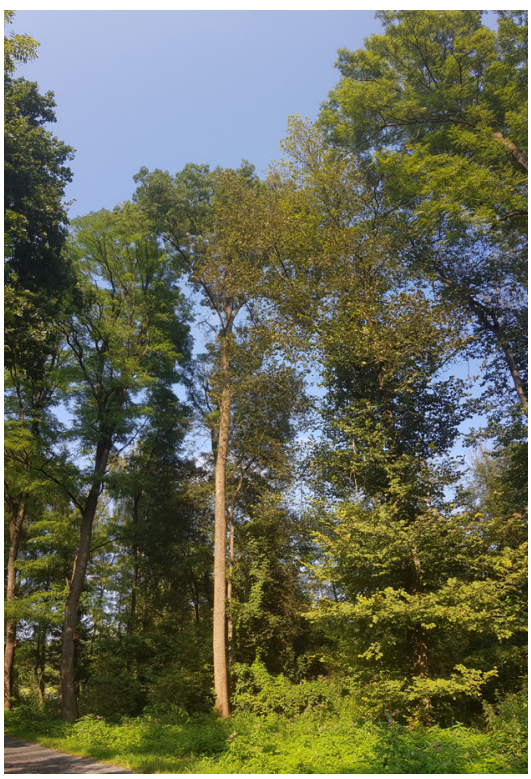

Figure 2.3-4: Floodplain forest with Fraxinus excelsior, Ulmus laevis, and Quercus robur out of reach of flow alterations, but still within the boundaries of regularly flooded areas

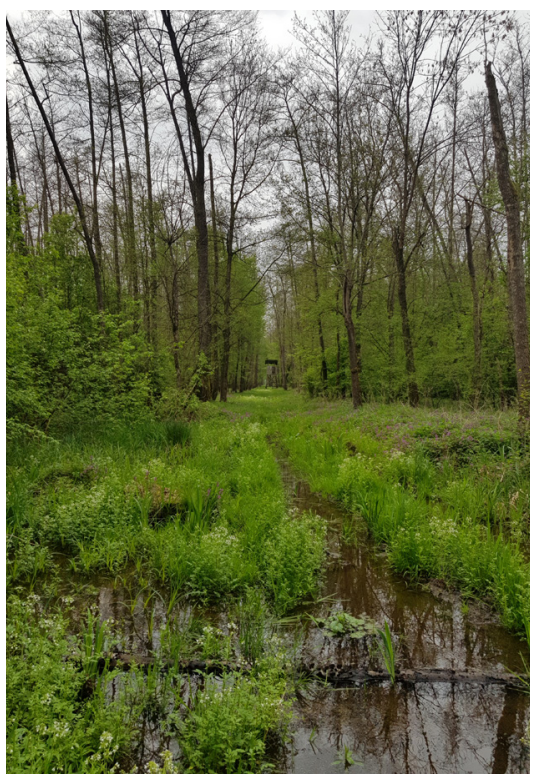

Figure 2.3-5: Swamp forests with Alnus glutinosa 


\subsection{Forest habitat types}

\section{Introduction}

Floodplains along the Mura, Drava and Danube rivers are home to many forest habitat types and subtypes. To conserve them, many of them were officially designated and included into the Natura 2000 network. Perhaps the most widely spread, known and relevant from the ecological, economic and social point of view are the *91E0 Alluvial forests with Alnus glutinosa and Fraxinus excelsior (Alno-Padion, Alnion incanae, Salicion albae), 91F0 Riparian mixed forests of Quercus robur, Ulmus laevis and Ulmus minor, Fraxinus excelsior or Fraxinus angustifolia, along the great rivers (Ulmenion minoris), 91L0 Illyrian oak-hornbeam forests (Erythronio-Carpinion) and 9160 Sub-Atlantic and medioEuropean oak or oak-hornbeam of the Carpinion betuli.

The four forest habitat types differ in their ecology. The first and the most heterogeneous ${ }^{*} 91 \mathrm{E} 0$ forest habitat type consists of different habitat subtypes, commonly belonging to two larger groups, for practical reasons named willow and black alder groves, respectively. The willow grove is a typical representative of a riverine forest for it inhabits moist, often flooded, but considerably well drained sites adjacent to a watercourse (Fig 2.41). By contrast, black alder forest habitat subtype usually inhabits wet and poorly drained sites in a floodplain and forms swamp forests. Their sites are often characterized by anaerobic conditions caused by the long-lasting flooding and stagnant waters and heavy soils.

The other listed forest habitat types inhabit floodplain core areas and are therefore referred to as typical floodplain forests. Their dominant species is the pedunculate oak. However, unlike black alder swamp forests, pedunculate oak forest communities are highly dependent on regular flooding caused by flowing water, groundwater and precipitation. The differences in tree species composition between these habitat types are often barely discernible and are due to the fine differences in elevation in the undulating terrain.

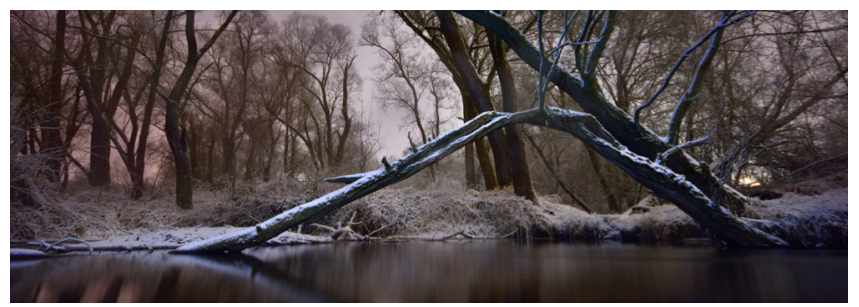

Figure 2.4-1 Natural willow groves in Bavaria, Germany 


\section{Forest habitat type *91E0 Alluvial forests with Alnus glutinosa and Fraxinus excelsior (Alno-Padion, Alnion incanae, Salicion albae)}

The priority forest habitat type of *91E0 contains three subtypes. The first, belonging to willow groves, commonly develops two successional portrayals. A rather unstable pioneer stage inhabits sites adjacent to watercourses such as cutbanks, bars and islands and is composed of bushes and small sized willow and alder trees (Salix sp., Alnus sp.). By contrast, a more developed stage is composed of large willow (Salix sp.), alder (Alnus sp.), elm (Ulmus sp.) and ash trees (Fraxinus sp.). Commonly it resides on stabilized adjacent plains that are often exposed to regular flooding caused by water flow alterations.

Soil fertility of both sites is poor due to sedimentary soils, composed of coarse and fine-grained gravel, sand and silt. In stabilized sites, hydromorphic soils are developed.

The second habitat subtype is characterized by arboreous galleries alongside watercourse banks, mostly composed of large white willow (Salix alba) and black poplar (Populus nigra) trees. Both species also form individual stands. These sites are well to moderately drained and often consist of moderately deep and deep loam and clay soils.

The third habitat subtype is represented by lowland black alder (Alnus glutinosa) swamp forests. This habitat subtype inhabits lowest terrain levels in floodplains that are composed of rich humus layers and gleysols and are flooded with stagnant waters due to precipitations and groundwater for most of the year. Black alder forms homogeneous and mixed stands. In the case of mixed forests, the terrain undulates and thus develops swamp and fresh sites, whereby fresh ones are often inhabited by pedunculate oak (Quercus robur), elm (Ulmus laevis), ash (Fraxinus excelsior) and similar species.

The habitat type *91E0 as a whole is rich with willow, poplar, elm, ash and shrub species and consists of many forest associations. Its regeneration differs from place to place. Riverine forest habitat structures, adjacent to watercourses, active and nonactive oxbows, with willowed galleries and small-sized swampy black alder groves regenerate naturally. Conversely, large-sized willow, poplar and also black alder stands may also be regenerated artificially (example: black alder forest of Polana and Black Forest, located between villages of Mala Polana and Mostje/Banuta, Slovenia). The main reason is aggressive ground vegetation that suffocates saplings and hardens (or even inhibits) the germination process. 
The ${ }^{*} 91 \mathrm{E} 0$ forest habitat has a great ecological role. As it combines terrestrial and aquatic environment, it is home to numerous plant and animal species. It also has a huge protective role since it regulates water regime and water cycle and thus contributes to protection against floods. Also notable is its role from the forest management point of view. Black alder, white willow and poplar stands are known to produce quality and fast-growing timber to be used in the wood and energy industry.

All the three subtypes of this riverine forest habitat type *91E0 are vulnerable and highly susceptible to destruction. The most influential factors, affecting their further presence in the environment, are their rarity, shapes of their habitats, adjacency to more compact forest types and human encroachments. The first two factors are purely ecological. While rarity cannot be managed, the shapes of habitats can be sustained and improved by keeping their core areas stable and free from more competitive native and non-native tree species that invade them. Human encroachments, such as habitat fragmentation, agricultural land drain and land use conversions should be carefully planned, monitored and regulated by adequate legislation.

Forest habitat types 91F0 Riparian mixed forests of Quercus robur, Ulmus laevis and Ulmus minor, Fraxinus excelsior or Fraxinus angustifolia, along the great rivers (Ulmenion minoris), 91L0 Illyrian oak -hornbeam forests (ErythronioCarpinion) and 9160 Sub-Atlantic and medio-European oak or oak hornbeam of the Carpinion

Habitat types with the codes of 91F0, 91L0 and 9160 have similar ecologies and often can be distinguished only in terms of specific factors such as site drainage, soil type, moisture, precipitation, presence of groundwater and flooding regime. From a forest succession point of view, these floodplain forest habitat types are considered the most evolved of all riverine floodplain forests. In this context it is worth mentioning that forest habitat type 9160 is often considered just a differently classified habitat type 91F0. Due to unevenly deposited soils, alluvial floodplains are not truly a plane. Their undulations at the level of microrelief create a variety of habitats for ground vegetation, shrub and tree species that differ with regard to their tolerance to moisture. The sites are mostly poorly drained, composed of moderately deep or deep loamy, clayey and even sedimentary particles and material.

The differences among these three habitat type tree species compositions are often intangible. All three are dominated by 
pedunculate oak (Quercus robur), which is admixed with elm (Ulmus laevis), ash (Fraxinus angustifolia, F. excelsior) and some other accompanying species. However, if a plain is sufficiently elevated and thus less exposed to long-lasting flooding, it also hosts hornbeam (Carpinus betulus), sycamore maple (Acer platanoides) and some other species less tolerant to soil moisture and water. Significantly shorter floodings as well as less moist terrain are thus the major difference between the 91F0/9160 and 91L0 forest habitat types. Nevertheless, all three habitat types host many ground, shrub and tree plant species.

The origin of these riparian forest habitat types varies greatly. Although their portrayals look similar to naturally regenerated ones, especially large complexes are often established through sapling and acorn planting. Natural regeneration of pedunculate oak is challenging and often unsuccessful. The main factors are demand for light, presence of many vertebrate species, insufficient fructification, aggressive ground vegetation, game browsing and material transport during flooding (see 3.1.4 Regeneration of pedunculate oak stands: natural and with direct sowing).

Forest management potential of the riparian $91 \mathrm{~F} 0$ and ${ }^{*} 91 \mathrm{E} 0$ habitat types is huge. Like all riparian forest habitat types, it contributes to water regime and water cycling and is home to many plant and animal species. Additionally, timber of pedunculate oak and admixed species such as elm, ash and occasionally hornbeam is valuable in the wood industry where it is used in the production of veneers, planks/boards, furniture and wooden haberdashery (see 3.2.2 Optimization of the production of high-quality logs in hardwood stands).

Since all three aforementioned forest habitat types inhabit ecologically similar sites, they are all suffering from the same factors i.e. land drainage systems, tree plant diseases, penetration of non-native and more competitive tree species, as well as human fragmentation and land use changes. By far the most harmful factors seem to be plant diseases, succumbing some of the habitat's elementary tree species to local extinction and lowered groundwater table due to draining of adjacent agricultural lands. 


\subsection{Common forest management forms in riparian forests}

Although riparian forest communities at first sight appear to be stable over time, they are exposed to a variety of disturbances that change in regard to their proximity to watercourses. Consequently, stands adjacent to the watercourses are more exposed to water flow alterations, floods, strong currents and material transport and deposits that is exhibited in broken and fallen trees, tree wounds, washed-away soils and organic matter along with laid seeds, growing seedlings, and saplings. Conversely, stands away from direct water effects are more exposed to the long-lasting waterlogging and regular forest management. Naturally, all forests occasionally experience natural hazards (i.e. forest wildfires, strong winds and snowstorms, resulting in burnt, knocked down and broken trees over larger areas), but riparian tree species are especially adapted to ecological niches frequently disturbed by flooding events.

To adapt to ever-changing environmental conditions, tree species and shrubs have developed two opposing mechanisms of regeneration and reproduction: asexual vegetative reproduction, known in forestry as coppicing and cloning, and sexual regeneration from seed. Coppicing, the oldest known form of vegetative reproduction, largely produces what are known as coppices or low forests (small trees due to short rotation periods), while the second technique produces what are known as high forests with tall and mature trees propagated from seed.

Coppices and high forests are the two most common stand forms of riparian forests. Because of unstable site conditions and smallscale management interventions, coppices are a prevalent stand form in riverine forests. Their most frequent sites are cutbanks, islands, watercourse banks and the lowest terraces. Most of these sites are inhabited by willow and alder shrub and tree species, while poplar, ash, elm and oak may occur in more stable and drier areas.

As a very traditional stand form, coppice forests also occur in typical floodplains away from flowing waters. However, due to changing human needs and priorities, large areas of coppice forests were replaced by high forests about 200 years ago through natural regeneration and acorn planting (Fig. 2.5-1). The main reason for this change was the production of high-quality wood for the timber industry. The most common tree species that form high forests are oak, elm, ash, hornbeam and associated species. In addition, white willow, native black poplar, and a variety of 
poplar clones are also used in the establishment of large-scale high forest complexes.

The last stand form, also very traditional, which has almost disappeared from the riparian forests, is the middle forest, also known as coppice with standards. This form has similar characteristics to the two forms mentioned above in that it includes a certain number of large and tall trees, traditionally oaks and ash, dominating the upper canopy storey, and a coppice dominating the lower storey. Tall trees, traditionally grown from seed, are often referred to as standards. The lower storey is cut and vegetatively regenerated several times until the standards are mature. This system involves two different rotation periods, schematically fitting the shorter one of the lower storey at least three times into the longer rotation period of the standards. In terms of management, harvesting the standards can be very similar to single tree and group selection.

All three stand forms play an important role in the conservation of riparian forests. While the potential of high forests to contribute to gene pool enhancement, woody biomass, and production of high-quality timber is fairly well understood, studies dealing with coppice and middle forests are still in progress. Recent studies in many different forest environments show that their tree species compositions are generally more diverse than those of high forests and that they can contribute significantly to the conservation of light-demanding species. Furthermore, both variants of coppicing are very old forest management techniques that have contributed significantly to societal development in many regions of Europe and worldwide over the last centuries and should be preserved as cultural heritage. Finally, unlike conventional expanding gap system ("Femelschlag"), which is very suitable for managing larger forest areas, both coppicing forms, especially the one with standards, are very convenient for small landowners since they can provide them with a wide range of wood assortments (e.g. timber and firewood) and non-wood forest products.

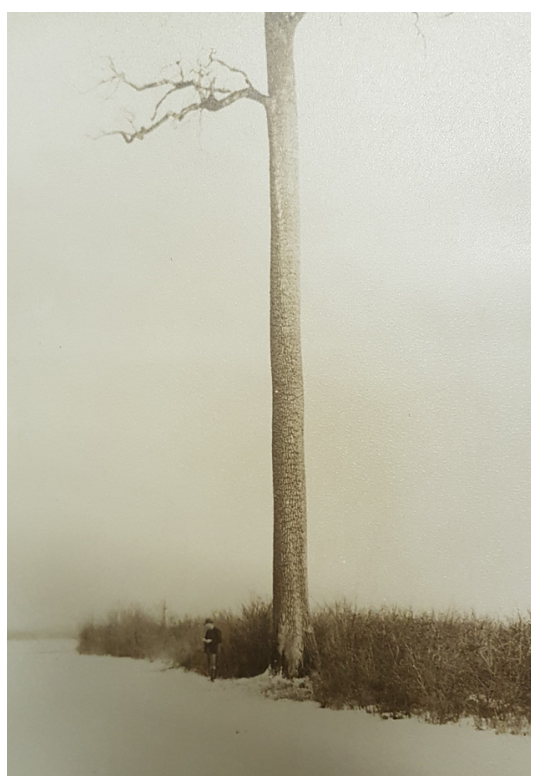

Fig. 2.5-1: Historical photograph of a solitary ash tree in front of a large homogeneously regenerated area in Vinkovci, Slavonia, Croatia 


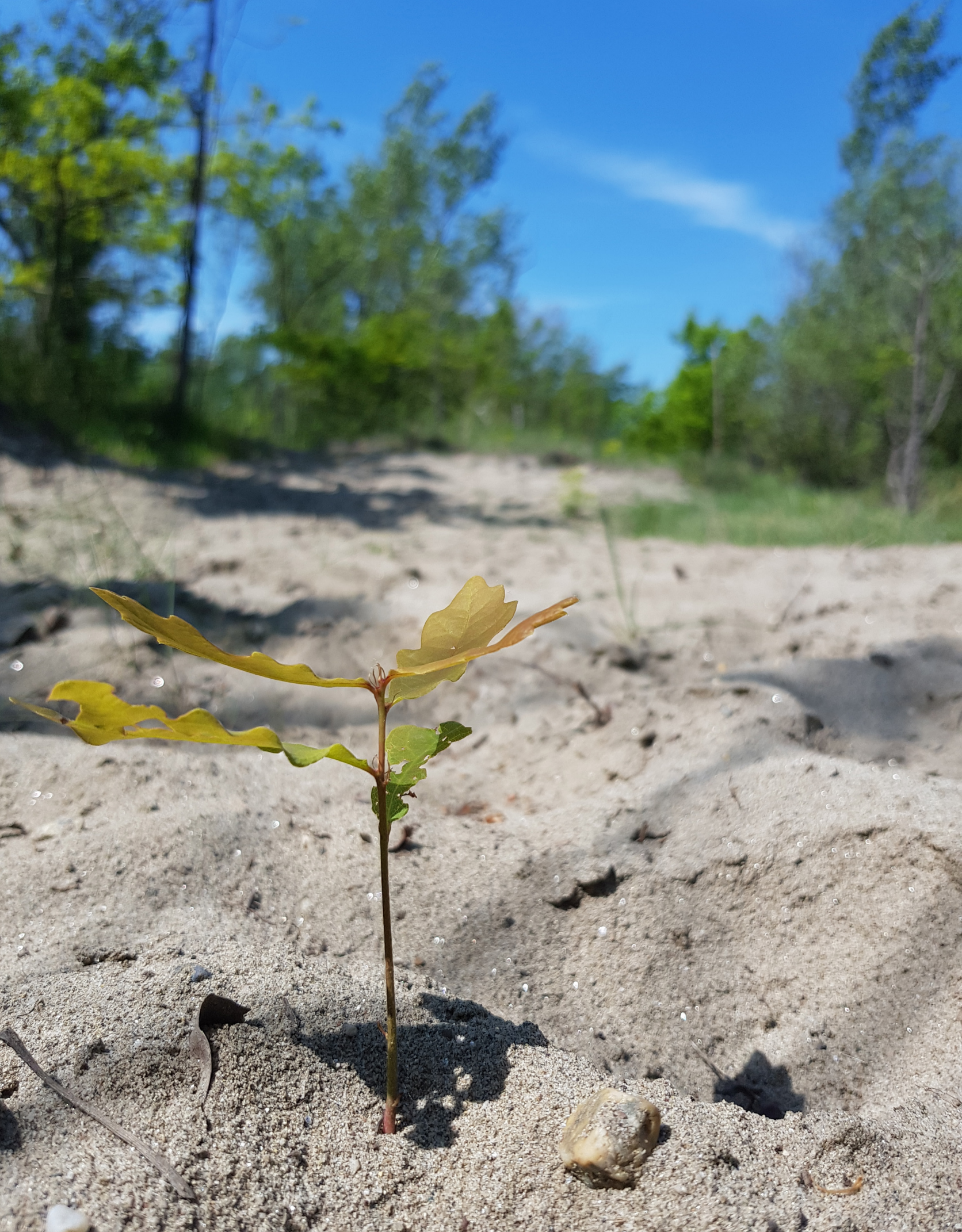




\section{MANAGEMENT GUIDELINES FOR RIPARIAN FORESTS}

\subsection{Forest regeneration and genetics}

\subsubsection{Choosing natural or artificial regeneration}

Marjana Westergren, Gregor Božič, László Nagy

\section{Introduction}

Regeneration is the most important part of the life cycle of a forest. It is a phase in which a forest can adapt to changing environmental conditions through natural selection.

Both natural and artificial regeneration play an important role in close-to-nature sustainable management of riparian forests. Where possible, natural regeneration should be encouraged because:

- natural selection has already acted on the progeny during germination and early seedling development, resulting in increased adaptedness,

- choice of species mixture can be based on autochthonous tree species,

- lower costs

However, natural regeneration is often not possible in riparian forests because the tree species composition is altered too much, the ground vegetation (often consisting of alien plant species) is very dense and may prevent suitable light and moisture conditions, the river dynamics have been changed too much, browsing is extensive, etc. In such cases, the solution is artificial regeneration. Artificial regeneration also allows a forest owner to manipulate the tree species composition and expected wood assortment to achieve a higher monetary gain. Enrichment planting is a form of artificial regeneration in which natural regeneration is artificially supplemented to enhance ecological, societal, or productive forest functions.

For artificial regeneration, seeds can be sown (e.g. oaks) or seedlings, cuttings, stool shots and root suckers (willows, black poplar, black alder) can be planted.

The best option for artificial regeneration is access to high-quality 
forest reproductive material with increased tolerance to biotic and abiotic stresses. Production of such material requires appropriate selection of seed sources, seed collection and processing, promotion of genetic diversity, and good nursery conditions that also promote the presence of mycorrhizae. From the point of view of conserving genetic diversity, this means that seed should be collected in equal quantities from a sufficient number of unrelated adult trees, usually at least 25 , preferably 50 . These trees should be adapted to current or possible future environmental conditions. The use of qualified and tested forest reproductive material will usually have the highest genetic quality and add the most value to production forestry.

Both natural and artificial forest regeneration are important in the riparian forests of the Mura-Drava-Danube Biosphere Reserve. According to an expert assessment within the REFOCuS project, natural regeneration predominates in Serbia (64\%) and Croatia (80\%), while artificial regeneration prevails in Hungary, Slovenia and Austria with $80 \%, 75 \%$ and $60 \%$ of the total forest regeneration in the Biosphere Reserve, respectively. These figures are strongly determined by the predominant forest types and the corresponding regeneration techniques. Natural regeneration works best with oaks and willows, but leads to lower success with other riparian tree species.
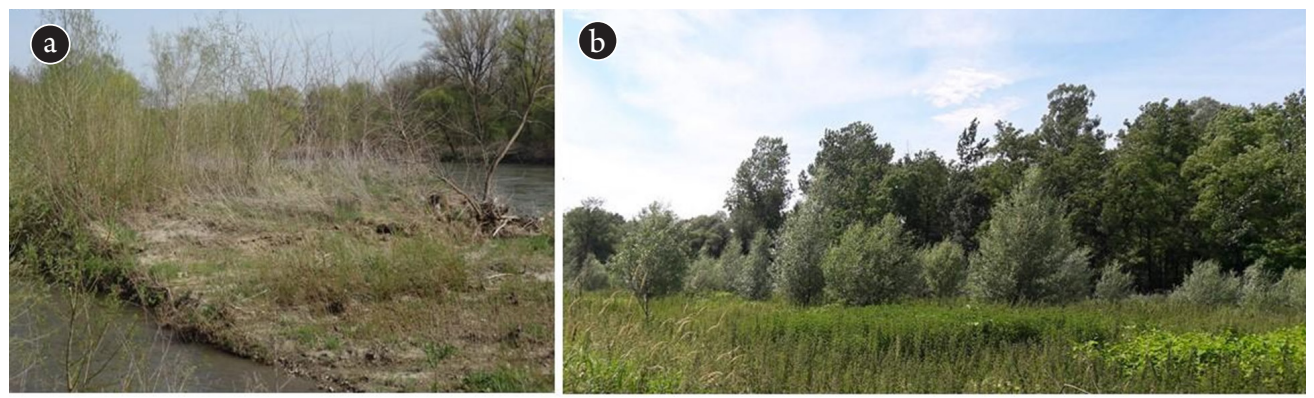

Figure 3.1.1-1: Regeneration of softwood forests along the Mura River in Slovenia; a) Natural regeneration; b) The result of artificial regeneration of white willow on an alluvial site

Guiding principles for the regeneration of riparian forests

Both natural regeneration and artificial regeneration should follow principles that are based on the natural processes of riparian forests and take into account the biology and ecology of tree species. These principles are:

- The choice of tree species and provenance should be based on the site conditions. This ensures the use of species 
and provenances that are well adapted to particular site conditions and therefore can withstand biotic and abiotic damage while achieving high growth rates.

- Native tree species and provenances are assumed to be better adapted to local site conditions. Because they have coevolved with other plant and animal species in a particular region, that region represents the best habitat for them. This view is being challenged by environmental changes, and sometimes it may be more appropriate to source forest reproductive material from neighbouring regions (see 3.1.2 Supporting adaptation of forests by selecting suitable forest reproductive material).

- Non-native tree species should only be planted if they are not invasive and in situations where this is an economic necessity or as insurance if all native tree species fail. Restrictions on their planting imposed by legislation must be respected. In any case, non-native tree species should form a minor component of a forest.

- The introduction of non-native species can disrupt symbiosis within a habitat and lead to reduced species diversity. If the presence of non-native species has adverse effects, their removal may be required before or during natural or artificial regeneration.

- The protection of rare and endangered tree species and provenances must be incorporated into regeneration activities by giving them priority in species mixtures.

- The density of the game population must be in balance with the carrying capacity of the site.

\section{Natural regeneration}

When possible, preference should be given to natural regeneration. For natural regeneration to be successful and promote the conservation of genetic diversity, there must be at least 50 healthy reproducing trees of a target tree species in a stand, spaced at least $30 \mathrm{~m}$ apart to avoid relatedness. At the same time, ground vegetation should not be too dense. After successful seedling recruitment, adult trees in a stand must be cut in a way to allow suitable light and moisture conditions for the development of seedlings of a target tree species.

Natural regeneration works best with oaks and willows, and to some extent with poplar. Successful natural regeneration of poplar requires fortunate timing of precipitation events, availability of nutrient-rich groundwater, and the presence of suitable surface provided by adequate stream dynamics. Waterlogged areas with 
a lack of oxygen are not suitable. However, natural regeneration of black poplar may consist of hybrids with non-native poplars. For this reason, natural regeneration of black poplar is not used in Hungary.

If the success of natural regeneration is low, natural regeneration can be supplemented by enrichment planting, or artificial regeneration should be carried out.

\section{Canopy opening}

To encourage natural regeneration, opening the canopy stimulates adult trees to produce seeds and provides adequate light on the ground. However, opening the canopy too much can result in a dense herbaceous layer that prevents recruitment of natural regeneration. Different light conditions can be created to allow the right conditions for different species.

\section{Ground preparation}

For black poplar and willows, disturbance of the soil on sandy bedrock is required for the establishment of natural regeneration prior to seed set, i.e. in the spring when natural geomorphological processes have not yet created suitable habitat. For other tree species, the shrub or herbaceous layer may need to be cut or mowed in late summer before seed set. Sometimes the soil needs to be tilled to facilitate seed germination.

\section{Browsing control}

Successful regeneration, especially in areas with high roe deer and wild boar populations, depends on browsing control. Regeneration areas must be fenced, with the fence set at least 30 $\mathrm{cm}$ deep into the ground to prevent its removal by animals.

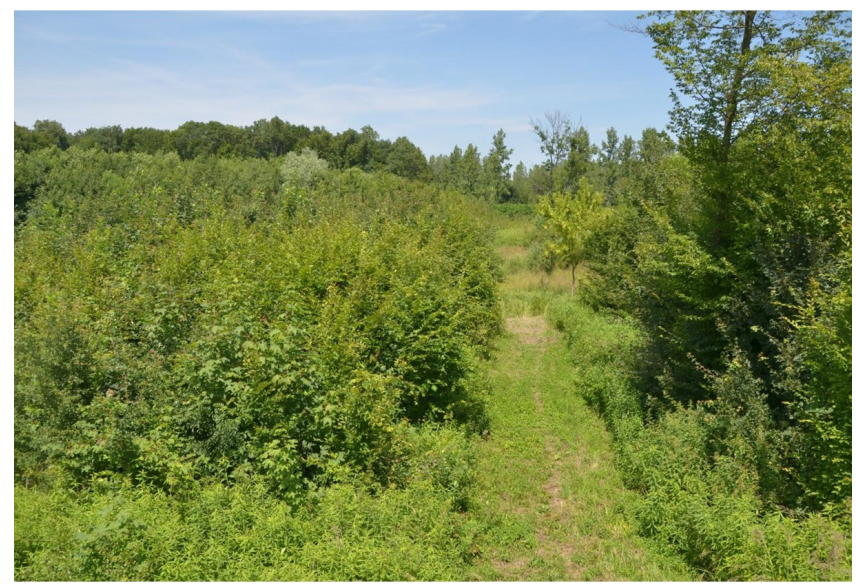

Figure 3.1.1-2: Natural regeneration of hardwood tree species 


\section{Artificial regeneration}

Artificial regeneration is used in situations where natural regeneration is not possible or sufficient. These include, but are not limited to: the need to change tree species composition, the lack of suitable light conditions due to dense ground vegetation (often consisting of non-native plant species), a lowered water table in the floodplain that prevents natural regeneration, or when certain ecosystem services need to be considered. Artificial regeneration is therefore mainly used to regenerate old riparian forest stands, to restore stands disturbed by diseases, pests or windthrow, to establish new riparian forests on bare areas (plantation conversions, afforestation) and to ensure genetic diversity and support natural processes leading to resilient forests.

\section{Ground preparation}

Before planting or sowing, most woody residues from tree cutting, such as stumps or branches, must be removed. Some woody residues should be left to protect biodiversity as they provide habitat for numerous animals and fungi (see 3.2.6 Integration of deadwood portions into regular management). If weeds such as Rubus spp., shrubs or non-native plants are present, they should also be removed before sowing or planting (Fig. 3.1.1-4).

On sensitive soils and in sensitive habitats such as marsh or swamp areas, tussock formations, small river beds, etc., the use of heavy machinery should be avoided as it causes soil damage and compaction.

\section{Selection of forest reproductive material}

There are four categories of forest reproductive material: sourceidentified, selected, qualified and tested. The genetic quality and control of the characteristics of the artificially regenerated stand increases from the source-identified to the tested category. Qualified and tested forest reproductive material usually comes from seed orchards, parents of families, clones, or clonal mixtures, while source-identified reproductive material may come from seed sources or stands, and selected reproductive material comes from forest stands that show visible superiority in a number of important traits.

Where possible, qualified or tested forest reproductive material should be used. If this is not possible, selected material is preferable to source-identified. However, qualified and tested forest reproductive material is often the result of intensive breeding activities, which are usually accompanied by a reduction in genetic diversity.

National legislation on the origin of the forest reproductive 
material to be used must be respected.

\section{Species selection}

Different species are recommended for artificial regeneration in riparian forests, depending on the habitat. 1) Riverine willow shrub is a pioneer vegetation that develops specifically in riverbanks; it is connected to the rivers and often forms a narrow belt between a riverbed and softwood forests. Willow mire shrubs, usually occupying areas lacking surface drainage and old oxbow lakes, are also covered here. 2) Softwood riparian forests are growing on the lower parts of floodplains, these hygrophilous, willow and poplar dominated forests still get regular flooding. 3) Hardwood riparian forests are occurring on the higher parts of actual or former floodplains in lowlands, wide valleys of colline regions, and at foothills. 4) Transition forests include heavily transformed, artificial forests or intensively managed plantations.

Table 3.1.1-1: Tree species recommended for artificial regeneration in riparian forests, depending on the habitat.

\begin{tabular}{|c|c|c|c|c|}
\hline Species & Willow shrubs & Softwood forests & Hardwood forests & Transition \\
\hline Acer campestre & & & $\mathrm{X}$ & $\mathrm{X}$ \\
\hline Acer pseudoplatanus & & & $\mathrm{X}$ & $\mathrm{X}$ \\
\hline Alnus incana & & $\mathrm{X}$ & $\mathrm{X}$ & $\mathrm{X}$ \\
\hline Carpinus betulus & & & $\mathrm{X}$ & $\mathrm{X}$ \\
\hline Fraxinus excelsior & & & $\mathrm{X}$ & $\mathrm{X}$ \\
\hline Juglans nigra & & & & $\mathrm{X}$ \\
\hline Malus sylvestris & & & $\mathrm{X}$ & $\mathrm{X}$ \\
\hline Prunus avium & & $\mathrm{X}$ & $\mathrm{X}$ & $\mathrm{X}$ \\
\hline Populus nigra & $\mathrm{X}$ & $\mathrm{X}$ & $\mathrm{X}$ & $\mathrm{X}$ \\
\hline Populus $\mathrm{x}$ canescens & & $\mathrm{X}$ & & $\mathrm{X}$ \\
\hline Pyrus pyraster & & & $\mathrm{X}$ & $\mathrm{X}$ \\
\hline Quercus robur & & & $\mathrm{X}$ & $\mathrm{X}$ \\
\hline Salix alba & $\mathrm{X}$ & $\mathrm{X}$ & & $\mathrm{X}$ \\
\hline Salix fragilis & $\mathrm{X}$ & $\mathrm{X}$ & & $\mathrm{X}$ \\
\hline other Salix spp.* & $\mathrm{X}$ & & & \\
\hline Tilia cordata & & & $\mathrm{X}$ & $\mathrm{X}$ \\
\hline
\end{tabular}

${ }^{*}$ including S. cinerea, S. elaeagnos, S. purpurea, S. triandra, S. viminalis, S. daphnoides, S. fragilis, S. pentandra 
When the use of non-native tree species is justified and allowed by the legislation, non-native Populus spp. and their hybrids, as well as Juglans nigra, may be used. Every decision should be taken carefully, be well planned and the actions monitored. Robinia pseudoacacia and Quercus rubra, two species that are common in riparian forests, are sometimes more competitive than native species and their uncontrolled spread may lead to biodiversity loss. Although black locust and black walnut are important nonnative tree species with many benefits for a forest owner and other stakeholders such as beekeepers, intensive plantations in close vicinity of forest reserves and endangered habitats should be avoided to prevent further invasion.

Planting of non-native tree species in riparian forests is possible only if it is allowed by the relevant forestry and nature protection legislation.

\section{Sowing and planting}

In riparian forests, sowing or planting in larger open areas has better success. The size of a planting area of less than 1 ha favours the establishment of invasive ground cover vegetation. However, in some countries, current legislation dictates the largest size of an open planting area (which is often too small for optimal success). Planting should be done between October and March when the seedlings are fully dormant and can best tolerate the stress caused by lifting, handling, storing, transporting, and the planting itself.

Depending on the distance between seedlings planted, which ranges from 3 to $2 \mathrm{~m}$, between 1,100 and 2,500 seedlings are needed for a planting area of 1 ha.

For most riparian tree species, the best seedling stock type is $1+2$ when the seedlings are three years old. For oak, seedlings planted in small holes should be 1.0 to $1.3 \mathrm{~m}$ tall. Black poplar and willow seedlings should be between 2.0 and $4.0 \mathrm{~m}$ tall and planted in holes 0.8 to $1.0 \mathrm{~m}$ deep.

Sometimes oak sowing may be preferred to planting because of the less labour required to achieve comparable results if wildlife, particularly wild boar, can be excluded from the regeneration area, e.g. by fencing. In flat terrain, spring sowing of acorns with a special machine that tilts the soil and simultaneously sows acorns has proven successful (see 3.1.4 Regeneration of pedunculate oak stands: natural and with direct sowing). In hilly terrain, spring sowing of two to four acorns in small holes after manual tillage has proven successful. 


\section{Tending}

Manual tending of seedlings and saplings (removal of weeds around the plant) is required at least once per growing season; multiple interventions are necessary if ground vegetation is aggressive. However, seedling survival increases with each additional tending. Two to four tending's per growing season are optimal.

At a minimum, tending should be performed until a seedling is taller than the surrounding weeds. For poplar, tending should be done once a year, for two to four years after the seedlings are taller than the ground vegetation, to eliminate competition for water and nutrients and accelerate their early growth.

\section{Browsing control}

Fencing of large areas to protect seedlings and young trees works best against browsing. Regeneration areas must be fenced, with the fence set at least $30 \mathrm{~cm}$ deep into the ground to prevent its removal by animals. Individual protection of seedlings can be also used (see 3.2.4 How to manage game and protect forests from damage).
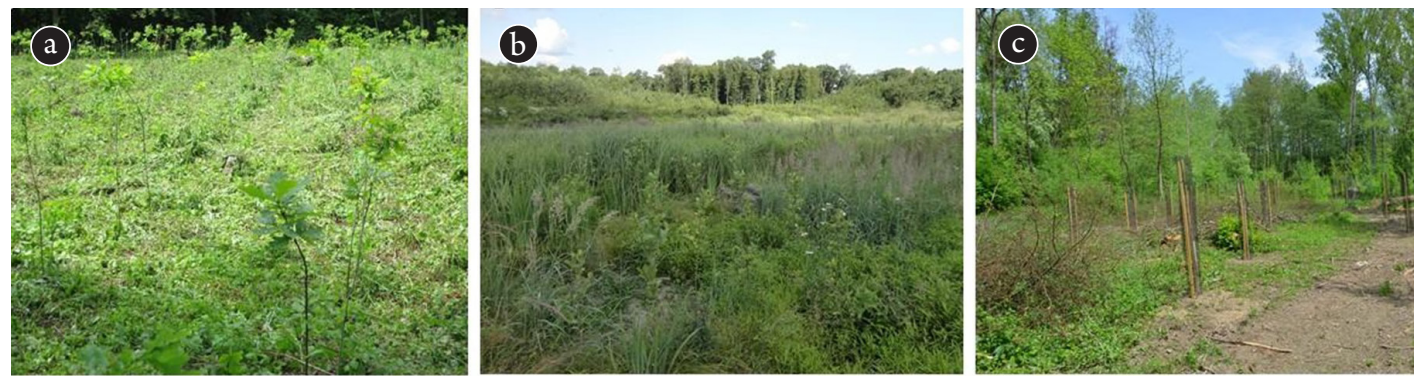

Figure 3.1.1-3: Artificial regeneration in Slovenia; a) Growth of pedunculate oak seedlings in the first growing period; b) Tending work is needed to free planted seedlings of black alder; c) Individual protection of black poplar immediately after planting is a necessary measure to protect seedlings against browsing

\section{Coppice and coppice with standards}

Coppice is often found in riparian forests and works well with poplar, willow, oak, ash, and alder. Coppice is based on rapid regrowth after trees are cut down, allowing the stumps to regenerate for a few years.

Coppice rejuvenates vegetatively from stump sprouts (stool shoots) and root sprouts (root suckers). To support vigorous regrowth, sufficient light must penetrate to the ground. Therefore, a sufficiently large part of the coppice, i.e. 0.1 to 0.2 ha, should be cut at the same time. However, trees cannot be coppiced continuously rotation after rotation, as after a few rotations they tend to lose their vigour, stop sprouting and eventually die. Two, 
sometimes three rotations are acceptable for oak, ash and alder. Poplars and willows, especially on poor sites, are often coppiced for more rotations. Therefore, the influx of seedlings resulting from sexual regeneration must occasionally be allowed. Both natural regeneration and planting can be used to rejuvenate parts of the coppice forest, provided the considerations described above are taken into account.

Coppicing can serve as a useful tool for in situ conservation measures or, if the aim is to reduce management intensity, for biodiversity conservation in general.

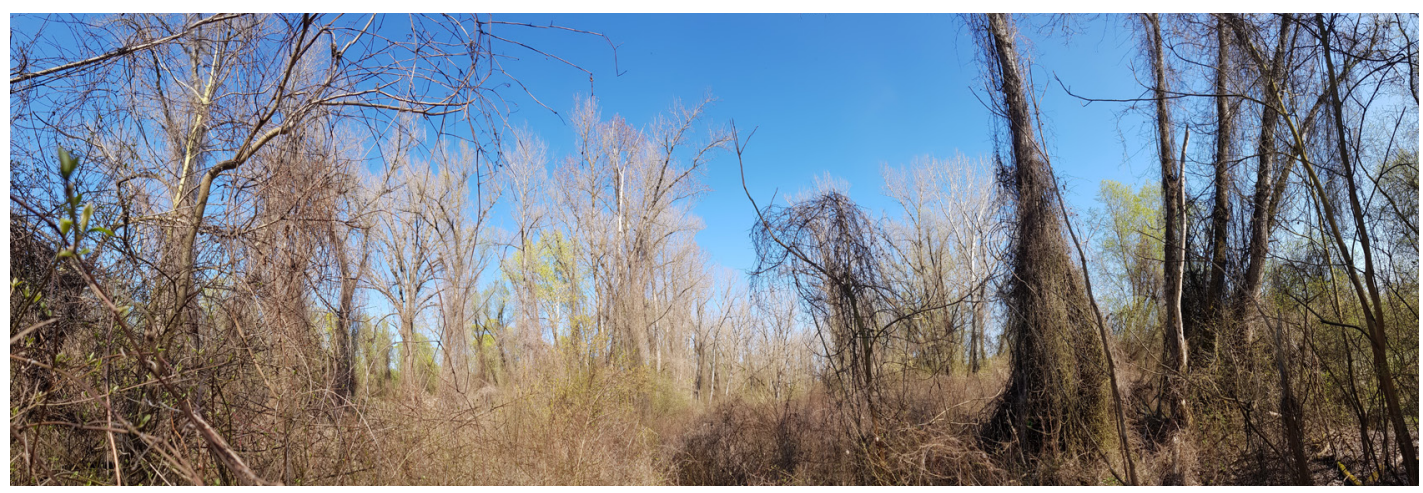

Figure 3.1.1-4: Aggressive wild vine overgrowing regeneration in a canopy gap at the Drava River, Hungary

\section{Summary and outlook}

Regeneration allows a forest to adapt to changing environmental conditions. Both natural and artificial regeneration play an important role in close-to-nature sustainable forest management of riparian forests. Preference should be given to the former as it allows adaptation through natural selection and is less costly. However, it is often not possible in diseased and disturbed forests and in the absence of suitable seed sources. Artificial regeneration is then used, through which adaptation to changing conditions is also possible. A decisive step in artificial regeneration is the selection of tree species and provenance, especially taking into account the future climate. In riparian forests, natural regeneration often requires human intervention, through regulation of the amount of light, soil preparation, care of the seedlings and protection from animals. Similar care is required for artificial regeneration.

\section{Acknowledgement}

We thank Silvija Krajter Ostoić, Markus Sallmannshofer and Marko Kovač for their insights concerning this chapter. 


\subsubsection{Supporting adaptation of forests by selecting suitable forest reproductive material}

\section{Markus Sallmannshofer, Silvio Schüler}

\section{Limitation of national seed transfer and provenance regions}

The presence and extent of forest ecosystems in Europe and the Danube region, as well as the distribution ranges of tree species, are not limited by national borders. In addition, local adaptation of tree species follows topographic structures (e.g. mountain ranges) and climate zones rather than national or regional boundaries. However, regulations for the utilization and conservation of forest reproductive material (seed, seedlings, cuttings, etc.) have been developed mainly at a national, in some cases even at regional levels.

At a nationallevel, riparian forests frequently constitute only a small part of a country's forest ecosystem. This underrepresentation creates a serious shortcoming of suitable planting material well adapted to riparian forests when only national forest reproductive material may be utilised. Without considering the transnational connectivity of riparian forests, forest reproductive material may be regulated in accordance with legislation, but be incorrectly assigned to ecological conditions of riparian forests. For example, forest reproductive material of non-riparian forests of the same national provenance region may be maladapted and generally unsuitable for planting in a riparian forest, potentially resulting in lower forest stability, higher pest infection rates and lower forest resilience.

\section{Climate change driven abiotic stressors}

Climate change is expected to result in changing environmental conditions across all forests, including riparian ones. Climate change includes not only an increase in temperature, but also changes in the frequency and seasonal distribution of precipitation patterns, as well as an increasing frequency and magnitude of climatic extreme events, such as storms, droughts and floods. In Southern Europe, drought frequencies are increasing, especially in spring and summer, while in Southern and Eastern Europe floods are expected to decrease. As a consequence of climate change, the distribution ranges of forest tree species are changing - following changes in their habitat suitability.

\section{Consequences and interactions of climate change with biotic stressors}

Biotic disturbances are expected to increase with the shifting 
distribution ranges of pests and pathogens and of their tree host species. For example, warmer winter temperatures can positively change survival rates of pests and diseases and result in their potential range expansions, while the hosts' susceptibility can increase. Additionally, the ability to adapt is expected to be higher for pests and diseases than for host tree species because of their faster generation turnover. Similarly to pests and diseases, the distribution of non-native plants can increase, resulting in a higher competitive pressure on native plant communities.

\section{Adaptation lags and assisted migration}

Compared to other organisms, life cycles of trees are long. Thus, the adaptive capacity and migration ability of forest trees is smaller than the speed of climate change disrupting the link between climate and local adaptations. This challenges the "local is best" paradigm. A so-called "adaptation lag" is expected to occur for many forest trees. A delay in adaptation, caused by rapidly changing environmental conditions, is expected to result in serious malfunctioning of forests ecosystems.

Artificial transfer of forest reproductive material from matching locations has been suggested by forest and conservation scientists around the world to speed up adaptation processes and reduce the adaptation lag. Not only survival rate could be increased, there is also a chance of performance gains both in growth and resistance. Therefore, forest managers are confronted with a challenge of finding well-adapted planting material for reforestations for future forests.

\section{Guideline on how to use REFOCuS seed transfer zones and species distribution models with changing climate}

To support reforestation planning in riparian forests, species distribution models and seed transfer zones were developed for the REFOCuS project countries (http://www.interreg-danube.eu/ approved-projects/refocus/outputs). With the ongoing climate change, these zones will also dynamically change their spatial extent. The developed tool allows forest and conservation managers to select forest reproductive material that is suitable for future climate conditions of a given area.

The results are provided as a set of transboundary maps for seven riparian tree species that are present in Austria, Croatia, Hungary, Serbia, and Slovenia as well as parts of the neighbouring countries. Descriptions and links to high resolution maps can be found in the appendix. To identify forest reproductive material to 
be planted, two types of maps should be used in three steps:

1. Future suitability of climatic conditions at the planting site should be checked.

2. If conditions in the future are acceptable for the species in question at a planned planting site, a provenance suitable for future conditions needs to be selected. To find this provenance, a seed transfer zone that is likely to appear in the future at a planting site must be identified.

3. Afterwards, a map of the seed transfer zone that will appear in the future at a planting site must be located under current climate. A seed transfer zone under current climate represents an area where forest reproductive material for planting is to be sourced.

Sets of maps both for an extreme (RCP 8.5) and a moderate climate change scenario (RCP 4.5) are available.

\section{Example A}

The forest management of an enterprise located in western Lower Austria (red cross on the map, Fig. 3.1.21) faces climate change driven fallout of their main tree species. Therefore, they want to plant Quercus robur there. First, they check the suitability of the site - the red cross - for Q. robur under future climate conditions with both RCP 4.5 and 8.5. The occurrence probability for Q. robur at the site is $0.8-1.0$ for both scenarios and the management decides to plant Q. robur (Step 1). Now, they need to choose a provenance. The chosen provenance should be adapted to climatic conditions that are likely to appear in future. Therefore, they check which seed transfer zone will be present at the enterprise's site around 2100 . They see that this will be the seed transfer zone "CL4" (Step 2). Finally, forest reproductive material of a provenance that currently grows under the same climatic conditions (i.e. "CL4"), is selected to be transferred (Step 3).
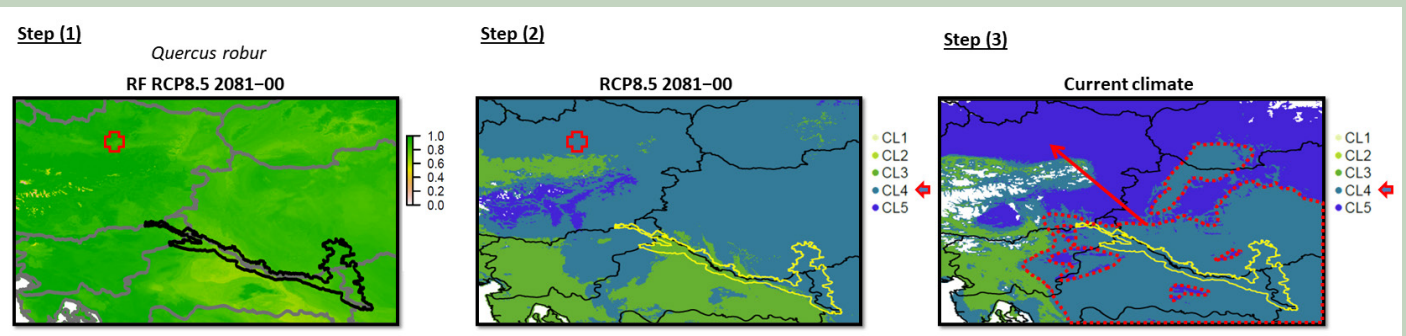

Figure: 3.1.2-1: Transfer of forest reproductive material according to the modelled REFOCuS seed transfer zones 


\section{Example B}

A forest enterprise aims to conserve and restore the current potential vegetation within the Mura-DravaDanube Biosphere Reserve at the Croatian-Hungarian border (red cross on the map, Fig. 3.1.2-2). Ulmus laevis is the species of interest. The current climatic conditions are excellent and the occurrence probability for $U$. leavis is 0.8-1.0 (not displayed below). However, the climate conditions for the future with both RCP 4.5 and 8.5 predict the site to become less suitable for U. leavis. The predicted occurrence probability under RCP 8.5 is below 0.2 (Step 1). Nevertheless, for conservation purposes the managers decide to plant U. laevis counting both on:

- the natural ability of the tree species to adapt to future conditions, and

- $\quad$ selecting an origin of climatic conditions that are likely to appear in the future.

Therefore, they check which seed transfer zone will be present at the site around 2100 . They see that this will be the seed transfer zone "CL5" (Step 2). Finally, forest reproductive material of an origin that is showing the same climatic conditions already today, thus, the current zone "CL5" is selected to be transferred (Step 3).

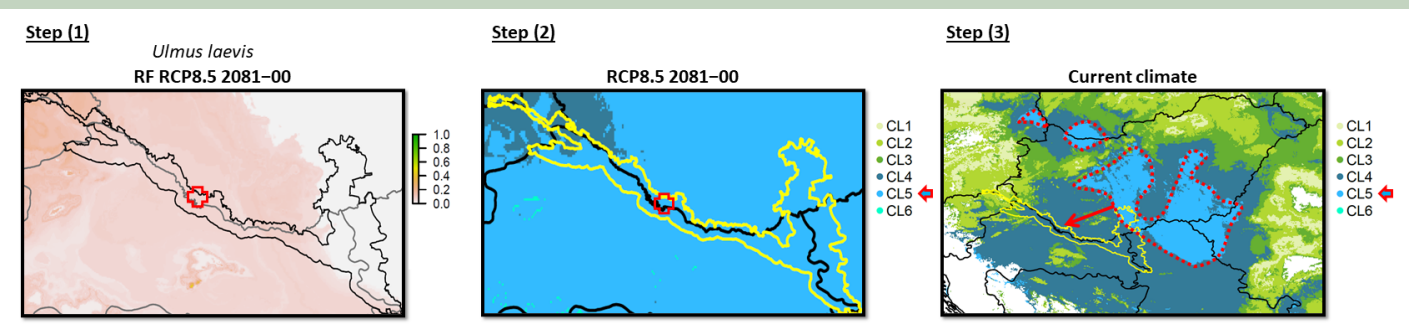

Figure: 3.1.2-2: Transfer of forest reproductive material according to the modelled REFOCuS seed transfer zones

\section{Limitations}

The maps are an up-to-date-tool to support practitioners. Nevertheless, there are some limitations to be considered when using the maps:

- The models include only climatic variables. Other biotic and abiotic factors must be considered by forest managers based on their knowledge of local conditions (e.g. ground water supply and level, soil, storms, pests and diseases etc.).

- The ability of tree species to adapt to changing climate conditions is difficult to quantify for tree species and single populations. Therefore, the extent of the adaptation lag cannot be quantified precisely. However, careful transfer of forest reproductive material considering also putative negative effects (e.g. increasing frost sensitivity) is for some tree species considered as the best option to overcome the adaptation lag.

- Climate change scenarios include uncertainties

- Interpolated and downscaled climate data may not fit to local conditions of a (micro)site of interest or provenance to be 
transferred.

- Present tree occurrences, the training basis of the models, were strongly influenced by humans. 


\subsubsection{Genetic conservation for practitioners}

\section{Gregor Božič, Marjana Westergren, Marko Kovač}

Long-lived forest trees must withstand a variety of abiotic (e.g. climate) and biotic (e.g. diseases) stressors during their lives. The essence of forestry ethics guiding professional forestry must therefore be sustainable forest management that takes into account the principle of genetic sustainability. Only in this way can all the present benefits of the forest be secured for the future. Forest tree species grow under diverse ecological conditions to which they have adapted through natural (and sometimes artificial) selection. On average, forest tree species have high genetic diversity within populations. This high genetic diversity within populations makes forest stands more resistant to various abiotic and biotic stresses, as genetic differences between trees allow some to survive and reproduce even when others do not, enabling continuous adaptation to new environments through evolutionary change.

The genetic diversity of trees is not easy to observe and quantify. Usually, we observe and study it through:

- phenological diversity,

- differences in growth,

- trunk form,

- degree of resistance to biotic and abiotic adverse effects, and

- allele polymorphism (molecular markers) within and among populations.

Conserving and sustainably using the genetic diversity of forests is a necessary task, but not an easy one. In the past (and in much of the world still today), a forest, the ecosystem services it provides, and its genetic resources have little value in practice. Globally, the main threats to forest genetic resources are the following: industrial forestry using materials with a narrow genetic base, habitat loss due to deforestation, fragmentation, urbanization and fire, changes of autochthonous forests with plantations of nonnative tree species, inappropriate and uncontrolled use of forest reproductive material, the loss of local races and autochthonous populations, invasive species, and climate change.

However, the rapid pace of climate change and its unpredictable patterns at local scales require, as a precautionary measure, the conservation of genetic diversity, including the adaptive potential of forests. These issues are becoming one of the most important tasks for forest science, policy and practice.

Forest regeneration is the key phase for the transfer of genetic 


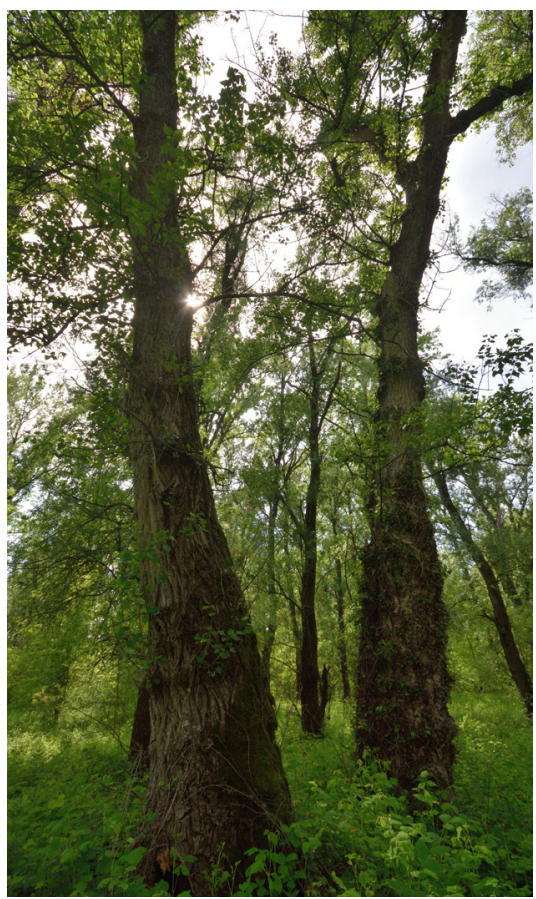

Figure 3.1.3-1: Black poplar (Populus nigra) in situ gene conservation unit and seed stand in Croatia information from the old stand to the new. However, despite natural regeneration, forest genetic resources can be threatened, depending on the silvicultural practices used and the number of trees that pass on their genes to the next generation. Sometimes artificial regeneration is required to enrich a stand with new genetic variants. When selecting provenances for planting, safeguarding genetic diversity and stability must be a priority. Forest reproductive material from advanced breeding programmes has better growth characteristics but often lower genetic variability. On the other hand, genetic variability usually increases in seed orchards where cross-pollination and exchange of genes between trees is encouraged. An emerging area is breeding for resistance to diseases such as ash dieback. There needs to be a reservoir of existing genetic diversity to enrich breeding programmes with new genetic variants as new stressors emerge.

Genetic resources can be conserved by static and dynamic conservation, ex situ or in situ. There is consensus that dynamic in situ conservation in so-called gene conservation units is best suited to maintain evolutionary processes in tree populations and thus the adaptive potential of forest trees. Gene conservation units are forest stands that have adapted to specific environmental conditions or have distinct characteristics. They are typically located in forests managed for multiple use, in protected areas or in seed stands (Fig. 3.1.3-1). Their management aims to maintain and enhance the long-term evolutionary potential of these tree populations. They are usually naturally regenerated, and occasionally also with forest reproductive material collected in the same stand or in its vicinity, i.e. within the same population.

Static ex situ conservation consists mainly of collections and living

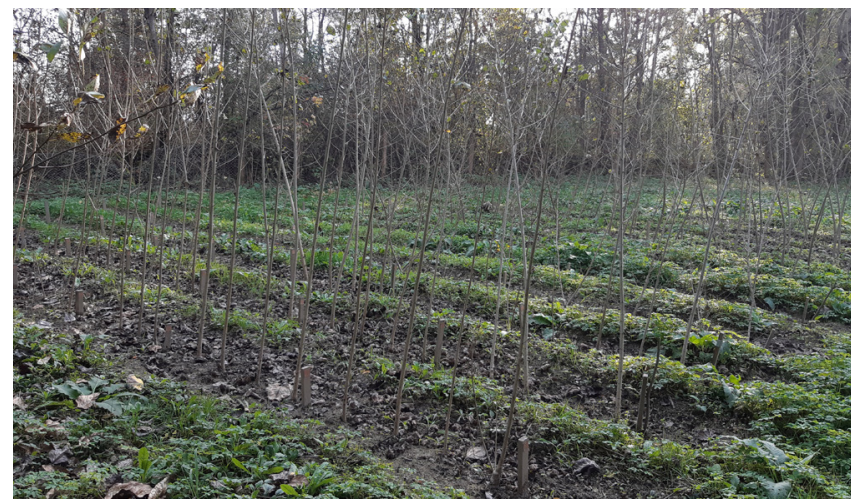

Figure 3.1.3-2: Ex situ clonal collection of selected old black poplar trees from the river Mura in Slovenia 
archives, e.g. clone collections, seed plantations and provenance and progeny tests, established outside forests. Such collections and archives are often marked and fenced off in such a way that unauthorised access is not possible (Fig. 3.1.3-2).

The delineation of seed stands and the production of forest reproductive material must pursue not only economic interests (e.g. to improve wood quality) but also the maintenance of genetic diversity and the improvement of the resilience of forest tree stands. Thus, enough reproducing trees (dominant and co-dominant trees that flower and pollinate each other) must be present in seed stands at sufficient distances to avoid family structures and thus inbreeding. In addition to enough reproducing trees, forest reproductive material should be collected from sufficient trees to ensure adequate genetic variability. The origin of forest reproductive material also plays a role. The use of local forest reproductive material is still considered most desirable, but see also 3.1.2 Supporting adaptation of forests by selecting suitable forest reproductive material.

\section{Practical measures for conservation of forest genetic resources in riparian forests}

The development of floodplain forests is modulated by water. In close proximity to streams, forests are exposed to the daily fluctuations of pulsating water flow, constant movement of material, and prolonged flooding. Conversely, forests farther from a watercourse are less disturbed; flooding and material movement are seasonal, and groundwater has a much greater influence here. Depending on their distance from a watercourse, trees have developed different strategies for natural regeneration. Where daily fluctuations occur, vegetative reproduction (from the tree itself or washed-up plant material) is most effective because of the high intensity of disturbance. Sexual reproduction via seed tends to occur in areas less exposed to constant water fluctuations. Due to disturbance in floodplain forests and the difficulty of their regeneration, the following measures are recommended for the conservation of forest genetic resources:

- Regeneration of coppices of pioneer tree species growing directly along watercourses should be gradual.

- Tending of stands should be based on the removal of damaged and non-vital trees or their parts. All autochthonous willow (Salix sp.), poplar (Populus sp.) and alder (Alnus sp.) species should be encouraged.

- In coppice forests, cutting of trees above a certain $\mathrm{DBH}$ threshold should be avoided, since this removes the most vital 
and high-quality trees and consequently the genetic variability of these trees from a stand. The poor and less vital trees should however be removed, while the quality and vital ones should be left to set seed and reproduce.

- Where natural regeneration is possible, it should be encouraged and carried out by creating inhomogeneous light conditions through cutting adult trees. If sun-loving tree species are present, allowing enough light is necessary to avoid their plagiotropic growth (e.g. in oak). Pioneer tree species should be used for tending the stand.

- In areas where natural regeneration is disturbed, enrichment plantings of target tree species of local provenance should be made. To prevent fragmentation of a floodplain stand, an appropriate minimum width and area of plantings should be considered.

- Where natural regeneration is planned or ongoing, grazing of cattle and sheep should be prevented. The density of the game population should also be regulated to enable establishment of a sufficient number of saplings per hectare. If this cannot be ensured, regeneration should take place within fenced areas.

- At the time of regeneration (and otherwise), the establishment of invasive plants should be prevented (see 3.2.5 Management of non-native plants).

- Along watercourses, shrubs and other plants that constitute habitats for animals, should be left to grow. Where beavers are present, softwood tree species (Salix sp., Populus sp., Alnus sp.) should be planted or left along a watercourse to avoid damage.

In every planting, appropriate sourcing and handling of forest reproductive material must be ensured. Thus, despite high financial inputs into soil preparation, planting, protection and tending of seedlings, the work may be in vain if the planted tree provenance cannot survive and grow well in its planted environment.

\section{Summary and outlook}

Conservation and protection of forest genetic resources does not preclude forest management; it just means that any action must be considered in terms of its impact on genetic diversity and population genetic structure. Failure to do so may result in long-lasting negative consequences for forests and genetic forest resources.

\section{Website recommendation}




\subsubsection{Regeneration of pedunculate oak stands: natural and with direct sowing}

\section{Gyula Kovács, Markus Sallmannshofer}

\section{Introduction}

Natural regeneration of oaks is a very favourable solution from an ecological and nature conservation point of view. The economic advantage of this method is that usually inexpensive local reproductive material is used. The disadvantage is that there is not enough acorn crop every year for natural regeneration, which has been made worse by frequent and intensive droughts recently and even more importantly, by the decrease in the groundwater level. However, if the tree crowns are small, even good environmental conditions will not secure a good crop.

Natural regeneration of oak is difficult if there is a large game population, by the high demand of pedunculate oak for light and strong weed competition, and the competition of invasive non-native trees (Acer negundo, Fraxinus pennsylvanica, Robinia pseudoacacia, Ailanthus altissima). When there are not enough acorns, under-sowing may be used to imitate natural regeneration. The advantage is that forest reproductive material with better genetic properties can be used. This increases the timber value of the future forest, but is more expensive compared to the natural regeneration.

In Hungary, riparian oak stands have been almost exclusively regenerated artificially either with seedlings or with acorn sowing. The latter is preferred in forestry practice since the costs of seedling production are eliminated and the negative effects of the transplanting shock can be avoided. However, obtaining an adequate amount of quality acorns every year is difficult while planting with seedlings is easier to plan.

Today, the awareness for a proper selection of forest reproductive material that matches management goals, especially future environmental conditions, is much higher.

\section{Management of natural regeneration}

In riparian oak stands, natural regeneration is a demanding professional challenge. The duration of the regeneration period is determined by the high light requirements of young oaks. Naturally emerged seedlings can live in the shade for one to two, maximum three years, but only with a subsequent significant reduction of canopy closure to about 50\%. It is also not recommended to delay the final cut of the remaining trees after the canopy has opened, 
as there is a high risk of intensive development of suckers on the remaining trees.

Steps to establish natural regeneration (short version of the traditional shelterwood cut)

Preparation of forest stands for acorn production. Reduction of canopy closure: removal of individuals with small crowns, suppressed and malformed to avoid their reproduction. Only a moderate reduction is recommended due to the risk of sucker shoot development and emerging weed competition. If a dense understory layer of trees or shrubs is present it must be cut partly to allow for the establishment of regeneration. The function of stem and soil shading must be maintained.

After the appearance of regeneration, forwarding roads need to be set, followed by the final cut within one to two (three) years.

Enrichment planting can usually be done with artificially grown seedlings. Here it is possible to include mixtures of species, but frequently they also appear on their own and overgrow oaks in the initial phase. Growth dynamics needs to be monitored and included in planning of the spatial distribution of different species in a stand (see 3.2.6 Integrating biodiversity enrichment in poplar forest management and 3.2.2 Optimisation of the production of high-quality logs in hardwood stands).

Weed control is required for three to four years. This is usually done mechanically. However, chemical regulation is sometimes the only solution for successful weed and non-native species control. Problems with weeds and non-native plants arise mostly on wet sites. It is especially important to remove non-native invasive tree species (e.g. Acer negundo, Fraxinus pennsylvanica, see 3.2.5 Management of non-native plants). The regeneration of these tree species appears in large numbers in some places (e.g. along Danube in Gemenc), which makes natural regeneration of oaks impossible or achievable only at a great expense.

\section{Natural regeneration methods}

- One-step (clear-cutting) regeneration: in the case of a large acorn crop with clear-cutting two to three years after the appearance of regeneration.

- Gradual regeneration ("shelterwood cut"): a continuous multi-step method, applicable in homogeneous stands. It is the most commonly used method in large oak stands as found in Slavonia, Croatia.

- Group regeneration: Can be used in heterogeneous stands 
and takes a long time. With this method, it is difficult to give the pedunculate oak enough light. This method builds structural diversity and allows managers to incorporate other tree species into the forest stand by controlling the diversity of light conditions.

- Gap regeneration: It is similar to group regeneration but carried out on a smaller scale with gaps up to one tree length wide. Once the regeneration within a gap is two to three years old, gaps are widened according to the growth of regeneration.
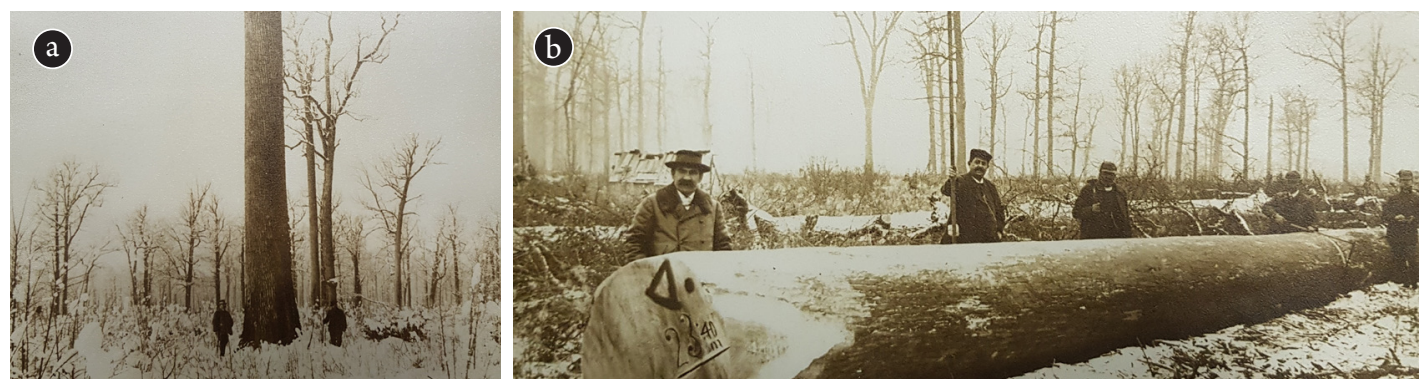

Fig. 3.1.4-1: a) In a shelterwood cut the best oaks remain in a forest stand for acorn production until the final cut; b) An oak log of $23.4 \mathrm{~m}$ length in front of a stand managed by a shelterwood system during the last cutting stage

\section{Practical application of the natural regeneration methods}

Along the Drava River, the so-called "acorn crop cutting" is carried out on the Hungarian side when large acorn crops are present. The clear-cutting is carried out in winter immediately after the acorn crop. The aim is to create good light conditions for the regeneration, which in this way is not in the shadow of the mother trees.

In the case of a normal acorn crop, a $40-60 \%$ reduction of canopy closure (gradual regeneration) is done in the year of the acorn crop. Simultaneously, shade tolerant species, understory and shrub layer are removed. The final cut is done within a maximum of two years. The minimum density of offspring for a good regeneration is three to four plants per $\mathrm{m}^{2}$. If not prohibited, chemical weed control in the year of the acorn crop can significantly support regeneration.

\section{Undersowing}

This procedure is a hybrid between natural and artificial regeneration. Low or insufficient acorn crops can be supplemented by sowing up to 300 to $400 \mathrm{~kg}$ of acorns per hectare. The advantage of this method is that regeneration with better genetic quality than the existing forest stand may be established. If sowing is done in 
lines, weed control can be mechanized. The expected density of seedlings is also three to four plants per $\mathrm{m}^{2}$.

\section{Artificial regeneration with acorn sowing}

In riparian oak stands, artificial regeneration is a common practice. It includes seedling planting (see 3.1.5 Supplemental enrichment, restoration and establishment of oak stands via artificial regeneration) or sowing acorns on large areas. Sowing is preferred when there are enough acorns available. After complete or partial soil preparation with a plough or mulcher, 300 to $400 \mathrm{~kg}$ of acorns per hectare are sown in rows with machines or manually. Row spacing of 1.5-1.8 m has proven successful in Hungary.

\section{Further problems and recommendations}

Dry winters followed by droughts in spring and summer inhibit oak regeneration. Powdery mildew is a significant problem in the first few years after regeneration. In some places, chewing by cockchafer grub can also inhibit regeneration. The infestation of old grown oaks by the oak lace bug (Corythucha arcuata) is presumed to influence seed production (Fig. 3.1.4-2, see 3.3.1 Forest pests and diseases in a changing world: the importance of early detection). Pest control against cockchafer grub is easiest in artificial regeneration. After removing the remaining stumps of the old stand, the soil can be chemically disinfected (if allowed) by turning the top $30-50 \mathrm{~cm}$. Injection of chemicals, which is

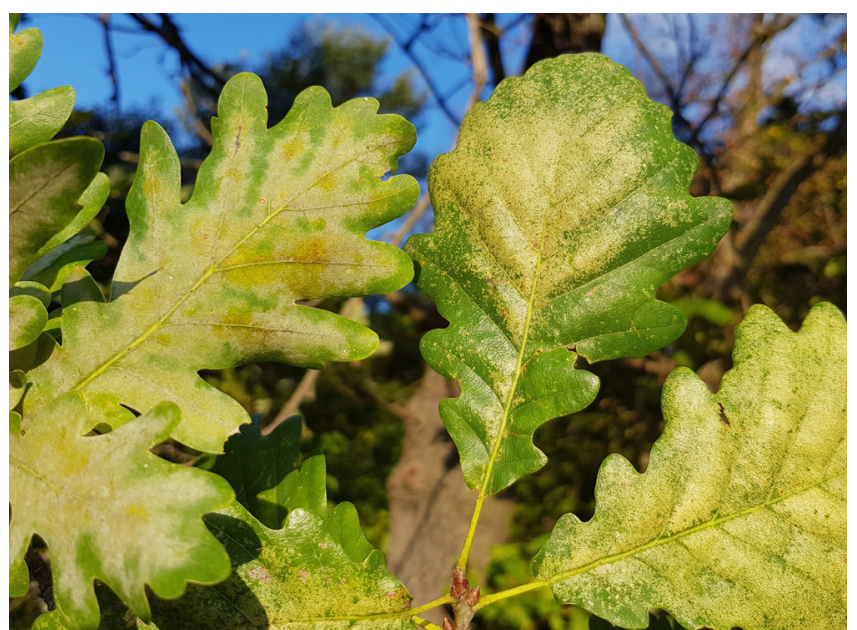

Figure 3.1.4-2: Pedunculate oak regeneration damaged by the oak powdery mildew (Erysiphe alphitoide, leaves on the left) and the oak lace bug (Corythucha arcuata, leaves on the right) 
usually less successful, can be applied when damage has already appeared. One of the most significant problems is a negative influence of wild animals such as rodents and ungulates on oak regeneration. Currently, ungulates can be stopped effectively only with fences (see 3.2.4 How to manage game and protect forests from damage), which is required for successful regeneration of oak no matter of the applied regeneration technique.

\section{Outlook and Summary}

Regeneration of oak demands silvicultural know-how and skills. In both artificial and natural regeneration, above ground weeds and invasive non-native tree species must be continuously removed. Further, protection against game is required to support regeneration of oak stands. Still, there is a lot of knowledge and experience available on how to regenerate pedunculate oak properly.

\section{Acknowledgement}

We thank Lajos Gyergyák and Zoltán Puskás for the discussion concerning this chapter. 


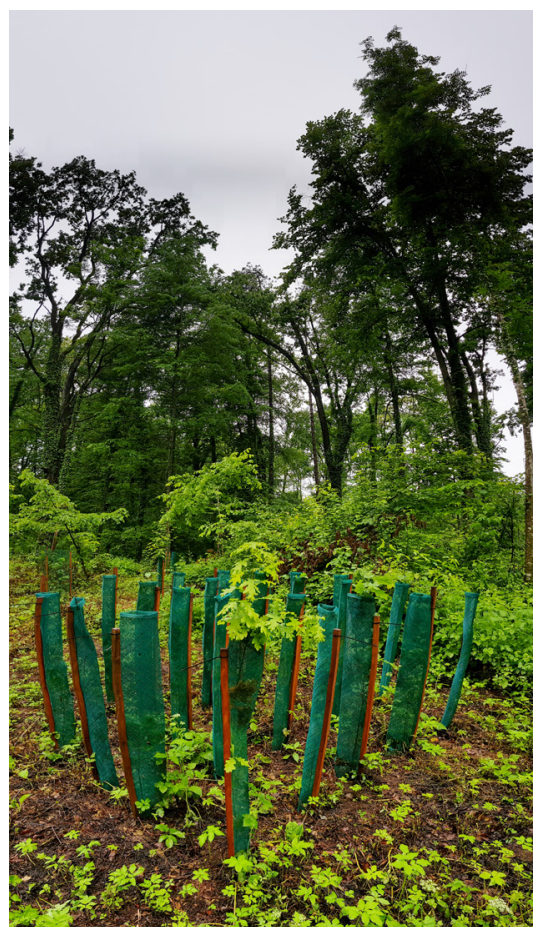

Fig. 3.1.5-1: Group planting of Quercus robur with 18-25 plants and $1 \mathrm{~m}$ distance is currently the favoured solution for oak regeneration in Austria

\subsubsection{Supplemental enrichment, restoration and establishment of oak stands via artificial regeneration}

Silvio Schüler, Hannes Schönauer, Werner Ruhm, Gyula Kovács

Managed and unmanaged riparian forests are in permanent change. In unmanaged riverine landscapes, changes occur due to fluctuations in water levels, flooding, and large-scale alterations of a river stream, which may result in abandoned channels and siltation of former watercourses. As a result, former softwood forest habitats become unsuitable for the majority of characteristic pioneer trees and undergo a shift to hardwood forests. Human river regulation has accelerated this process of forest change. Today, many softwood forests are isolated from riverine habitats, and both native and planted softwood species may face lower vitality and become unsuitable for altered habitats. Furthermore, invading non-native trees and pests and diseases pose additional challenges and threaten the ecosystem services provided by riparian forests.

Pedunculate oak, a typical species of hardwood riparian forests, shows a comparatively high resistance to pests and diseases and would thus be one of the most important target species to enable the persistence of riparian forests with high ecological and economic value. However, natural regeneration in oaks depends on the availability of nearby old-growth stands, on sufficient seed set during mast events, on competing ground vegetation as well as on game management. Therefore, the artificial establishment of oak stands might be a required management option for both the restoration of hardwood forests in conservation areas and the establishment of managed forest sites for the production of highquality timber. A typical management objective in oak silviculture is the production of $60-80$ high-quality logs per hectare with minimum sizes of $60 \mathrm{~cm}$ diameter at breast height within $80-150$ years. The production of such stems requires high stand density at early stages (qualification) to foster natural pruning and to reach a sufficient branch free stem length.

To realize such stand development, artificial regeneration of oak can be undertaken in two different planting designs: either using row planting with high initial densities of at least 5,000 seedlings per ha or using group/cluster planting where 60 to 80 groups of 25 seedlings per group are planted per hectare at distances of 10 to $13 \mathrm{~m}$. The distance between groups resembles approximately the distance between future target trees to allow an optimal development of tree crowns. Both planting designs have advantages and disadvantages, and the choice of planting design 
needs to follow site characteristics and available site maintenance options. A third regeneration design is the so-called nest planting, where 20 to 30 seedlings are planted with a very dense spacing of approximately $0.2 \mathrm{~m}$ between trees. Nest planting, however, was found to result in lower tree survival, growth and quality. Therefore, it cannot be recommended based on the ample negative experiences made in experimental trials throughout the last decades.

\section{Row planting}

Row planting is the most conventional planting design. Here, seedlings are planted in rows with a distance of 1 to $2 \mathrm{~m}$ between rows and $1 \mathrm{~m}$ within rows. Formerly, the distance between rows was typically around $1 \mathrm{~m}$ resulting in 8,000-10,000 seedlings/ha, row distances of $2 \mathrm{~m}$ were found to guarantee sufficient quality development and were thus favoured in the last decades. In row planting, oak can be combined with trainer species such as hornbeam (Carpinus betulus) or other shade-tolerant mixed species. In such cases, three rows of oaks should be followed by two rows of respective mixed species, to allow sufficient competition within species.

Row planting has advantages when it comes to large scale establishment and site maintenance, because row distances of $2 \mathrm{~m}$ allow efficient weed management with small machines and thus reduce maintenance costs. This is particularly important in riparian forests where competing vegetation of native or nonnative plants easily overgrows the light demanding oak seedlings. In addition, if weed management is done manually, oak rows can be identified more easily by workers resulting in low seedling losses.

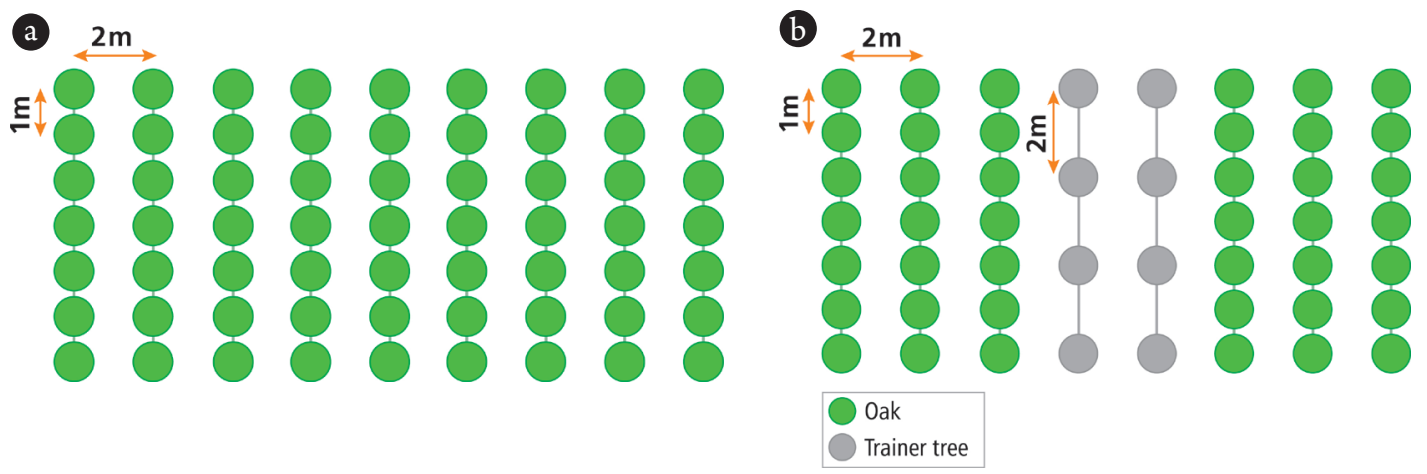

Figure 3.1.5-2: Two planting designs for row planting of oak: a) pure oak reforestation; b) oak mixed with a shade tolerant trainer tree species that can be chosen according to a respective site, but which should not outcompete oak 


\section{Group or cluster planting}

In this concept, oaks seedlings are only planted at those places of the afforestation site, where a potential target tree is required. The spatial distribution of groups depends on the planned target tree spacing, which can typically be found in distances of 10-13 m. Each group consists of 20-25 seedlings with distances of $1 \mathrm{~m}$ between trees. The groups can be arranged in a square or in two to three circles with increasing diameter. The latter arrangements are often called cluster planting. In case of cluster planting, an additional circle with trainer trees is recommended.

Between groups or clusters, a shade tolerant trainer tree species can be planted. However, if natural regeneration of one or several other tree species is available, they can serve as future training species. The advantages of group and cluster planting are the following:

- Oak groups and potential target trees are located where they are needed allowing for afforestation also on small and medium stands.

- Due to narrow distances among oaks, the stem quality, growth development and survival are comparable or even superior to row planting as shown by meta-analysis across Central Europe.

- Lower costs due to lower numbers of seedlings (1500 seedlings/ha) as well as the requirement of weed control only within and around groups or clusters.

- Ideal for enrichment planting to increase tree species diversity and make full use of natural regeneration without losses of productivity.

The disadvantages of group planting are minor and include:

- Requires strict competition control along the contact line between oak groups and natural regeneration to avoid oak being outcompeted by fast growing pioneer trees.

- Weed management requires more manual work as well as skilled and motivated staff to identify oak groups and avoid the loss of oak seedlings during management. Therefore, each seedling or at least the outer row should be marked with sticks to identify seedlings during weed control. 


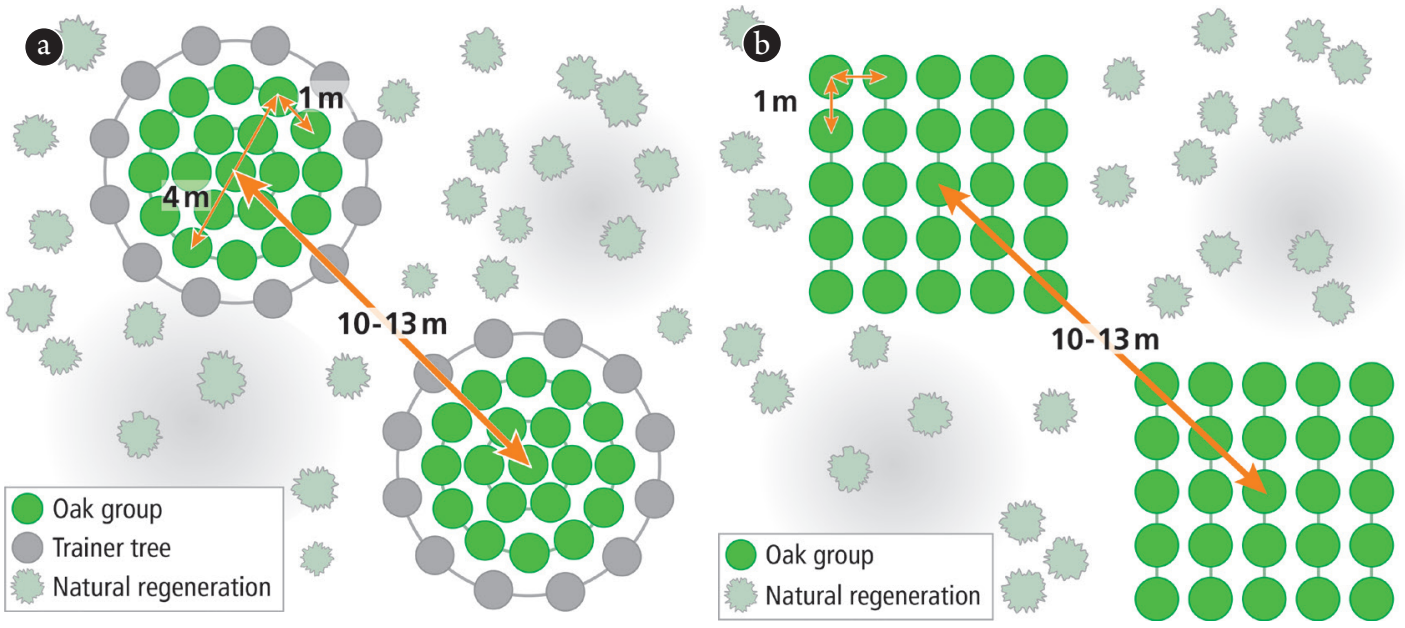

Figure 3.1.5-3: Two planting designs for planting oak: a) in groups; b) in clusters. If available, natural regeneration should be used to fill the area between oak groups/clusters. However, if not available, instead of natural regeneration any shade-tolerant tree species or tree species mixture can be planted in lower seedling density

\section{Summary and outlook}

Artificial regeneration of oak is an important technique to restore oak forests for forest conservation and the production of highquality stems. Depending on site conditions and management options, both row planting and group planting can be successfully applied. Both planting designs require, similar to natural oak regeneration, silvicultural skills and a continuous removal of weeds and invasive species as well as protection against game damage. The advantage of group or cluster plantings are its lower costs during establishment and the full integration of available natural regeneration possibly resulting in higher tree species diversity. Thus, group planting is also a preferred solution to enrich existing forest regeneration with oak or potentially any other valuable tree species. 


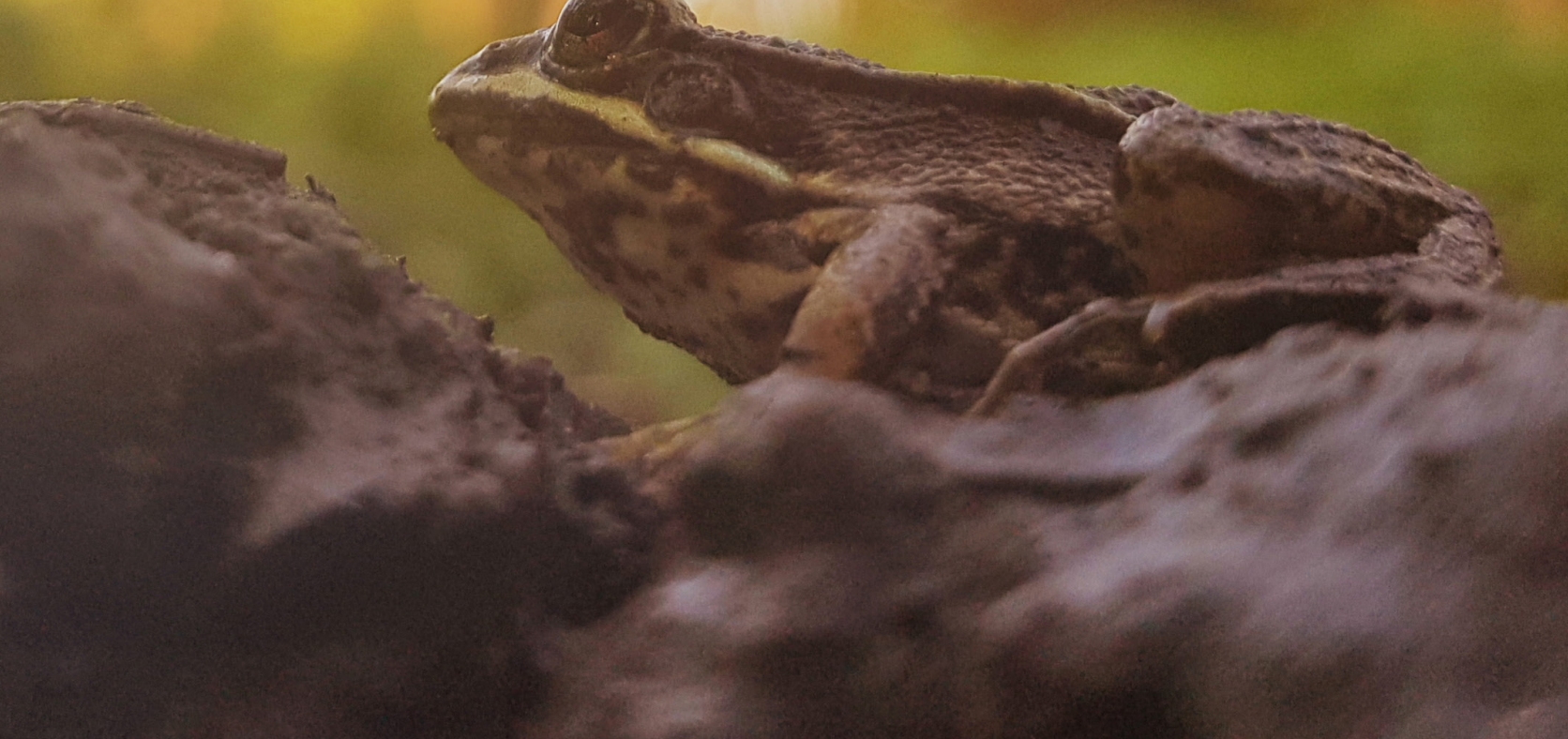




\subsection{Forest and conservation management}

\subsubsection{Biodiversity and Conservation management goals}

Katharina Lapin, Janine Oettel, Kerstin Böck, Maarten de Groot, Alen Kiš, Marjana Westergren

\section{Biodiversity in riparian areas is at risk}

Biodiversity is the variability among living organisms from all sources, including terrestrial, marine and other aquatic ecosystems and the ecological complexes of which they are part; this includes diversity within and between species or ecosystems. Riparian forests provide multiple ecosystem services and host large shares of terrestrial biodiversity in Europe. However, the biodiversity of riparian forests is at risk. The main threats to riparian forests are habitat degradation, climate change, river regulation and invasive species (see 2.1 Importance and threats to riparian forests).

To overcome the global biodiversity crisis of the $21^{\text {st }}$ century, forest biodiversity is addressed within international, regional, and local policies aiming at reaching biodiversity conservation goals. Namely, the United Nations Strategic Plan for Forests 2030 under Global Forest Goal 2 target foresees the contribution of all types of forests to biodiversity conservation to increase by 2030. Sustainable forest management, which respects genetic and species biodiversity and all ecosystem services, is the key tool for achieving this goal. In this chapter, we discuss the measures to preserve and promote biodiversity in riparian forests (Fig. 3.2.11).

\section{Indicators for Biodiversity}

Biodiversity conservation is one of the key objectives of sustainable forest management. A prerequisite for its integration into management planning is knowing the state of biodiversity, which can be obtained through its monitoring. Monitoring of biodiversity is extremely demanding and expensive, especially for rare species and habitats. In pan-Europe, under the auspices of the Forest Europe process, biodiversity within sustainable forest management is periodically monitored under criterion maintenance, conservation and appropriate enhancement of biological diversity in forest ecosystems. This criterion includes 10 indicators: diversity of tree species, regeneration, naturalness, introduced tree species, deadwood, genetic resources, forest fragmentation, threatened forest species, protected areas and common forest bird species. Some of these indicators are

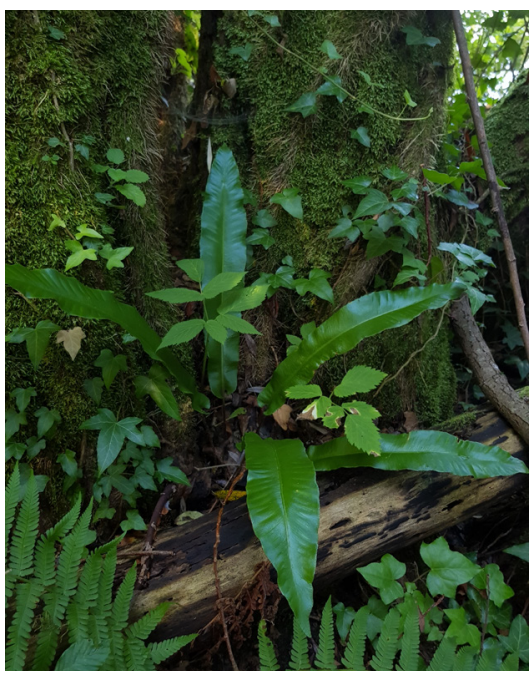

Fig. 3.2.1-1: Biodiversity can be expressed as richness in species, but also as diversity of habitats and landscapes or genetic diversity 
measured by National forest inventories on a predefined grid of permanent plots in a standardized manner. Since riparian forests are small by surface, only a small number of inventory points capture the state of biodiversity in riparian forests.

\section{Risks for biodiversity in riparian forests within the Mura-Drava-Danube Biosphere Reserve}

Riparian forests in protected areas within the Mura-Drava-Danube Biosphere Reserve provide habitats for several protected and threatened plant and animal species. Invasive species, changing climate, ecologically unsustainable management practices, constructions and lack of cooperation between different stakeholders all pose risks to biodiversity.

Intensive forestry practices, such as pure poplar plantations, change the quality of habitats and biodiversity. Large-scale clear cuts lead to a prompt and significant loss of habitats, plants and animals and therefore have a considerable impact on biodiversity. From a nature protection point of view, a high diversity of autochthonous species (plants and animals), their ages and natural processes is important and should also be supported by forestry practices.

\section{Measures to safeguard biodiversity}

There are numerous options that can help safeguard biodiversity in riparian forests from adapting management systems, tree species composition, providing structural heterogeneity, including deadwood and unmanaged patches into forests and others.

\section{Adapting management systems}

Management systems significantly influence biodiversity. Single tree selection ensures a continuously closed canopy cover, which is important for many organisms that depend on shade in a forest and results in an uneven-aged structure on stand level. Group selection gives the possibility to control the availability of light in gaps and to include a multitude of different tree and herb species. Clearcutting usually generates even-aged forests. It removes large canopy patches with effects that are similar to those of huge natural disturbances like forest fires or windthrows. It can lead to rapid habitat changes, uniform habitat development over a long period, extraction of nutrients and a faster mineralisation of humus. It is therefore important to consider spatial rotations and the management unit size to create a pattern of different age structures to sustain populations of vulnerable species.

Both economically and ecologically profitable sustainable management forms need to be found for riparian forests. An option could be conversion of existing plantations into seminatural forests with continuous forest cover by planting native and non-native, non-invasive tree species matching future climate. 
Through the development of new techniques, the usage of pesticides could diminish. Special attention should be devoted to fair compensation measures for forest owners when biodiversity protection becomes a primary management goal. This could be achieved through negotiations between forest management and nature protection authorities in a continuous process.

\section{Providing horizontal and vertical structural heterogeneity}

Structural heterogeneity within forests refers to differentiation of trees in diameter at breast height $(\mathrm{DBH})$ and tree height. It assures the establishment of diversely structured forests with trees of different dimensions and ages. Increasing structural heterogeneity is an important tool to promote stable forests that are resistant to natural hazards. Heterogeneity creates niches with different biotic and abiotic conditions, providing habitat for many species. Nevertheless, providing such conditions within the same forest patch can decrease species diversity by continuously low light availability.

\section{Adapting tree species composition}

Tree species composition can be adjusted by selectively promoting one or a group of target tree species in tending and harvesting operations. In this way, their share in a forest stand will increase, and tree species composition can be oriented in a specific direction. Additionally, tree species mixtures should be left in a stand during harvesting operations in order to ensure their natural regeneration. Tree species composition can be adapted also by (enrichment) planting by using suitable forest reproductive material in terms of tree species and seed provenances (see 3.1.1 Choosing natural or artificial regeneration and 3.1.2 Supporting adaptation of forests by selecting suitable forest reproductive material). Nevertheless, when suitable seed trees are present, preference should be given to natural regeneration to maintain genetic diversity within the present species. Additionally, the more is not always the merrier and sometimes less diversity is more appropriate for a given forest site, depending on disturbance conditions. However, functional diversity for current and future conditions needs to be targeted.

A variety of suitable tree species along with structural and genetic heterogeneity generally increases the biodiversity of a forest area. It increases the associated biodiversity, by creating more niches for birds, insects, plants, fungi and other species groups in the forests. 
The ownership of forest land, the right of its use, the rights for local people to use it, the stand size and the heritage law play central roles for the forests along the three rivers Mura, Drava and Danube. In the upstream Mura-Drava-Danube Biosphere Reserve parts, there are many small-scale forest owners who have inherited parcels of land with non-native and partly non-riparian species (such as Robinia pseudoacacia or Picea abies). For those landowners, it may be beneficial to find alternative species composition that can reduce the risks of losses and provide an adequate income and additionally change the structure of their forest to a more native one.

On a larger scale, different methods will be required to build up diverse and resilient forests. Supporting structures for further development of forest management should be built up in a joint effort of forest owners, authorities, and conservation stakeholders. This could range from consulting structures to conversion grants. Additionally, building up specialized forest nurseries for native tree species (including their local/regional adaptations and a diverse gene pool) with high timber value or high ecological value should be targeted.

Forest management and conservation should consider and actively promote natural habitats and target species (Fig. 3.2.1-2). Such target species could be umbrella species, which are species that are regionally selected for conservation decisions, because their protection implies the protection of many other species that build the ecological community of the respective habitat (e.g. Dendrocopos medius, Ficedula albicollis, Felis sylvestris could cover both lowland and upland forest habitats in the Mura-DravaDanube Biosphere Reserve).

Conservation measures for target species could include restricting forestry operations during the main breeding/spawning season, e.g. closing selected forest roads during periods of amphibian spawning and migration, or building passages under roads. Most measures would require subsidies from national/local funds or environmental budgets. Another approach to financial incentives would be an agreement that could be achieved through cooperation and contracts between forest managers and conservation authorities.

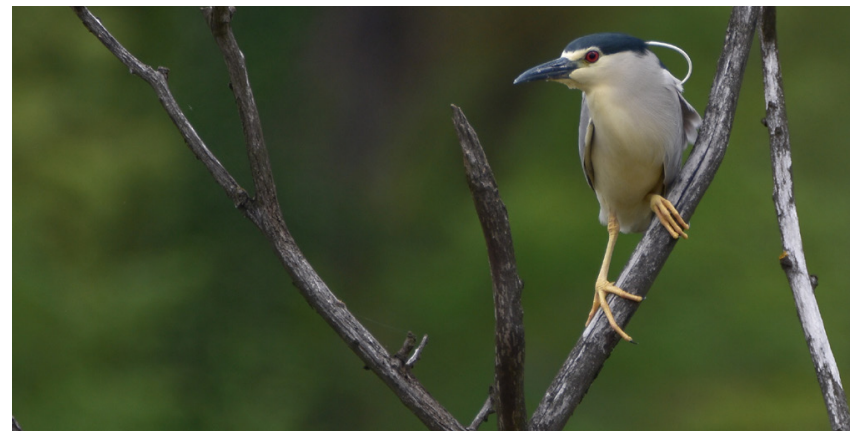

Fig. 3.2.1-2: Black-crowned night heron (Nycticorax nycticorax) is a typical species found in riparian forests that are rich in structural diversity 
Stream restoration could encourage natural regeneration and bring back natural pioneer habitats. This could very efficiently achieve a more natural state of an ecosystem by addressing one of the main causes of habitat degradation in riparian forests.

\section{Promoting deadwood quantity and quality}

Deadwood promotion means increase in quantity and quality of deadwood. Deadwood quality is defined by its accumulation, distribution, dimension, decomposition and type, which can be differentiated into standing, lying or stumps. Stumps are usually present due to frequent timber harvesting measures. In this way, many saproxylic species such as insects and birds can survive in riparian forests (see 3.2.7 Integration of deadwood portions into regular management).

As part of the Transboundary Mura-Drava-Danube Action Plan prepared by WWF in the frame of the Interreg DTP project coopMDD, a deadwood species program is proposed in conjunction with habitat improvements in the forest. The aim of such a program would be to increase the quantity and quality of deadwood habitats (standing or lying) in order to create suitable habitats for species that depend on deadwood (e.g. lichens, fungi, woodpeckers, bats or insects). Typical umbrella species to be targeted and monitored could be e.g. Osmoderma eremita (hermit beetle) or Cucujus cinnaberinus. Increasing the amount of deadwood in the forests of MuraDrava-Danube Biosphere Reserve should be done either by increasing the amount of unmanaged forests or by increasing the amount of deadwood that remains in the forests after harvest or tending. Monitoring these two options should provide an indication of how much deadwood needs to be left in managed forests to achieve near-natural abundance and diversity of deadwood species. In addition, especially in large monocultures, strips of natural succession could be introduced at the time of new planting. These strips could be left unharvested and unmanaged, allowing deadwood from a variety of tree species to form over time, with positive effects on deadwood species diversity.

\section{Conserving habitat trees and veteran trees}

Habitat trees are either living or dead trees of high ecological value. They may have various types of holes, rotten parts, many and coarse branches, epiphytic vegetation such as mosses or lichens, or they may be rare tree species in the surrounding forest. Veteran trees are older than the rest of the stand (Fig. 3.2.1-3). By including such trees, even stands with short rotation periods provide potential habitat left to natural development. Keeping single or groups of habitat or veteran trees significantly increases biodiversity. 


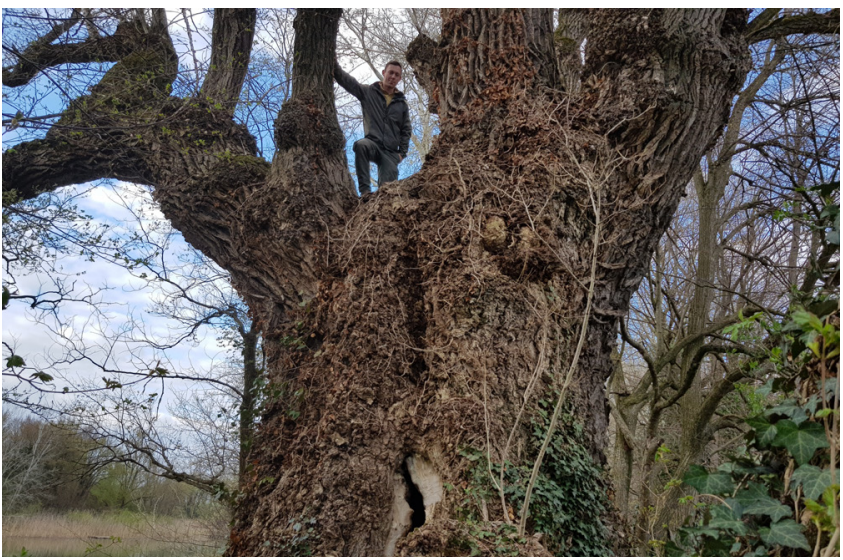

Fig. 3.2.1-3: Massive old-grown black poplar (Populus nigra) at the Drava River along the Hungarian-Croatian border

\section{Providing unmanaged forest patches}

A common approach to allow nature to develop and grow in an undisturbed and natural way is the definition of no-go areas and the development of a conservation management plan. In particular, gallery forests are an indication of natural river systems and are priority natural habitats. Natural development can also include their possible destruction due to meandering. As riparian forests are under pressure and natural development might not lead to forest states targeted by conservation managers, certain management actions such as the fight against non-native species (see 3.2.5 Management of non-native plants) might be required in order to conserve autochthonous tree communities (Fig. 3.2.1-4).

\section{Increasing the rotation period}

The rotation period refers to the age of the stand at harvest time.

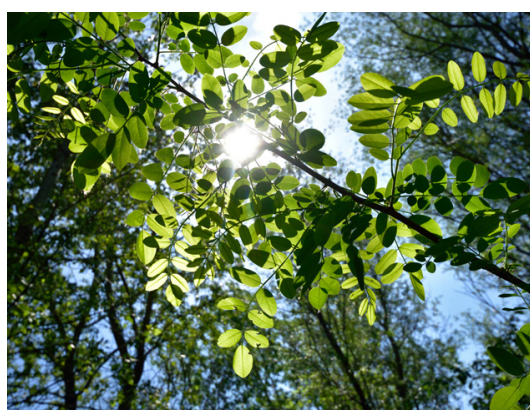

Fig. 3.2.1-4: Invasive non-native species such as black locust (Robinia pseudoacacia) are invading forest ecosystems
For uneven aged forests, it refers to the age of an individual tree before being harvested. Increasing the rotation period goes along with higher levels of forest maturity, but also with a higher risk of pests, diseases and subsequent mortality. Therefore, increasing stand age provides habitats for species that depend on mature forests and allows the provision of large-scale deadwood.

Avoiding forest fragmentation and providing heterogeneity at landscape level

At the landscape level, the structural diversity of forests and forest edges refers to varying tree species composition, age classes and development stages. This may include gaps with low forest cover or different management intensities and management systems. 
Forest loss, clear-cutting and extensive road construction can lead to fragmentation of forests. Reducing the number and use of existing barriers within natural or near-natural forests reconnects a natural river flow and its run-off area and contributes to achieving a more natural forest. This can be done e.g. by removing existing artificial structures from channels, opening channels by building bridges or large pipes instead of closed dams. In this way, vulnerable forest animals and plants have the possibility to sustain metapopulations by having the possibility to migrate to other populations and areas large enough for long-term survival.

\section{Active monitoring}

Active monitoring of forests refers to a continuous observation of different species and processes. It is the basis for detecting changes over time. Management should be adapted according to these changes. Monitoring is further used to evaluate the success of transformation and adaptation measures.

With regard to nature conservation, there is a need for continuous monitoring and control of protected areas to ensure that existing laws and regulations are respected. In this regard, a legal network of rangers could be established to monitor compliance with existing regulations and controlling measures. This would also increase the awareness of the population about the existing regulations. Monitoring is also necessary to identify measures that do not work or are inadequate and to adjust them if necessary.

\section{Implementing forestry certification schemes}

The production of timber and other natural goods with certification can lead to market advantages. There is a growing awareness in the forest industry of the benefits of labelling and certification as a minimum standard for sustainable timber production. In the long term, forest management that follows certification schemes not only maintains or improves biodiversity, but also the social and economic well-being of employed forest workers and local communities, and brings economic benefits. Support for the certification process needs to be established in different countries according to opportunities and barriers. Examples of good practice include a local or cross-border project covering the costs of the first round of certification, support for know-how from different certificate holders to those who aspire to it, or joint promotion of those forest enterprises that work to commonly defined standards. Further implementation must be driven by the forest managers. 
The UNESCO Biosphere Reserve label itself is suitable for marketing all goods, also wood, produced within MuraDrava-Danube Biosphere Reserve. For further certification, a joint negotiation process with key forestry and conservation stakeholders from across the Mura-Drava-Danube Biosphere Reserve of existing forestry certification schemes or standards (e.g. FSC, PEFC, ProSilva, etc.) should assess their suitability for use in the transition and buffer zones of the Biosphere Reserve. This could harmonize management within the zones across borders.

Encouraging and implementing cooperation between sectors (integrative planning) at a regional and transboundary level Collaboration between stakeholders and authorities of different sectors at national and transboundary levels, taking into account different interests, helps to increase understanding of needs, mutual respect, trust and efficiency. Such cooperation should include forestry, nature conservation as well as local residents, agriculture and water management. It has the potential to increase knowledge, understanding and trust between sectors and can also create new synergies to promote biodiversity conservation. 


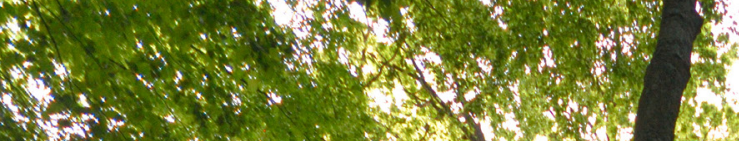

\section{8.}

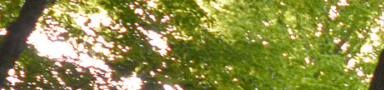

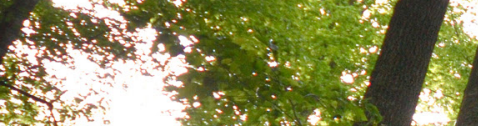

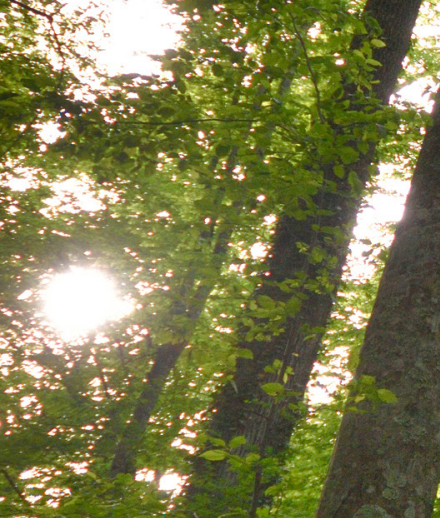

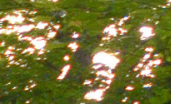

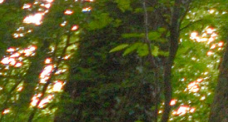

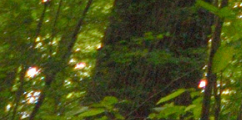

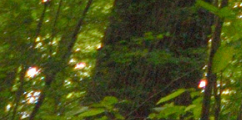

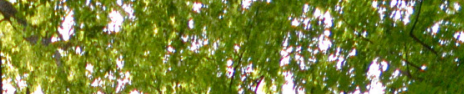

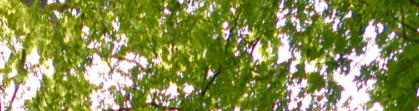

1.7.

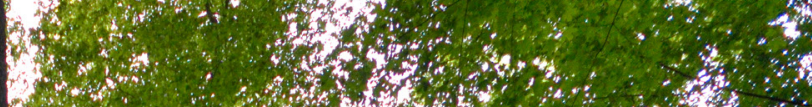

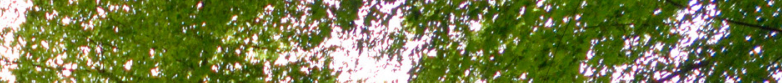

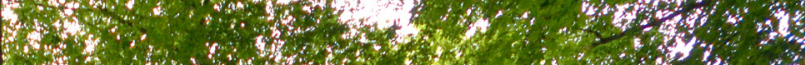

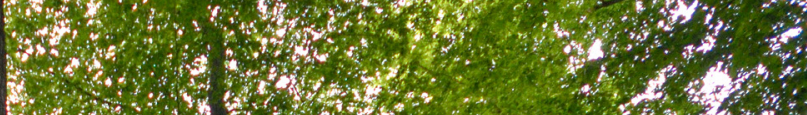

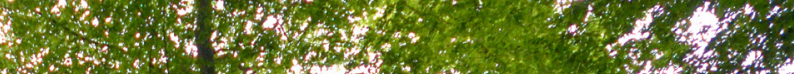
W6.

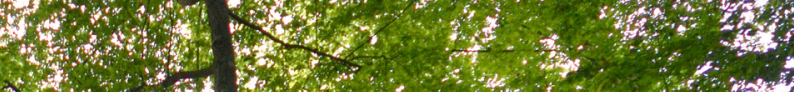
P.

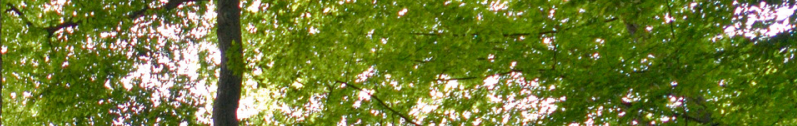

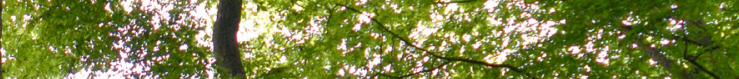

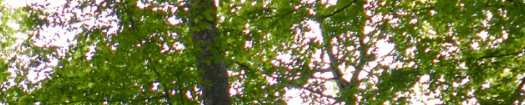

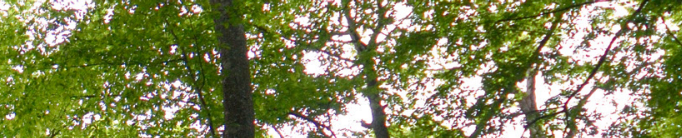
$+2003$ (5) $(1,5)$

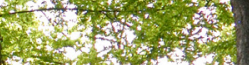
1.6.

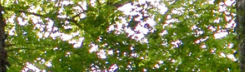

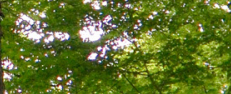

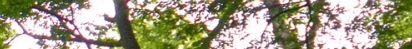

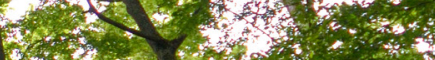

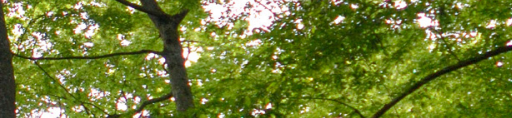
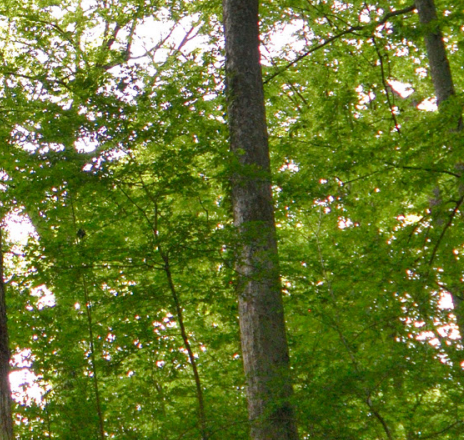

42,10

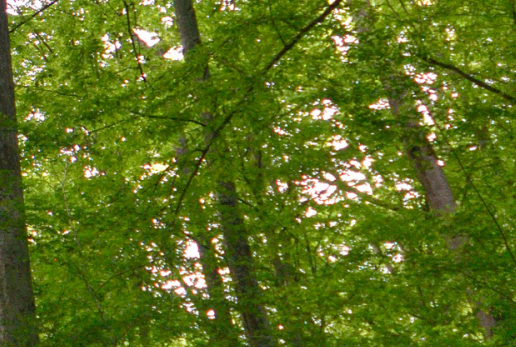

f is at: to

2 


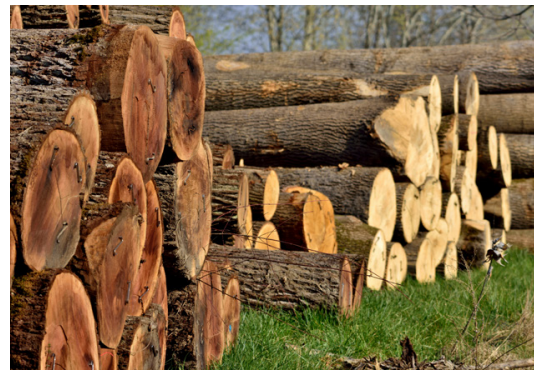

Fig. 3.2.2-1: High-quality trunks of desired dimension, quality and quantity demand silvicultural planning for the entire rotation period

\subsubsection{Optimization of the production of high-quality logs in hardwood stands}

Markus Sallmannshofer, Werner Ruhm, Hannes Schönauer

Natural hardwood floodplains are characterized by irregular short-term floods. These forest ecosystems have mature soils with higher humus content in comparison to softwood riparian forests. The particular soil conditions, which include nutrient richness, good water supply and soil aeration, support the high growth rate of noble hardwoods. Because of river regulations forest disturbances due to long flooding events have become very rare. However, the special characteristics of such sites still make them appropriate for the cultivation of several noble hardwood species. Hardwood auctions give evidence for a continuing demand for high-quality timber. The production of high-value timber requires an appropriate establishment of stands and consistent care to maximise quality and yield of trunks (Fig. 3.2.2-1). Moreover, genetic predisposition (proper provenance) also sets the course for quality and sustainable growth performance in future. Traditionally, hardwood stands are established with large numbers of plants and management is targeted at particularly long, branch-free trunks.

Until today, the growth potential of individual trees in relation to the desired properties of the produced wood were often given too little consideration. Modern hardwood silvicultural management focuses on individual tree quality and growth performance. Within an average forest stand, only a very limited number of trees have sufficient stem quality to produce high-quality wood. Further investments are reasonable only for such trees. The increase of stand value is determined by the development of tree diameter and the quality of the selected trees. With the right choice of site, genetics and silvicultural management measures, both parameters can be controlled. For hardwood, the term "quality" comprises 1) a strong, branch-free layer of wood with a thin branchy inner core, 2) a cylindrical stem form, 3) straightness, 4) low tension of wood fibres, and 5) a sufficient log dimension. This ideal determines yield and profitability and can be produced within the production steps described below.

\section{Branch-free trunk length}

Most hardwood species are so-called dead branch losers. With these tree species, a desired branch-free trunk length can be achieved by natural pruning in dense forest stands. In the case of dead-branch maintaining tree species (poplar, bird cherry) or 
low tree density without secondary layers, pruning is essential to avoid loss of quality.

Because tree height depends on site conditions, the branch-free trunk length should be chosen relative to the total height of a fully-grown tree. In order to obtain a sufficiently green crown for rapid diameter growth, approximately $25 \%$ to $30 \%$ of the total tree height have proven to be the target length for branch-free trunk. For example, soil conditions that allow for adult tree heights of 32 $\mathrm{m}$ would allow a branch-free trunk length of eight to $10 \mathrm{~m}$.

The branchy inner core of the stem are the remains of the dead branches. Comparable to the shape of a carrot, the branchy inner core increases in diameter with increasing height (Fig. 3.2.2-2). Thus, with increasing tree height, the valuable branch-free wood layer becomes younger and thinner and its share at higher parts of the stem is relatively small. Therefore, from an economic point of view, the branch-free trunk should not be too long as the vital green crown is required to drive the diameter growth. At the upper end of the log, the branch-free valuable wood should be at least two thirds of the diameter.

\section{Stand establishment}

Assuming that more than $80 \%$ of the total value is usually realized by the final cutting, the best possible growing conditions should be created for trees that will remain until the final cut. Even distribution of the trees of the final stand can only be achieved if the desired final spatial distribution is taken into account at the initial planning stage.

Whenever possible and genetically reasonable, natural regeneration should be used in order to save costs and support adaptation. Tree species, such as ash, sycamore maple and black walnut, frequently and sufficiently fructify. Natural regeneration of pedunculate oak, on the other hand, is often outcompeted by other deciduous trees and therefore requires appropriate regulation management of the tree mixture. Strong herb and shrub growth is common at many riparian forest sites. Thus, working with natural regeneration requires a lot of sensitivity regarding silvicultural interventions. In addition to a shelterwood system, group selection system with a continuous extension of openings to regenerate the area has proven to be very successful.

In absence of sufficient natural regeneration, planting is necessary (see 3.1.1 Choosing natural or artificial regeneration). With the choice of a planting distance, costs and benefits can be optimized. Mulching and planting in rows are recommended.

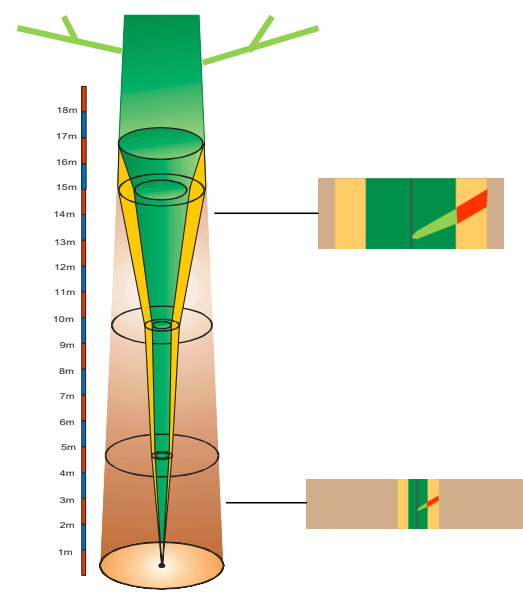

Figure 3.2.2-2: Schematic illustration of the inner core with branches (green) which has a similar shape as a carrot. It increases with tree height, resulting in a smaller share of valuable branch-free wood layers (brown) in higher parts of the stem. 
To reduce costs, the row spacing is chosen according to a desired crown size in the final stand. Large crowns allow a strong diameter growth. A row spacing of 10 to $12 \mathrm{~m}$ with a spacing of 1 $\mathrm{m}$ within a row is sufficient for hardwood stands. This means that there are a sufficient number of trees available in a row in order to have enough best-formed trees available to select for a final stand. However, also consider that at early stages, sufficient withinand among species competition is required for natural branch cleaning and thus, depending on the trees species rows might be required at shorter distances.

To prevent a crown from becoming too big at an early age and at the same time to promote height growth, sufficient trunk shading during the stands youth is necessary. For this purpose, a secondary training stand is used to reduce the costs of establishing a stand with a small number of plants. A mixture of tree species that is naturally occurring (including vegetative regeneration) on most of the sites that are suitable for noble hardwood cultivation can be used for this secondary stand. Interspecific competition can substitute positive effects of intraspecific competition, although careful observation of the growth relations is essential. In such concepts, the site-specific competitive interactions need to be considered and if crown competition from the secondary training trees is getting too strong, timely control interventions are required.

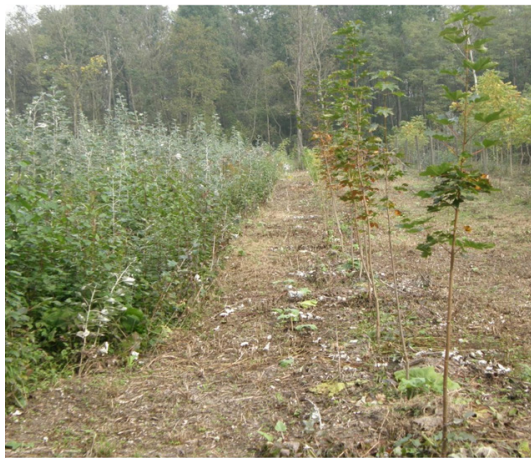

Figure 3.2.2-3: Maple row with a secondary, serving stand of poplars in the interspace. Interspecific competition can substitute positive effects of intraspecific competition to save planting costs, although careful observation of growth relations is essential. Poplars have a positive influence on qualitative development of hardwood and are harvested as industrial wood when they are approximately 10 years old.
In case of insufficient natural regeneration, alternatively the plantation of rows of poplar between rows of noble hardwood can be recommended in order to achieve functional, temporally limited mixtures (Fig. 3.2.2-3). Poplars have a positive influence on the qualitative development of hardwoods and are harvested as an industrial wood when they are around 10 years old. Alternatively, a subordinate mixture can be introduced (for example bird cherry, grey alder, or field maple), which remains in a stand as a permanent mixture.

\section{Culture maintenance}

Herb and shrub layers can be a strong competition for young trees. The above-described resource-saving, low-density design is optimized for the final stand. Monetary savings gained by this approach enable carrying out cost-intensive maintenance measures. In large forest enterprises, mechanical herb regulation is advantageous in terms of costs. The space between rows must be cut free for at least three to four years after plantation. Along a row, a rotor cutter is recommendable, while a brush cutter should 
be applied within a row. Climbing plants can be removed with scissors, hand in hand with an optional shaping cut of promising trees. By removing steep and thick branches, the development of a sufficiently long, straight trunk section should be promoted.

Until a desired knot-free trunk length is reached, no other interventions in the young stands are recommended not to interrupt differentiation and knot cleaning processes that are crucial for high quality. Mixing regulation, however, is necessary when desired species are not sufficiently dominant. Competition decreases diameter growth and thus reduces the expansion of a branchy core inside a trunk. Depending on the age structure and the spatial distribution, selective interventions can be necessary. Late interventions may result not only in naturally reduced numbers of the main species, but also in very thin, unbalanced plants, which often lay down under winter snow and permanently lose the straight axis of the lower and most valuable section of the trunk. Similar can happen in flash floods or ice jams.

\section{Thinning}

When a tree has reached the height that matches the expected branch-free trunk length, the best 70-100 trees per ha are selected, permanently marked and consistently given more space. This collective of selected future trees is now promoted in diameter growth by a consistent facilitation of a vital tree crown. There is a close connection between the development of the crown width and the diameter growth: if the crown receives permanent side competition, the lower branches die off, the crown base moves upward and as a result the tree is losing competitive ability and diameter growth potential. Therefore, the standing space of the selected future trees needs to be constantly expanded to avoid a further shift of the crown base (Fig. 3.2.2-4).

Several selective thinning interventions with the aim of supporting the highest quality trees lead to the final stand. Promoting crown development increases diameter growth, shortens rotation time for a given target diameter, reduces the share of produced thin logs and reduces the risk of age-related devaluations (rot, coloured cores). Interventions are recommended to be carried out in the area of the selected future-trees only. In the interspace, interventions are only recommended if they are needed to maintain the stability of the stand. By "beheading" or girdling, it is particularly possible to continuously expand the crown space, while trunk shading is maintained up to a certain height or slowly decreasing with time.

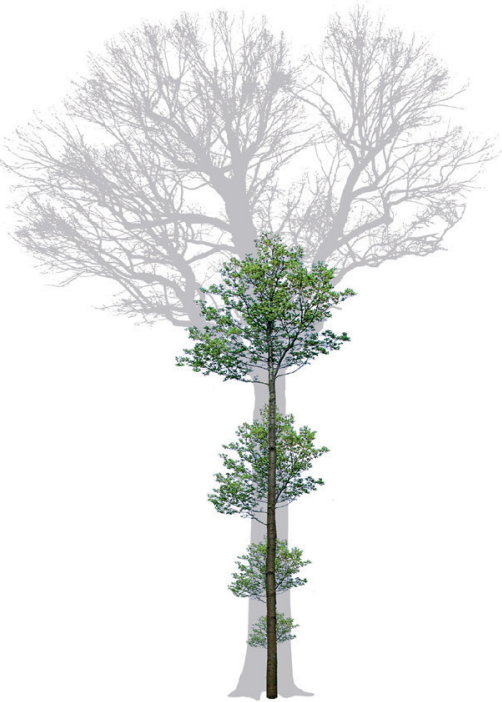

Figure 3.2.2-4: For the desired development of selected economically valuable trees, the standing space must be constantly expanded in order to obtain a sufficiently green crown for the rapid growth of a branch-free mantle and to prevent the crown base from moving up any further. 
The distance between selected trees depends on the area of single, mature crowns, which is necessary to achieve a certain target diameter. In order to reach the targeted DBH of $50-90 \mathrm{~cm}$, crowns of approximately $100-150 \mathrm{~m}^{2}$ are required. From this, maximum values can be derived. For tree species with a large crown expansion capacity, such as pedunculate oak, ash or black walnut, larger average tree distances of approximately $12 \mathrm{~m}$ are selected, which means that there is space for a maximum of 70 adult trees per ha. For tree species with medium crown expansion capacity, such as bird cherry, wild service tree and maple species, a maximum of 100 trees per ha is selected with an average tree spacing of approximately $10 \mathrm{~m}$.

\section{Summary and outlook}

The explained approach helps to optimize the production of valuable wood of strong and vital trees to maximize profit. Resources are saved when establishing a stand and focussing only on a single tree and yields are increased due to a higher quality. In the literature, such a concept is described with the terms "qualification" (phase 1 as branch cleaning until Z-tree selection and thinning) and "dimensioning" (phase 2) as a two-phase concept for hardwood production. 


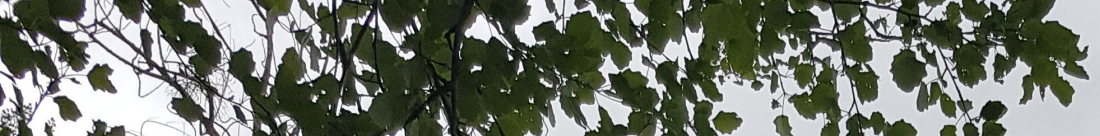

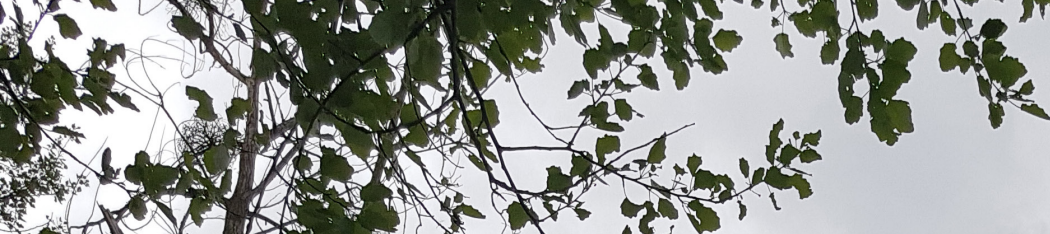

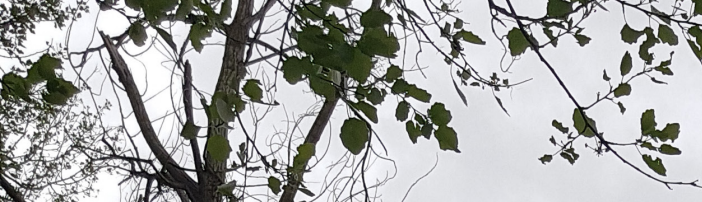
$\frac{1}{2}$

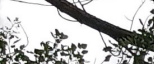

(4)

2.

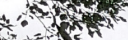
is 35

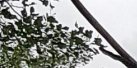

1.6.

4.

,

(4)
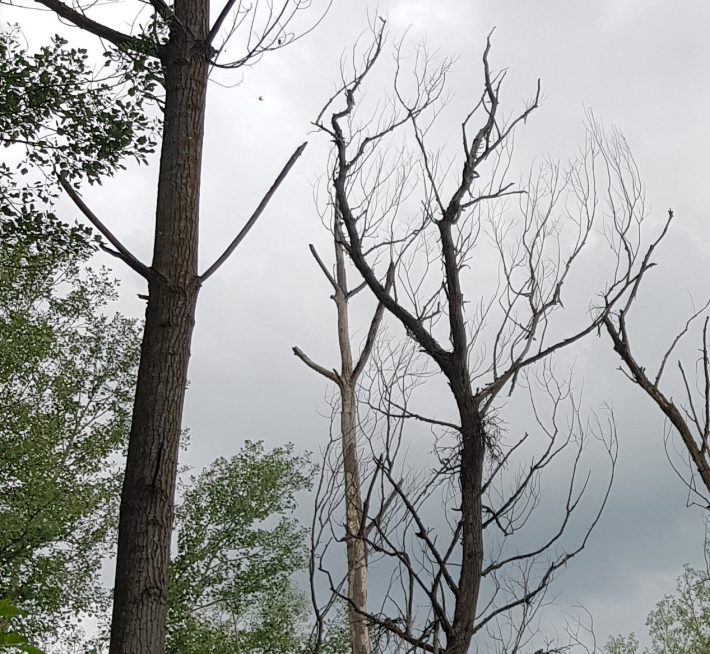

$6 \times$

5

a.

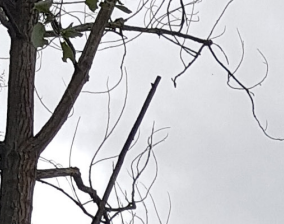

a
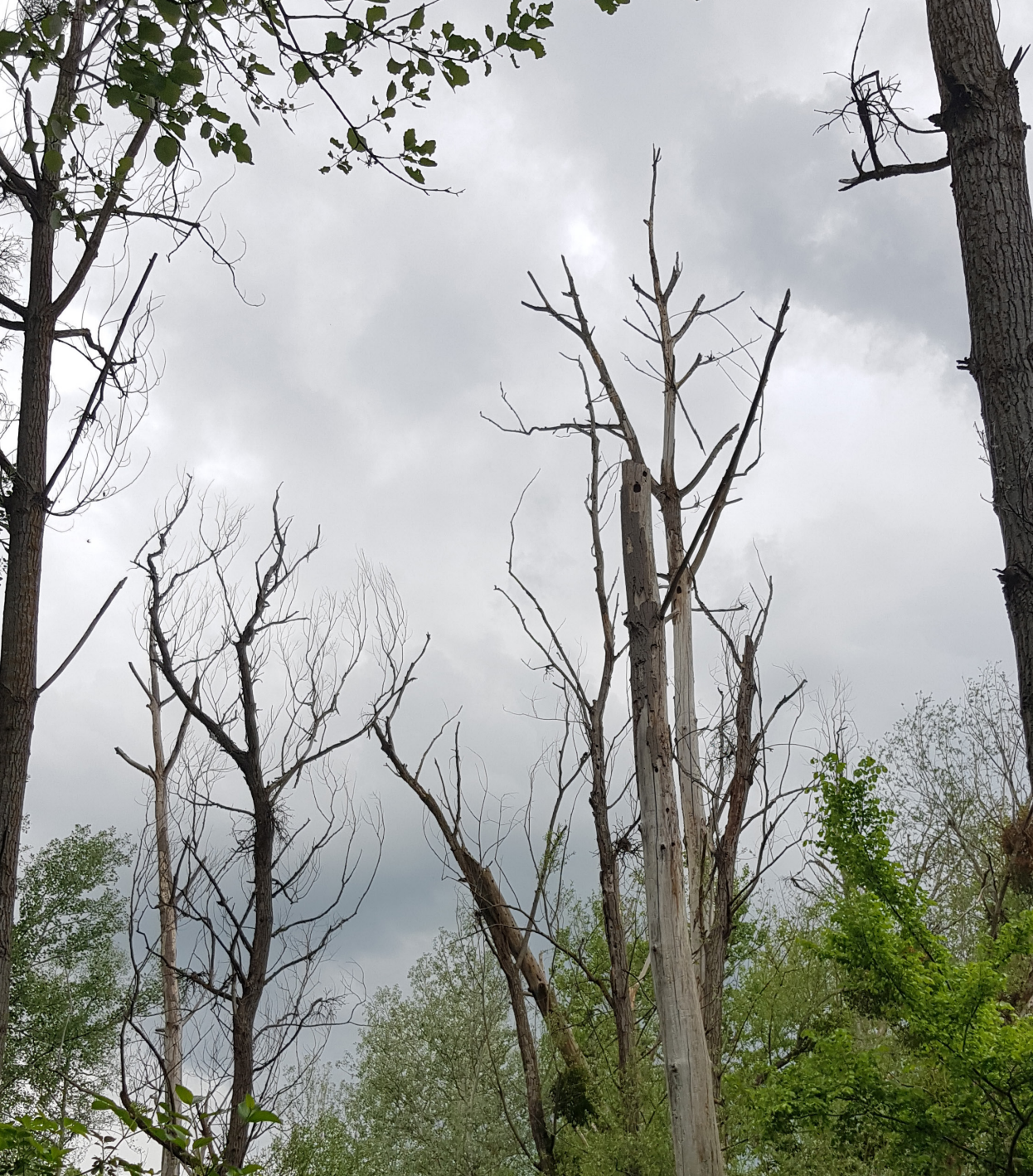

+.,
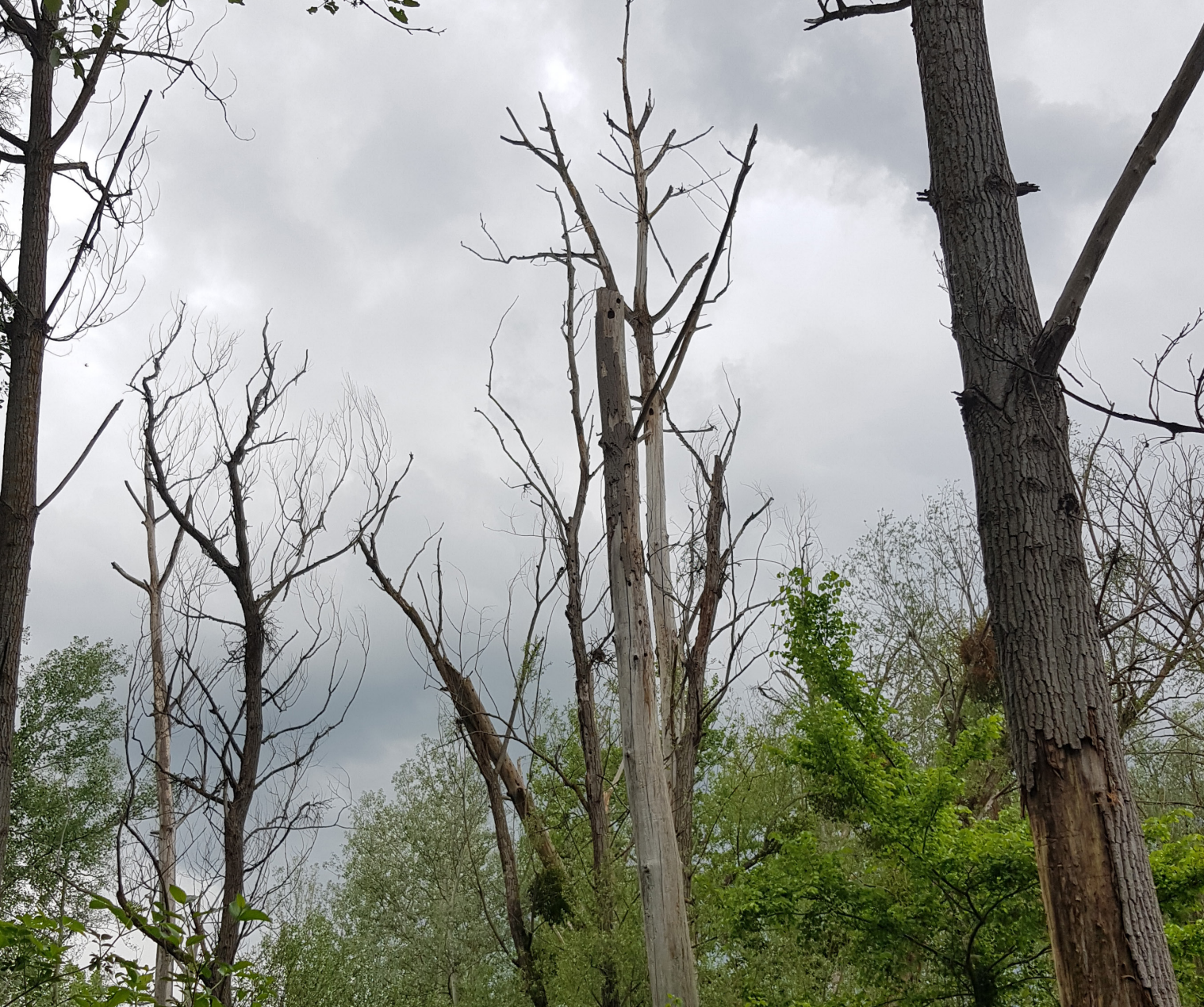

n. FN

4. 5 


\subsubsection{Challenges of climate change}

\section{Katharina Lapin, Maarten de Groot, Debojyoti Chakraborty}

\section{Introduction}

Climate change is one of the biggest challenges of our times. Worldwide, protected areas help to mitigate and adapt to climate change. The traditional way of designating protected areas, however, may not work in future due to the transnational nature of climate change. Recognizing the importance of critical habitats, biodiversity, and cultural landscapes, various types of protected or conservation areas have been designated worldwide. However, under climate change, the efficiency of these protected areas to fulfil their targets has become a subject of debate. A large number of studies have reported the likely consequences of climate change on protected areas, focusing mainly on the loss of habitat and biodiversity. In Europe, the effects of climate change on protected areas had been studied intensively.

Protected areas store $15 \%$ of terrestrial carbon and supply ecosystem services for disaster reduction, water supply, food and public health. Almost 30 million ha of European forests are protected. Therefore, forest ecosystems, especially, play an important role for safeguarding environmental functions. Between 2005 and 2015, for example, the average annual sequestration of carbon in forest biomass reached 719 million tonnes $\mathrm{CO}_{2}$. However, climate change is also among the biggest challenges for protected areas. The biggest current threats to the UNESCO natural World Heritage sites, for example, are invasive species, climate change and tourism impacts. The 2014 Outlook assessment stated that climate change is the fastest growing threat to the natural World Heritage.

Riparian forest ecosystems are among the most protected areas in Europe. They are of particular importance for accumulating carbon stocks, rapid carbon sequestration in the short-term and for providing ecosystem services, although they cover only $0.5 \%$ to $1 \%$ of the global land surface. Understanding the challenges of climate change on riparian forest ecosystems help to adapt to these new climate conditions and increase the resilience of riparian forest in future.

In this chapter, we synthesize the major challenges of climate change for practitioners, conservation and forest managers, and provide them with an outlook on management strategies for adaptation and mitigation in riparian forests. 


\section{Abiotic impacts}

Recent observations show variable responses of forests to climate change. Abiotic challenges include wildfire and storm damages, drought events, and decline in precipitation and changes in their distribution. Climate predictions of Europe show a geographically diverse picture of changes including an increase in high temperature extremes, drought events and heavy precipitation events. Extreme weather events will cause a decrease in forest productivity and vitality. In Southern Europe, an increase in forest fires is predicted, while in Central Europe damages from storms will increase due to climate change.

\section{Biotic impacts}

Biotic impacts are strongly linked to abiotic impacts and cause shifts of biotic threats to forest ecosystems. Europe's forest damages are most frequently caused by biotic impacts. Climate change causes the increase of biotic threats, which are extremely challenging due to their unpredictability. Biotic challenges include recently observed changes in growth rates, phenology, composition, shift of species distribution and an increase of pests and diseases infesting forests. The distribution of pests and diseases in forests will highly likely shift from southwest to northeast and increase damages in forest ecosystems under climate change. Furthermore, an increase in winter temperatures impacts the survivability of some pest species and period in time that species can have an effect on trees. Consequently, the magnitude of biotic threats may lead to a transformation of major vegetation types in Europe.

\section{Adaptive forest management}

The challenges of climate change require short-term, as well as long-term management measures. Here are few examples of management adaptation measures, which aim at supporting and assisting forests' stress resistance, resilience, and dynamic response in order to preserve ecosystem functions.

\section{Integrative spatial planning}

The resilience of protected areas can be supported by the integration of adaptation measures into spatial planning. A land use planning approach at landscape level will overcome crosssectoral limitations.

\section{Early warning systems}

The establishment of an early warning system, that detects biotic and abiotic threats should be a key target for future forest protection activities. Especially under climate change the importance of international and transdisciplinary exchange of 
information is important for a successful rapid response.

Silvicultural adaptation measures

Adaptation of the management of stand structures through silvicultural measures aims at transforming a forest into a resilient ecosystem in regard to local site conditions, needs, risks, management aims and feasibility. Shorter rotation periods, for example, lower the risk of wind throw and disease. However, longer rotation periods may lead to shady conditions, which are disadvantageous for many alien plants. In general, management disturbances, which result in changes of light conditions and vegetation cover, create a risk for alien species dispersal and should therefore be monitored carefully in the following years. Another approach is to deliberately use natural succession processes and species migration. An increasing tree diversity and the use resistant tree species, provenances or clones would make forests more resistant against pest and disease outbreaks resulting from climate change.

Tree species and provenance selection

The response of forests to climate change threats strongly depends on provenance, regeneration potential, and the composition of tree species. The use of well-adapted native tree species and provenances to the changed climate conditions is a widely accepted adaptive measure. A risk assessment needs to be performed before introducing non-native trees. Nonnative tree species that are already considered invasive cannot be recommended for planting (see 3.2.5 Management of nonnative plants).

\section{Ecosystem restoration}

Riparian forest ecosystems are highly modified by humans. The canalisation of river streams has led to changes in ground water levels and flooding characteristics, as well as a decrease of habitat connectivity of aquatic and terrestrial ecosystems. Riparian restorations, however, contribute to ecological adaptation to climate change.

\section{Summary and outlook}

Climate change is affecting protected riparian areas, as it is a threat to ecosystems worldwide. The major challenges of climate change include an increase in high temperature extremes, drought events and heavy precipitation events as well as biotic threats, such as the spread of pests and diseases in forests. Forest management measures can help to support and assist forests' stress resistance, resilience, and dynamic response in order to preserve ecosystem functions. 



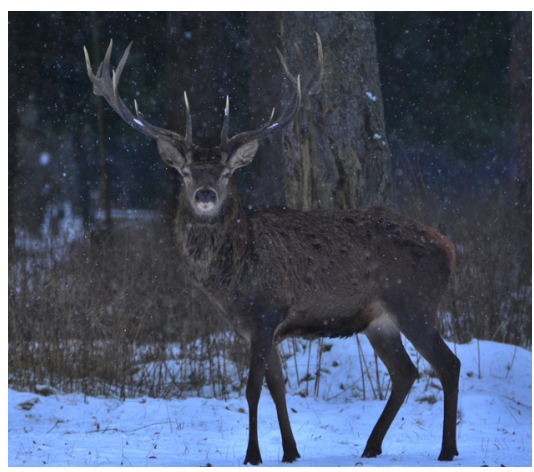

Figure 3.2.4-1: Red deer

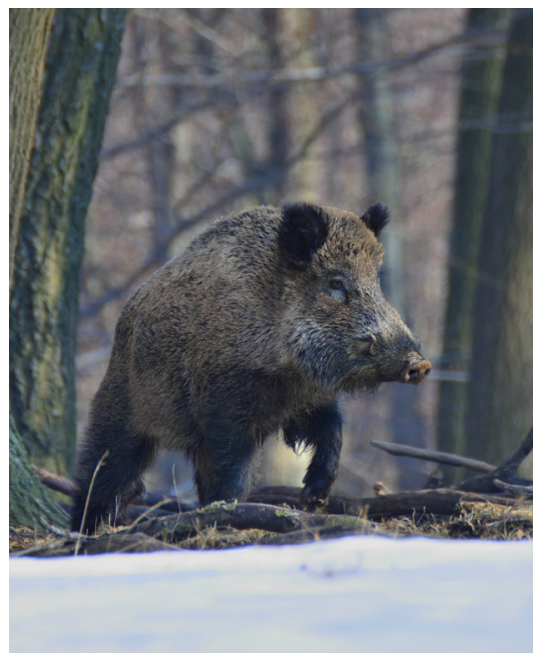

Figure 3.2.4-2: Wild boar

\subsubsection{How to manage game and protect forests from damage}

\section{Markus Sallmannshofer, Silvio Schüler}

\section{Game management and protection methods}

Autochthonous game species are native to forests. Fragmented habitats, disjunct migratory routes and disturbances by traffic and other human activities forced wild game to concentrate in calm areas with good protection. As a result, these species are today more strongly connected to forest ecosystems than they would be by nature. Riparian forests are rich in site productivity and plant diversity making them attractive for many hoofed-game species such as roe deer, red deer and wild boar (Fig 3.2.4-1, Fig 3.2.4-2). The attractiveness of a forest habitat for wild game is influenced by the wide range of food sources and food-independent qualities such as protective structures, forest climate, and low disturbance frequency. Additionally, fallow, sitka deer and mouflon were introduced to some areas for hunting purposes, as hunting a wide variety of game species was practiced by the nobility landowners historically and nowadays leisure time hunting is seen as an important income source for forest enterprises.

The biotic carrying capacity of forests for game species describes how large the game population could grow without natural or artificial regulation. It is described by habitat quality, consisting mainly of available food and space. The economic carrying capacity describes a population size that is not affecting silvicultural objectives. If it is below the biotic one, game damage on forest regeneration and tree stock occurs, which might reduce important ecosystem functions. Negative consequences include problems with forest regeneration by selected browsing, log infection by fungi with consequent wood depreciation, losses of annual increment, and overall decline of forest stability and biodiversity. A trade-off between economic benefits of hunting revenues and silvicultural losses is necessary. In total-cost calculations, the losses of revenue caused by game damage in forests do often surpass the income from land leasing for hunting.

\section{Game damage and its assessment}

Even though influence by game is not always negative, but can be beneficial, the classification of damage is always subjective. Game damage can be evaluated by comparing target and present forest conditions. Targeted conditions in forests are derived from several criteria including the requirement for forest regeneration, the share of intended tree species within a certain regeneration layer, 
and the expected time until a natural regeneration is established. The present forest conditions can be effectively assessed by a permanent or temporal random sampling of key figures. Such indicators are the amount of young trees per hectare, the number and degree of damage, and the share of tree species and type of mixture in different forest layers and age or height classes. Besides natural regeneration, older age classes also need to be assessed, for example in relation to bark stripping. Various criteria need to be related to forest type, management regime, present game species, targeted forest functions and expected ecosystem services.

However, game damage is not the only reason for problems with regeneration. Other factors to be considered include cattle grazing, lack of light due to dense crown layers, thick herb layers, the absence of parental trees or fructification, and a potential lack of tending (see 3.1.1 Choosing natural or artificial regeneration). A standard procedure to evaluate the impact of game on forest regeneration is to establish small, fenced control areas to monitor and compare occurring natural regeneration with and without protection. Such areas can be small $(3 \times 3 \mathrm{~m})$, but should be repeated throughout a respective forest.

With an increasing gap between biotic and economic carrying capacity, feeding pressure of game on forest plants and regeneration and the need to apply additional game defence and management actions increase.

\section{Wildlife ecological spatial planning to avoid game damage}

Wildlife ecological spatial planning aiming at the protection of game habitats and the avoidance of game damage to a forest is suggested to be a suitable instrument for integrating wildlife into land management. Its implementation on large scales needs the involvement of all stakeholders from forestry, hunting, agriculture, tourism and other land uses. Wildlife ecological spatial planning should aim at better spatial distribution of game populations to avoid game damages. Possible measures may include the identification of (seasonal) habitat areas, reconnection of biotopes, and coordination and modification of hunting activities. By decreasing a relative habitat quality (attractiveness for game compared to the surrounding environment) in vulnerable areas, spatial distribution of game can be controlled.

\section{Professional game regulation and hunting measures}

To reduce habitat attractiveness, disturbances within the area of priority should be raised, for example by concentrating hunting 
measures within priority areas. This requires a clear delineation of an area (recommended up to $100 \mathrm{ha}$ ) and consequent action enforcement. At the same time, disturbances outside the area of priority need to be lowered. Hunting in temporal intervals, such as hunting time reduced to a few intense weeks, can reduce disturbances, while the efforts to reduce population decrease (as game will be less shy). Additionally, game can be attracted to other areas of low vulnerability by increasing the biotope quality through meadows, dedicated browsing areas or extensive feeding. Feeding reduces game mortality during winter and increases the reproduction rate. It needs large-scale coordination and professional food supply (quality, amount, and feeding intervals temporally adapted to targeted game species). The regulation of game needs to follow a quantitative and qualitative regulation planning also including understanding of game sex ratio. For example, the regulation of females has the strongest impact on population growth. Reduction management needs to consider and control also for the invisible, not countable parts of the population (up to $50 \%$ of a red deer population are frequently missed in observation). The delineation of hunting territories has to be checked for effectiveness. Permanently changing hunting habits (temporally and spatially) avoids game adaptation. Proper hunting facilities and infrastructure are necessary. Professional hunting staff with high problem awareness might be necessary while hunting tenants that do not cooperate need to be exchanged. Flexible lease contracts with annual quitting options and selling single shooting treaties should be preferred if possible.

\section{Forestry measures}

The vulnerability of forest stands towards game damage is influenced by forestry: silvicultural management system, regeneration type and regeneration period, as well as the stand structure, mixture, and thinning influence vulnerability. Foresters are responsible to objectively control silvicultural success, to maintain shrubs and tree species without silvicultural interest (distribution of feeding pressure), to initiate technical protection measures for tree species of interest, to cooperate with hunters and to support game regulation by cutting shooting aisles.

\section{Agricultural measures}

Structural elements in forests surrounding landscape are important to allow game to leave a forest and still be protected, especially during winter. Meadows should be left for grazing during winter to reduce feeding pressure on forests. 


\section{Visitor management}

Habitat areas and quiet zones for game in sensitive areas can be facilitated by restricting walkways, a mandatory use of dog leashes, stakeholder education, and avoiding dead end trails. Visitors need to be temporally and spatially concentrated in less vulnerable areas.

\section{Technical tree protection}

Forced by high game populations, it is common practice in the Mura-Drava-Danube Biosphere Reserve to protect natural and artificial regeneration areas by technical means because game pressure has been too high for other options to qualify (Fig. 3.2.4-3). The choice of protection measures depends on the game species and the assets to be protected. The most common protection measures are summarized in the following table:

\begin{tabular}{|c|c|c|c|c|}
\hline \multicolumn{5}{|c|}{ Area protection } \\
\hline Type & Red deer & Wild boar & Advantage & Disadvantages \\
\hline $\begin{array}{l}\text { Structural steel } \\
\text { mesh with wooden } \\
\text { piles }\end{array}$ & Safe & Safe & Extremely robust & $\begin{array}{l}\text { High installations } \\
\text { costs }\end{array}$ \\
\hline $\begin{array}{l}\text { Wire mesh with } \\
\text { wooden piles }\end{array}$ & Safe & $\begin{array}{l}\text { Only if anchored in } \\
\text { the ground }\end{array}$ & Robust & $\begin{array}{l}\text { High installations } \\
\text { costs }\end{array}$ \\
\hline Wooden fences & Safe & Safe & $\begin{array}{l}\text { Easy installation of } \\
\text { prepared elements } \\
\text { Easy to repair in the } \\
\text { case of damage } \\
\text { Reuse possible } \\
\text { No removal } \\
\text { necessary }\end{array}$ & $\begin{array}{l}\text { Preparation efforts } \\
\text { and costs }\end{array}$ \\
\hline $\begin{array}{l}\text { Plastic mesh with } \\
\text { wooden piles }\end{array}$ & No & No & $\begin{array}{l}\text { Sufficient against roe } \\
\text { deer } \\
\text { Cheap and easy to } \\
\text { install }\end{array}$ & Not durable \\
\hline \multicolumn{5}{|c|}{ Individual tree protection } \\
\hline Wire mesh & Safe against stripping & Other purpose & $\begin{array}{c}\text { Opens from alone } \\
\text { with diameter growth }\end{array}$ & $\begin{array}{c}\text { Plants of } 2-3 \mathrm{~m} \text { height } \\
\text { necessary }\end{array}$ \\
\hline $\begin{array}{l}\text { Plastic covers with } \\
\text { wooden pile }\end{array}$ & Too short to protect & Other purpose & Easy installation & $\begin{array}{l}\text { Greenhouse effects } \\
\text { can induce too early } \\
\text { sprouting }\end{array}$ \\
\hline
\end{tabular}

In Hungary, Croatia and Serbia the dominant game species causing damage in reforestations is red deer. Therefore, the height of fences must be at least $230-250 \mathrm{~cm}$. Deer can jump over lower fences. When only acorns need to be protected from wild boar, fences of 120-130 cm high are sufficient (also see 3.2.6 Integrating biodiversity enrichment in poplar forest management). 


\section{Conservation}

Areas with no management, such as core zones of national parks are very attractive for wild game. In relation to surrounding habitats, such areas are often calm and perceived as safe. Game will concentrate in such areas in densities that exceed natural levels. The consequence is a high feeding pressure on available plants. Depending on management goals, game regulation might also be required in such areas of high conservation value to enable the co-existence with a diverse forest plant community. Particularly, game management is needed if specific plant communities and habitat features and their state of preservation are a major conservation objective. In contrast, if large scale natural processes itself are being protected, game influence might be considered a part of the natural system that eventually modifies natural vegetation and future forest composition.
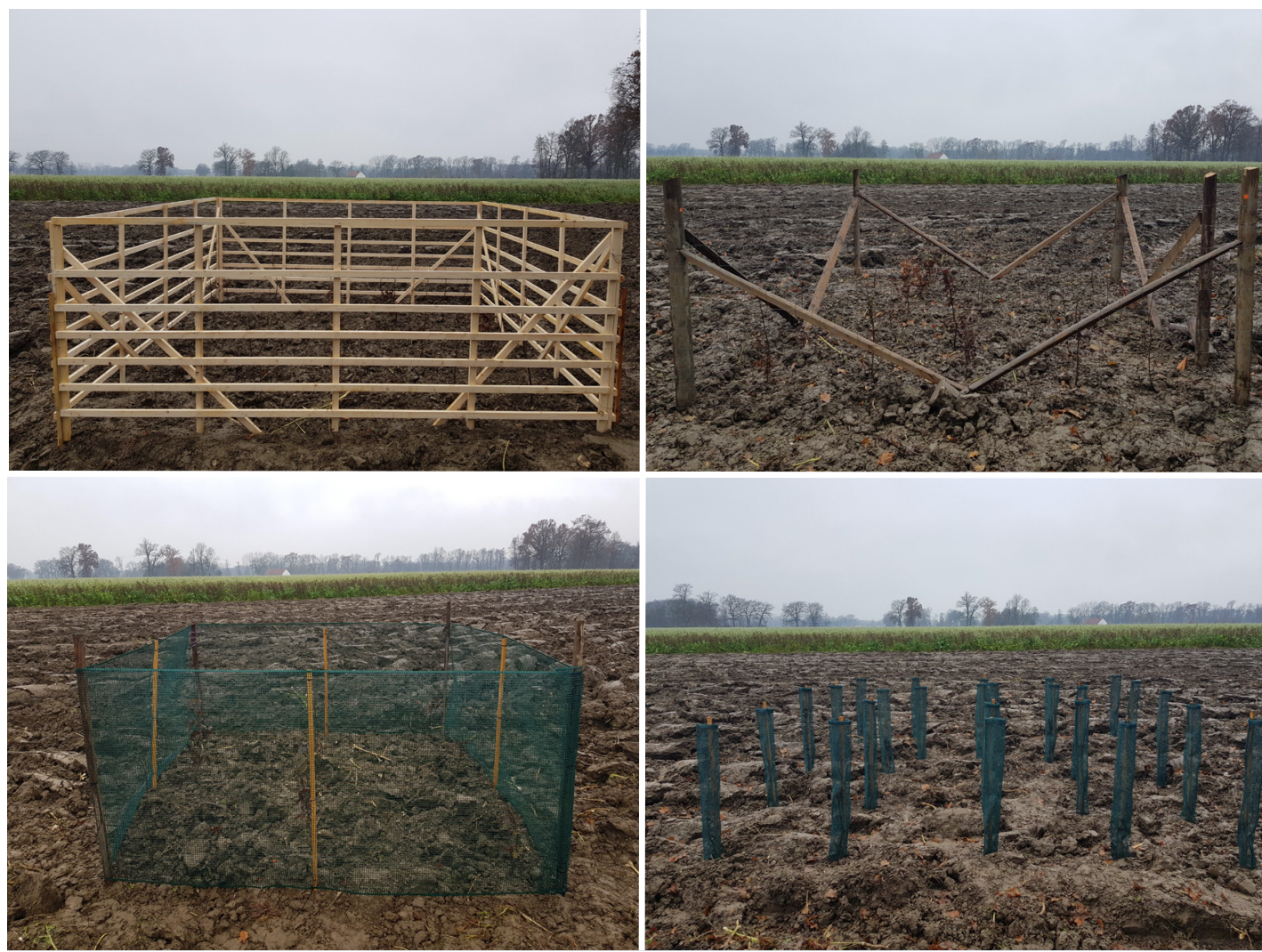

Figure 3.2.4-3: Technical tree protection installations of different strengths and costs 


\section{Summary and outlook}

The aim of proper game management is to enable the coexistence of diverse forest tree and plant communities with wildlife populations, to generate sustainable income from both forestry and hunting activities, to maintain rural traditions, and to meet high ethical and moral standards when regulation is necessary. Game is an essential part of our forests and is not causing damage to plant communities by nature. The classification of damage is strongly subjective and results from its conflict with other human objectives. During the past decades, cost intensive technical protection has become necessary in forestry. A trade-off between revenue from hunting and losses, respectively protection costs in forestry and biodiversity management are required to reach long-term conservation and forest management goals. Wildlife ecological spatial planning across the spatial scale of game movement areas involving all stakeholders is expected to support a smart and balanced land management and avoid conflicts.

\section{Acknowledgements}

Thanks and appreciation go to Prof. Dr. Reimoser, whose work at the University of Natural Resources and Applied Life Sciences Vienna provided the basis for this chapter. We also thank Gyula Kovacs and Silvija Krajter Ostoić for their comments. 


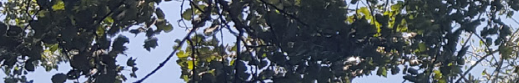

(2)

$20,1,2,4$

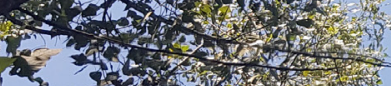

30.7)

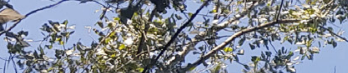

2 5

$x^{2}$ H.

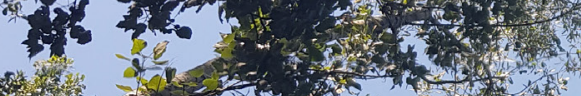

ent.1.5.

x.

tres

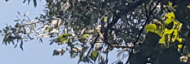

7

into

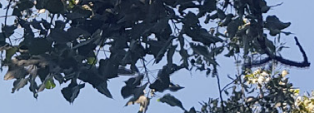

(3)

, the

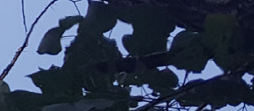

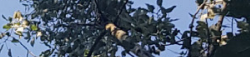

(3)

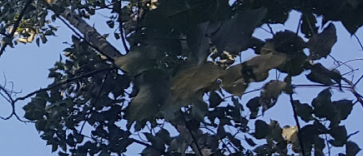

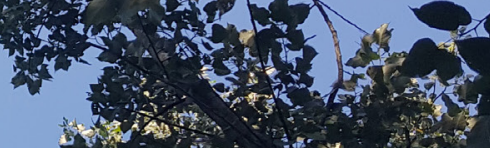

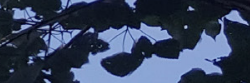

(x)

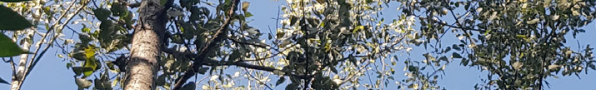
$x^{2}-a^{2}$

$10 \times 2 x^{2}$

8 .

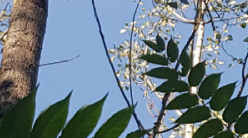

3.

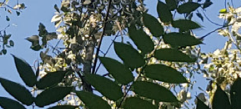

7.

-142

7

(x) 12

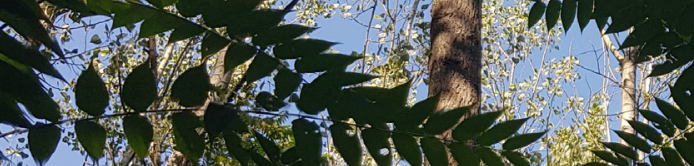

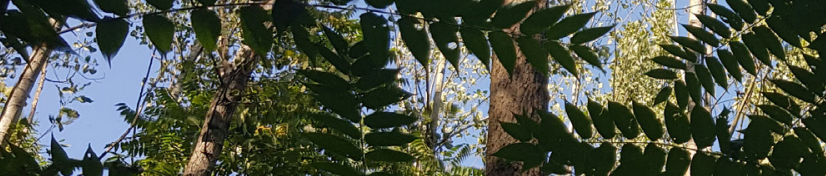
4

to

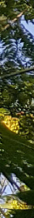

intom

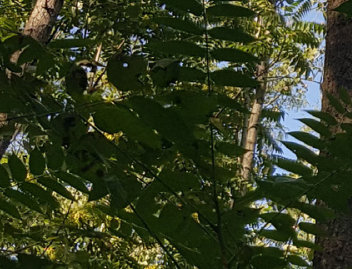

(4)

(4) 3 ,

$+x$

sol?

1.

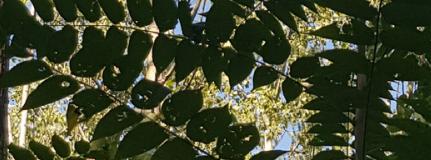

il.

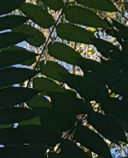

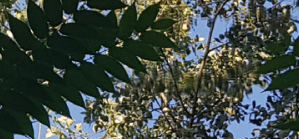

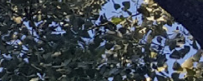

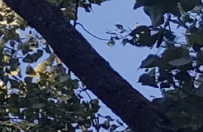

W.

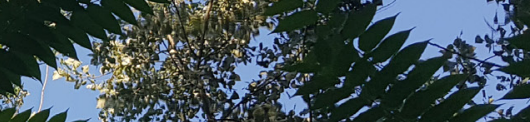

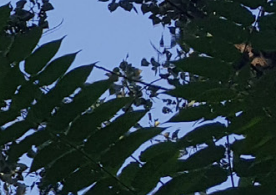
140 . 140 ,

3.

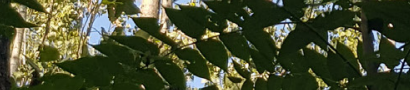

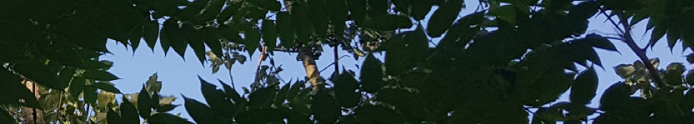

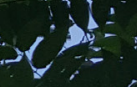

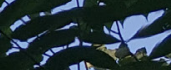

(4)

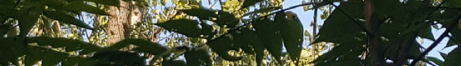

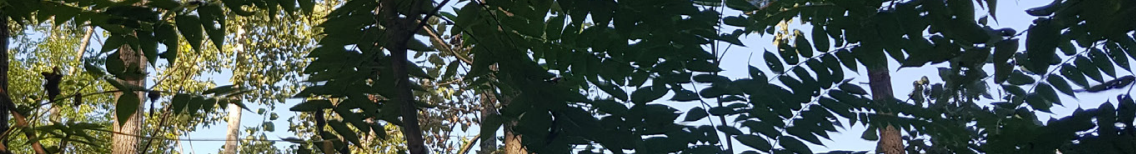

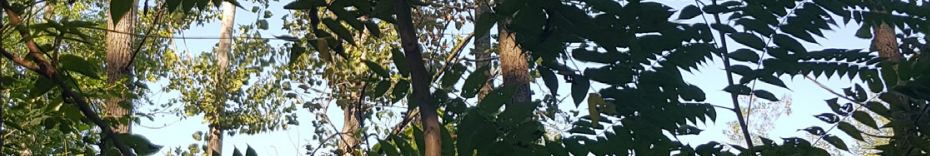

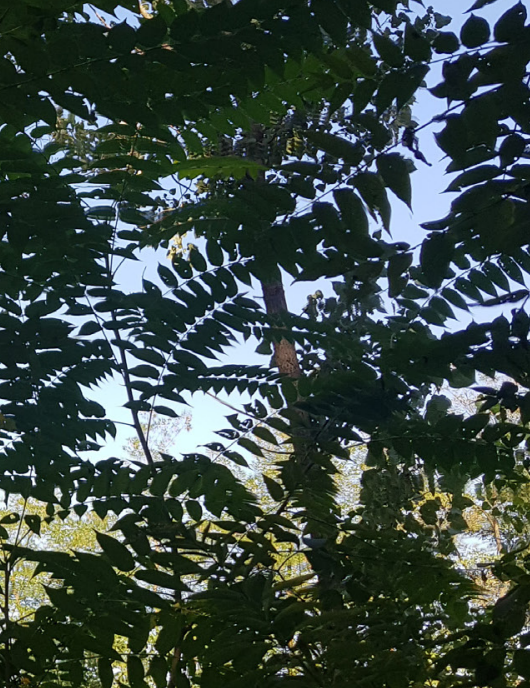




\subsubsection{Management of non-native plants}

Katharina Lapin, Aleksander Marinšek, Maarten de Groot, László Demeter, László Nagy, Marjana Westergren

\section{Introduction}

Alien or non-native plant species are species introduced outside its natural past or present distribution. If alien plant species becomes problematic, they are termed as invasive alien plant species. Once an invasive alien plant establishes in a new area, it can have negative ecological, socio-economic and human health impacts. Today invasive alien plants are one of the major threats to global and local biodiversity, and their spread is not culminating. Nutrient-rich and frequently disturbed riparian forests are among forest types that are most vulnerable to invasion of alien plants. In riparian forests, high nutrient levels and frequent natural and man-made disturbances facilitate invasions, and rivers additionally serve as highly effective propagation corridors for invasive alien plants. Therefore, the management of invasive alien plants in riparian areas is highly important to preserve and/or restore biodiversity and ecosystem services of this endangered ecosystem.

This chapter of the forest and conservation management handbook for riparian forests aims to collect and to provide synthesis of practically-orientated information of management measures, applicable for every stage of biological invasion: from the first appearance of invasive plants to the successful spread in a new area. Although we intended to collate management measures as comprehensive as possible, it needs to be stressed that each presented management measure needs to be adapted to local circumstances of a given area. Furthermore, we need to note that certain eradication measures can be strongly influenced by phenology and other ecological characteristics of each individual alien plant species. Therefore, we always recommend researching the biology of invasive alien plants before planning and implementing management actions. Furthermore, it is important to respect the local legislation when implementing chemical and non-chemical management measures. The purpose of this chapter is to help with data collected to prevent the establishment and spread of invasive alien plants in riparian forests of your working area. Once established, the chapter offers prevention measures to be implemented.

\section{Impact mechanisms and impacts assessments}

The threats caused by invasive alien plants in forest ecosystems 


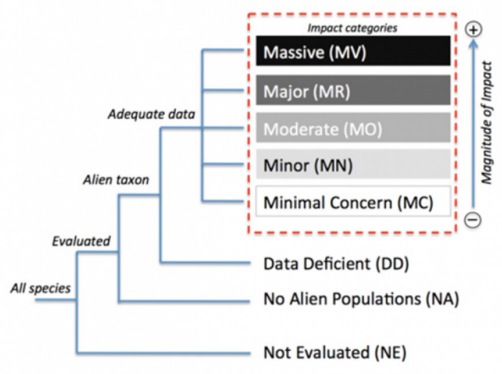

Figure 3.2.5-1: The EICAT Categories displayed in assessment process scheme that classifies alien species into one of five categories, according to the magnitude of detrimental impacts on the environment. include hybridization, transmission of diseases and species competition. Competition for resources, for example when an alien plant competes with native taxa for resources (light, water, space), is the most common reported impact mechanism leading to a harmful impact on native taxa in riparian forests. Competition for light with native species, for example, has been observed for invasive plant species Solidago gigantea, Impatiens glandulifera and Conyza canadensis in riparian mixed oak-elm-ash hardwood forests along great rivers.

Another impact mechanism of invasive alien plants are chemical impacts, such as the ability of alien plants to alter chemical and biochemical soil properties, which in turn can cause changes in native species richness above and below ground. The invasive alien plant Impatiens glandulifera, for example, changes soil fungal and bacterial communities. Furthermore, the chemical composition of plant litter from alien plants, such as the invasive alien tree Robinia pseudoacacia, can cause high levels of nitrogen in the upper soil layer, thereby exerting an effect on the regeneration of native tree species.

Several policies and legislations are in place to regulate the spread of invasive alien plants to mitigate the negative impact in forest ecosystems. As financial resources for invasive alien plant management are usually limited, we recommend prioritizing the present and potentially occurring alien species according to the magnitude of environmental impacts of alien species. The internationally adopted methodology of the Environmental Impact Classification of Alien Taxa (EICAT - the IUCN Standard for the classification of the impact of alien species on the environment) protocol can be effectively applied to categorize and quantify the impacts of all alien species within an entire taxonomic class based on the systematic review of literature (Fig. 3.2.5-1).

The EICAT assessment of invasive alien species (insect, fungi and plants) in the Mura-Drava-Danube Biosphere Reserve revealed that alien plants Amorpha fruticosa, Heracleum persicum, Humulus japonicus, Impatiens glandulifera, Reynoutria japonica, Reynoutria sachalinensis are among alien species with the most severe potential environmental impact in riparian forests.

\section{Prevention measures}

A large number of human activities are supporting the introduction and spread of invasive alien plants to riparian 
forests. Prevention measures, aiming to identify and adopt these human activities as well as the pathways of invasive alien plants, are among the most effective and cost-efficient management measures. In riparian forests, for example, clearcutting changes light conditions and resource availability in ways that favour alien plant species. The latter are usually heliophytes, adapted to a habitat with a very intensive insolation, due to the construction of its own structure and metabolism. Furthermore, the construction of forest roads and walking paths can promote the spread of alien plant seeds and specimens through the movement of contaminated soil and construction material. Therefore, the risk of forest roads functioning as pathways for invasion should not be underestimated. Fodder used in big game winter feeding can be a source of infestation.

Additionally, the ability to identify alien plant species is to detect invasive alien plants at an early stage of spreading in a riparian forest site. Target group-specific training material can help to increase the knowledge on invasive alien plant risks. Citizen science programmes, such as the DanubeForestHealth tool, also offer a large set of technical tools to engage with the public to identify invasive alien plants.

Prevention measures also include legally binding and non-binding measures that inhibit the establishment of invasive alien species in an area. The European Union Regulation (No 1143/2014) on the prevention and management of the introduction and spread of invasive alien species, which entered into force on 1 January 2015, for example, restricts invasive alien species to intentionally or negligently bringing into the Union, reproducing, growing, transporting, buying, selling, using, exchanging, keeping and releasing invasive alien species of the EU's concern into the EU. The current list of invasive alien species of the Union's concern contains 36 plant species, and many of them occur in riparian areas, such as tree of heaven (Ailanthus altissima), Japanese hop (Humulus scandens) or Himalayan balsam (Impatiens glandulifera).

\section{Risk assessment}

Sometimes alien plants, such as non-native trees or herbs in meadow seed mixtures, are intentionally used in forestry or ecosystem restoration. In these cases of intentional use of nonnative species, we recommend conducting a site-specific risk assessment. The minimum standards for a risk assessment include the following: 1) basic species description; 2) likelihood of 
naturalisation or invasion; 3 ) distribution, dispersal, and impacts; 4) assessment of pathways of introduction; 5) assessment of impacts on biodiversity and ecosystems; 6) assessment of impacts on ecosystem services; 7) assessment of socioeconomic impacts; 8) consideration of species status (threatened or protected) or habitat under threat; 9) assessment of future climate change impacts; 10) completion possible even when there is a lack of information; 11) documentation of information sources; 12) summary in a consistent and interpretable form; 13) incorporation of uncertainty; 14) quality assurance. However, we recommend that you consult a national specialist who can provide more detailed information on risk assessment in your area and for the alien species of interest to you.

\section{Monitoring}

Early detection and rapid eradication at an early stage of invasion is a cost-effective measure to stop the spread of invasive alien plants, which usually follows the successful detection of an invasive alien plant population in a monitoring. Over the past several decades, many different monitoring systems have been implemented at a local, regional and national scale. The basic principle of an invasive alien plant monitoring is the repeated observation of systematically located plots in a site of concern over several years. Monitoring requires staff time of trained inspectors and identification material for the identification. Other technical tools have been developed to simplify and to improve the monitoring process: Environmental DNA (eDNA), for example, can be used for surveying genetic material obtained directly from water or sediment samples.

\section{Mechanical control}

Mechanical control measures include hand-pulling, cutting, mulching, girdling treatment etc., including the use of different tools such as mowers or trimmers to uproot, cut, bury, smother or burn entire invasive alien plants or parts of plants.

The success of manual mechanical control methods, such as hand pulling, depends on the morphology of the invasive alien plant species and the skills and techniques of the trained personnel. For most plant species, it is important to completely or repeatedly remove the root system as well as the overlying parts of the plant if a species is capable of vegetative propagation. Sometimes it takes several years for a plant to be successfully removed or depleted (e.g. Solidago gigantea/canadensis, Reynoutria japonica, F. $x$ bohemica, Acer negundo, Ailanthus altissima, Amorpha fruticosa etc.). In this 
case, perseverance and consistency are required. Special attention should also be paid to the handling of plant residues. These must be collected on plastic sheets and transported in plastic bags, so that seeds, fruits and other parts of plants (the possibility of vegetative propagation!) do not spread further in other areas. Plant residues need to be dried, incinerated or handed over to competent services dealing with such waste material.

Cutting and grazing are effective solutions for herbaceous and woody invasive alien species. It is recommended to conduct cutting and grazing measures prior to fluorescence and seed production. Grazing is less labour intensive and it has reportedly positive side effects on landscape ecology. For example, in respect to local legislation, grazing with cattle, horses, domestic pig and sheep can be effectively used to prevent the spread of alien invasive shrub species in floodplain forests (Fig. 3.2.5-2, 3.2.5-3). Once these invasive shrub species are established (2-5 years after germination), reduction of their abundance requires a patient and permanent grazing in floodplain forests (e.g. in poplar plantations).

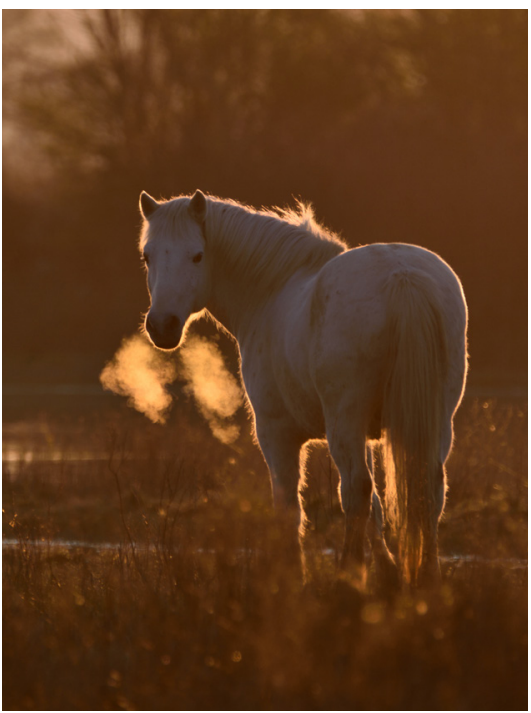

Figure 3.2.5-3: Grazing by horse at the Isola Della Cona wetland nature reserve in Friuli-Venezia Giulia, northeast Italy
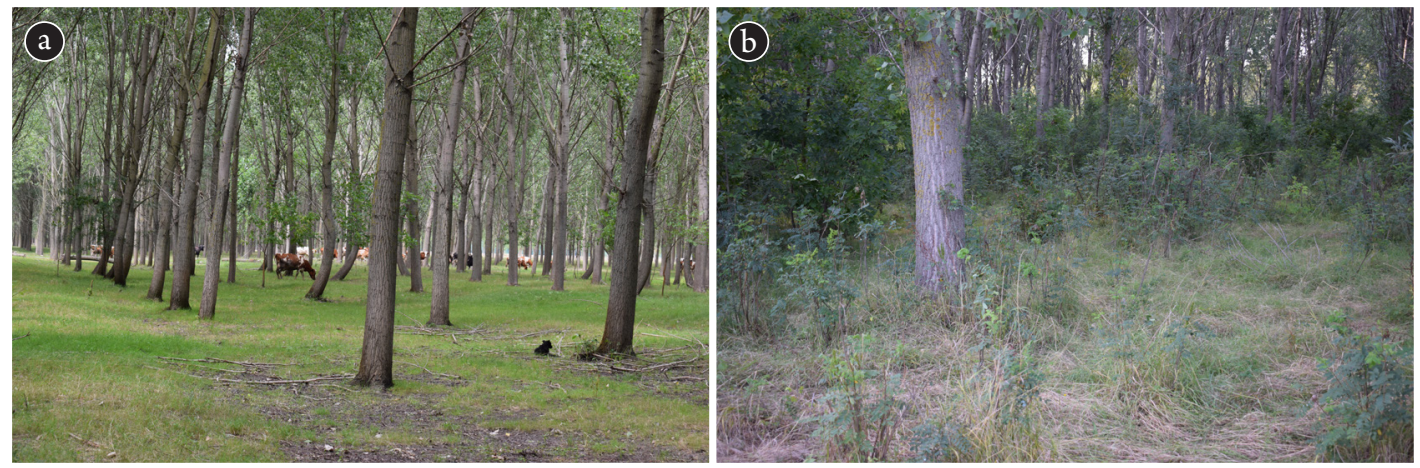

Figure 3.2.5-2: a) Regular grazing prevents the establishment and spread of invasive shrub species in poplar plantations along the Timis River in Serbia; b) Dense Amorpha fruticosa and Fraxinus pennsylvanica shrub layer in an ungrazed poplar plantation

Mulching is a relatively non-destructive mechanical control method, which excludes light from germination and inhibits photosynthesis, by covering a seedling with straw, bark, cuttings, plastic covers or paper. This measure is commonly used in agriculture practice to control mostly annual weeds. Mulching has been successfully used to control Impatiens glandulifera.

Depending on the area, we recommend learning about restrictions and the species reproductive biology. In general, the use of mechanical control measures requires a planned strategy 
that includes surveillance, containment, treatment and follow-up measures to assess the success. In many cases mechanical control measures are only feasible in the initial stages of invasion. On the one hand, the goal of mechanical control is rarely achieved without high effort and costs. Therefore, mechanical control measures are usually attempted in small defined areas. On the other hand, mechanical control measures, if applied correctly, are less harmful to the environment and native ecosystem than chemical measures. This makes mechanical control measures very useful for protected areas, where chemical or biological control is no option or is legally prohibited. In riparian forests, mechanical control measures have been successfully used to eradicate small stands of Himalayan balsam (Impatiens glandulifera), tree of heaven (Ailanthus altissima), hogweeds (Heracleum ) or common milkweed (Asclepias syriaca).

\section{Chemical control}

Chemical control measures refer to selective and localised spraying or smearing of plant protection products. The application of herbicides, in particular glyphosate applications, are cost-effective chemical control measures that help avoid soil surface disturbance and subsequent germination of invasive alien plants, but negatively affects non-target plant species and the environment. The sites need to be monitored in the following years to evaluate the success and negative side effects of the treatment. Occasionally, the treatment needs to be repeated in the following years. Especially in riparian forest ecosystems, the use of chemical control measures is not recommended. Furthermore, legal restrictions are often inhibiting the use of herbicides in forest ecosystems.

\section{Biological control}

Biological control measures refer to the introduction of living organisms (a biological agent) to lower the competitive ability of invasive alien plant species. These measures can have negative long-term effects and require the consultation of a local expert before implementation. National and local legislation needs to be respected and an appropriate risk assessment needs to be conducted prior to any release of biological agents. In practice, the application of biological control measures includes a wide range of organisms:

Rabbit grazing, for example, was used to control milkweed (Asclepias syriaca) in the Kiskunság National Park, Hungary. In experimental studies, specific rust fungi (Puccinia komarovii var. 
glanduliferae) were used to control Impatiens glandulifera (Fig. 3.2.5-4). Furthermore, fungi in the genus Verticillium spp., such as an isolate of Verticillium nonalfalfae, are currently considered the most effective biological agent against Ailanthus altissima.

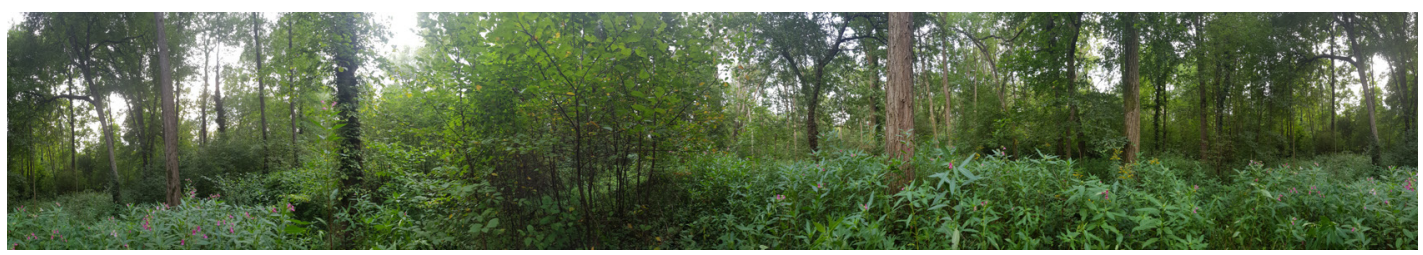

Figure 3.2.5-4: Invasion by Himalayan balsam (Impatiens glandulifera) and giant knotweed (Reynoutria sachalinensis)

\section{Adaptation of silvicultural measures}

Recommendations concerning the adaptation of silvicultural measures include preventive actions such as the recommendation to plant native tree species. Furthermore, continuous tree cover and longer rotation periods are recommended where appropriate to promote shadier conditions. Soil preparation of clearcutting should also be avoided, especially when the area is regularly flooded, because the propagules of invasive alien species can easily be transported by water to a prepared soil, where they can also find sufficient light for germination and growth. The slight thinning of forest areas should be avoided to reduce the risk of management disturbances that may function as pathways for the introduction of alien plant species into a forest. Forest edges should be preserved because dense, multilayer canopy can prevent or slow down entrance of invasive species from surroundings. Regular mowing of corridors along forest roads is effective management of this pathway. Finally, alternative cutting regimes to simple clearcutting, such as selection or shelterwood systems applied in continuous-cover-forestry, should be preferred.

\section{Restoration of damaged ecosystems}

The long-term resilience of riparian forests can be improved by carrying out appropriate restoration measures to assist the recovery of an ecosystem that has been degraded, damaged, or destroyed by invasive alien plants or other invasive organisms (for example insects or fungi). The costs of any control measures could be high and disproportionate to the benefits of restoration. However, in some cases, traditional land use practices, such as forest grazing, can be a cost-effective tool for restoration.

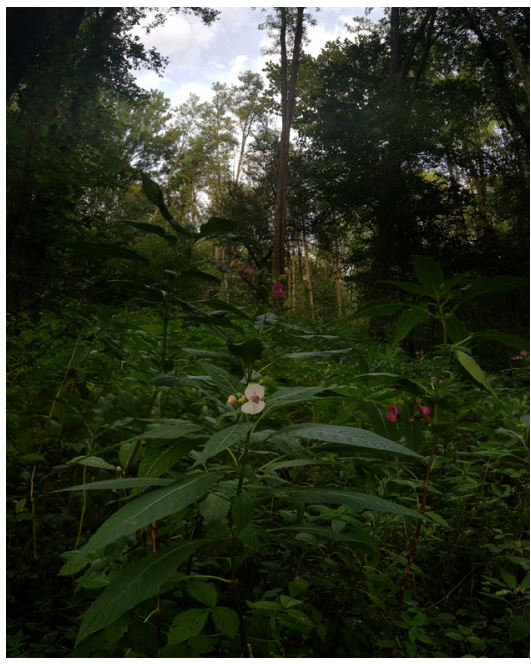

Figure 3.2.5-5: Himalayan balsam (Impatiens glandulifera) is native to Asia 


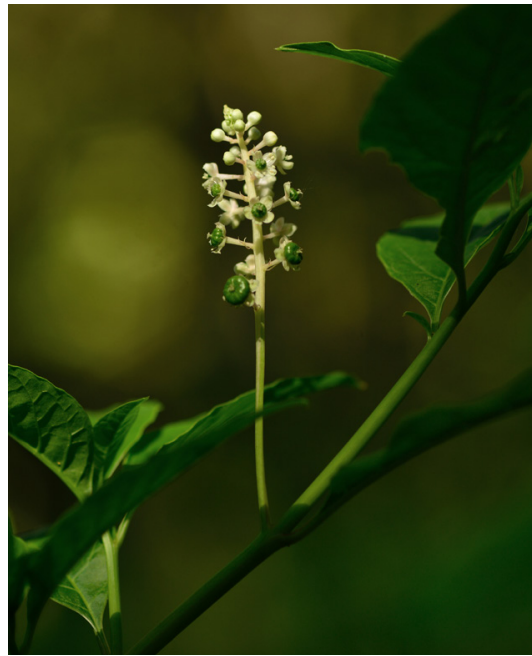

Figure 3.2.5-6: Pokeweed (Phytolacca americana) is native to North America and is spreading in Europe

\section{CHECK LIST WVASIVE ALIEN D 1 N}

Recommendations for the planning process of management measures for

invasive alien plants in riparian forests.

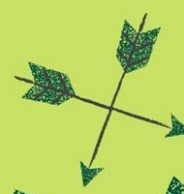

1 SET A GOAL

Identify the environmental risks of a currently or potentially occurring invasive alien plant in your area of interest.

\section{KNOW YOUR ALIENS}

Certain eradication measures can be strongly influences by the phenology and other ecological characteristics of each individual alien plant species. Therefore we always recommend researching the biology of the invasive alien plant before planning the management actions.

\section{RESPECT LEGISLATION}

Respect the local, national and regional legislation when implementing chemical and non-chemical management measures.

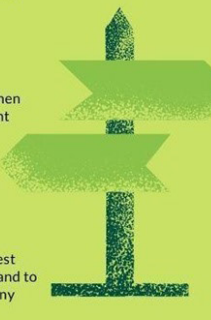
roads, and human activates in the riparian forest site and to increase the awareness of the land-use managers or any other person involved in the human activates along potential pathway for invasive alien plants.

5 PRIORITIZE THE ALIENS

As financial resources for invasive alien plant management are usually limited, we recommend to prioritise the present and potentially occurring alien species according to their the magnitude of environmental impacts of alien species.

\section{TALK ABOUT YOUR WORK}

Target group-specific training material can help to increase the knowledge on invasive alien plant risks. Citizen science programmes also offer a large set of technical tools to engage with the public

to identify invasive alien plants.

\section{ADAPT YOUR MANAGEMNT}

Management measures need to be adapted to the local circumstances of the given area.
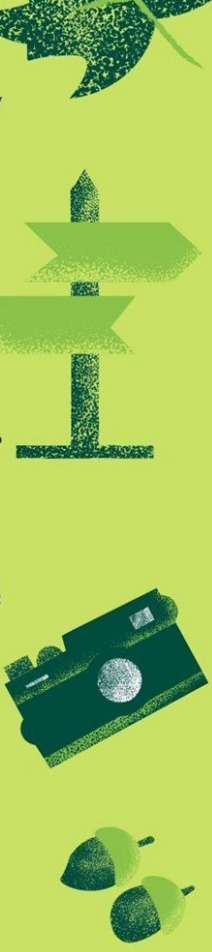

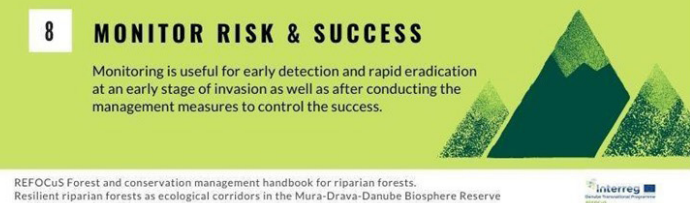

Figure 3.2.5-7: Check list for invasive alien plants 


\subsubsection{Integrating biodiversity enrichment in poplar forest management}

\section{Markus Sallmannshofer, Werner Ruhm}

\section{Background}

Due to highly productive soils and locally variable environmental conditions, riparian forests are particularly rich in species diversity including many specialized plant and animal communities. Typical character tree species of softwood floodplains, such as different willows, black and white poplars, are adapted to the highly dynamic geomorphology caused by the eroding and depositing forces of rivers. These light-demanding pioneer species preferentially germinate on raw soils and thus require soils free of vegetation, sand and gravel banks. At such habitats, they can withstand flooding better than any other tree species. Due to river regulations, the natural dynamics of softwood riparian forest has been lost and softwood tree species lost their typical habitats and evaded to secondary locations such as gravel pits. The decreasing frequency of flooding along many regulated rivers also promotes competitive vegetation and the maturation of pioneer softwood into more shade-tolerant hardwood forests.

\section{Poplar breeding}

In the second half of the $19^{\text {th }}$ century, breeding and trade of poplar varieties with special properties such as high growth performance and disease resistance was initiated. Hybrid poplar breeding started at the beginning of the $20^{\text {th }}$ century: particularly fastgrowing crosses between different poplar species became popular in forestry. Finally, the lack of wood caused by the Second World War supported the foundation of poplar research institutes and the introduction of hybrid poplars in many countries.

Current poplar cultivars are selected for high growth performance, shape and disease resistance. This reduces rotation time and increases timber quality. At some forest sites, poplar cultivars show higher yield than any other tree species - which is why many forest companies and small forest owners prefer their cultivation. Today softwood alluvial forests and the transition area to hardwood floodplains are the predominant cultivation areas for poplar and poplar hybrids. At present, high-performance clones can be managed with rotation periods of less than 30 years at optimal sites.

\section{Poplar forest management and conservation}

At many riparian forests, hybrid poplar stands were traditionally 
managed as monocultures (Fig. 3.2.6-1) which has drawn the attention of conservation scientists as it may further decrease native softwood habitats and its connected species communities. On the other hand, continuing demand for poplar wood (e.g. for packaging wood) and the short rotation period makes hybrid poplar one the economical key species for forest companies managing floodplain forests, especially as other native species such as Elm and Ash experience severe dieback. Therefore, a coexistence of hybrid poplar management with integrated nature conservation measures are required to better balance ecological and economic interest. In this chapter, we describe an approach that takes poplar biology and ecology as well as the specific site conditions of riparian forests into account with an aim of increasing the biological diversity of poplar stands in a resource-efficient way, while at the same reducing costs of poplar management.

\section{Establishment of poplar stands}

Traditional poplar management included the planting of rooted cuttings (poplar hybrids are reproduced vegetatively) in fixed rows and distances of $2 \times 2 \mathrm{~m}$ or $3 \times 3 \mathrm{~m}$. As poplars do not shed branches by themselves, management includes pruning and thinning activities.

As an alternative to traditional spacing, applying wide distances of $8 \mathrm{~m}$ between planting rows reduces planting and management costs and enables the development of natural side vegetation. Depending on a site, white poplars (Populus alba), willows (Salix sp.), alders (Alnus sp.) and bird cherries (Prunus padus) frequently establish themselves naturally, often from root or stump sprouts. If such beneficial mixed tree species do not naturally occur by succession, the diversity can be increased by tree or shrub

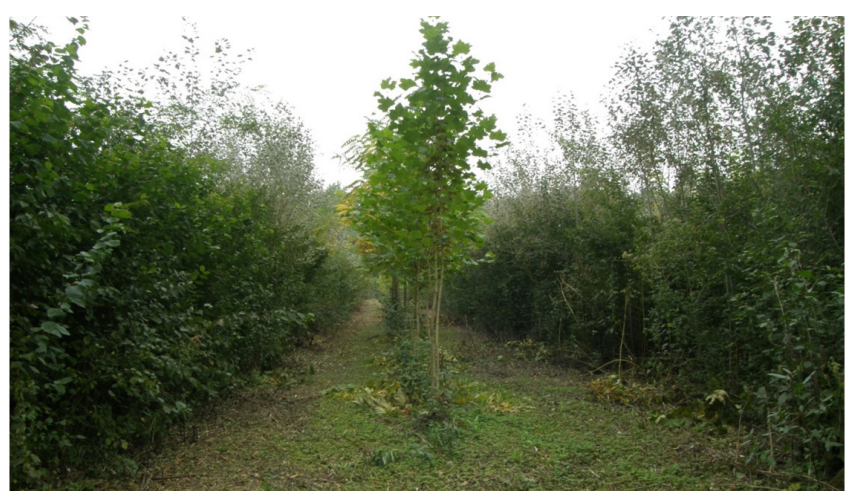

Figure 3.2.6-2: Maple trees between poplar rows

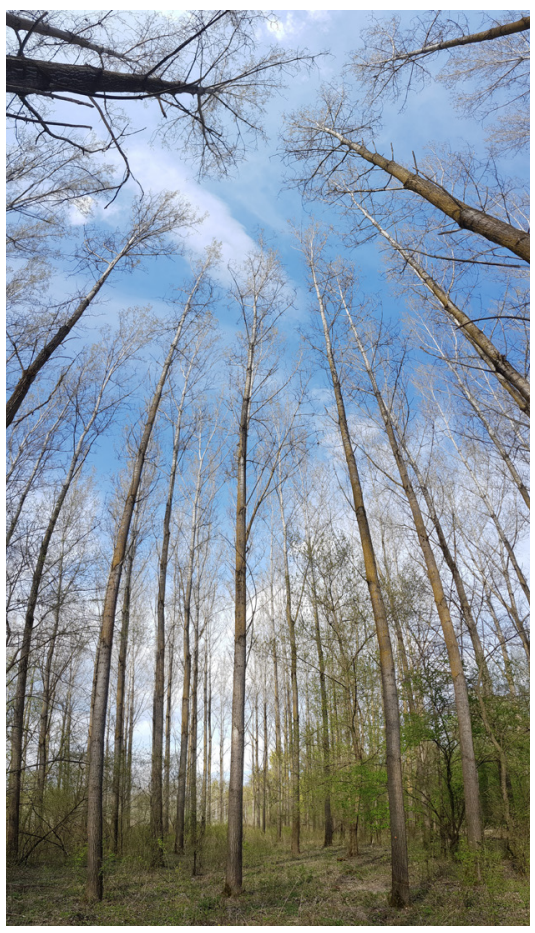

Figure 3.2.6-1: Poplar stands are an important woody resource and important income for forest enterprises active in riparian forests. 
planting between poplar rows (Fig. 3.2.6-2).

Prior to planting, the strips where the rows of poplars will be established may need to be mulched if there is heavy ground vegetation present. Outside the rows, vegetation is left to develop naturally. Planting can be done with a planting plough or by digging holes. Primarily 2-year-old plants about $2.5 \mathrm{~m}$ tall or taller with large roots are recommended. Planting trees in rows can have a negative visual effect, but allows for a streamlined workflow, both for planting and for necessary maintenance work. To avoid conflicts with forest visitors, the visible edge of the stand can be treated differently, e.g. by leaving hedges or planting mixtures of native shrubs and trees.

Poplar cultivars are reproduced in nurseries by clonal propagation via cuttings. A spatial and temporal mixture of several varieties increases genetic diversity and ensures risk diversification. Knowing where a cultivar/clone was planted in this mixture (e.g. planting maps) is a basic requirement to later compare the success of cultivars.

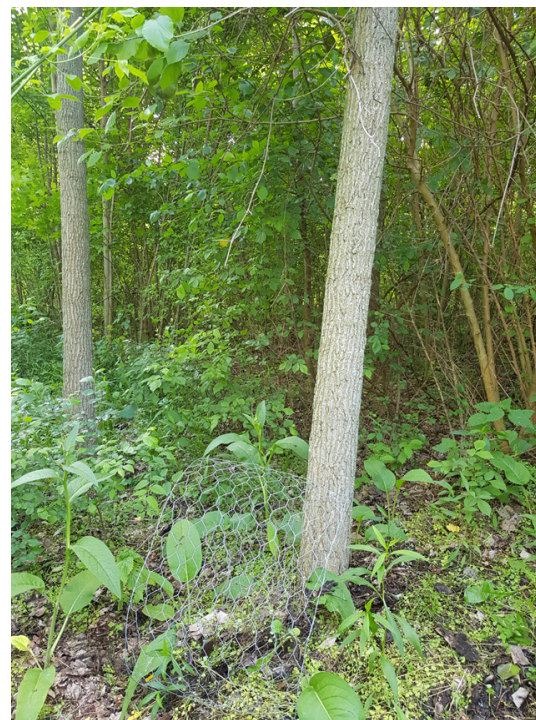

Figure 3.2.6-3: To prevent a tree from being constricted by a fence when growing thicker, the closure should only be a light wire loop that opens up with increasing tree diameter.

\section{Specific culture protection}

If only roe deer are present, painting the trunk is often sufficient protection against deer rubbing. Against red deer, protection of individual trees or fencing of an entire area is necessary. In Serbia, a method has been developed in which poplar seedlings/cuttings are wrapped with rabbit wire mesh during the planting process. The closure with a light wire loop that slips open prevents a tree from being constricted by the fence as it grows in diameter (Fig. 3.2.6-3). Problems arise when red deer graze shoots above the fence and break the stem (Fig. 3.2.6-4, see 3.2.4 How to manage game and protect forests from damage).

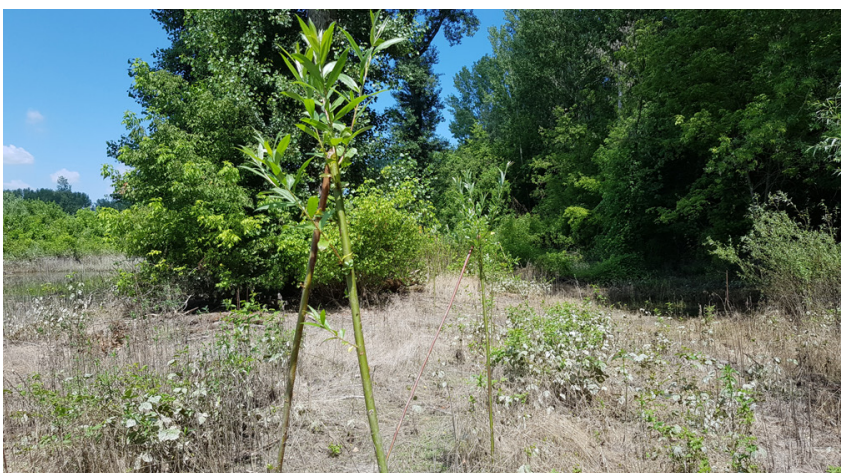

Fig. 3.2.6-4: Red deer bend down the young poplar trees for grazing and might break the young stems. 


\section{Culture maintenance}

Floods occurring immediately after planting regularly lift plants that have not yet had sufficient time to root themselves. Such uprooting requires repair. For the first 1-2 years after planting, it is suggested to cut vegetation along the rows of poplar trees with a rotary cutter. If necessary, climbing plants such as wild hops and clematis shall be removed with hand shears, because the pulling down of poplars may slow down or even damage the young plants.

\section{Pruning}

The production of valuable poplar wood requires pruning, usually done in three phases with a pole saw up to a height of 6 meters. A secondary stand of mixed tree species can make a decisive contribution, reducing the growth and thickness of branches. Thus, some phases of pruning can be omitted.

\section{Thinning}

Between the age of seven to ten years, tree density is usually schematically reduced to the final stand density by thinning (e.g. with a plant spacing of 4 meters per row every second poplar is removed). The removal not only benefits the best poplar trees, but also promotes the secondary stand.

\section{Summary and outlook}

Wide spaced poplar cultures support the growth and stability of individual trees, while the space between poplar trees enables the establishment of a secondary stand of mixed tree species by natural regeneration. The focus on fewer trees reduces planting costs and pruning interventions. Overall, wide spaced poplar cultures allow a better integration of economic and ecological interest in riparian forest management.

\section{Acknowledgement}

We thank Herbert Tiefenbacher $(\mathrm{PhD})$ for his valueable inputs. 


\subsubsection{Integration of deadwood portions into regular management}

Janine Oettel

\section{Introduction}

Creating, maintaining and managing deadwood is a key component of improving the ecological state of forests. Deadwood characteristics have been used as indicators of forest naturalness, provision of ecosystem services and the status of forest biodiversity. International initiatives such as the Convention on Biological Diversity (CBD), Forest Europe (formerly the Ministerial Conference on Protection of Forests in Europe) and the European Environment Agency's 'Biodiversity Baseline' project include deadwood as a key indicator of sustainable forest management. Subsequently, certification schemes (FSC, PEFC) have implemented deadwood in their standards aiming at safeguarding biodiversity and conserving environmental values.

Deadwood contributes to ecosystem functioning and fluxes in forests by changing microclimate, such as soil moisture by increasing water storage capacity and increasing nutrient availability. Further, deadwood facilitates natural tree regeneration, particularly in forests in cool climates such as temperate mountain forests. Moreover, 25\% of forest-dwelling species are dependent on deadwood. For instance, deadwood provides essential resources for saproxylic (deadwood-dependent) species like wood-decaying fungi, arthropods, bryophytes, lichens, birds and bats.

The importance of deadwood for species protection is quite well documented in beetles. According to the European Red List of Saproxylic Beetles, $18 \%$ of 688 investigated species are considered threatened and further $13 \%$ are considered near threatened in Europe. They depend on deadwood and old trees as they develop in decaying wood and caves. It is therefore urgent to establish landscapes and forests with a diverse tree age structure, species diversity and a sufficient number of trees providing microhabitats as well as a sufficient amount of deadwood in different stages of decomposition.

While in natural temperate forests, volume and composition (e.g. state of wood decomposition, dimension) of deadwood is impressive, in managed forests deadwood is a severely reduced forest component. Accordingly, many biota in Europe that are dependent on deadwood - particularly species that depend on specific types of deadwood or large amounts of deadwood - have 
greatly declined in managed forests and often are reduced to isolated populations in unmanaged forest remnants. It is wellknown that deadwood volume and composition are driven by a wide range of factors (e.g. stand age, natural tree mortality, tree species composition), and that it is strongly contingent on silvicultural forest management. For European forests, a basic threshold range of $20-50 \mathrm{~m}^{3}$ per ha for deadwood volume has been suggested as a minimum requirement. Actual average volumes, however, are much lower in Northern Europe with $8 \mathrm{~m}^{3}$ per ha, while it is somewhat better in Central and Western Europe with $20 \mathrm{~m}^{3}$ per ha.

\section{Riparian forests}

Generally, riparian forests are special habitats that are often highly productive and represent areas with high biodiversity. High productivity often results in a high input of deadwood. Reports show that volumes of deadwood may vary. For instance, the volume is $51 \mathrm{~m}^{3}$ per ha in Austria, between 22 and $88 \mathrm{~m}^{3}$ per ha in Poland, between 36 and $165 \mathrm{~m}^{3}$ per ha in Slovenia and can be even as high as $206 \mathrm{~m}^{3}$ per ha as reported for Italy. Depending on the location and proximity of a river, deadwood may also enter water through flooding and be carried away or accumulate in certain locations.

The richness of saproxylic beetles is correlated with deadwood volume. Around 242 saproxylic beetles were reported in the Austrian floodplain forests of the Donau-Auen National Park. Such a high value clearly underlines the conservation value of

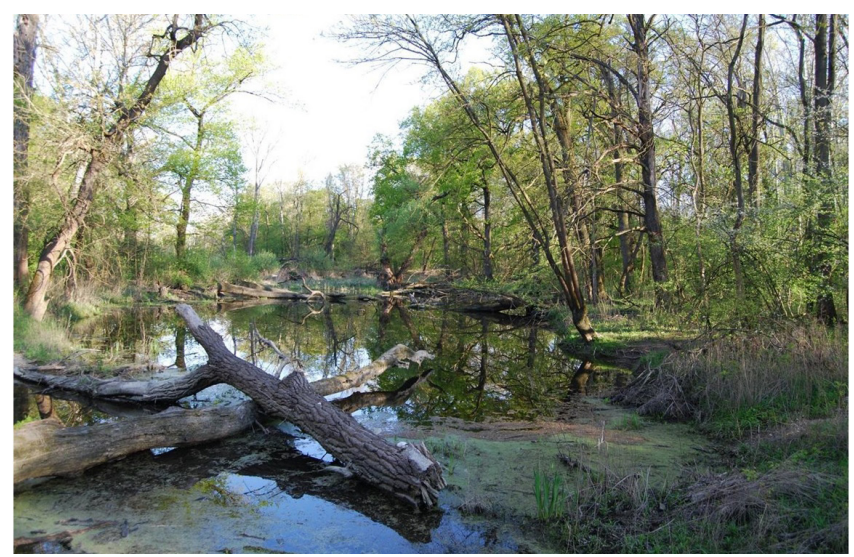

Figure 3.2.7-1: Deadwood volumes of $30-50 \mathrm{~m}^{3} \mathrm{ha}^{-1}$ on average in a hardwood floodplain forest in Austria. The exclusion of forest areas or single large trees with ecological value from management are options to increase the availability of deadwood and thus biodiversity in forests 
riparian forests. Various studies agree that saproxylic species richness is highly influenced by deadwood volume and diameter. Experts put threshold values of deadwood volume for floodplain forests at diameter of $22 \mathrm{~cm} \mathrm{DBH}$ and $32 \mathrm{~m}^{3}$ per ha, below which the richness of saproxylic species decreases significantly. Additionally, the availability of deadwood in advanced decomposition stages is positively correlated to species richness, while small diameter deadwood, as well as a high stand basal area, are negatively correlated to species richness.

\section{Management options to increase deadwood proportions}

Deadwood properties and forest structural variables highly influence species richness. The active promotion and integration of deadwood in forest management is therefore of great importance and has been implemented in various management concepts over the last decades. Various management concepts similarly recognize the value of old and dead wood and include its promotion through different measures, such as 1) establishing forest reserves, or 2) leaving groups of old trees for natural disintegration. In addition, by 3 ) leaving habitat trees with cavities or nests, and 4) increasing the amount of standing and lying deadwood, residual populations of saproxylic species will be preserved through habitat connectivity and thus distribution of these species strengthened. Recommendations for increasing deadwood proportions in riparian forests include $4 \mathrm{a}$ ) leaving harvested material on site, 4b) creating artificial stumps with the height of $0.5-1 \mathrm{~m}$ and $4 \mathrm{c}$ ) striping the bark of single, large-

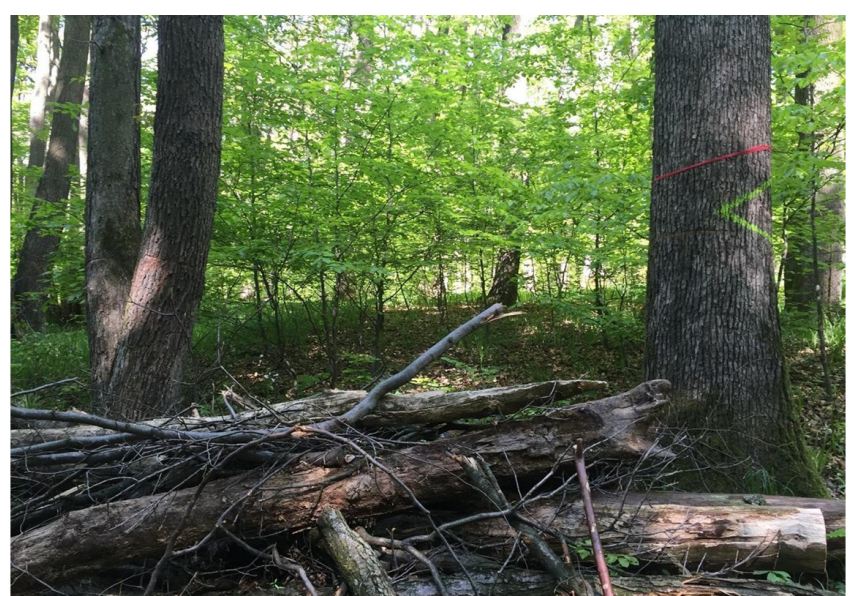

Figure 3.2.7-2: Accumulation of dead wood after wood harvesting operations. By leaving branches, trunks and stumps of little or no economic value behind during a harvesting process, the integration of deadwood into regular management is promoted 
diameter trees in preferably sun-exposed locations to artificially create deadwood. Moreover, 5) prolonged rotation periods can assure a continuous supply of deadwood and the availability of deadwood at later stages of decomposition. However, various management concepts vary in definitions and target values for single measures. For instance, the number of habitat trees per ha varies from 5 to 10 , or deadwood volumes vary from 20 to $40 \mathrm{~m}^{3}$ per ha.

Standing dead trees can pose a threat to traffic safety and occupational safety in forests. Along and around public roads, railway lines, paths and other infrastructural facilities, as well as in the area of buildings, the protection of life and health and thus traffic safety is a priority. Generally, it is important to periodically assess the risk of standing dead trees and to cut them if necessary. Measures with regard to work and traffic safety include cutting stumps as far as necessary to avoid risk. These measures should be kept within reasonable limits. By setting aside groups of habitat trees or deadwood, the risk is concentrated on a smaller number of areas, thus reducing the overall risk.

\section{Summary and outlook}

Measures to integrate deadwood into regular forest management include setting forest reserves aside, excluding individual ecologically valuable trees from management and actively providing standing and lying deadwood. This can be realized during harvesting operations by leaving branches, stems and stumps of low or no economic value. Deadwood volumes with at least $30 \mathrm{~m}^{3}$ per ha and medium to large deadwood with a minimum diameter of $20 \mathrm{~cm}$ have been shown to have a positive effect on related species. Aspects of forest protection and safety must be considered in any case. Necessary measures should be kept to a minimum while ensuring safety and averting risks. In doing so, it is feasible to integrate deadwood management into forest management. 


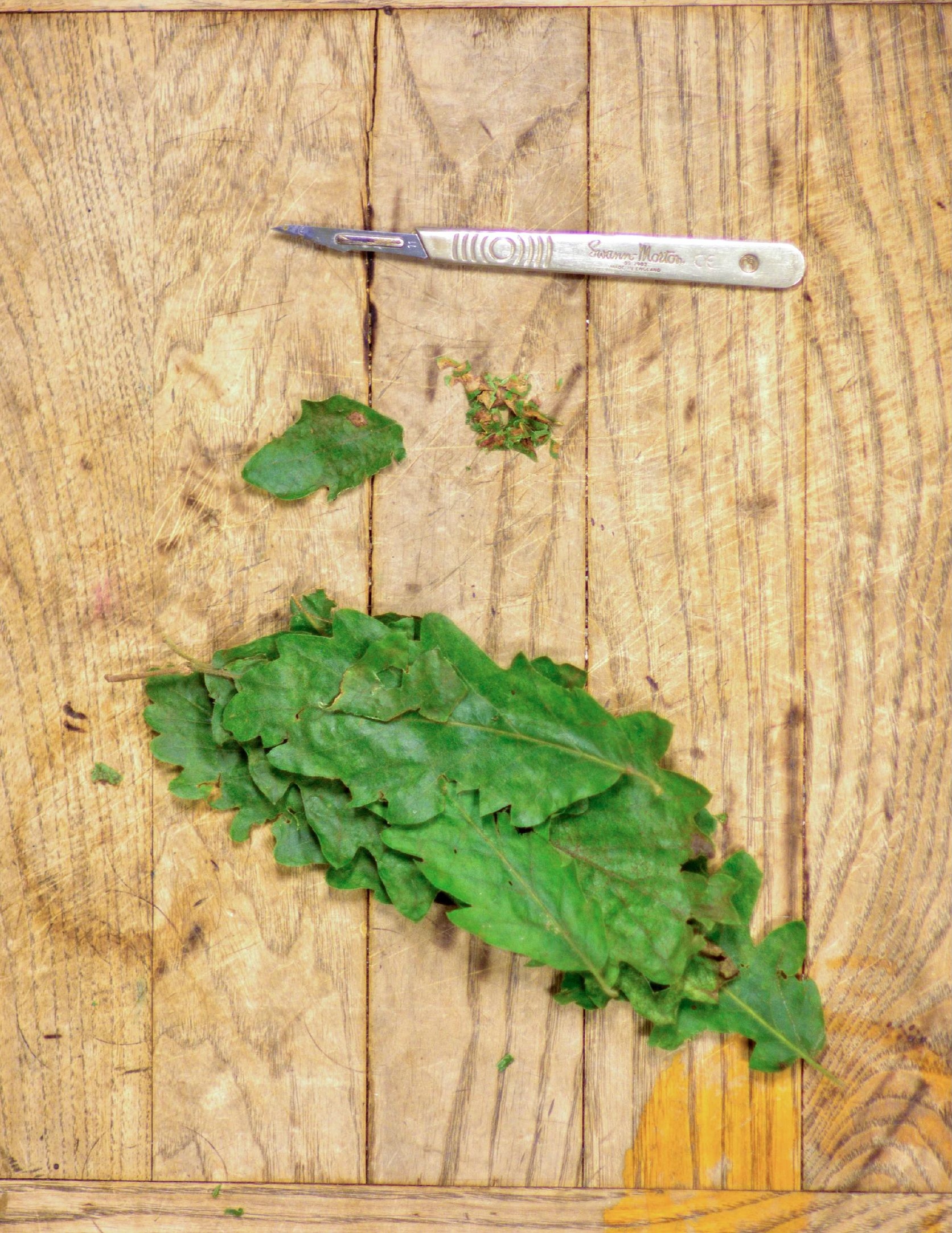




\subsection{Forest health}

3.3.1 Forest pests and diseases in a changing world: the importance of early detection

Maarten de Groot, Thomas Cech, Gernot Hoch, Nikica Ogris, György Csóka

\section{Epidemic pests and diseases, an actual problem for riparian ecosystems}

Global trade and climate change put strong pressures on the riparian forests in Central Europe. Global trade gives the opportunity to alien species to be brought from their native range to the European forests. Although most of these species are harmless, some have the potential to become invasive and can therefore cause a lot of damage in the forests to biodiversity, economy and human health. On the other hand, in the last decade there was an increase of global temperature and of frequency of extreme weather events - effects of the ongoing climate change. These increases of global temperature and extreme weather events weaken the forest trees and make the area more suitable for certain (native) pests and diseases, which can be followed by outbreaks. These species are also called eruptive pests and diseases.

Riparian forests are especially in a very vulnerable position as they are mainly in the lowlands with often high temperatures, influenced by floods which mean potential stress, but also under high pressure by human activity like monoculture plantations or over exploitation with regard to recreation. Almost all tree species in the central European riparian forests are currently threatened by different pests and diseases. For instance share of ash (Fraxinus excelsior and F. angustifolia) has been decreasing in the last decades due to the arrival of ash dieback (Hymenoscyphus fraxineus, see 3.3.4 Ash dieback as a major threat to riparian forest biodiversity), while oaks have been suffering from a complex of factors causing oak decline (see 3.3.3 Oak decline - an example for a disease phenomenon characterized by various interacting causal agents) or outbreaks of gypsy moth (Lymantria dispar) and browntail moth (Euproctis chrysorrhoea). Also, the alder species are under pressure by Phytophthora alni, Armillaria sp. and Neonectria sp. complex that causes extreme dieback in certain places. These are only the pests and diseases that are already here, while there are still others to come. The Emerald ash borer (Agrilus planipennis) is slowly spreading from 
Russia and the Ukraine to the west and at this rate will likely be here in a few decades and will cause strong dieback of ash. Also, the Asian longhorn beetle (Anoplophora glabripennis) and the Citrus longhorn beetle (Anoplophora chinensis) are not yet in the riparian forests, but attack deciduous trees, and can have therefore strong potential effects on the riparian forest ecosystem when introduced. To mitigate these forest health problems, management measures should be prepared.

\section{Mitigating impact from epidemic pests and diseases}

Early warning and rapid response are key requirements for effective management of forest pests and diseases. In the case of outbreaks of native species, this means that the forester can become active before an outbreak occurs, while in the case of potentially invasive alien pests, the species should be found as soon as possible after its arrival so that it can be eradicated. The key here is to detect the outbreak and identify the invasive alien pest or disease before it causes widespread damage. The aim of this chapter is to assist practitioners in their pest or disease detection activities by outlining methods and providing information on pest and disease characteristics.

\section{Detection methods for pests}

For forest pests, the focus will be mainly on three approaches: visual survey for symptoms, trapping methods and other detection methods.

The first way to detect potential pest outbreaks and invasive alien insect species is by watchfully spending time in the forest and knowing what to look for. Recognizing symptoms and signs of pests is therefore of uttermost importance. Often the pest itself will not be the first thing encountered while symptoms are already recognized from some distance. The most obvious characteristic may be that the tree or parts of the crown are dying or does not carry anymore leaves or shows discoloured leaves. These are good reasons to have a closer look on the tree. Insect pests can be categorized into four different damage classes: the bark- and wood-borers, defoliators, sap-sucking insects and the gall-formers (Fig. 3.3.1-1). Bark- or wood-borers are often beetles or moths which are feeding as larvae in the wood or under the bark. One important group is the bark beetles (Coleoptera: Curculionidae: Scolytinae), which make very distinct and often species-specific patterns of galleries. Buprestid beetles (Coleoptera: Buprestidae) often make a zigzag pattern under the bark and have a distinct 

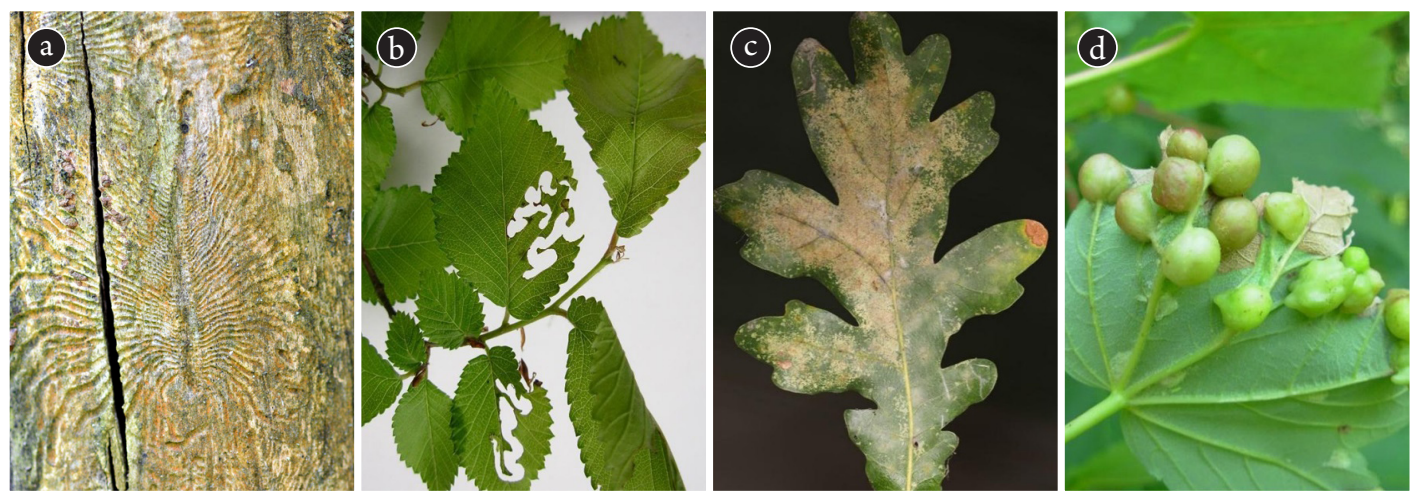

Figure 3.3.1-1: Different damage types caused by insects: a) galleries caused by large elm bark beetle (Scolytus scolytus); b) defoliation by elm zigzag sawfly (Aproceros leucopoda); c) sapsucking damage caused by oak lace bug (Corythucha arcuata); d) galls caused by maple gall wasp (Pediaspis aceris)

oval or a D shaped exit hole. Longhorn beetles (Coleoptera: Cerambycidae) have a more random pattern of the gallery while the exit holes are more oval to round. Defoliating insects have the capacity to completely defoliate a tree. Most defoliators are larvae of moths (Lepidoptera), larvae of sawflies (Hymenoptera: Symphyta), or beetles (Coleoptera). The species are often host specific and can have a certain pattern of feeding - some species feed only inside the leaf or needle (miners). However, while the pattern of damage can give an indication, it will often not be possible to determine the damaging agent based on the symptom; therefore, the causing insect should be found. For defoliators it is therefore advised to investigate the tree when a part of the crown is defoliated and try to sample the insect which is causing it. Sometimes other signs (as egg masses, caterpillar nests) may help to identify the defoliating insects. Sap-sucking insects are insects which are sucking the sap from leaves, shoots, twigs and even stem and are mainly found in the family of bugs (Hemiptera). Damages are visible by discoloration on the leaves or needles. When there is a large outbreak the whole tree crown can show the discoloration and leaves can fall off earlier in the season (Fig. 3.3.1-2). A fourth group which is known to affect adult trees and saplings are the gall forming arthropods. Mites (Acari), gall midges (Diptera: Cecidomyiidae), aphids (Homoptera: Adelgidae) and gall wasps (Hymenoptera: Cynipidae) can cause the tree to form prominent and often species-specific galls. These species lay eggs on different organs of the trees and their developing larvae induce galls on the plant tissues. Although individually not harmful, in large numbers they can affect the photosynthesis or interact with diseases as an entrance to the tree. The galls can be found on leaves, branches and seeds. Further information on damaging forest insects can be found in our recommended literature and on many websites 
In many cases, the insect causing a particular damage will be encountered in the larval stage (e.g. leaf feeding caterpillars,

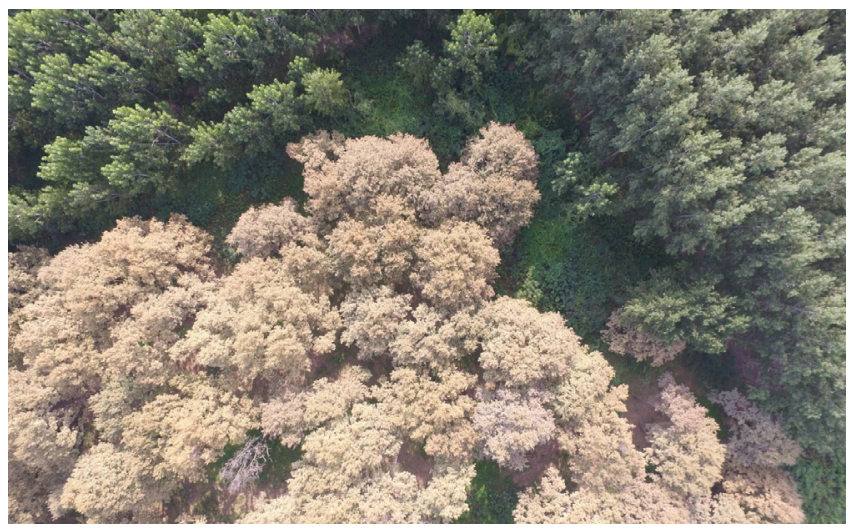

Figure 3.3.1-2: Oak stand attacked by oak lace bug (Corythucha arcuata) surrounded by poplar and willow stands in Serbia

larvae of woodborers developing under the bark). In general adult insects are mostly not easy to find. Therefore, you need help of different methods. One of the methods is to establish traps and lures. There is a range of traps, which are either nonspecies-specific or group/species-specific, which are using a type of attractant. An example of non-species-specific traps are flight intercept traps. These traps are set in the forest or on the forest edge and catch everything that flies by. The problem is that there are a lot of species being caught. For moths that are active during the night, a good way to detect them is with light traps. Small light weight can be operated with rechargeable batteries. Other species are attracted by certain colours as we can see with aphids but also beetles like buprestids. The emerald ash borer for instance is attracted by green and violet traps. Coloured traps are often combined with sticky surfaces. Besides or in addition to colour, insects can be attracted by odours, such as host tree volatiles or pheromones. The first type attractant is more general and is based on the volatiles emitted by the host tree. This would attract all species which are attracted to this particular host. Pheromones are volatiles produced by the insects themselves and are most specific; they will attract mostly one species. A problem is that not for all pest species a synthetic pheromone is developed. Very promising is the recent development in multilure trapping which is using different types of attractants. This would be very useful when you are looking for a particular species group which is difficult to detect.

There are several other methods available, but one detection 
method which is also very promising is the use of detection dogs. They have shown to be very accurate for the detection of invasive alien species like Asian and citrus longhorn beetles and emerald ash borer in points of introduction, but also in places where there are outbreaks. Detection dogs also have been used for eruptive species like Ips typographus. Although they can be very effective, dogs must be trained first to identify particular species.

In recent years, remote sensing became increasingly important in detecting damage in forests. Such methods can be helpful in collecting information on the extent or spread of damage. However, in most cases it will not be possible to determine the causal agent. Images taken by drones from less accessible forest spots may provide early warning of discoloration or leaf loss.

\section{Detection methods for diseases}

Diseases of trees and shrubs are mostly caused by fungal or fungal-like organisms, more rarely by bacteria, viruses and viruslike organisms. Most of the species produce only microscopic structures, which impedes a proper field diagnosis.

Identification of fungal/bacterial or viral origin of symptoms in the field is based on the knowledge of specific symptoms and/ or the finding and identification of reproductive structures of a pathogen. In diagnostic literature, symptoms are usually grouped according to plant organs they affect: leaves/needles, shoots/ twigs/branches, stems, roots and flowers/fruits. Similar to pests, pathogens are often limited in their activities to one or several plant organ types. Thus, the first step after recognizing a symptom is to identify and delimit the range of organs the symptom affects: diseases (mostly of fungal nature) affecting leaves or needles are usually rather specialized and often limited to these organs. In addition, they are mostly host genus-specific and the morphology and size of the symptoms (spots) are often quite characteristic: here we even find examples where the causal agent can be identified macroscopically in the field (e.g. Rhytisma acerinumleaf spot of maples). However, there are pathogens that are able to infect different plant organs, e.g. Hymenoscyphus fraxineus, agent of ash dieback, causing leaf spots, discoloured leaf-rachises, shoot/twig/branch and stem bark necroses, collar and coarse root necroses, as well as a wood discoloration.

In the bark, necroses of fungal origin often show reproductive organs of fungi, usually visible as "minute pustules" on the surface. Their presence strongly indicates the fungal origin of a lesion, however identification of species requires microscopic 
analyses by a diagnostic laboratory. In $H$. fraxineus-bark lesions, fungal fruiting bodies always belong to a secondary bark fungi benefitting from $H$. fraxineus-dieback.

A group of pathogens easily detectable are those producing readily appearing larger and mostly bracket-like fruiting structures. They belong to the "higher" mushrooms or Basidiomycota and are usually wood inhabiting and cause rot, however, in most cases as wound parasites. Some of them can be identified by specialists in the field according to the morphology and size of a fruiting body. Doubtlessly, the most difficult group to detect (and even more to identify) are fungal species active in roots. A practitioner relies on the presence of special symptoms in a crown or on a stem indicating root problems: these are typically a simultaneous decline of an entire canopy with leaves reduced in size and number, a reduction in increment affecting a whole crown (i.e. crown decline), commonly heavy fruiting and often stem bleeding as a reaction of a tree to stress or pathogens. A combination of exudates on a stem and crown decline is usually referred to root or stem-base infections by a fungal-like organism Phytophthora. However, some other pathogens, or even abiotic stress factors, may cause similar symptoms.

For detection of pathogens in the field, primarily based on a detailed knowledge of symptoms characteristic for target species, all symptoms including different stages of symptom development should be carefully and comprehensively documented (photos and descriptions). Sampling for lab confirmation and diagnosis should follow special requirements for target species, but in general samples should be significant and abundant and should reflect different stages of deterioration of affected tissues (taking samples only from dead material will mostly not track the target organism, but a set of secondary agents). Samples of leaves should be pressed and dried before sending them to a lab. All samples should be sent or delivered in rather dry condition (never wrap them in dense plastic sheets!), any decomposition under humid conditions (moulding) should be strictly avoided. Only tracking Phytophthora usually follows two different techniques. If stem lesions are present, these pathogens can be isolated directly from symptomatic bark tissues. The sampling procedure for this is presented in Fig. 3.3.1-3. If bark necroses are lacking, but crown symptoms indicate the presence of a root destroying Phytophthora species, soil samples should be taken from the rhizosphere: at four sites of the stem, the organic soil layer should be removed locally to a depth of about $10 \mathrm{~cm}$. From the soil below, samples 


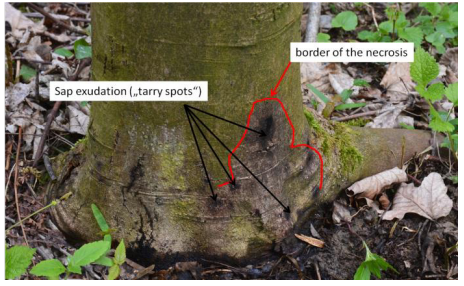

\section{Sample active necroses}

Sample only from active (fresh) necroses. These are light brown to reddish, not quite dry, not blackish, and not decomposed. They have a fruity odour and do not stink (bacteria or yeasts).

Take a sample from the stem necroses. Remove the outer bark tissue in the transition zone between dead and living inner bark tissue (=edge of the lesion) with a sharp knife or a chisel. Clean the knife or chisel immediately afterwards with $70 \%$ ethanol. Using a knife, cut out approx. $10 \times 5 \mathrm{~cm}, 2-5 \mathrm{~mm}$ thick shields from the inner bark tissue; the samples must contain the border between dead and living tissue!

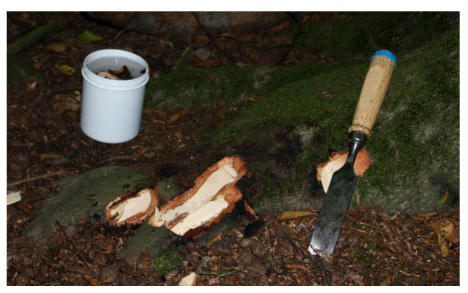

\section{Store the samples}

The samples must be placed immediately in a watertight jar containing tap water. After 10 minutes, make the first water change (replace brown water with fresh tap water). Repeat this procedure every 2 hours until the water is no longer discoloured, two to three times depending on the tree species.

Figure 3.3.1-3: Phytophthora - sampling from symptomatic stem tissues in 3 steps

containing fine roots should be taken (approximately 1 shovel per hole). The four samples can be mixed and a mixed sample of approximately $1 \mathrm{~kg}$ should be taken out. This sample can be stored prior to baiting experiments in a lab for a couple of months under dry conditions.

Furthermore, fungi can be detected with spore traps. Spore trap as a sampling technique is the fastest method for the collection of both nonviable and culturable airborne spores. This spore trap method is apt for identification and quantification of fungal spores to classify them as genus or morphologically similar groups present in air regardless of its viability. There are several models of spore-traps on the market, including the Burkard spore trap and the Lanzoni sampler. There are also Andersen samplers that are commonly employed for culture-based sampling; these have multiple openings that allow the impaction of spores onto the agar surface of one or more Petri dishes. Spore trap samplers and culture-based samplers give different pictures of the air spores. 
Spore traps capture all spores, viable and nonviable; however, culture-based sampling is only useful for fungal spores that can germinate and grow on a culture medium used under appropriate incubation temperatures.

Some fungi are insect-borne, where insects act like a vector for disease. Such insects often carry spores of the fungi in special structures on their bodies (called "mycangia") and infect a host tree themselves when making galleries. Examples for insectborne diseases are thousand canker disease, caused by a fungus Geosmithia morbida, which is vectored by a walnut twig beetle (Pityophthorus juglandis), Dutch elm disease caused by a fungi Ophiostoma ulmi and O. novo-ulmi and transmitted by elm bark beetles (Scolytus sp.), pine wilt disease caused by a nematode Bursaphelenchus xylophilus vectored by longhorn beetles from the genus Monochamus. For early detection of insect-borne diseases of forest trees, we use trap techniques along with specific pheromone lures as described above.

\section{Management recommendations for detection of invasive}

\section{alien species and eruptive forest pests}

- Design and establish a monitoring system considering the risk of invasive alien species and eruptive pests (i.e. number and location of traps).

- Use appropriate methods for a given species. Before the detection starts, know what you want to find.

- Start monitoring potentially invasive alien species or eruptive pests early, i.e. before damage occurs.

- Involve the public in spotting pest outbreaks or the presence of invasive species through awareness raising campaigns.

- Consult experts for advice. In many cases such a cooperation provides mutual benefits.

○ Get feedback for the methods you apply,

- Get support in the field.

- Participate regularly in training courses as new pests and diseases emerge frequently.

- Use the provided identification support of the information system DanubeForestHealth (www.danubeforesthealth.eu) and report pests and diseases.

\section{Summary and outlook}

Pests and diseases can have a major impact on riparian forests. To reduce the damage these pests and diseases can cause, early detection should be established. In the project REFOCuS, an 


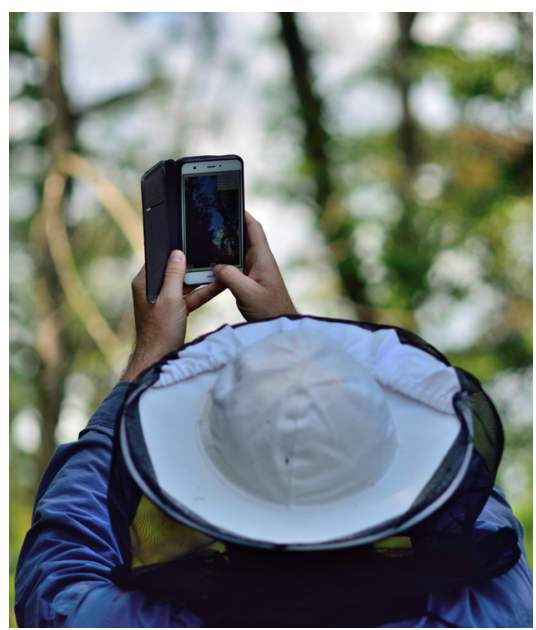

Figure 3.3.1-4: Application of the DanubeForestHealth mobile app during field observations information system called DanubeForestHealth was prepared (Fig, 3.3.1-4). In this chapter, we described symptoms and detection methods of pests and diseases. The best detection methods for insects are checking trees for symptoms, using traps, but also methods like remote sensing. For diseases, symptom detection in the field is also very important, but for some species confirmation is needed in a laboratory. Other methods for detecting diseases are spore traps and sampling vector organisms like insects. Based on the described detection methods, management recommendations are given. 


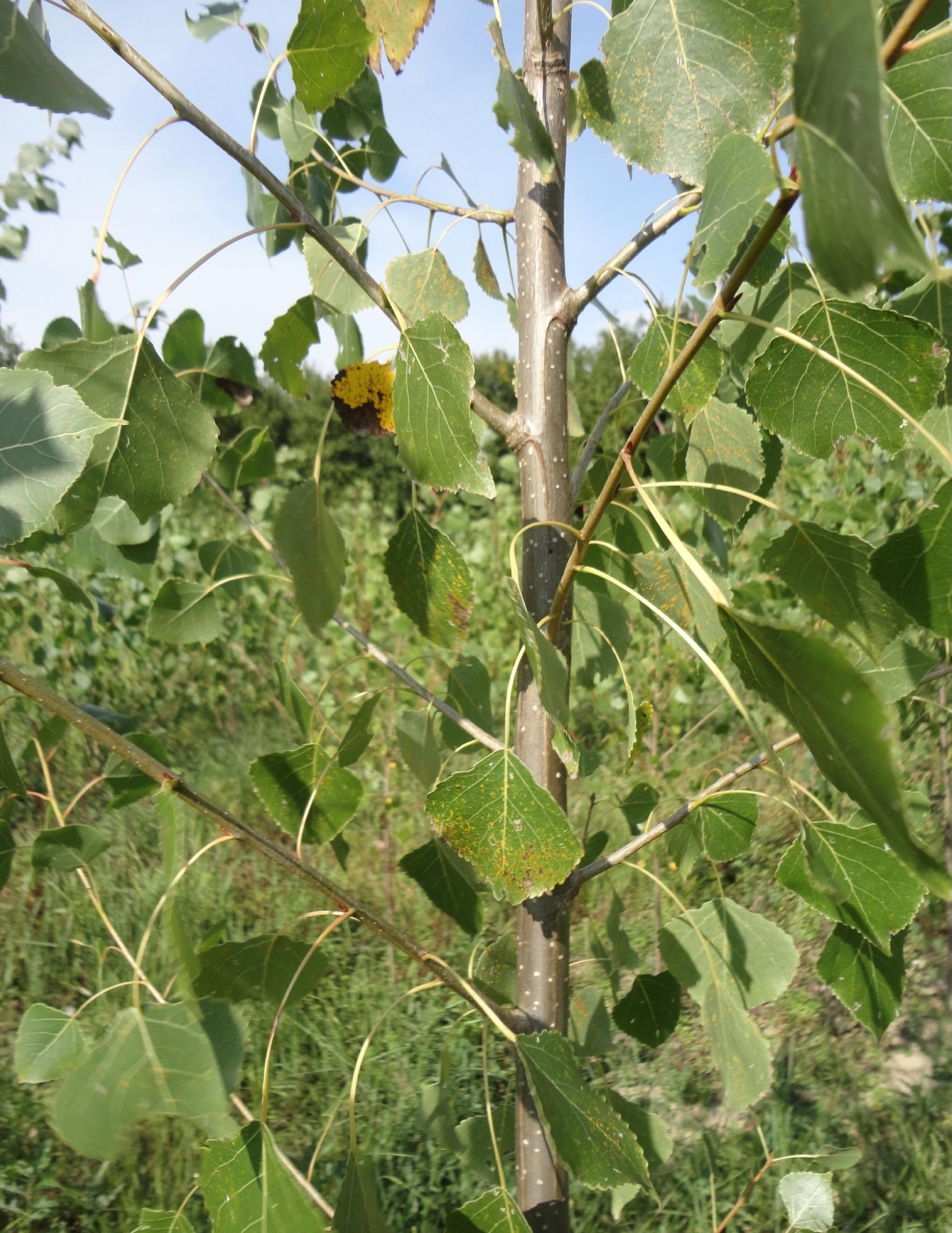




\subsubsection{Diseases of poplars and their hybrids with an emphasis on disease management recommendations}

Milica Zlatković, Predrag Pap, Imola Tenorio-Baigorria, András Koltay, Nikica Ogris, Thomas Cech

\section{Leaf diseases}

\section{Leaf rust}

Leaf rust caused by Melampsora spp. is the most common disease of poplars, especially in plantations and nurseries. It is one of the key problems of poplar production. A typical disease symptom is a fine, yellowish orange "powder" of spore masses that covers the underside of leaves (Fig. 3.3.2-1, 3.3.2-2). Infection takes place in spring, but typical symptoms are most obvious in summer when the disease can cause early defoliation.

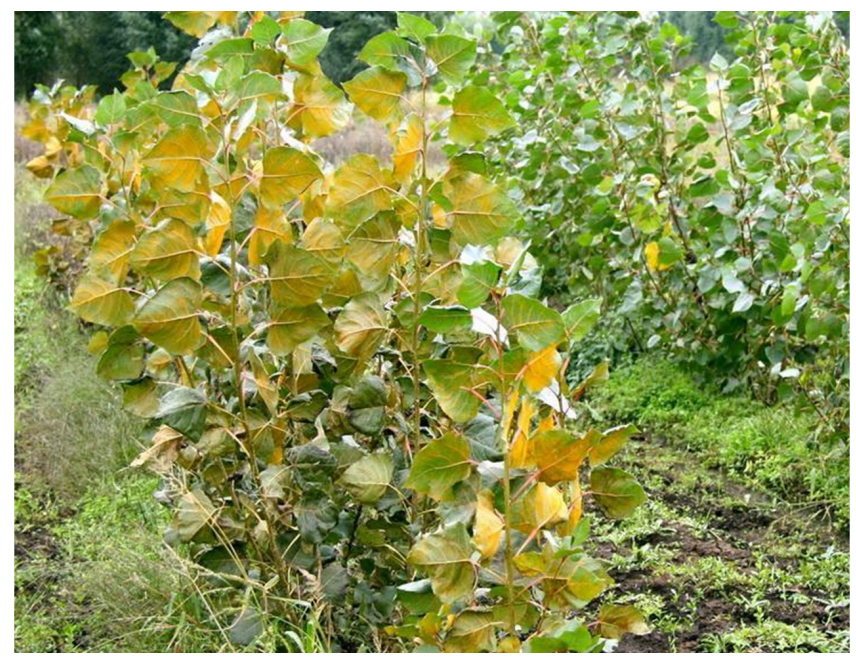

Figure 3.3.2-1: Leaf rust on leaves of Populus $\mathrm{x}$ canadensis

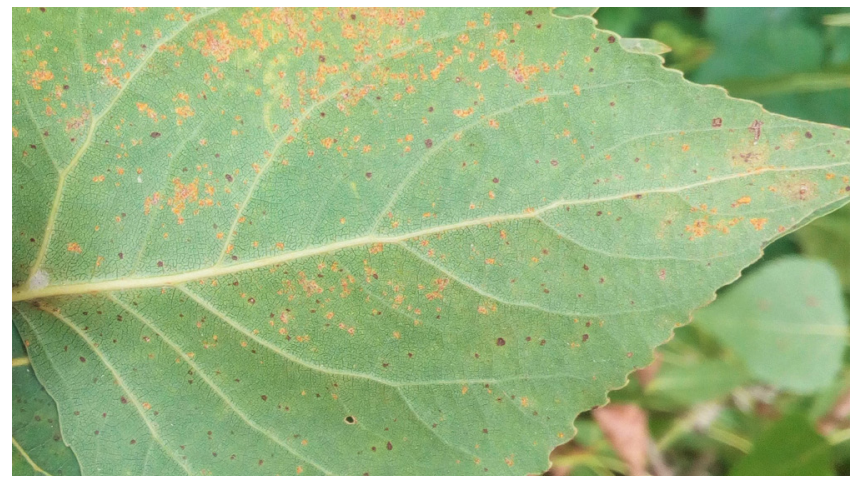

Figure 3.3.2-2: Leaf rust and brown leaf spot disease on a leaf of a Populus $\mathrm{x}$ canadensis tree 


\section{Brown leaf spot}

Brown leaf spot caused by Drepanopeziza brunnea (Ellis \& Everh.) Rossman \& W.C. Allen mostly occurs in poplar plantations and nurseries. A typical disease symptom is the appearance of brownish spots on leaves (Fig. 3.3.2-2, 3.3.2-3). In an advanced stage of the disease development, leaves first turn yellow, then bronze-colored, and might fall off prematurely. Populus $\mathrm{x}$ canadensis clones are especially susceptible to the disease (Fig. 3.3.2-2, 3.3.2-3).

\section{Ecology and economic importance of leaf diseases}

Fungi that cause leaf diseases are usually "primary parasites" and they can infect healthy plants. If not treated in time, leaf diseases, especially in intensively cultured poplar plantations, can affect plant growth and hence the production of wood. Severe infections may reduce growth potential by decreasing leaf photosynthetic area. Leaf scars formed after premature leaf drop during the vegetation season represent a perfect entrance for secondary pathogens. Repeated infections and premature defoliation of highly susceptible clones weaken plants and predispose them to other biotic and abiotic stresses, including stem diseases (e.g. Dothichiza populea), insects, high temperatures and drought. These "other stresses" often kill a tree. Nursery stool beds are especially vulnerable to leaf diseases as plants are usually densely planted, the relative air humidity is high, and these conditions are favorable for leaf disease development. Leaf diseases represent one of the poplar culture's most common enemies and thus should not be overlooked neither by a poplar breeder during the selection of clones nor a poplar grower during the establishment and management of a poplar plantation.

\section{Recommendations for disease management}

- The most effective way to prevent leaf diseases is by planting resistant or at least tolerant poplar clones.

- Rust fungi have a complex ecology and they often require two hosts to complete their life cycle. The second host depends on the species of rust. A poplar grower must have a sufficient knowledge of secondary hosts to avoid establishment of poplar plantations in their proximity or to try to eradicate them in areas near the plantation.

- If above recommendations are not possible, fungicides (e.g. cooper and carbamide based fungicides) can be used to prevent infection, especially in nurseries, but they must be applied before infection occurs.

- Leaf pathogens can survive and finish their life cycle on fallen

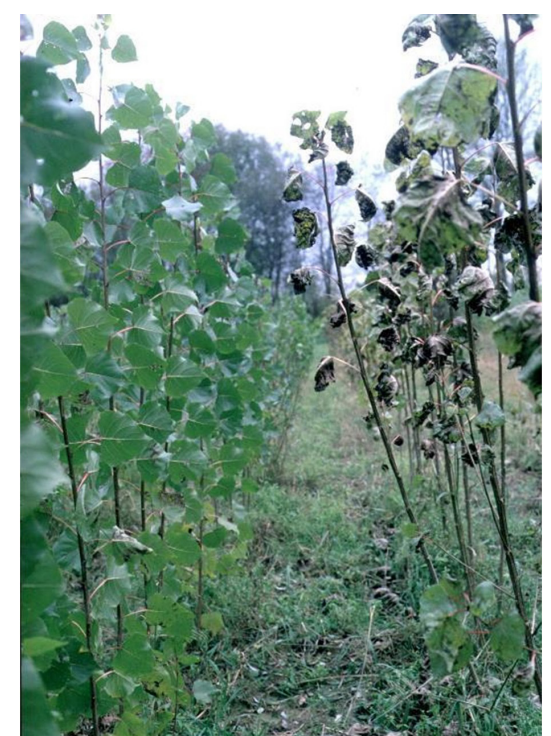

Figure 3.3.2-3: Brown leaf spot caused by Drepanopeziza brunnea: heavily infected leaves of a sensitive Populus x canadensis clone "I-214" on the right side; resistant clone on the left side 
dead leaves, so it is necessary to remove all dead leaves from the plantation before the onset of the following growing season or at least, to cover them with soil.

- Leaf diseases can also be managed by planting of poplars at a proper spacing and weed competition must be prevented to avoid high relative humidity that favours the disease development.

- Careful monitoring of leaf diseases should be a part of an integrated pathogen management in poplar plantations. Not only can new aggressive strains and pathogens be imported, but pathogen populations can change and may overcome host resistance over time.

Foliar diseases are also present in natural poplar forests where high humidity favours leaf disease development. Since infection is more likely to be transmitted between genetically similar hosts, maintaining genetically diverse populations of poplar species is the best way to combat these diseases in riparian forests.

\section{Branch and stem diseases}

\section{Diseases caused by fungi}

\section{Dothichiza canker}

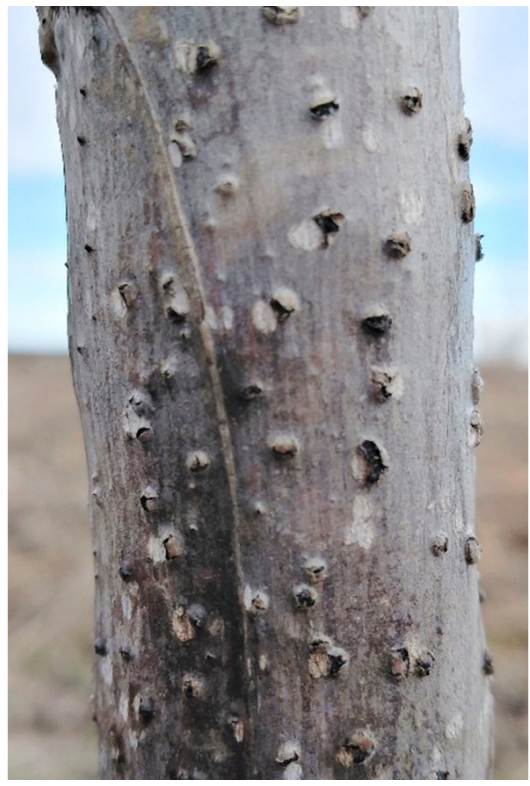

Figure 3.3.2-4: Dothichiza canker with fruit bodies (pycnidia) formed in the bark of a young Populus $\mathrm{x}$ canadensis tree
Dothichiza canker caused by Dothichiza populea Sacc. represents one of the most common and widespread diseases affecting poplars used for intensive cultivation. It was the main reason for failure of large-scale production of several poplar clones and cultivars despite their high growth rates and other good characteristics. The pathogen mostly infects a plant in late autumn or winter when the host is in the resting stage, but spring infections are also possible. The dangerous feature of this pathogen is that it has a long incubation period of up to one year, and thus the plant can be infected in the current year, but disease symptoms may appear only the next year. Trees most susceptible are those under stress in nurseries or young plantations usually where poplars are planted on too sandy soil prone to periodical water shortages.

The first typical symptom of the disease is the appearance of black necrotic lesions (Fig. 3.3.2-4) on the bark. As the disease progresses, the lesion surface becomes sunken, and usually a callus tissue forms at its ages as the host seeks to stop the lesion from spreading, thus forming a "canker" appearance. Moreover, black fungal fruit bodies (Fig. 3.3.2-4) appear in rows or in concentric circles around the penetration point of the pathogen on the lesion surface. Dothichiza populea infects plants through wounds and natural openings and thus lesions usually appear at 
leaf scars, or bark injuries. In severe cases, a canker expands and girdles the plant. Plants that survive infection are usually broken by wind or their wood is of a lower quality compared to healthy plants.

\section{Cytospora canker}

Cytospora canker caused by Cytospora spp. is a common disease in natural forests, plantations, and nurseries. These pathogens cause sunken cankers like those of D. populea. However, Cytospora fruit bodies produced in the bark are clearly smaller compared to those of $D$. populea, they are more randomly arranged, and release masses of orange, yellowish-white or reddish coloured spores that stain the tree bark (Fig. 3.3.2-5). Cytospora spp. mostly infect plants that are already weakened by some sort of abiotic or biotic stress. These fungi are common on trees of all ages, especially if trees are in the state of an advanced dieback caused by some other pathogen, usually $D$. populea. Poplar cuttings that fail to produce roots are often killed shortly after planting by Cytospora species (Fig. 3.3.2-6).

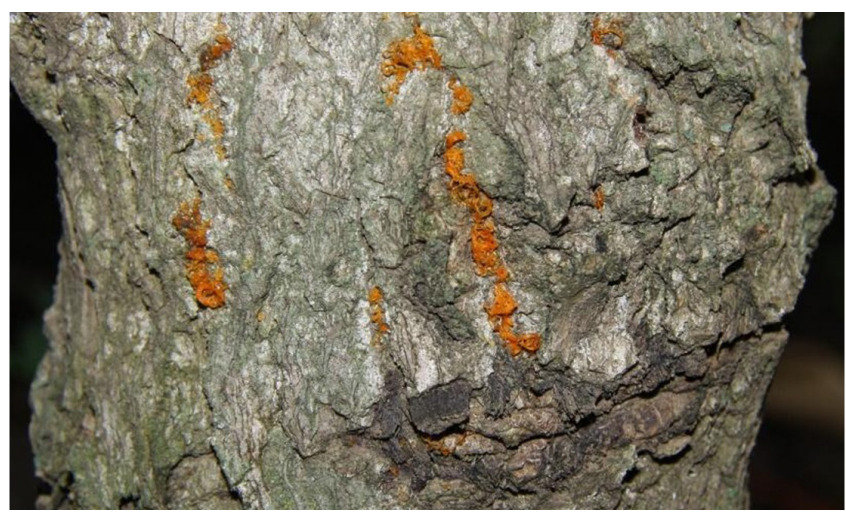

Figure 3.3.2-5: Orange coloured masses of Cytospora sp. spores extruded from fruit bodies (pycnidia) on the surface of a dead bark of a Populus $\mathrm{x}$ canadensis tree

\section{Diseases caused by bacteria}

\section{Lonsdalea canker}

Bacterial canker caused by Lonsdalea populi is an extremely serious disease of Populus $\mathrm{x}$ canadensis in Europe. The bacterium infects poplars in nurseries and young plantations. Typical disease symptoms appear in summer and autumn when the climate is warm and humid, and these include branch and stem cankers with cracks in the bark and copious amounts of sticky and often foamy exudates with a rotten smell that ooze from the cracks

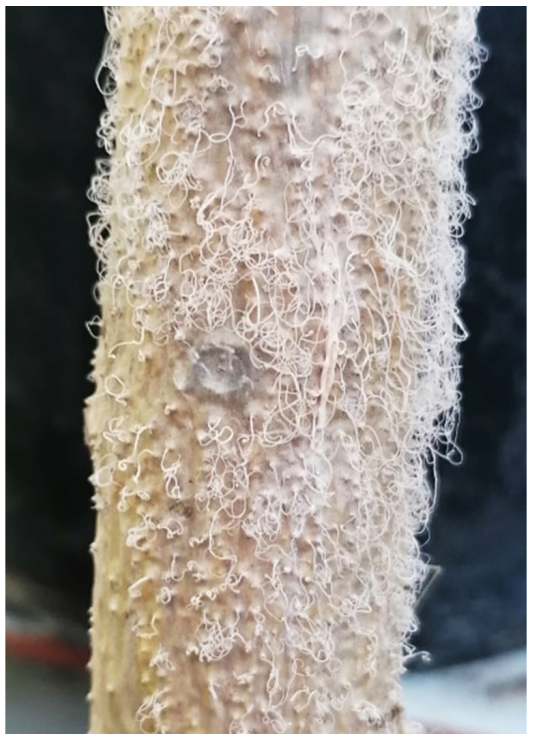

Figure 3.3.2-6: Whitish Cytospora sp. spores oozing out of pycnidia formed in a dead bark of a Populus $\mathrm{x}$ canadensis rooted cutting 
(Fig. 3.3.2-7 a, b). Once exposed to the air, exudates darken and cause staining of the tree bark (Fig. 3.3.2-7 b). Moreover, exudates attract various insects including lady beetles and stink bugs that are speculated to act as vectors of the disease, spreading it to the nearby trees. Sometimes, the infected bark peels away from a sunken canker area exposing a rotten wood with a fermentation odour and a creamy mass of white exudates (Fig. 3.3.2-7 c). In an advanced stage of the disease, cankers may cause crown dieback and diseased trees die within a few weeks. Cankers can be a few meters in length, and they can appear on any part of the stem. In rare occasions, the tree defends itself by producing huge amounts of callus tissue and cankers may heal. However, wood is useless for further processing in sawmills or veneer factories and the tree usually gets broken by strong winds in autumn and winter (Fig. 3.3.2-7 d).
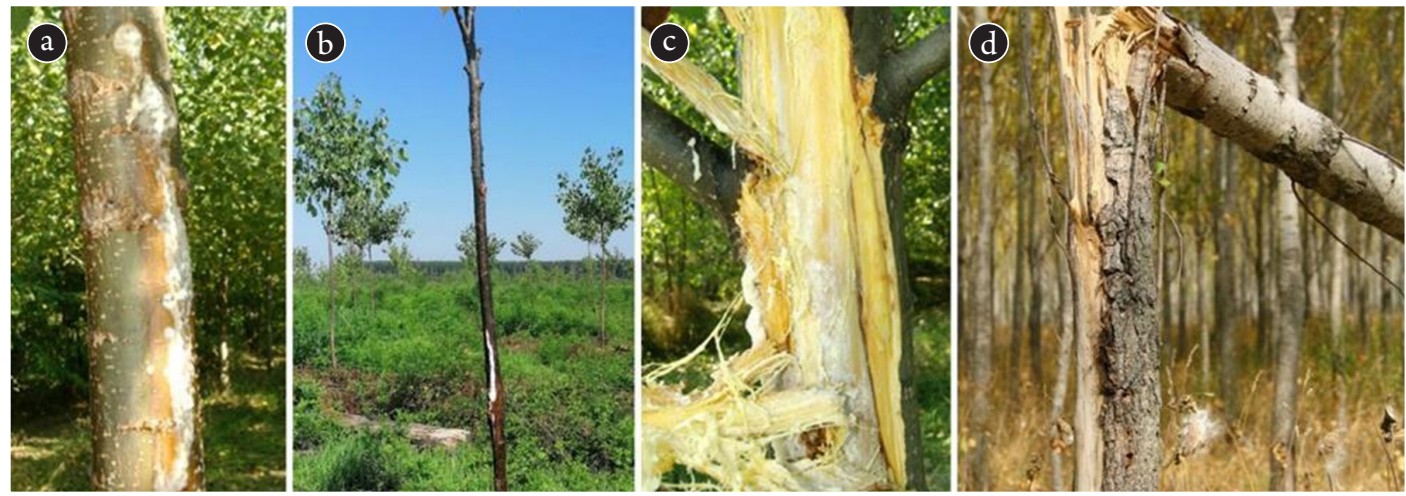

Figure 3.3.2-7: Symptoms of a bacterial canker disease of Populus $\mathrm{x}$ canadensis caused by Lonsdalea populi in Serbia and Hungary; a) White, foamy sap oozing from the cracks in the bark; b) Oozing canker with exudates staining the bark. The tree was previously damaged by Sciapteron tabaniformis; c) The bark peels away exposing white, creamy exudates and rotten wood with a fermentation odour; d) The production of exudates stops in autumn, but the tree gets broken by wind

\section{Ecology and economic importance of branch and stem diseases}

Stem diseases cause structural alterations of wood and thus a significant loss of its quality. Fungi that infect branches and stems are usually "wound parasites" and "opportunistic parasites" and they enter the tree through wounds or natural openings in the bark and infect the plant when it is under stress. These pathogens can therefore take advantage of even small accidental and nonaccidental injuries caused during various cultural practices or poor management, including premature defoliation caused by leaf pathogens, previous attacks by insects and climate extremes (e.g. long term water stagnation due to intensive rain events, water shortages due to drought and/or unsuitability of the soil for 
poplar growing, "Heat waves"). A combination and succession of diseases is common in both natural poplar forests and intensively cultured poplar plantations.

Disease management recommendations

- Selection of resistant or at least tolerant clones is currently considered the best solution for Dothichiza and Lonsdalea disease control.

- A good management approach for the control of poplar branch and stem diseases is also to promote the general health and vigour of trees through various cultural practices including fertilization, watering (especially in summer to prevent drought stress), and avoidance of mechanical injuries.

- Infected branches with cankers or necrotic lesions should be pruned to prevent the pathogen from entering the main stem. Pruning should be done by cutting below the canker and wounds should be sealed using grafting wax or sprayed with protective fungicides (that also have bactericidal effect, e.g. some copper-based fungicides). Pruning should be completed during the dormant season and if infected trees are pruned, cutting tools should be sterilized before pruning healthy trees.

- Plants should be properly protected against insect pests as they can weaken plants, spread the disease, and create wounds that pathogens can use to enter the tree.

- It is also important that poplar growers apply cultural practices that reduce infection by leaf pathogens, including weed control and maintenance of an optimal plant density.

- Good cultural practices also assume planting of poplar clones resistant or tolerant to leaf diseases as well as planting of clones that are best suited for the environment in which they are grown.

- Nurseries and plantations must be established on soils suitable for poplars to reduce weakening of plants.

- Cuttings should be collected only from disease-free, vigorously growing plants and they should be planted during periods of favourable moisture and temperature to minimize stress.

- Pathogens that cause stem and branch cankers can survive on wood debris left on the ground, so it is especially important to remove all the cut branches and other dead wood material from the plantation.

- Severely infected trees with stem cankers and/or bacterial ooze should be harvested before cankers reduce quality and 
yield potential and they should be removed from a plantation as soon as possible to slow the spread of the disease.

- Soil from areas known to be infected with bacterial canker must not be moved, neither on plant material nor equipment.

Selection and breeding for disease resistance are considered the best solution for the control of branch and stem diseases in natural poplar forests.

\section{Root diseases}

Poplar root diseases are mostly caused by fungi and fungus-like organisms. Species of Armillaria spp., Phytophthora spp., Pythium spp., and Phytopythium spp. are associated with crown dieback and root rot of Populus spp. in natural forests, plantations, and nurseries. Natural poplar forests occur on alluvial plains along large rivers where wet soil conditions and seasonal flooding create favourable conditions for the spread, infection, and survival of fungus-like organisms, including Phytophthora species. For management recommendations, see 3.3.6 Measures against the spread of Phytophthora in riparian forests.

\section{Summary and outlook}

Because of preferential planting of highly productive "superior" clones over vast areas and consequently low genetic diversity, intensively cultured poplar plantations are especially vulnerable to pathogen attacks. Therefore, poplar enhancement programs that constantly seek for new clones resistant or at least tolerant to diseases, adapted to the local climate and with an optimal growing capacity are preferred management strategies in poplar plantations. Moreover, environmentally friendly biological control options should be considered whenever possible, as well as cultivation practices that minimize pathogen attack. 


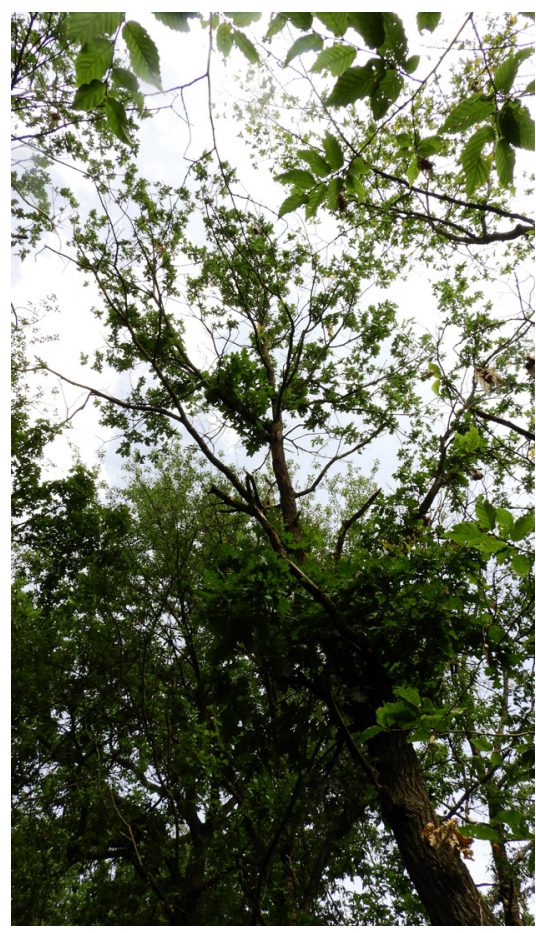

Figure. 3.3.3-1: The syndromes of oak decline comprise crown thinning and branch dieback

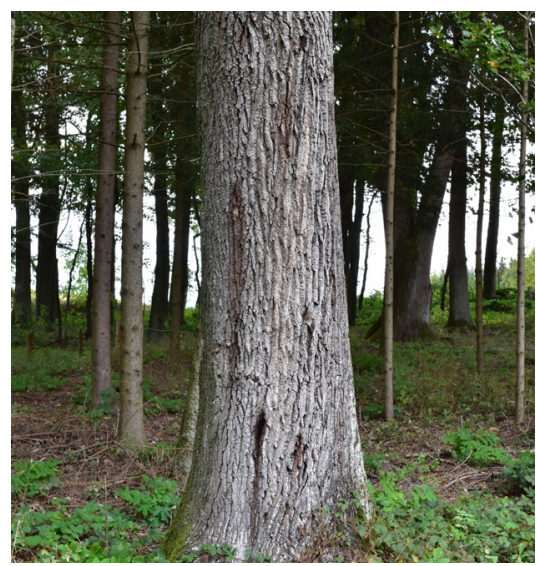

Figure 3.3.3-2: Stem bark bleeding of oaks

\subsubsection{Oak decline - an example for a disease phenomenon characterized by various interacting causal agents}

\section{Thomas L. Cech}

Oak decline is a complex of disease symptoms on oaks (Quercus spp.) have been known in Europe and North America for more than 100 years. The decline comprises crown thinning, dieback of branches and finally the death of trees as a consequence of the interaction of both abiotic and biotic factors (Fig. 3.3.3-1). In Europe, the last extensive episode of oak decline took place from the late 1970s to the beginning of the 1990s. At that time, one hypothesis was that it was caused exclusively by certain wiltfungi (Ophiostoma spp.). However, this could not be proven. The detection of numerous impact factors associated with oak decline triggered multiple research approaches involving scientists from a wide spectrum of disciplines. Though the weight of individual causal agents and the way of their interaction could not always be identified, oak decline was generally understood as a combination of a set of crown defoliating and stem feeding insects, root pathogens (e.g. Phytophthora, Gymnopilus fusipes, Armillaria spp.), late spring frost episodes, water stress caused by extreme drought periods and human impact on water resources. In several European countries, a widespread lowering of soil water level was caused by the extensive exploitation of water for agriculture and by drainage of swamps and creeks as well as "cleaning" the landscape from small-size woodlots (see 2.1 Importance and threats to riparian forests). By the end of the 1990s, the phenomenon decreased in impact and abundance and many oak stands recovered.

Recently, a decline phenomenon that proceeds more rapidly was described in the UK as Acute Oak Decline. It is characterized by stem bark bleeding of oaks (Fig. 3.3.3-2) and a combined impact from certain bacterial species (Brenneria spp. and others) and bark breeding buprestids (Agrilus spp.).

\section{Detection and confirmation}

Since symptoms of oak decline may vary considerably according to different and also changing agents, detection of the contributing factors is a first prerequisite to delimitate the decline phenomenon from monocausal impact factors (e.g. crown thinning only due to defoliating insects). Usually the symptoms affect the whole canopy; leaves are sparse and remain smaller than usual and they can be yellowish instead of dark green. Often, 
shoots remain short (stunted growth) with densely packed leaves on twigs. These symptoms are usually accompanied or followed by a progressive dieback of twigs and single branches. After several years, trees show a deteriorated crown with numerous dead branches. Commonly, trees react by producing epicormic shoots, which may also occur as a consequence of a sudden exposition to sunlight following thinning measures. Occasionally a whole tree dies, but also recovery was observed.

Crown symptoms (leaf size, abundance, colour) as well as thinning index should be assessed. The canopy should be checked carefully for presence of defoliating (feeding or sucking) insects, oak mildew or other leaf inhabiting pathogens. To achieve this, good binoculars are essential. In addition, leaves which can be reached from the ground should be inspected for insects and spots or fungal coatings, and sampled for lab diagnosis.

Dead branches should be examined for presence of visible mechanical damage. Larger wounds (such as storm, lightning, pruning, or bark feeding mammals) at the base of a dead branch or on the stem below are not a symptom of oak decline, since they obviously cause death of a branch. Cracks, on the other hand, may indicate abiotic stress (most commonly frost and drought); later cracks may resemble mechanical damage, therefore they should be checked at different stages of development.

Inspection of stem should be performed by a careful search for bark cankers and their origin. Here several fungal species can be causal agents (e.g. Biscogniauxia mediterranea, Fusicoccum quercus, Stereum rugosum, Pezicula cinnamomea). Moreover, tarry exudates (sap flow) are another significant feature indicating impact to living bark tissues. These usually point to collar or aerial necroses by the fungus-like organism Phytophthora. In oaks, they mainly indicate Phytophthora cinnamomi and only rarely other species such as $P$. ramorum, the causal agent of Sudden Oak Death in North America. Thus, if large bark necroses are present extending upwards from the collar region, but mining insects are lacking, bark samples should be taken for Phytophthora identification.

Tarry spots associated with only small $(5-10 \mathrm{~cm})$ bark lesions which are not extending tongue-like from the stem basis, but may show traces of larval galleries of buprestid beetles (two-spotted oak buprestid, Agrilus biguttatus), indicate a comparatively new syndrome of Acute Oak Decline. In this case, fresh liquid from sap flow should be sampled using sticks topped with cotton, which are to be sent to a diagnostic laboratory for identification of bacterial species. 
If there are symptoms affecting the whole crown (thin canopy, small sized leaves) indicating root disorders, but no bark lesions are present on the stem, soil samples should be taken for baiting Phytophthora from the fine root region; several Phytophthora species affect fine roots of oaks causing a progressing decrease in tree vitality.

Two parasitic mushrooms profit particularly from drought stress in oak stands. Honey fungus (Armillaria spp.), affecting many tree species, can be easily detected by the presence of root-like mycelial strands (rhizomorphs), white mycelial lobes under the bark and characteristic fruiting bodies, which are present in fall. Impact from Armillaria generally increases after drought or other, even biotic stress agents (e.g. Hymenoscyphus which causes ash dieback). Typically, the pathogen quickly kills the whole root system. Spindle shank (Gymnopus fusipes) attacks coarse roots. It produces spindle-shaped fruiting bodies from mid-summer on and causes a typical orange stain of the infested roots. This pathogen is becoming increasingly important due to extraordinary dry and hot summers in recent years. Other than with Armillaria, the deterioration of roots may take many years.

Following the assessment of the set of pests and pathogens present on tree and/or site, climate data of the past 10 to 20 years should be collected from the closest meteorological station and analysed for extreme episodes of drought, heat or frost.

\section{Management strategies}

Having gained evidence for the presence of a complex disorder of oaks on a site, strategies should consider the factors regarded as most decisive for the disease. Based upon the assumption that any oak decline phenomenon is basically a consequence of stress to a tree, any measure apt to improve the vigour of a tree should be taken into consideration. Any self-evident activity leading to drainage or ground water deficiency should be strictly avoided.

On sites increasingly subject to weather extremes, oak individuals able to withstand these extremes are required. This can be achieved by silvicultural practice such as thinning at the right time, changing pure oak stands to mixed forests, but also game and cattle management to minimize damage by wounding. In mixed stands, the abundance of each tree species is much lower than in pure stands and consequently specialized pests and pathogens are less effective in establishingharmful populations.

Oak stands should be regenerated with suitable seed material adapted to local conditions - and considering the ongoing 
climate change. Non-adapted oaks can be affected by devastative pathogens; this is shown by recent cases of decline of red oaks in Austria and Czech Republic with important involvement of Spindle shank-fungus; Q. rubra is especially susceptible to Gymnopus fusipes-root rot if planted on alkaline soils and subject to drought stress (Fig. 3.3.3-3).

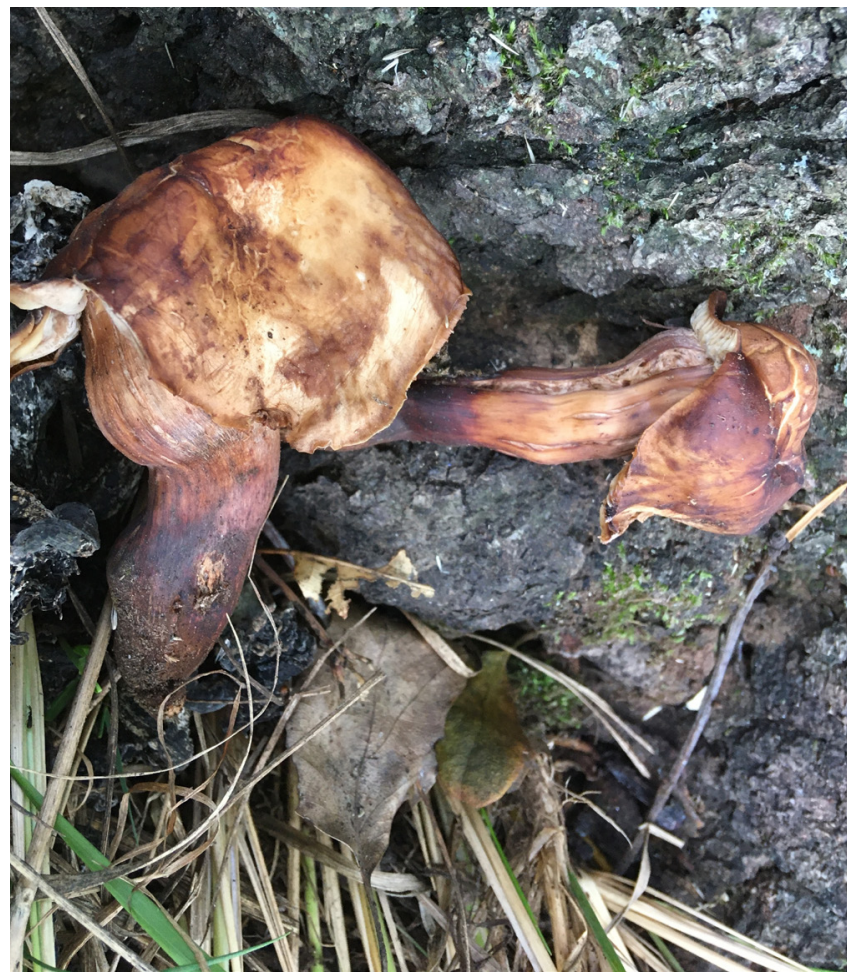

Figure 3.3.3-3: Gymnopus fusipes-root rot on Quercus rubra

\section{Summary and outlook}

Oak decline is a complex disorder-phenomenon caused by the interaction of abiotic and biotic agents. For detection and interpretation, a careful assessment of contributing factors is needed as well as an analysis of climate on affected sites. Apart from specific measures apt to fight single pests and pathogens, oak decline can only be limited or reduced by silvicultural and hygienic measures strengthening the vigour of trees. On the landscape level, natural water supply for riparian oak stands should be restored and guaranteed. 


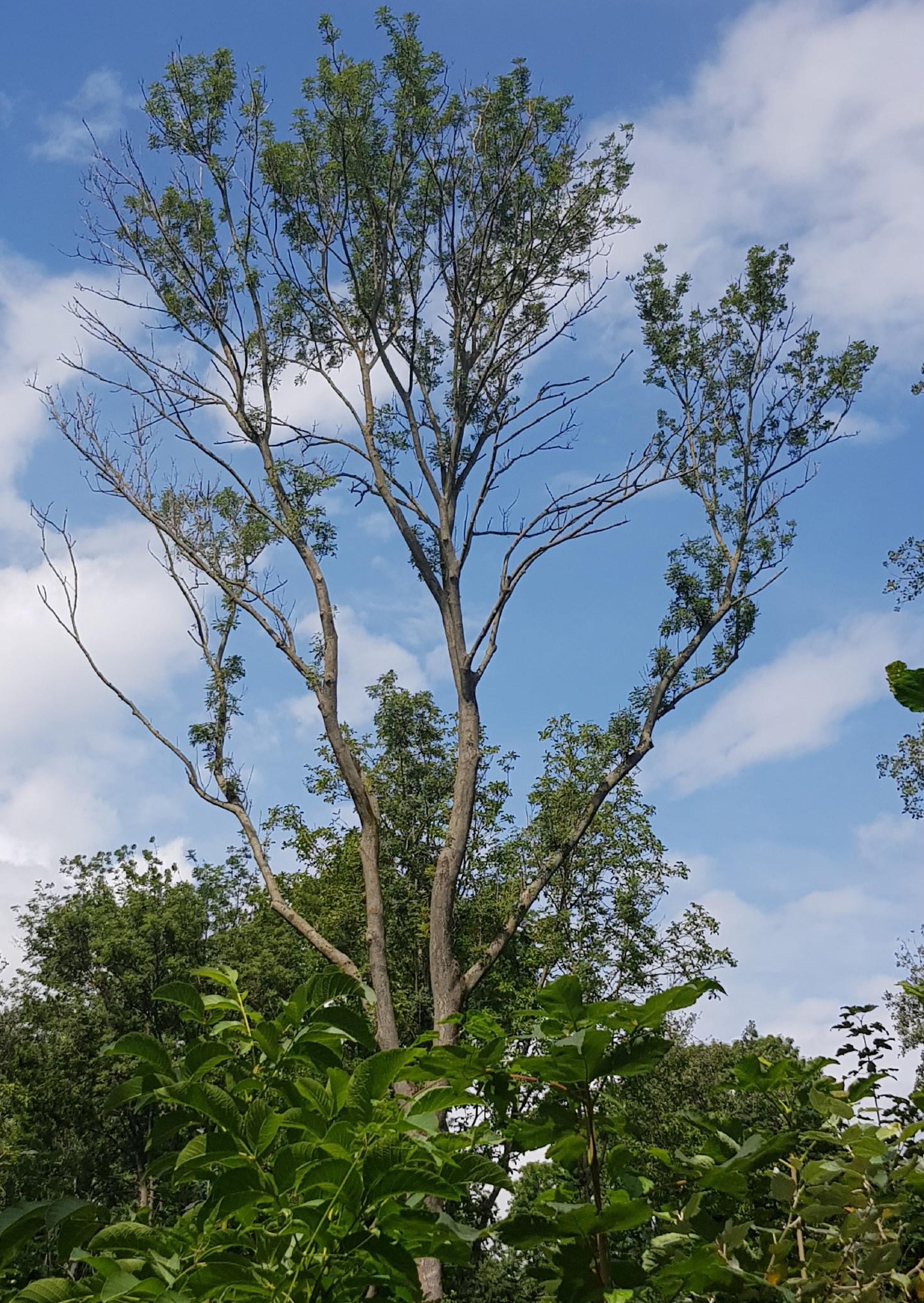




\subsubsection{Ash dieback as a major threat to riparian forest biodiversity}

\section{Thomas L. Cech, Katharina Schwanda}

\section{Introduction}

Ash dieback is a serious fungal disease of several species of ash (Fraxinus sp., Fig. 3.3.4-1) caused by fungal species Hymenoscyphus fraxineus. The pathogen started to affect ash trees in the early 1990s. It spread from the Baltic countries and Poland to Scandinavia; in the mid-2000s it reached Central Europe showing an epidemical character and representing one of the most serious forest health problems in Europe. The disease affects all age classes of ash. Damage is more severe in younger trees compared to older ones, where the disease is usually more chronic. However, even old trees finally succumb to the disease due to the repeated infections and attacks by secondary pathogens. The fungal species is highly aggressive to Europe's most widespread species of ash, common ash (F. excelsior) and narrow-leafed ash (F. angustifolia). At the place of origin, East Asia, it causes only little damage to indigenous ash species. The way of introduction to Europe is not yet fully explained. Most likely trade and movement of plants and plant material introduced this highly aggressive pathogen to Europe.

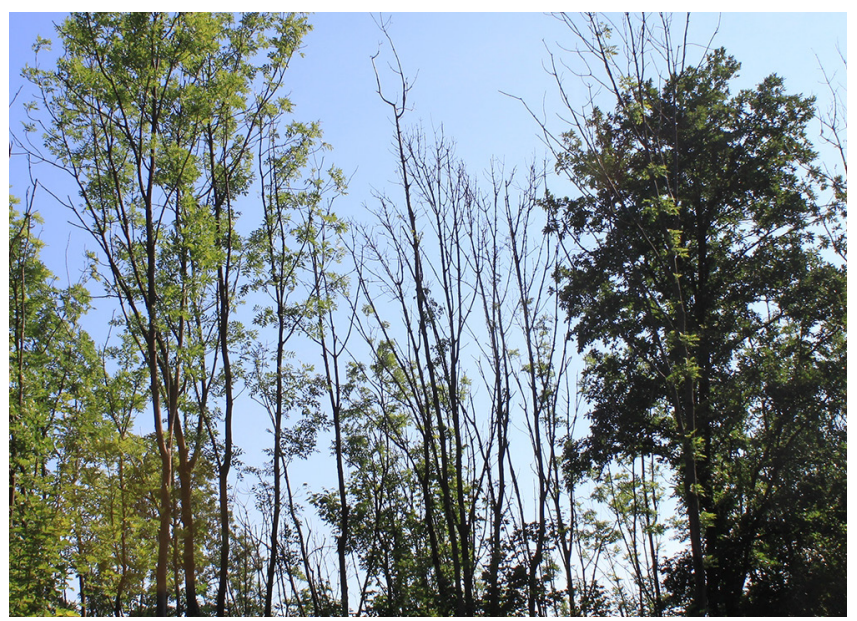

Figure 3.3.4-1: Ash dieback is a serious fungal disease of several species of ash caused by fungal species Hymenoscyphus fraxineus

Ashes play important economical and ecological roles. Timber is highly valuable for the production of furniture, veneers, flooring, composite wood, tool handles and sport equipment. Leaves can provide fodder for livestock in rural areas during drought periods. 
Furthermore, the bark contains substances of medical potential (e.g. anti-malarial properties). The ecological value is enormous; ashes are a habitat for a high number of insects, fungi, lichens and mosses, some of them highly specific.

Thus, it can be expected that ash dieback poses a major threat to biodiversity especially in riparian forests, which have already been impoverished by the loss of elms, alders and oaks as a consequence of the Dutch Elm Disease, Phytophthora alni, and other Phytophthora species. The loss of a high proportion of ash trees is likely to have a cascade of ecological effects on ecosystem services and biodiversity. Furthermore, excessive loss of ashes especially in riparian forests means gaps, which may be filled by invasive herbaceous plant species, but also tree species such as Acer negundo, Ailanthus altissima, or Juglans nigra.

\section{Infection and disease development}

Hymenoscyphus fraxineus primarily infects green leaves of ashes with airborne ascospores released from small fruiting bodies growing on leaf remnants in forest litter (Fig. 3.3.4-2). First symptoms are nonspecific brown spots on leaflets. Following successful infection, fungal mycelium grows into leaf rachis and later, by entering a shoot through a leaf petiole, into the woody parts of an ash tree. In wood, it causes a typical greyish to brownish discoloration. Subsequently, twigs develop extensive bark lesions and dieback due to girdling. The infested leaves are shed in autumn and black plates (stroma) develop mostly on rachises, petioles and even leaflet veins. In the following spring and summer, small, white fruiting bodies (approximately 2 to $7 \mathrm{~mm}$ large) develop from this stroma. Ascospores are released mainly from late June to September, depending on local climatic conditions, and the disease cycle of ash dieback starts again.

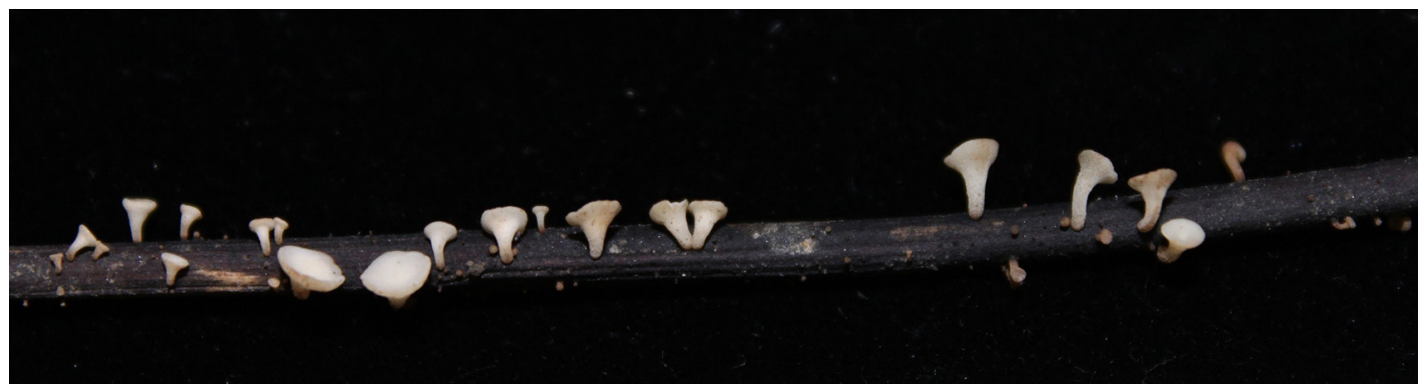

Figure 3.3.4-2: Fruiting bodies of Hymenoscyphus fraxineus growing on leaf remnants in a forest litter 
Production of fruiting bodies and spores requires humidity. On humid soil, white discs appear quickly and produce infectious spores; when they become dry, they shrivel. Therefore, the maximum of sporulation is reached on sites with continuously high air humidity near the ground. Black fungal stroma is extremely fertile: a single rachis can produce fruiting bodies throughout the vegetation period and even for several years. Considering the long duration of spore release of several months, only extended drought periods can significantly reduce the amount of produced inoculum. Furthermore, spores of $H$. fraxineus can enter trees at the stem base and root collar via lenticels causing wood discoloration and bark lesions. This facilitates the attack of ash trees by secondary colonizers, mostly Armillaria spp., which accelerates the decline and death of host trees. Following the attack by root rot fungi, breakage of stems or throwing by wind has been increasingly observed in several countries (Fig. 3.3.4-3). This severely reduces tree stability resulting in many trees that need to be cut, especially along roads and hiking trails for safety purposes.

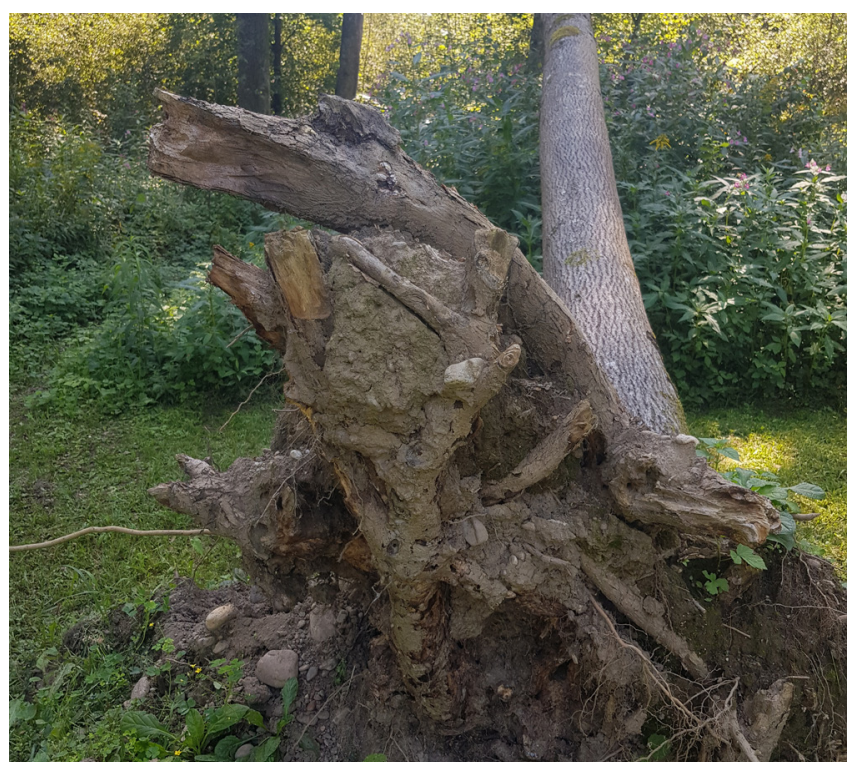

Figure 3.3.4-3: The attack of ash trees by secondary colonizers, mostly Armillaria spp., accelerates the decline and death of host trees. Following the attack by root rot fungi, breakage of stems or throwing by wind have been increasingly observed in several countries

\section{Management strategies}

Riparian forests provide favourable conditions for the fungus (high humidity, dense undergrowth that prevents ventilation). 
Therefore, it is in these forests that ash dieback causes the heaviest losses. Near large bodies of water, humidity is high, which is further supported by dense undergrowth that reduces aeration. On the other hand, a structured and dense understory can also prevent ejected spores from reaching the leaves in the crown. Flooding can also have a limiting effect on the inoculum; deposited silt layers can cover the rachis of ash trees and thus prevent spore release. This phenomenon has been observed at Austrian monitoring sites along rivers. However, as ash trees are very common in many riparian forests, such attenuating effects of flooding can be offset by a high density of infected hosts producing very high inoculum loads. Currently, there are two different strategies to fight ash dieback:

- Support genetically inherited resistance or tolerance of a small number of ash trees to $H$. fraxineus.

- Hygienic and silvicultural strategies.

\section{Supporting natural resistance}

Ash dieback is a nearly ubiquitous phenomenon in Central European forests; stands with a high share of affected trees are not uncommon, especially in riparian forests where pure ash stands frequently occur. However, individual trees showing no or only slight symptoms can be observed even in severely diseased stands. This is confirmed as inherited resistance or tolerance and has been studied in several countries. Breeding programs are underway to produce plant stock apt to withstand ash dieback. In addition to this option, promoting likely resistant trees in ash stands may also increase resistance in the population. This requires selective preservation of individuals showing no or only slight symptoms and conducting measures which favour their regeneration. Thus, fencing of areas around symptomless ash trees to prevent browsing and keeping sites free from competing tree species are recommended in forests where ash dieback is threatening ash stands.

\section{Hygienic and silvicultural strategies to keep the impact of ash dieback low in riparian forests}

Disease intensity in ash stands is correlated with stand density and age; the incidence of new infections is higher in more dense and younger stands. Conversely, a higher admixture of other tree species will reduce the likelihood for new infections. Therefore, the process of natural selection should be principally ensured and the development of mixed stands with low to moderate share of ash should be supported by appropriate tree species. Moreover, 
open stands provide less suitable conditions for infection, since they are drier and usually warmer than closed and less aerated stands. However, considering the airborne nature of the infection, any hygienic measure aimed at inoculum reduction on a site should be a part of a regional concept since spores can disperse from unmanaged neighbouring stands up to several hundred meters. Several studies confirmed the influence of tree species composition on disease intensity. This can be explained by an enhanced decomposition of infested rachises in certain types of litter. For example, leaf litter of lime (Tilia spp.) significantly enhanced biodegradation of infective ash leaf petioles. According to a study in Czech Republic from 2013, ash dieback intensity was negatively correlated with the percentage of conifers (mainly Abies and Pinus) admixed with ash.

\section{Strategies considering secondary pests and pathogens}

During the past decade, an intensification of secondary pathogens infesting ashes suffering from $H$. fraxineus infections became apparent. This refers primarily to root rot fungi, such as honey fungus (Armillaria spp.). Armillaria species are favoured by various stress factors affecting a host tree, but most commonly by drought stress. Ash trees impacted by crown dieback for many years and, especially trees affected by basal stem lesions, are weakened and increasingly become subject to attacks by honey fungus and other root and stem pathogens. This phenomenon has become nearly ubiquitous during the last years in some countries; riparian forests were the first ash ecosystem showing fatal development (e.g. along the Danube River in Austria). Where ash forests provide multiple ecosystem services, safety of work and safety along roads or of people visiting forests is of high importance. To better manage these risks, diagnostic tools are being developed to evaluate the stability of trees. Among insects, ash bark beetle (Hylesinus fraxini) is the most probable beneficiary. However, it has not yet developed into a major secondary agent able to attack ashes not affected by dieback. Generally, tree assessment is a necessary tool in decision making on possible management options. 


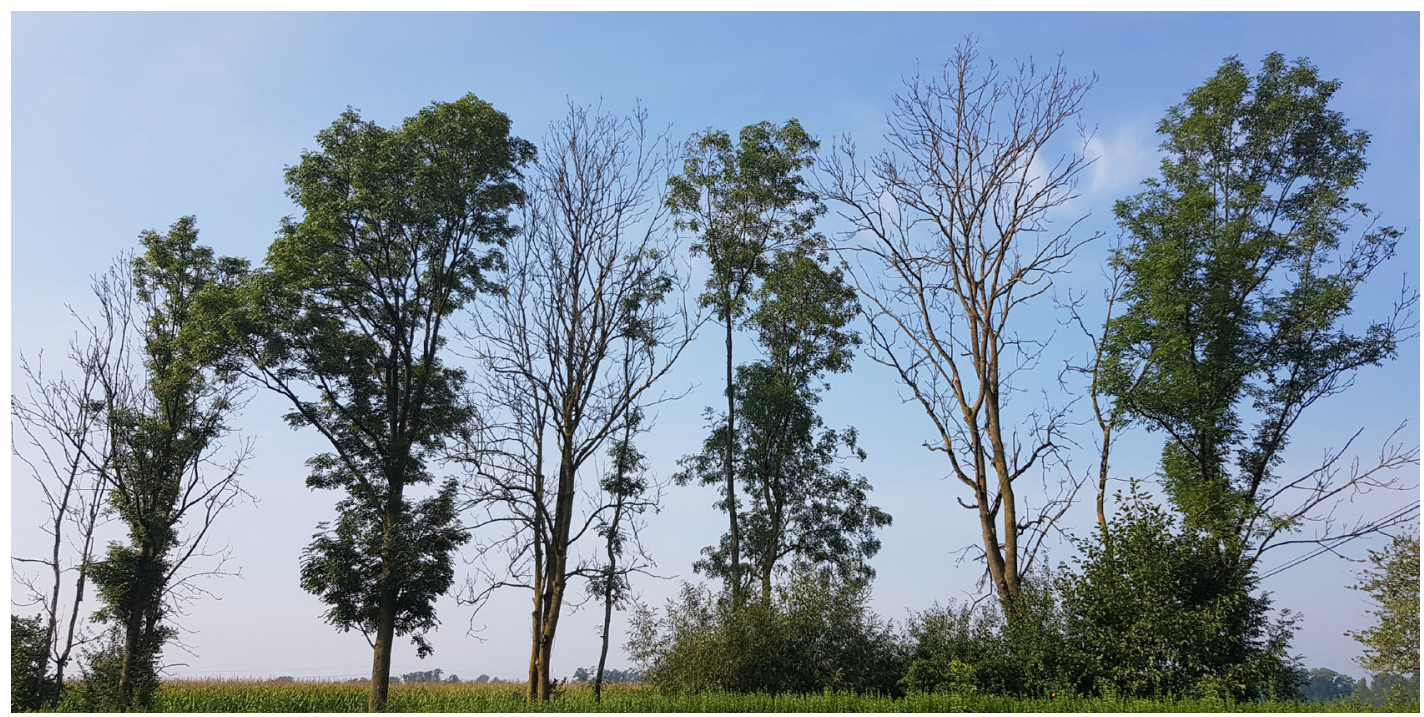

Figure 3.3.4-4: Various ash dieback stages of neighbouring common ash (Fraxinus excelsior) trees in Styria

\section{Summary and outlook}

Replacing ash trees that have been severely affected by ash dieback with various other broadleaves such as Prunus avium, Quercus spp. or Juglans regia and keeping ash in a low proportion in mixed stands is considered as the best chance to reduce the risk of total loss of ashes in riparian ecosystems. In addition, supporting natural resistance by selecting and sheltering diseasefree trees is an option to enable adaption to the new selection factor naturally. Resistance breeding programs may additionally provide suitable plant material in the following years. In forests targeting habitat conservation, natural succession should be enabled. Any silvicultural or forest hygienic measures aimed at inoculum reduction in infested ash stands should be conducted within a regional concept, since Hymenoscyphus fraxineus is a wind-spread disease. 

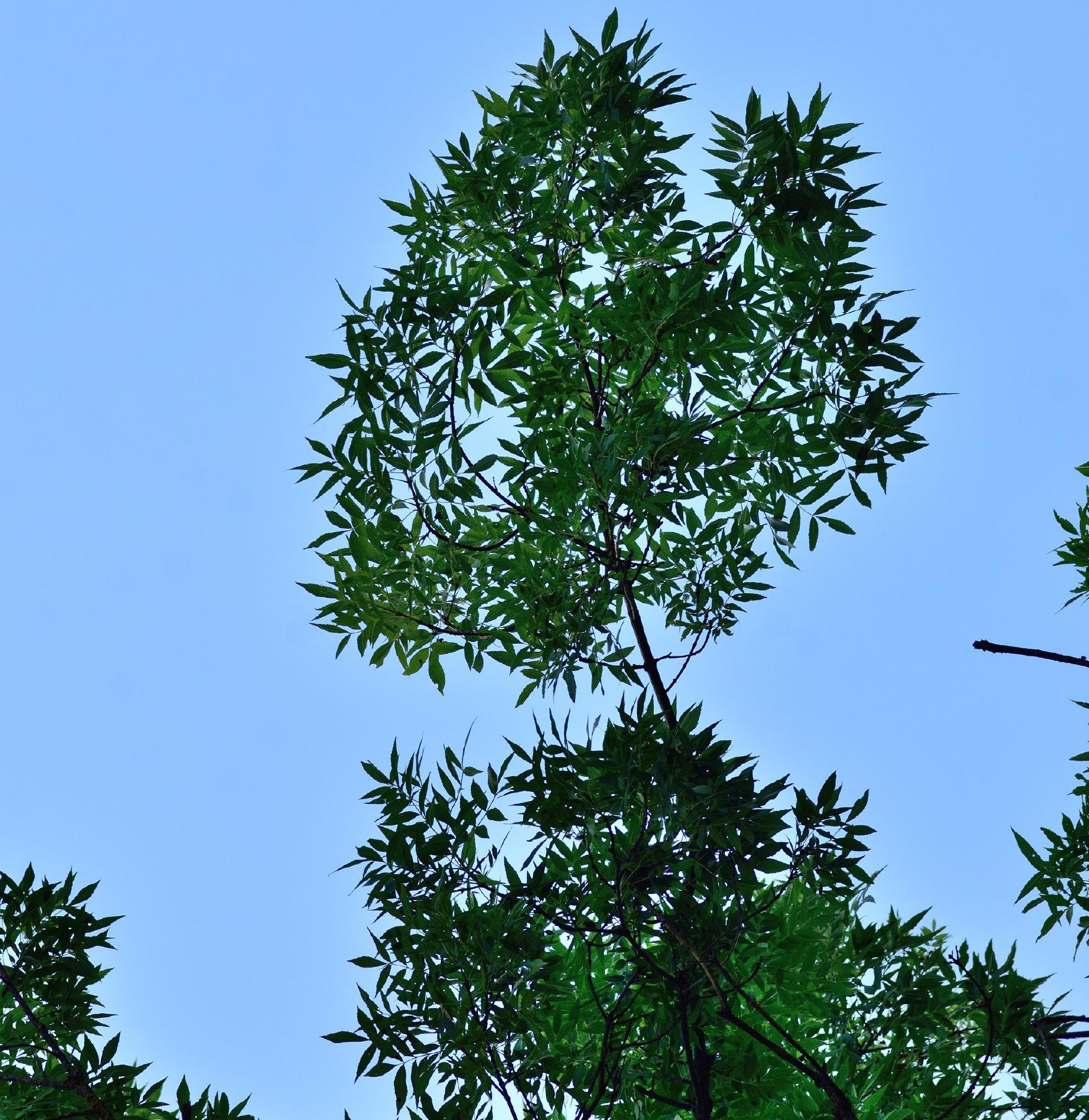


\subsubsection{Ash in distress: conservation and resistance breeding programme for Fraxinus excelsior in Austria}

Gregor M. Unger, Heino Konrad, Katharina Schwanda, Thomas

L. Cech, Gernot Hoch, Andreas Fera, Thomas Kirisits, and Thomas Geburek

In 2015, the Austrian Research Centre for Forests (BFW) together with the University of Natural Resources and Life Sciences, Vienna (BOKU) started a project "Ash in distress" ("Esche in Not", http://www.esche-in-not.at/). The aims were to locate putatively resistant common ash trees in severely affected forest stands throughout Austria, to determine their disease resistance based on the performance of their progenies exposed to high levels of natural inoculum of the ash dieback pathogen (Hymenoscyphus fraxineus) in a common garden experiment and to select superior genotypes for resistance breeding. Both common ash (Fraxinus excelsior), which is an important forest tree species throughout Europe, and narrow-leaved ash (F. angustifolia), which occurs in the north-east of Austria (mainly in floodplain forests along the Morava/March River), are highly susceptible to ash dieback (see 3.3.4 Ash dieback as a major threat to riparian forest biodiversity).

Since 2005 the pathogen has spread all over Austria resulting in major changes in the composition and ecology of hardwood forests because of severe damage of ash trees leading to dieback and even death. Proactive forest management of ash has recently been discontinued, as old trees were increasingly harvested while natural regeneration is scarce. However, in intensively affected stands a low portion of only slightly damaged trees are regularly observed, and these individuals are suspected to display a high level of heritable resistance or tolerance towards the ash dieback pathogen.

Evidence for differences in resistance of $F$. excelsior to $H$. fraxineus in Austria mainly comes from observations in three clonal seed orchards, which were established between 1993 and 2000. Each consists of 50 to 70 grafted clones from plus trees. Damage assessments from 2009 to 2011 in these ash seed orchards indicated a great variation among ash clones ranging from almost no $(<5 \%)$ to severe dieback. Although the overall level of ash dieback has subsequently increased and the health condition of many clones deteriorated substantially, by 2018 some genotypes were still only negligibly affected by the disease. These observations and several other European studies have provided evidence that resistance of common ash to $H$. fraxineus is genetically determined and has a 
high heritable component. Breeding for resistance was therefore chosen as a promising strategy to maintain ash as one of the main hardwood species for forestry and nature conservation in Austria. Project phase I of "Ash in distress" (2015-2019) revealed a high potential to save common ash by ex situ conservation and resistance breeding. Strict criteria for selecting forest stands and individual trees were defined: only stands with high damage levels (indicating a high local infection pressure of $H$. fraxineus) were considered, and selected ash trees did not show root collar lesions and only negligible crown damage. Likewise, their diameter at breast height $(\mathrm{DBH})$ was limited to $20-25 \mathrm{~cm}$ (maximum $30 \mathrm{~cm}$ ) and only trees bearing fruits (female and hermaphroditic trees) were chosen. Based on these criteria, a total of 716 putatively resistant single trees across Austria were selected for seed harvest in 2015 and 2017. After single tree progenies had been grown, four progeny trials with a total of 35,718 seedlings were installed from 2017 to 2020 in the BFW research nursery in Tulln (Lower Austria; resistance trials R1 to R4; Fig. 3.3.5-1), where they were subjected to natural infections by $H$. fraxineus. Seedlings from severely damaged mother trees were included as negative controls in the tests.

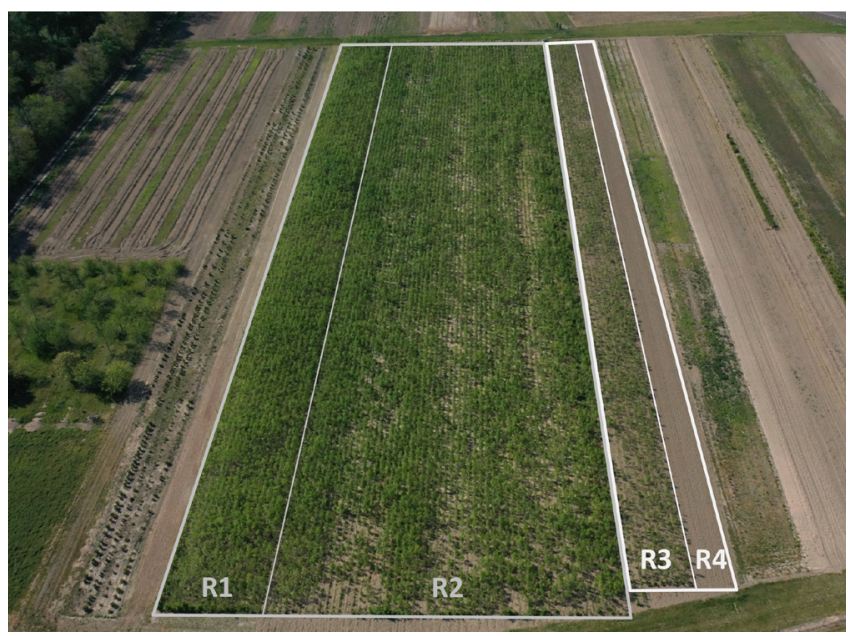

Figure 3.3.5-1: Drone image of the common garden experiment in the BFW research nursery in Tulln established in the course of "Ash in distress". According to seed collection in 2015 and 2017 and germination over a period of 4 years, plantings had to be organized in four separate, but adjacently arranged resistance trials, R1 to R4 (photo taken on 08 May 2020)

In order to infer on the resistance levels of seedlings in the trials, the intensity of ash dieback on woody parts (main stem, side twigs, root collar) was assessed annually (in summer) by visual 
inspections and using six damage classes $(1=0 \%$ damage, $6=$ $100 \%$ damage, dead plant; Fig. 3.3.5-2). The proportion of healthy seedlings in trial R1 (established in 2017) has substantially decreased from 2018 to 2020 (Fig. 3.3.5-2). In the first assessment in $2018,82.4 \%(4,970$ of 6,030$)$ of seedlings were not damaged by ash dieback; this proportion decreased to $57.6 \%$ in 2019 , and further to $24.0 \%$ in 2020 . A few half-sib families were overall only slightly affected by the disease. Likewise, damage intensity among progenies differed greatly in relation to their mother trees, which is indeed in line with genetically determined, inheritable resistance of F. excelsior to H. fraxineus. Resistance trial R2 (planted in 2018, two assessments in 2019 and 2020) showed a similar trend of disease development as trial R1, trial R3 (initiated in 2019) was evaluated only once (in 2020), and trial R4 (established in 2020) will be evaluated for the first time in 2021. A substantial ash dieback intensity in trial R1 suggests a high infection pressure of $H$. fraxineus in the BFW research nursery, ensuring that only superior genotypes among the various progenies are selected for resistance breeding. While disease intensity may further increase over time (but likely at a slower rate), it is expected that a considerable portion of healthy and only slightly damaged ash individuals will continue to perform superiorly.

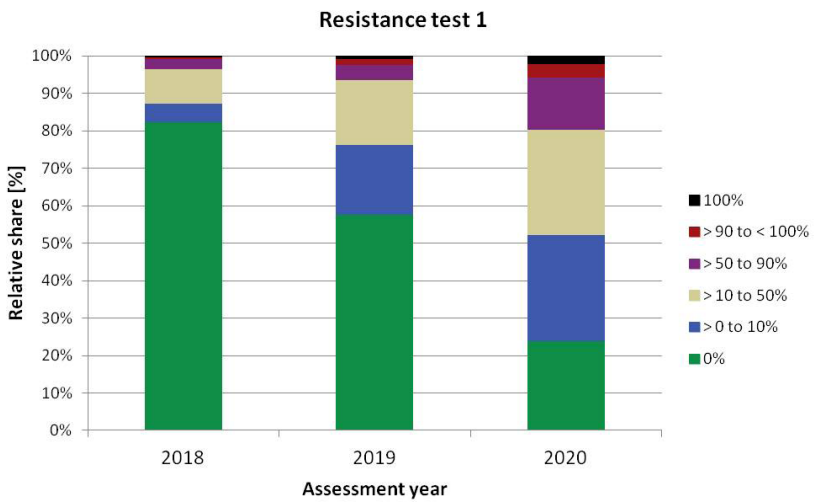

Figure 3.3.5-2: Development of ash dieback intensity in the resistance test 1 (R1) from 2018 to 2020 . Stacked bars show the relative distribution of ash plants in the six damage classes (R1 was established in 2017 with 6,330 one-year-old seedlings from 426 mother trees)

Project phase II (2019-2024) focuses on the characterization and selection of superior genotypes in a common garden experiment. Healthy individuals chosen among progenies with overall low damage levels due to ash dieback (Fig. 3.3.5-3) are being 
further screened with molecular markers associated with disease resistance. Genotypes selected based on these characteristics will finally be tested by artificial inoculation with $H$. fraxineus and Armillaria spp. (honey fungus), which are secondary but important pathogens on trees damaged by ash dieback. In parallel, horticultural techniques to optimize propagation of common ash by rooted cuttings and grafting are being tested. At the end of phase II, the installation of field trials using a final progeny selection (if possible propagated by rooted cuttings) as well as the establishment of one or more seed orchards is envisaged. The set-up of new seed orchards of ash with a large number of locally adapted and superiorly resistant clones should overcome the major problem for the development of resistance in natural populations where the scattered occurrence of few remaining highly resistant trees makes mating between them unlikely and thus poses difficulties to pass their resistance traits to their progenies.

Apart from the conservation initiative for common ash, the project "QEsche" was launched in 2018 for resistance breeding in Fraxinus angustifolia, following a similar approach. Within the natural range of $F$. angustifolia in Austria, damage is less evident on mature trees, but ash dieback heavily affects natural and artificial regeneration. Thus, the selection criteria for resistant trees were modified to include especially young trees with a $\mathrm{DBH}$ of less than $20 \mathrm{~cm}$. The overall goal of the project "QEsche" is the establishment of field trials with vegetatively propagated elite clones and seedlings from putatively resistant seed-bearing trees. These trials will form the basis for further ex situ conservation and resistance breeding in this species as well.

Ex situ conservation measures, such as those described here, should be supplemented by in situ conservation of ash trees putatively resistant to ash dieback. In recent years, and particularly since 2016, ash trees have been felled and entire ash stands cleared at large scale in the course of salvage cuttings in Austria. In many cases, these operations are executed undifferentiated, meaning that trees are felled regardless of their health condition. However, to favour the adaption of ash populations to the novel selection factor $H$. fraxineus, we strongly recommend preserving and promoting exceptionally disease tolerant ash trees, especially in severely diseased stands, and facilitate their natural regeneration. The fate of common and narrow-leaved ash relies not only on disease resistance breeding, but is also in the hands of forest owners, foresters and other practitioners who take part

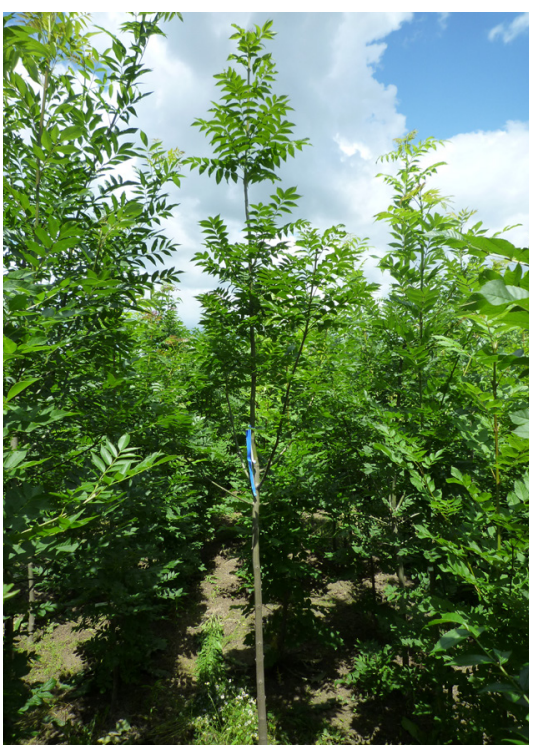

Figure 3.3.5-3: Three-year-old elite common ash tree in trial R2 of "Ash in distress" selected for clonal propagation and further resistance breeding. The tree comes from a half-sib family with overall superior performance and by 2020 (after two years of assessment) was still unaffected by ash dieback (photo taken on 24 June 2020) 
in preserving these ecologically and economically valuable tree species and are also willing to plant improved, more resistant reproductive material of Fraxinus spp.

\section{Acknowledgements}

"Ash in distress" (DaFNEplus Nr. 101113 and 101476) was financially supported by the Austrian Federal Ministry of Agriculture, Regions and Tourism (BMLRT), the Austrian Chamber for Agriculture, the State Forestry Administrations of all Federal Provinces, the Forest Office and Urban Agriculture (MA 49) of the Vienna City Administration, the Austrian Foresters Association and the Departments for Nature Conservation of the Provincial Administrations of Salzburg and Upper Austria. The project "QEsche" (2018-2022) has been financially supported by the Federal Government of Austria, the Federal Provinces and the European Union (European Agricultural Fund for Rural Development). We thank all the staff of the BFW research nursery in Tulln as well as many colleagues from the BFW for extensive technical support. 


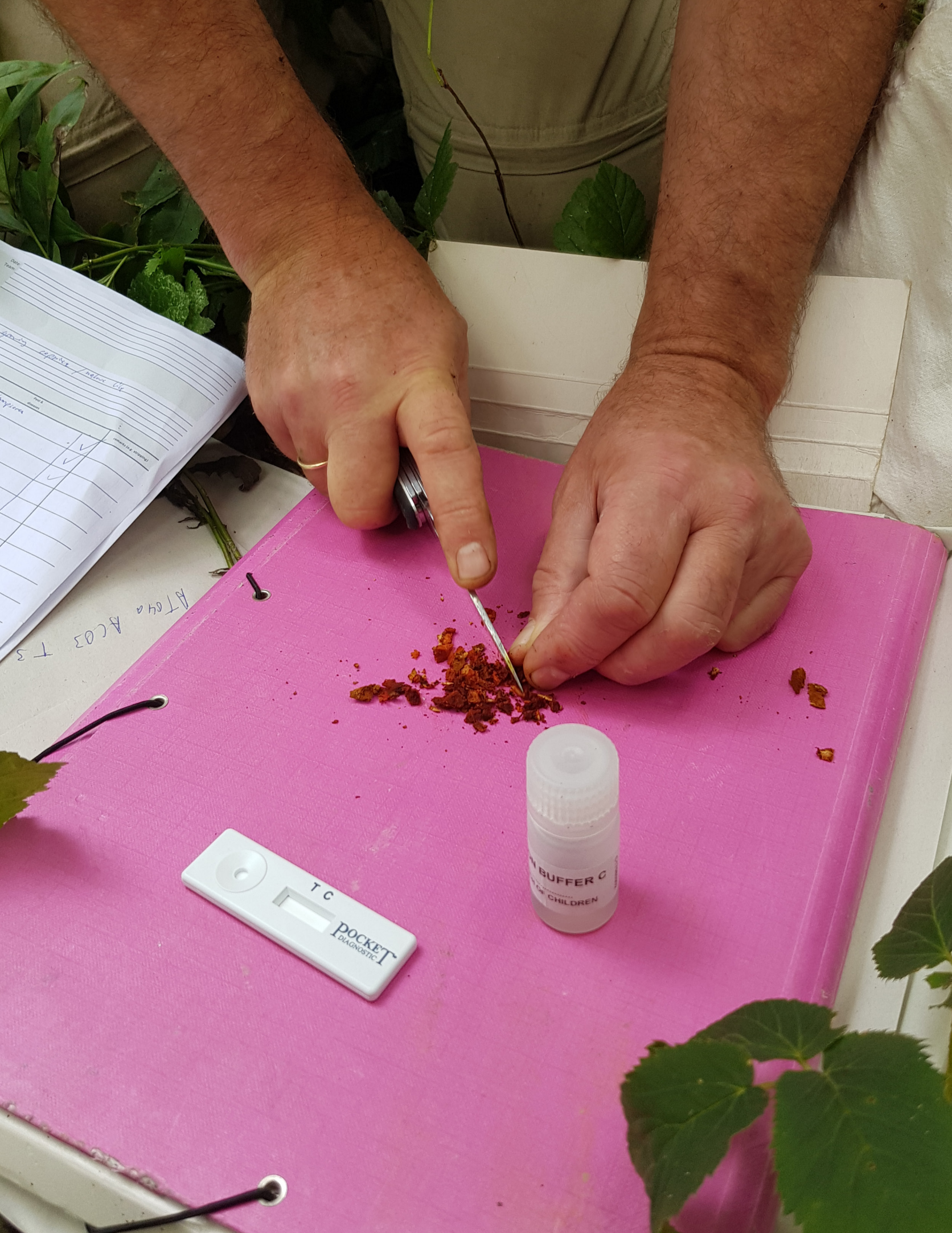




\subsubsection{Measures against the spread of Phytophthora in riparian forests}

\section{Thomas L. Cech}

\section{Introduction}

The genus Phytophthora (Chromista, Peronosporaceae) consists of plant pathogens causing worldwide damage to both herbaceous and woody hosts. As predominantly root inhabiting organisms, they are mainly spread by infected plant stock, by free running water, sometimes by other human activities (e.g. tourism, forest management) and more rarely by wind and rainsplash. A high number of species originated in tropical forests where they adapted to a wide host spectrum. Species like a widespread P. cinnamomi can infect several thousands of plant species. As a consequence, Phytophthora species often "discover" new hosts, which are particularly vulnerable and usually heavily harmed because they lack any co-evolution with these pathogens. A second factor increasing the harmfulness of this genus is frequent hybridisation accompanied by changes in pathogenicity. From this point of view, tree nurseries are of special risk according to the high diversity and abundance of potential hosts in close vicinity. Phytophthora species need water to develop and spread their most infective units, zoospores. The latter are released in rain, soil water and especially in free water of ponds, lakes and rivers. The impacts of some species on natural ecosystems are high (for instance P. cinnamomi on Australian woodlands, P. ramorum on North American redwood forests and P. austrocedrae on South American Austrocedrus forests) and effective measures against these disasters are comparatively sparse. Most of them target prevention of infection; only few curative control strategies have been developed.

Riparian forests are especially at risk from Phytophthora infecting roots and root collar because of the recurring floods that are characteristic for these forest types. Floods inevitably allow the infestation of forests along rivers, since river water is always harbouring germs of various Phytophthora species. In Europe, Phytophthora-decline of alders (Alnus sp.) caused by P. x alni and other Phytophthora species (Fig. 3.3.6-1, 3.3.6-2) is the most striking example for this. From the 1990s on, millions of planted alders developed Phytophthora-collar rot and stem bark lesions after infection from the roots. Zoospores produced in the bark lesions were released into river water during natural flood events and subsequently infected the base of stems of healthy alders located downstream; infections led to quick girdling and death of the trees. 


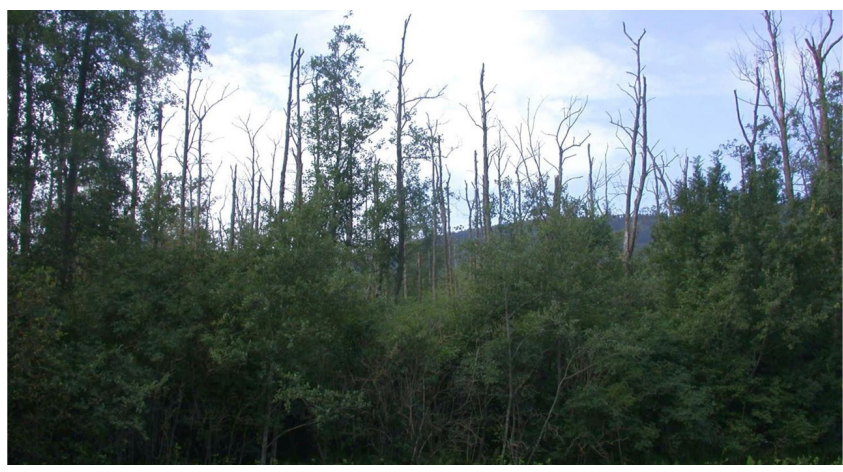

Figure 3.3.6-1: Since 1990s, millions of planted alders developed Phytophthora-collar rot and stem bark lesions after infection from roots and died

\section{Preventive versus curative strategies}

The most serious impact of Phytophthora is related to root and collar infections, which are usually lethal. However, some curative methods are available. One of the most effective measures to enable survival of infested trees is a stem bark treatment with certain phosphides. These compounds stimulate defence mechanisms of trees (wound callus formation) as well as increased growth of fine roots. This treatment is commonly applied to individual urban trees. However, it will be hardly feasible in forests. Therefore, preventive measures are the primary method targeted at minimizing the spread of Phytophthora into riparian forests.

\section{Adaptation of forest nurseries to enable Phytophthora-free plant production}

Keeping plant production free from Phytophthora poses several challenges for nurseries. Preventing the introduction of the pathogen into plant stock must be combined with regular monitoring and control systems by plant protection authorities.

In order to produce Phytophthora-free plant stock, nurseries have to meet several crucial prerequisites. Avoiding the exchange of plant stock among nurseries and avoiding the infestation of plant stock, which predominantly occurs via irrigation with river water, are the most important challenges for nursery management.

Nurseries must guarantee the following:

- no introduction of Phytophthora-germs into the production sites via plant stock from other nurseries occurs,

- there is no introduction of Phytophthora-germs into production sites via irrigation,

- there is no introduction of Phytophthora-germs into

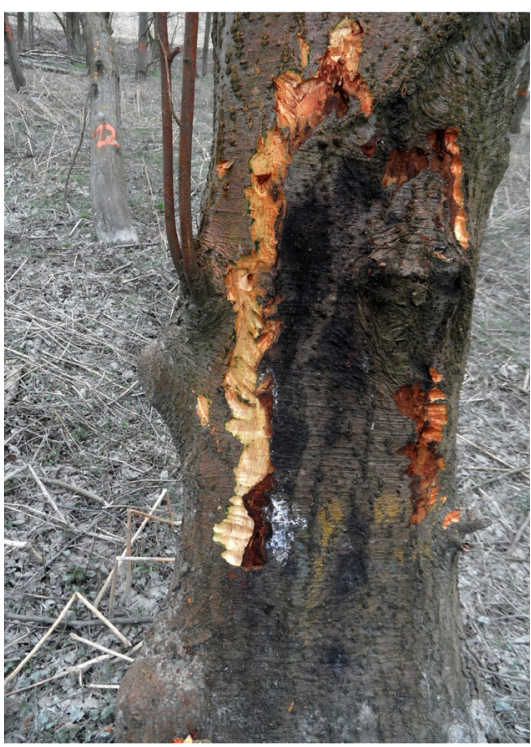

Figure 3.3.6-2: Stem bark lesions caused by Phytophthora infection visible after a cut with a knife 
production sites by inundation from nearby waterways, ponds or lakes,

- there is no introduction of Phytophthora-germs into production sites by any contaminated soil material, equipment, tools, clothes, shoes, or vehicles.

\section{Seeds}

Though comparatively few Phytophthora species are seed borne, the following safety measures should be considered:

- Avoidance of seed collection from known or likely infested plants or areas.

- Avoidance of seed collection from ground or within splash zone (within about $0.5 \mathrm{~m}$ of soil surface if feasible).

- Surface sterilisation before storage and sowing.

- Removal of symptomatic seeds (most obvious for large ones) before sowing.

- $\quad$ Seed treatments to eradicate pathogens (e.g. heat, chemicals).

In case of risk (depending on the plant species), diagnostic laboratory analysis of seeds before sowing is essential.

\section{Plant production}

Container plants are the preferred type of plant stock regarding Phytophthora-free material, since the substrate can be pre-sterilized and subsequently kept clean from contamination. The risk is higher in bare root plants growing in production fields in the open due to the existence of a higher number of unpredictable contamination pathways. For container plant production, the following measures are essential:

- $\quad$ Sterilisation of the substrate by heat treatment for at least 2 hours at $60^{\circ} \mathrm{C}$ before sowing seeds or planting scions. Evidence for this requires checks done by a diagnostic laboratory.

- On the production sites, plants are to be placed either on the ground without influence of natural soil and free running water or, preferably, elevated from soil for at least $1 \mathrm{~m}$. Contact of foliage with natural soil as well as splashing water from soil onto the foliage is to be avoided.

- Never mix plant sets with other plants containing nonsterilised substrate. During the time of plant production any contact with free-flowing water (flooding from adjacent rivers, snowmelt) must be excluded.

- Avoidance of irrigation practices wetting the foliage for prolonged periods ( $>24$ hours). Sprinklers are to be used only in the morning to allow for quick drying. 
Irrigation should be done preferably by well water or ground water or by tap water, since these water sources are usually free from Phytophthora germs. For nurseries dependent on use of water from ponds or rivers, water treatment before irrigation is obligatory; irrigation water can be filtered to remove pathogens. This practice is likely only convenient for large nurseries, since the systems are expensive (also regarding the maintenance) and require a lot of space. Furthermore, the systems usually do not guarantee that the water is completely free from Phytophthora germs. Irrigation water can be also decontaminated with chemicals. Using commercial chlorine will remove germs, however for a large-scale treatment of water legal constraints must be considered.

To ensure effectiveness, random checks of substrate for Phytophthora should be done (diagnostic laboratory). In addition, checks of both substrate and plantlets must be performed prior to delivery of plants to clients or other nurseries. Irrigation water must be tested periodically for contamination with Phytophthora by a diagnostic laboratory.

\section{Further strategies to prevent riparian forests from invasions by Phytophthora}

Interruption of the spread of Phytophthora by floods can only be achieved by preventing its entry into rivers, which requires the extension of the listed measures to ornamental plant production. In addition, certain hygienic requirements must be followed in forest management, since, for example, harvesting machines can spread germs through contaminated chains and soil material foreign to the forest is often used in the construction of forest roads. Overall, however, increased awareness among the population of the risks posed by contaminated plants is necessary to support the abovementioned, usually cost-intensive measures.

\section{Summary and outlook}

Reducing the risk of Phytophthora infestations in riparian forest ecosystems can only be considered as preventive measure with a sustainable balance between pathogens and forest trees. Furthermore, such prevention requires integrated and comprehensive approaches involving particularly plant production and plant trade, but also forest and urban tree management, and finally, increasing the public awareness of the risk by these pathogens. Changes in plant protection legislation, as well as awareness raising of people dealing with trees and the public, will be needed. 


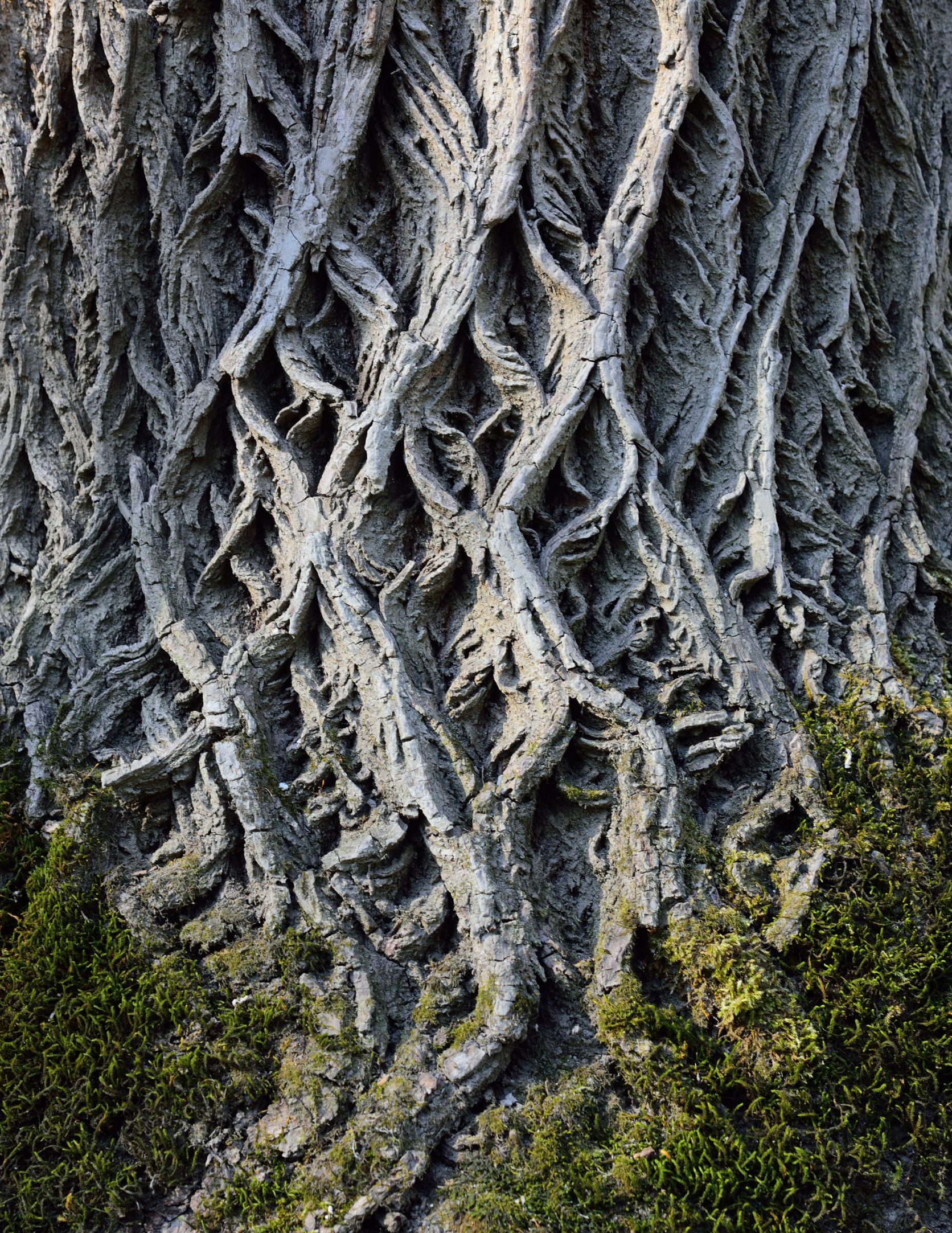




\section{APPENDIX}

\subsection{Tree species occurrence and seed transfer}

\subsubsection{Species occurrence probability under climate change}

A selection of 10 maps (combined on one single page in two columns and five rows) shows the present probability of occurrence as well as the modelled future probability of occurrence for two selected climate change scenarios (moderate climate change: RCP4.5; strong climate change: RCP 8.5) and two time periods (mid of the century and end of the century) for the seven most important riparian tree species. The left side shows the overall probability occurrence for the spatial extent of the five project countries (Austria, Slovenia, Hungary, Croatia, and Serbia), the right side is cropped to the extent of the Mura-DravaDanube Biosphere Reserve. The map on the top is modelled with current climate, followed by two maps for RCP 4.5 in the middle and by two maps for RCP 8.5 at the bottom. The first map under each of the two RCP scenarios is for years 2041 to 2060 and the second for 2081 to 2100 . The legend to the right of each map refers to occurrence probability (probability of survival and successful growth) of given species under given conditions.

White and red colours display a low probability of occurrence, followed by yellow for medium, and green for high probability of occurrence. The boundaries of the Mura-Drava-Danube Biosphere Reserve are displayed in black colour on the maps, national borders are in grey.

\subsubsection{Seed transfer zones and their predicted spatial change over time}

A selection of six maps (combined on two pages per species) shows the development of seed transfer zones during both selected climate change scenarios. The first page is for RCP 4.5, the second page for RCP 8.5 for each species. The map at the top is modelled with current climate, followed by a map for the period 2041-2060 in the middle and a map for 2081-2100 at the bottom.

All coloured areas have occurrence probability above $0.5(0.2$ for Ulmus laevis). Areas displayed in white have occurrence probability below 0.5 ( 0.2 for Ulmus laevis) and show areas where tree species are not expected to grow. Different colours
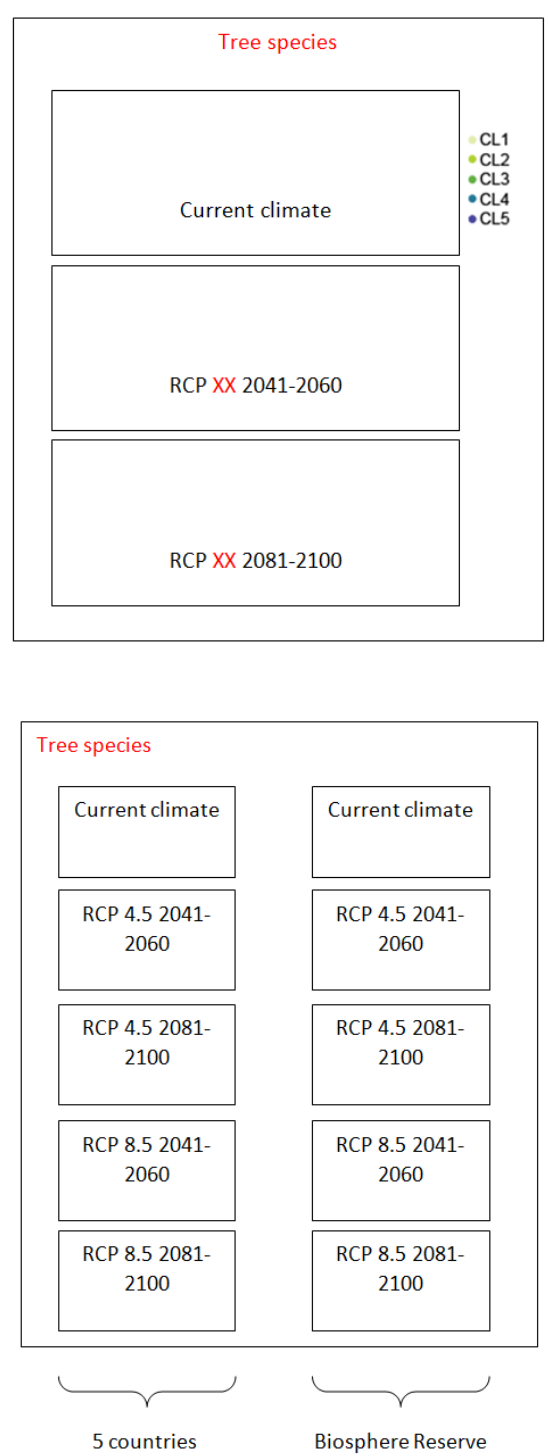
show spatial zones (clusters) with similar climate conditions, representing different seed transfer zones. Clusters - seed transfer zones are labelled as CL1, CL2, CL3, etc. Therefore, areas in CL1 are climatically more similar than they are similar to areas in any other CLs. Colour codes for the clusters (CL) are depicted to the right of each combination map.

The boundaries of the Mura-Drava-Danube Biosphere Reserve are displayed in yellow.

\section{Download links for high resolution maps}

Target species 1: Alnus glutinosa

https://danubeforesthealth.eu/dat/Output3.3/Alnus glutinosa/

\section{Target species 2: Fraxinus angustifolia}

https://danubeforesthealth.eu/dat/Output3.3/Fraxinus_angustifolia/

Target species 3: Fraxinus excelsior

https://danubeforesthealth.eu/dat/Output3.3/Fraxinus excelsior/

Target species 4: Populus nigra

https://danubeforesthealth.eu/dat/Output3.3/Populus nigra/

Target species 5: Quercus robur

https://danubeforesthealth.eu/dat/Output3.3/Quercus_robur/

\section{Target species 6: Ulmus leavis}

https://danubeforesthealth.eu/dat/Output3.3/Ulmus laevis/

Note: The maps of seed transfer zones for all other species are limited to the area with an occurrence probability above 0.5 . For Ulmus laevis this threshold is 0.2 to fit the current natural distribution. For this species we additionally provide a set of maps without threshold in order to show which zone will be present in the future, even if the occurrence probability is predicted to be below 0.2 .

Target species 7: Ulmus minor

https://danubeforesthealth.eu/dat/Output3.3/Ulmus minor/

Additional species 1: Salix alba

https://danubeforesthealth.eu/dat/Output3.3/Additional_species/Salix alba occurrence.pdf

Additional species 2: Juglans nigra

https://danubeforesthealth.eu/dat/Output3.3/Additional species/Juglans nigra occurrence.pdf

Additional species 3: Robinia pseudoacacia https://danubeforesthealth.eu/dat/Output3.3/Additional_species/Robinia pseudoacacia occurence.pdf 


\subsection{Tree species portraits}

Viktoria Valenta

\subsubsection{Autochthonous tree species}

\section{Alnus glutinosa - common alder}
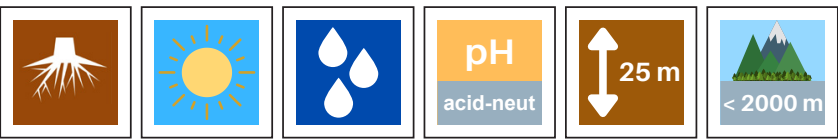

Common or black alder (Alnus glutinosa (L.) Gaertn.) is a small but fast-growing deciduous tree, reaching heights of 10-25 m (max. $40 \mathrm{~m}$ ) and getting up to 120 years old. Its crown is conical and trunk straight with smooth brown bark that gets darker and rougher with age. The wood is mostly used in the furniture industry, is not suitable for outdoor use, but for underwater construction.

\section{Distribution, habitat and ecology}

Alnus glutinosa can be found all over Europe, from about $65^{\circ} \mathrm{N}$ to northern Africa, and from Ireland to Russia, where aridity is the limiting factor. It grows on a variety of soil types: while it tolerates dry or poor soils (gravels and sands), it grows better in moist, damp conditions and can survive flooding better than other species (inundation tolerance "very high"). Alnus glutinosa can tolerate an annual precipitation of 400 - 2,000 $\mathrm{mm}$. Black alder is able to colonise disturbed areas quickly due to its symbiotic relationship with the bacteria Frankia alni, which enables it to fix nitrogen. As part of mixed floodplain communities, this quality is also beneficial for other species (Betula spp., Fraxinus spp., Quercus spp, Salix spp.), which tend to outcompete Alnus glutinosa once the canopy closes, not letting enough light through for this pioneer species.

The tree species can be found in the entire area of the Mura-Drava-Danube Biosphere Reserve from Austria to Serbia.

\section{Forestry and climate change}

Black alder is considered an important forest species, both because of its multiple uses in silviculture and the wood industry and its suitability for the stabilisation of riverbanks. As it retains relatively high levels of nitrogen in its leaves, its litter layer improves soil fertility in autumn. In addition, it provides valuable food for wildlife throughout the winter. However, afforestation with alder is problematic at present, since it is severely threatened by a disease caused by oomycete fungus Phytophthora alni, which has been spreading through Europe.

Climate change can affect Europe's black alder populations in various ways: it could extend its natural range further north where it is limited by the length and intensity of frosts. Decreasing amounts of rainfall on the other hand will have negative impacts on its distribution and survival rate.

\section{Description}

Leaves: obovate, double-toothed, indented tip (distinguishing it from A. incana), dark green; soil improving. Flowers: monoecious, young buds are very sticky (hence "glutinosa") female: red; male: yellow catkins, develop in autumn of previous year, and appear early in spring; wind-pollinated.

Fruits/seeds: ovoid; unripe grey-green, later dark brown, woody; corky float chambers; distributed via wind or water; low germination capacity.

Bark: smooth, green-grey at beginning; later angular longitudinal cracks. 


\section{Fraxinus angustifolia - narrow-leaved ash}
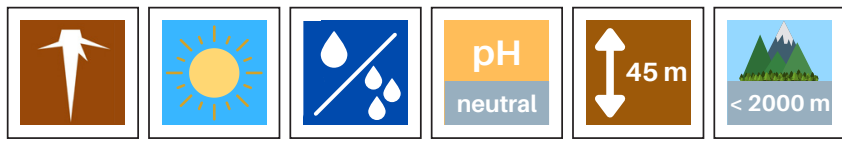

Narrow-leaved ash (Fraxinus angustifolia Vahl) is a relatively fast-growing deciduous tree, between $40 \mathrm{~m}$ and $45 \mathrm{~m}$ tall. The crown is dome-shaped and the wood is, similar to that of common ash ( $F$. excelsior), strong and flexible, but of lesser quality. It is used in pulpwood products, like veneers.

\section{Distribution habitat and ecology}

Narrow-leaved ash can be found throughout central southern Europe, northwest Africa and the Middle East. It partly overlaps with the distribution of common ash, with which it can hybridise. Narrow-leaved ash grows in riparian forests with moist, aerated soils. Its inundation tolerance is "high". On drier sites, it can be found at higher altitudes. Frost limits its distribution in higher latitudes. As a light-demanding species, it is part of mixed broadleaved forests together with e.g. poplars (Populus spp.), willows (Salix spp.) or maple (Acer spp.) species.

The tree species can be found in all countries of the Mura-Drava-Danube Biosphere Reserve from Serbia to Austria, where it has its northern boundary. It overlaps with Fraxinus excelsior, especially in the central parts of the Mura-Drava-Danube Biosphere Reserve, but replaces it towards the south east.

\section{Forestry and climate change}

Ash plantations are generally established from nursery-grown seedlings, as F. angustifolia does not tolerate heavy competition from weeds. It requires a mild climate and precipitation between 400 and $800 \mathrm{~mm}$. Frost is likely to be a major factor limiting the species' distribution. Therefore, it might increase its range when European climate becomes warmer.

\section{Description}

Leaves: compound, odd-pinnate, 3-8 cm long, shiny green, hairless.

Flowers: monoecious; inflorescence: simple, unbranched raceme (compound - panicle - in $F$. excelsior), 10-30 flowers; wind-pollinated; early spring; brown terminal buds.

Fruits/seeds: samaras, $3-4 \mathrm{~cm}$; ripening at the end of summer.

Bark: grey, smooth, becomes fissured. 


\section{Fraxinus excelsior - common ash}
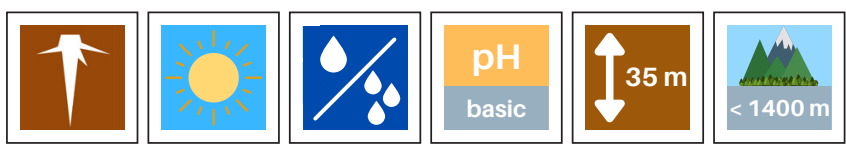

Common ash (Fraxinus excelsior L.) is a relatively fast-growing deciduous tree species. It lives up to 300 years, growing 20-35 m (max. $45 \mathrm{~m}$ ) tall. Its trunk is long and straight with an open and domed crown. Especially young trees grow very symmetrically. The bark is pale grey and smooth, but develops fissures with age. The timber is light-coloured, strong and tough, but rather flexible. It is used for tools and sports equipment, flooring and musical instruments due to its structural properties.

\section{Distribution, habitat and ecology}

Common ash can be found throughout Europe, from the Atlantic coast to the northern parts of the Middle East - extending further than the distribution of the two other European ash species, narrow-leaved ash (F. angustifolia) and manna ash (F. ornus). Common ash is a species of floodplain forests, but also grows in mountainous areas in moist stream valleys. It grows best on deep, rich soils that are adequately aerated; either with high silt or clay fractions, but also rather dry calcareous soils. It can tolerate seasonal waterlogging, but not prolonged flooding - its inundation tolerance being intermediate up to 60 - 102 days. This ash is dominant in its younger stages due to its shade tolerance, but becomes a strong light-demander after the first years.

It is found in all countries from Austria to Serbia but is increasingly replaced by Fraxinus angustifolia in Hungary and Croatia towards Serbia. This tree species can be found in the entire area of the Mura-DravaDanube Biosphere Reserve.

\section{Forestry and climate change}

Common ash rejuvenates/regenerates easily and abundantly. Annual fruit production sets in about 20 to 30 years of age with more abundant production every 2-5 years. Indirect importance for forestry is based on its dense root system, which stabilises slopes that are prone to slipping as well as stream and riverbanks.

This ash would generally cope well with global warming, if it had not become threatened by a fungus (Hymenoscyphus fraxineus, also known as Chalara fraxinea), which is the cause of the ash dieback. The dieback has been spreading through Europe since the early 1990s, causing massive death rates in some countries. This disease also increases susceptibility to other pests and diseases, like the emerald ash borer (Agrilus planipennis) - an invasive beetle from eastern Asia with wood boring larvae, which was first found in Europe in the early 2000s.

\section{Description}

Leaves: compound, with 9-13 leaflets, odd-pinnate, serrated; leaves unfold relatively late in spring and are shed still green; soil improving.

Flowers: complex sexuality, monoecious, dioecious; inflorescences compound panicle (simple, unbranched raceme in F. angustifolia); wind-pollinated; in bunches of 100-400; black terminal buds; dark red flowers.

Fruits/Seeds: oval shaped samaras, $2-5 \mathrm{~cm}$ long, in bunches; seeds lie dormant for 2 years.

Bark: grey, smooth, later fissured. 
Populus alba - white poplar
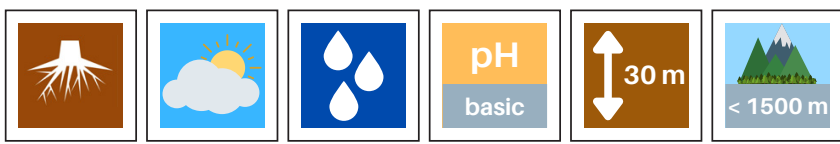

White poplar (Populus alba L.) is a medium-sized tree that can get up to 400 years old and about $30 \mathrm{~m}$ tall. The trunk is irregular with a rounded crown. The wood is not of great economical importance, but used in the energy sector and in propagation and breeding programmes.

\section{Distribution, habitat and ecology}

White poplar can be found in central and southern Europe in riparian and coastal forests. Like other poplars, it prefers moist, loose, gravel-clay soils rich in nutrients. To a certain extent, it tolerates long-term inundations and low levels of soil salinity. It is a fast-growing, light-demanding species, common in early to mid-seral communities. White poplar hybridises with other poplar species, like Eurasian aspen (P. tremula) and forms mixed stands with ashes (Salix spp.), elms (Ulmus spp.), oaks (Quercus spp.) and others.

The tree species can be found in the entire area of the Mura-Drava-Danube Biosphere Reserve from Austria to Serbia. It overlaps with the distribution of other poplar species, including P. nigra.

Forestry and climate change

As white poplar produces many saplings and is tolerant of heat and frost, it will become more important in the context of global warming. Due to its extensive, adaptable root system, it can stabilise dunes and is therefore appreciated in pioneer forests near a coast. Along riverbanks and roadsides, it acts as windbreaks and erosion control.

\section{Description}

Leaves: alternate, variable, 3-5 lobes, coarsely toothed, 6-12 cm; shiny dark green on upper side, white with dense hair below.

Flowers: dioecious; flowering before leaf burst.

Fruits/seeds: male catkins grey with red stamen; female catkins grey-green, fluffy seeds in early summer.

Bark: creamy white with black diamond-shaped spots (young trees); black and cracked (base of older trees). 
Populus nigra - black poplar
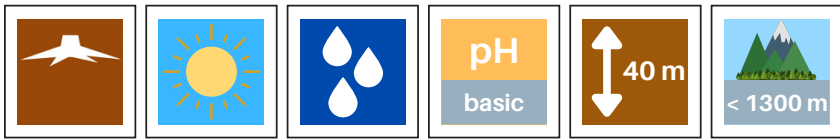

Black poplar (Populus nigra L.) is a fast-growing deciduous tree, reaching heights of up to $40 \mathrm{~m}$ and an age of up to 400 years (mostly 100). It develops strong branches and a broad, low-set crown. The wood is used for furniture, but also in paper production and the bioenergy sector.

\section{Distribution, habitat and ecology}

Populus nigra can be found throughout Europe - from the Mediterranean to the British Isles - in North Africa and to central Asia. It is an important species of floodplain forests, where its reproduction is closely linked with annual flood cycles. Dissemination of the seeds is via wind and water and germination depends on soil-water conditions. Root development is also subject to soil-moisture after flood events. Moist, deep and nutrient-rich forest soils are optimal, calcareous locations are preferred, waterlogged and acidic sites are avoided. High water levels and high temperatures can be tolerated, however, droughts are problematic. As a pioneer species, it is light-demanding and can colonise disturbed sites, especially via vegetative regeneration. It can hybridise easily with other poplars and occurs in mixed forests together with other Salicaceae like white poplar $(P . a l b a)$ and willows (Salix spp.), but also with alders (Alnus spp.), elms (Ulmus spp.) and maples (Acer spp.).

The tree species can be found in the entire area of the Mura-Drava-Danube Biosphere Reserve from Austria to Serbia.

\section{Forestry and climate change}

Although black poplars are economically important and can be propagated without difficulty via cuttings, they are among the most threatened tree species in Europe. Since they hybridise easily, they are important in various breeding programmes, e.g. for obtaining Populus $\mathrm{x}$ canadensis (P. deltoides $x$ P. nigra) and other exotic hybrids. These hybrids are widely planted, replacing native populations. The transfer of genes from such hybrid clones into the gene pool of Populus nigra also poses a threat. However, such hybrids are also better adapted to various climatic conditions and forest pests. Poplars provide important ecosystem services, including pollution mitigation, watershed protection, soil stabilisation and erosion control. In addition, they emit volatile organic compounds like isoprene, which could have an impact on climate change.

\section{Description}

Leaves: variable, longer than wide, triangular, globous, serrated edges, lighter upper side.

Flowers: dioecious (either male or female); male: red, hanging catkins; female: yellowish catkins; flowers appear before leaves; wind-pollinated.

Fruits/seeds: capsules, thick, pointed, greenish-brown, petiolate; seeds are hairy.

Bark: greyish, later darker, deeply cracked. 


\section{Prunus avium - wild cherry}
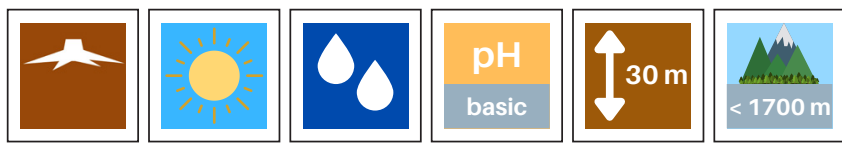

Wild cherry (Prunus avium L.) is a medium sized, fast-growing tree, which grows to about 15-30 $\mathrm{m}$ high and usually 70-100 years old. It develops a mostly straight trunk with thin, grey bark. The wild cherry is one of the most important hardwood trees of the family Rosaceae in Europe. The timber is fine grained and dense with distinctly coloured heartwood, which is used for furniture making, decorative joinery and musical instruments.

\section{Distribution, habitat and ecology}

Wild cherry has a very wide natural range in Europe's temperate forest regions; it can be found from planar to submontane areas from the British Isles and Scandinavia in the north to southern Spain, the Maghreb and the Caucasus in the south. However, its natural populations are mostly scattered, but planted and naturalised forms can be found quite widely distributed. It grows on the banks of streams and along forest edges. Wild cherry has medium to high nutrient requirements and can cope with different soil types, preferring fresh, calcareous soils with good water supply at sunny locations. It does not tolerate waterlogging and is sensitive to drought. It can be considered a pioneer species that can colonise openings by seeds or suckering. It grows rapidly when young until the age of about 40, which gives it a competitive advantage in early succession, but it is often outcompeted by other hardwoods in later stages. As a member of mixed forests, it can be found together with beeches (Fagus spp.), oaks (Quercus spp.), hornbeam (Carpinus betulus), maples (Acer spp.) and elms (Ulmus spp.).

Prunus avium can be found from Austria to Serbia. It occurs in the area of the Mura-Drava-Danube Biosphere Reserve, but is not occurring in northern Serbia and eastern Hungary.

\section{Forestry and climate change}

Prunus avium is the wild form of a domesticated sweet cherry, whose fruits (together with the sour cherry, $P$. cerasus) are economically very important edible cherries. It is often planted for bird protection and to preserve biodiversity. The wild cherry is used for afforestation of agricultural land. Due to its root system, it is suitable for soil erosion protection and slope stabilisation. In terms of climate change, it is considered a winner, provided that drought does not persist over longer periods as rainfall is already a limiting factor in the southern parts of its distribution. In the north, it is however limited by colder conditions, which will change with a warming climate. This could significantly increase its vulnerability to certain pests and diseases (e.g. gypsy moth, Lymantria dispar, cherry leaf roll virus CLRV) where conditions become less favourable.

\section{Description}

Leaves: ovate, long pointed, roughly serrated; stem with red nectar glands; in autumn yellow to red; soil improving.

Flowers: monoecious, hermaphrodite; clusters of 2-5 white flowers; insect-pollinated.

Fruits/seeds: red-purple drupes, long stalked, 1-2 cm in diameter, shiny; bittersweet, edible; late spring to summer; bird dispersed.

Bark: smooth, shiny grey-brown, large horizontal lenticels; peeling horizontally. 


\section{Quercus robur - pedunculate oak}
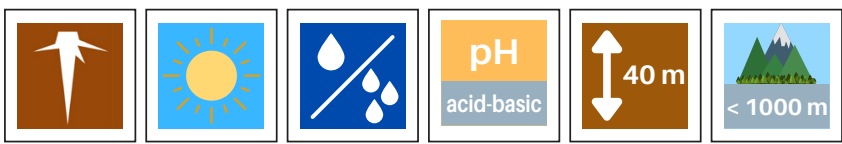

Pedunculate oak (Quercus robur L.) is a tall deciduous tree, growing sometimes over $40 \mathrm{~m}$ high and over 1,000 years old. They vary in shape, with an irregular crown that lets through a lot of sunlight. The trunk can be richly branched in solitary trees with grey to brown bark, which is fissured showing deep longitudinal cracks. Its very hard, heavy and versatile wood is used in the furniture and construction industries and due to its resistance to liquids as barrels and in ship making.

\section{Distribution, habitat and ecology}

Like Quercus petraea (sessile oak), Quercus robur can be found across Europe - from southern Norway in the north, to the Mediterranean in the south, where it hybridises with other oaks (Q. frainetto and Q. pubescens). It is an important species of riparian mixed forest and occurs on fresh to moist, loam and clay rich, heavy soils in warm locations. It tolerates soils with poor nutrient supply. Regular flooding is not a problem and due to its deep taproots it can cope with moderate droughts. Pedunculate oak is a light-demanding species that develops its leaves relatively late, thereby letting sunlight through to the forest floor. This not only avoids damage from late frost events, but also allows for diverse regeneration. Pedunculate oak is a pioneer species in plains and hills, but a late successional species in floodplains and valleys. Oaks can be found together with hornbeam (Carpinus betulus), forming a Carpinion betuli alliance, which includes also ashes (Fraxinus excelsior and F. angustifolia) and maples (Acer campestre, A. platanoides).

The tree species can be found in the entire area of the Mura-Drava-Danube Biosphere Reserve.

\section{Forestry and climate change}

Oaks need a lot of light and intensive care when young and are therefore considered challenging tree species. It is possible to obtain valuable wood from 90-120 years of age - economic rotations are about 130 years. Oaks can be coppiced and pollarded easily. Where possible natural regeneration should be prioritised - where plantations are necessary introduction of exotic genotypes could pose a threat. Oaks provide a valuable food source for mammals, birds and insects. Forest pests such as oak mildew (Erysiphe alphitoides syn. Microsphaera alphitoides) and oak processionary moth (Thaumetopoea processionea) can cause serious damage and limit productivity by preventing light from reaching the leaves or defoliating the trees. A relatively new threat is Acute Oak Decline, which might be attributed, among other reasons (pollution, bad silvicultural practices etc.) to climate change.

\section{Description}

Leaves: simple, obovate-oblong, round lobed; $16 \mathrm{~cm}$ long; short stalk (2-7 mm; difference to Q. petraea); upper side dull dark green, leaf base with veins.

Flowers: monoecious; wind-pollinated; female: small, reddish, inconspicuous; male: yellow-green drooping catkins; appear just after first leaves.

Fruits/seeds: acorns, in a scaly cup, with long stalks (difference to Q. petraea) and longitudinal stripes, large reserves for development.

Bark: grey to brown, deep longitudinal cracks when older. 


\section{Ulmus laevis - European white elm}
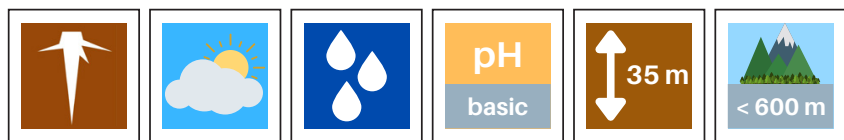

European white elm (Ulmus laevis Pall.) is a medium-sized deciduous tree, growing to about $30 \mathrm{~m}$ high and over 100 years old. The crown is very variable, from dome-shaped to conic. The trunk has furrowed, greybrown bark and heartwood of the same colouration. What is special about this tree is that it forms buttress roots - connections between roots and trunks, otherwise found in rainforest species. Elms in general have good-quality wood and are suitable for underwater use. Ulmus laevis has cross-grained wood of a lower density.

\section{Distribution, habitat and ecology}

Of the three elm species native to Europe (U. laevis, U. glabra and U. minor), European white elm has a more eastern range from central France to the Ural Mountains. Elms can be found in floodplains and near rivers and streams. They prefer nutrient-rich and periodically flooded soils (their inundation tolerance being about 119 days/year), however they are able to tolerate moderately dry soils. European white elm is suitable as a mixed tree species in oak forests and occurs together with willows (Salix spp.), poplars (Populus spp.), alders (Alnus spp.) and ashes (Fraxinus spp.).

The tree species can be found in the entire area of the Mura-Drava-Danube Biosphere Reserve from Serbia to Austria, where it occurs in the eastern regions and along the Danube.

\section{Forestry and climate change}

Elms are used to mitigate soil erosion along river sides, especially U. laevis can cope at more disturbed and flooded sites. However, due to water-basin regulation and habitat loss its populations have become small and fragmented. In the future, particular focus will need to be placed on genetic diversity of the species, since outbreaks of Dutch elm disease in the last centuries have led to losses in the gene pool, which combined with landscape changes could make it more difficult to cope with the changing climate.

\section{Description}

Leaves: varied; alternate, dark green, acuminate at apex, toothed, smooth and downy on upper side; sheds leaves earlier than U. minor.

Flowers: hermaphrodite, monoecious; long-petioled; appear before leaves; clusters of 10-30; long stems (2 $\mathrm{cm})$, no petals, dark red; wind-pollinated.

Fruits/seeds: ovate samaras; single central nut, membrane with hair-fringed margin; matures in late spring.

Bark: brown-grey, deeply grooved. 


\section{Ulmus minor - field elm}
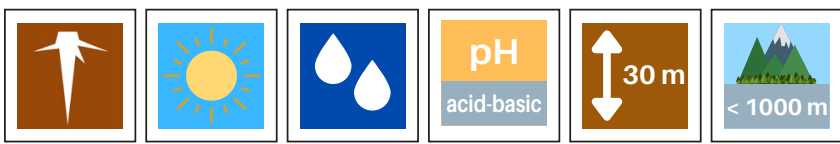

Field elm (Ulmus minor Mill.) is a medium-sized deciduous tree growing up to $20 \mathrm{~m}$ high and in exceptional cases up to 600 years old. The crown is rounded and the bark of the trunk is rough and furrowed lightly, often with cork strips. The heartwood is reddish-chocolate brown and of good quality for flooring and furniture. As it is very resistant to water decay, it is also used in underwater construction.

\section{Distribution, habitat and ecology}

Ulmus minor has the more southern distribution of the three European elm species (U. laevis and U. glabra). It can be found up to Iran, Israel and Algeria in the south; the northernmost extent is, however, the Baltic. This riparian tree grows along streams in southern and central Europe and in wooded steppes in the north as it is able to deal with both waterlogging (inundation tolerance of up to 151 days) and drought stress. The field elm is a light-demanding, fast-growing pioneer species, which can reproduce quite rapidly. It is part of mixed floodplain communities together with ashes (Fraxinus spp.), willows (Salix spp.) and oaks (Quercus spp.).

The tree species can be found in the entire area of the Mura-Drava-Danube Biosphere Reserve from Serbia to the eastern and northern regions of Austria.

\section{Forestry and climate change}

Elms are used to mitigate soil erosion along riversides, with Ulmus minor tolerating inundation better than other species, such as common ash. Field elm has been used along roadsides and in urban areas due to its ability to re-sprout easily and propagate by suckers. It has also been coppiced for use of small-wood products and animal fodder. Outbreaks of the Dutch elm disease in the last century have badly affected field elms and their gene pool, which placed them on the red list of endangered species as the regionally most threatened elm species. The cause of the massive elm dieback is an infection with the tubular fungus Ophiostoma novo-ulmi. The fungus is transmitted by the elm bark beetle when it feeds on branches of healthy elms.

The field elm hybridises with wych elms (U. glabra) - producing intermediate forms known as Ulmus $x$ hollandica (Dutch elm) - and with Siberian elms (U. pumila), which was introduced from Asia. In general, Ulmus minor is a very polymorphic and genetically complex species, with several subspecies and varieties adapted to different conditions, which can be an asset in a changing climate. Studies in Germany have shown that U. minor is among the best adapted species for a warmer and drier climate.

\section{Description}

Leaves: asymmetrical, globous, shiny; have only one tip (different to the wych elm); toothed, 4-10 $\mathrm{cm}$ long; black glands along leaf veins.

Flowers: monoecious, hermaphrodite; clusters of 10-30, closed to shoot; bell-shaped, purple-red; appear before leaves in spring.

Fruits/seeds: ovate samaras, single nut seed above centre of wing membrane; maturing in late spring.

Bark: rough, furrowed, often with cork stripes. 
Salix spp. - willows
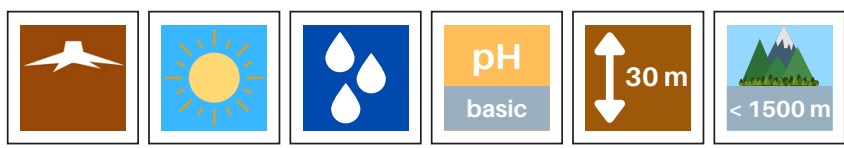

Willows (Salix spp.) are fast-growing deciduous trees, reaching heights of about $30 \mathrm{~m}$ and are relatively shortlived - about 20-30 years old, but can get up to 100 years old. There is a high number of species of willows in Europe, which have a variety of economic uses, including timber for sports equipment, baskets and fences, tannin and salicin and other non-wood products.

\section{Distribution, habitat and ecology}

In Europe, willows can be found from the Mediterranean to the British Isles and the Baltics. They occur from Spain to China, mainly in temperate and boreal forests. Different from other taxa, the number of willow species increases from the south to the north. Willows can hybridise quite easily and have been cultivated extensively, so their natural range is difficult to determine. White willow (Salix alba L.) is widely distributed in riparian forests. Like other willow species, it can be found on a variety of soils, provided the roots have access to water. Willows prefer clay (S. fragilis) or silts (S. alba), calcareous (S. caprea) or sandy soils (S. purpurea). They are in general very tolerant to inundation, with $S$. alba being particularly good in coping with floods (inundation tolerance of up to 300 days/year). Other species are a bit more susceptible to continuous flooding, like $S$. caprea, but still rank high compared to other riparian species. Salix species are light-demanding and do not tolerate shade very well. They mostly grow in open areas. Salix caprea, however, is one of the few willow species that can be found in forest understories. Willows occur in mixed forests together with species like beech (Fagus spp.), elms (Ulmus spp.), oaks (Quercus spp.) and poplars (Populus spp.).

Willow species, including Salix alba, S. caprea and S. purpurea, can be found in the entire area of the MuraDrava-Danube Biosphere Reserve from Austria to Serbia.

\section{Forestry and climate change}

Willows hybridise easily with each other, resulting in several hybrids, including Salix $x$ rubens (S. alba $x$ S. fragilis), Salix $x$ margaretae (S. purpurea $x$ S. fragilis) and Salix $x$ wimmeriana (S. purpurea $x$ S. caprea). This fact might help to adapt to climate change as hybrids can be planted to reclaim disturbed land where other species cannot cope any longer. Additionally, most willows can be coppiced or pollarded and reproduce vegetatively from suckers, with the exception of the goat willow (S. caprea), which can only occasionally be vegetatively propagated by cuttings. In terms of ecosystem services, willows are important for watershed protection, soil stabilisation and erosion mitigation among others. They are used in ecosystem restoration and phytoremediation, but also in agricultural landscaping as hedges and windbreaks. Willows in Europe can be found in a wide variety of climatic conditions. With a changing climate, a change in tree species composition can be expected in Europe's forests, so that some willow species might replace others in their native range. Willows can tolerate inundation, but species growing in tidal wetlands (e.g. S. alba and $S$. viminalis) will also be affected by salt intrusion due to climate change. Mature trees were shown to be able to cope with such oligohaline conditions.

\section{Description}

Leaves: long and narrow (lanceolate), finely serrated; silver-grey on top, underside with dense white hairs; alternate.

Flowers: dioecious; male catkins yellow, up to $5 \mathrm{~cm}$ long; female catkins greenish-yellow, become fluffy white, shorter; appear early in spring before leaves; insect-pollinated.

Fruits/seeds: capsule fruits, grey-felted, egg-shaped; without stem; very small seeds.

Bark: reddish to greyish-brown, later yellow-grey; longitudinal cracks. 


\subsubsection{Alternative tree species and clones}

\section{Juglans nigra - black walnut}
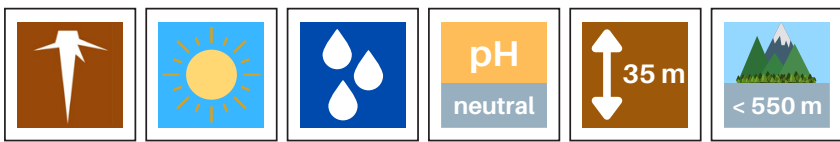

Black walnut (Juglans nigra L.) is a fast-growing, light-demanding deciduous tree introduced from North America. It grows to $25-35 \mathrm{~m}$ (max. $40 \mathrm{~m}$ ) high and 200-300 years old. It develops long trunks up to $2 \mathrm{~m}$ thick with a broad crown. The wood is strong, straight grained and durable. It ranks among the most expensive furniture woods in the world, but is also used for flooring, veneers, sculpturing and musical instruments.

\section{Distribution, habitat and ecology}

The native range of black walnut is North America, including eastern and central parts of the US and the southern Ontario. It was probably introduced to Europe around the beginning of the $17^{\text {th }}$ century. Since then it has been planted in about 15 European countries as an ornamental and forest tree. Juglans nigra requires rich soils with high nutrient levels (e.g. Ca, $\mathrm{K}, \mathrm{Mg}$ ). Black walnut prefers loamy soils with a $\mathrm{pH}$ of 6-7. It does not tolerate limestone, is sensitive to pseudogley and requires a deep layer of soil $(>60 \mathrm{~cm})$ over strongly calcareous or chalk bedrock. Ideal sites are on south or south-west facing slopes in warm and sheltered areas. Here the widespread root system with a deep taproot can stabilise both tree and soil. Soils need to be well-drained, but constantly supplied with water - either ground water or rain (minimum yearly rainfall variable from $600 \mathrm{~mm}$ to $900 \mathrm{~mm}$ ). Mature trees can survive inundation of up to 90 days during the growing season. Reports on drought resistance vary from moderately resistant to very sensitive. However, it can tolerate summer drought, if the soil is adequately saturated. Seedlings can be damaged by browsing animals like deer or voles. Nonetheless, black walnut depends on seed dispersal by rodents and birds, for which the nuts are highly nutritious (as they are for humans).

Native to North America, Juglans nigra has been introduced to all partner countries. In Austria, the first experimental cultivations in the Danube floodplain forests took place towards the end of the $19^{\text {th }}$ century. In Slovenia and Serbia, black walnut was first introduced into forests at the end of the $19^{\text {th }}$ century (1889 and 1890 respectively). In Serbia it covers about $0.1 \%$ of national forests. In Hungary, Juglans nigra was first introduced in the $18^{\text {th }}$ century and today covers approximately $0.4 \%$ of the forested area, being considered as one of the most valuable exotic tree species. In Croatia, the first plantations of black walnut were established around 1890. It was and is planted in the lowland forests in the vicinity of the Danube River on sites too dry for indigenous species like pedunculate oak.

\section{Forestry and climate change}

Black walnuts are mainly cultivated for the production of high-quality wood. They are also used in agroforestry systems, nut production and in ecosystem restoration. Juglans nigra is very light-demanding and does not tolerate shade, especially as a mature tree. Due to this low shade tolerance natural regeneration via seeds is rare. Across Europe, black walnut is preferably regenerated using 1-year-old seedlings that are at a minimum $30 \mathrm{~cm}$ tall. Young seedlings grow fast with up to $1 \mathrm{~m}$ per year. They start fruiting at about 8 to 10 years, when they are 7-8 $\mathrm{m}$ high. Substantial seed crops can be expected from 20-30 years onwards. In mixed stands they are cultivated with species like ashes (Fraxinus spp.), maple (Acer spp.) or oaks (Quercus spp.), where they grow faster than native species. Black walnut is also susceptible to pests and diseases. As black walnuts can cope with low winter temperatures (down to $-40^{\circ} \mathrm{C}$ ), there is low risk of frost damage. However, they are very sensitive to late frost in spring, which limits their distribution. Climate change is expected to increase its importance 
in various parts of Europe, since it is well adapted to drought and some limiting factors will no longer apply.

\section{Description}

Leaves: compound, even-pinnate, acuminate, 9-23 leaflets; alternate; serrated edge; dark-green, hairy underside.

Flowers: monoecious; male catkins drooping, $8-10 \mathrm{~cm}$; female flowers terminal, clusters of 2-5, appear before the male; self-compatible.

Fruits/seeds: greenish husk, corrugated nut, $8 \mathrm{~cm}$ diameter; ripen in October; dispersal by birds and rodents. Bark: grey-black, deeply furrowed into thin ridges. 
Populus x canadensis - "hybrid poplar"
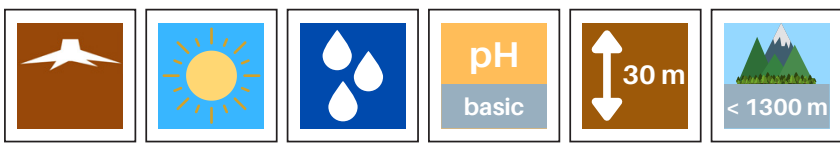

Poplar hybrid Populus $\mathrm{x}$ canadensis reaches over $30 \mathrm{~m}$ in height. It is a fast-growing tree with parent species $P$. nigra from Europe and $P$. deltoides from North America. Many varieties differ stronger in their growth performance as well as in their ecological requirements than in their morphology, which makes taxonomic identification very difficult. The hybrids provide adaptability to various soil and climate conditions as well as to some pests and diseases, which makes them attractive for forestry.

\section{Distribution, habitat and ecology}

Canadian poplars from North America were crossed by forestry towards the end of the $19^{\text {th }}$ century with various European poplar species. Populus $\mathrm{x}$ canadensis is cultivated and runs wild in many European countries. It requires well aerated and water-supplied eutrophic soils for good growth - sandy-loamy soil types in a $\mathrm{pH}$ range of 6.0 to 7.5 are favoured. Poplars are fast-growing trees that are very light-demanding when young and are therefore pioneers in colonising open areas. Bastard poplars can be found planted and growing wild, especially on floodplain sites, which are flooded during high water, but also on ruderal sites. In the area of silver willow floodplain, bastard poplars are not able to survive in the long term because of excessive flooding. Therefore, they are mainly planted on hardwood floodplains. Populus $\mathrm{x}$ canadensis is very capable of regeneration - after cutting it forms meter-long shoots in the first year. It reproduces vegetatively by root shoots from roots up to 35 $\mathrm{m}$ long. As there are no crossing barriers and bastard poplars are more common than black poplars, the latter have hardly any pure offspring.

Populus $\mathrm{x}$ canadensis is cultivated all over the Mura-Drava-Danube Biosphere Reserve from Austria to Serbia.

Forestry and climate change

Hybrid poplars were planted for timber production due to their uniform trunk - producing light, soft, diffuseporous wood. Due to their rapid growth, rotation, periods of 25 years are possible at good sites - recently, they have also been cultivated in extreme short rotations for energy production. The predicted climate change will favour the species hybrids, as on otherwise suitable sites, they can also survive droughts and other weather extremes.

In terms of forestry with hybrid poplars, the focus is on variety breeding, as diseases are a problem. Rust fungus infestation on leaves is the most important disease in poplars. Two fungal species from the genus Melampsora attack Populus x canadensis (M. allii-populina Kleb. and M. larici-populina Kleb.). Additionally, fungus Dothichiza populea colonizes branches already damaged by frost. It is a typical weakness parasite, which occurs more frequently in locations with fluctuating water balance or stagnant moisture. Only by constantly developing new varieties can such diseases be kept in check. Another problem for Populus canadensis is white mistletoe, Viscum album, which only affects hybrid poplars, not native black poplars.

\section{Description}

Leaves: sprouting leaves are reddish (green in black poplars) and hairy on the edges. Glands are often found at the base of leaf stalk. Mature leaves are triangular with a long, extended tip, 7-10 cm long and serrated to notched at the edges. The long petiole is laterally flattened.

Flowers: dioecious, male and female inflorescences are hanging catkins up to $9 \mathrm{~cm}$ long. Bastard poplars are mainly propagated as male clones.

Fruits/seeds: capsules, thick, pointed, greenish-brown, petiolate; seeds are hairy.

Bark: light-grey, fissured; horizontal cork bulges (different from black poplar). 


\section{Robinia pseudoacacia - black locust}
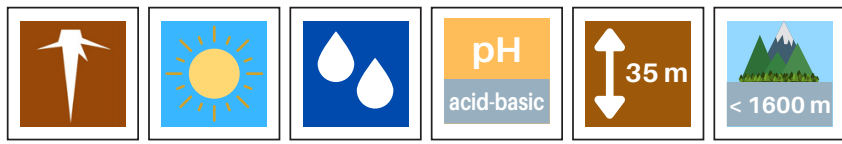

Black locust (Robinia pseudoacacia L.) is a fast-growing, medium-sized, deciduous tree, introduced to Europe from North America. It can grow up to $35 \mathrm{~m}$ high and lives about 60-100 years. The trunk mostly shows a strong curvature, but the wood is durable and resistant to insect damage. It is used for flooring and furniture, but also for outdoor use like boatbuilding or railway sleepers. Additionally, it can be used as firewood and for biomass production.

\section{Distribution, habitat and ecology}

The natural range of black locust is in eastern North America, particularly in the Appalachian Mountains to altitudes of $1,500 \mathrm{~m}$. It was introduced to Europe in the $17^{\text {th }}$ century, with widespread planting in the $18^{\text {th }}$ and $19^{\text {th }}$ centuries. Since then, it has become naturalised across the whole continent. Today it can be found from Portugal to the Caucasus and from Scandinavia to southern Italy. Robinia pseudoacacia is a light-demanding pioneer species, which grows in a variety of soil conditions from acidic $(\mathrm{pH} 3)$ to alkaline $(\mathrm{pH} 8)$. It tolerates dry and salty sites, but avoids wet (low inundation tolerance) and compacted locations. The favoured mean annual rainfall range is $700-2000 \mathrm{~mm}$. Black locust is very sensitive to frost and is a weak competitor in closed, shaded stands. In open areas, like forest edges or disturbed ground, it is very competitive. It can be found on very nutrient poor sites, since it forms a symbiotic relationship with rhizobia bacteria. This enables it to fix atmospheric nitrogen, thereby changing soil conditions also for other species. Profiting from this ability, it grows very fast when young. It begins flowering and producing seed as early as at the age of three, which makes it an important food source for insects like bees and butterflies.

Black locust can be found in all countries of the Mura-Drava-Danube Biosphere Reserve. It is the the most widespread tree species in Hungary, occupying approximately $24 \%$ of the forested land.

\section{Forests and climate change}

In some areas of Europe, the use of black locust in forestry has been strongly encouraged although it is considered a highly invasive tree species in Europe in several European databases. Due to its fast growth, high ability to reproduce via suckering and soil improving capacity, it can be used to recultivate brownfields such as former mining sites. However, this soil enrichment can also lead to the displacement of rare native species that depend on nutrient poor sites. In this way, black locust has the capability to change entire ecosystems. Management measures are expensive, labour and time-intensive. They focus on ringbarking because cutting the trees promotes regrowth. Therefore, its introduction should be well considered and the risks and benefits weighed beforehand. Where it is considered safe to plant and the silvicultural purpose is clearly defined, it can yield high-quality wood products with high impact resistance, tensile strength and durability without impregnation. As frost is a limiting factor, its distribution is expected to increase due to climate change and it might displace native species in their ecosystems and in forestry.

\section{Description}

leaves: composed, pinnate, 2-12 pairs, $10-30 \mathrm{~cm}$; leaf blades oblong, elliptic to ovate; opposite; pair of spines at base.

Flowers: monoecious, hermaphrodite; white to cream, yellow spots inside; grouped in pendent racemes, 10$20 \mathrm{~cm}$ long.

Fruits/Seeds: legume; dark brown pods, $5-10 \mathrm{~cm}$; 4-10 seeds; hanging in winter; dispersal via gravity and wind; fruiting 1-2/year.

Bark: greyish-brown to dark brown; becoming fissured longitudinally with age. 


\subsection{Glossary}

\begin{tabular}{|c|c|}
\hline Term & Explanation \\
\hline Adaptation & $\begin{array}{l}\text { The adjustment of organisms to their environment in order to improve their chances at } \\
\text { survival in that environment }\end{array}$ \\
\hline Allele & An allele is one of two or more versions of a gene or DNA region \\
\hline Autochthonous & $\begin{array}{l}\text { A population is considered autochthonous if it has developed characteristic properties } \\
\text { that distinguish it from other populations of the same species, without human influence. } \\
\text { Autochthonous populations are normally adapted to their habitats and can survive over } \\
\text { long periods under stable environmental conditions. The forest stands, which were } \\
\text { exclusively naturally regenerated in the past, are autochthonous. If artificial regeneration } \\
\text { is used, the stands are considered autochthonous only if forest reproductive material used } \\
\text { for regeneration was collected in the same stand or in adjacent autochthonous stands that } \\
\text { grow in the same site condition. }\end{array}$ \\
\hline $\begin{array}{l}\text { Bacterial ooze or } \\
\text { exudate }\end{array}$ & A sign of a bacterial infection being composed mostly of bacterial cells \\
\hline Canker & $\begin{array}{l}\text { A dead section on the bark of a stem or branch. It is caused by parasitic infection and it is } \\
\text { bounded by callus cells, which is a plant mechanism for healing wounds }\end{array}$ \\
\hline Coppice & $\begin{array}{l}\text { An area of forest in which the trees are periodically cut back to ground level to stimulate } \\
\text { growth to provide firewood or timber }\end{array}$ \\
\hline Dieback & A progressive death of twigs, branches, shoots, or roots, starting at the tips \\
\hline Enrichment planting & $\begin{array}{l}\text { A form of artificial regeneration, where natural regeneration is supplemented artificially by } \\
\text { planting a limited number of seedlings to enhance ecological, societal, or productive forest } \\
\text { functions }\end{array}$ \\
\hline $\begin{array}{l}\text { Forest reproductive } \\
\text { material }\end{array}$ & $\begin{array}{l}\text { Fruits, seeds and cones; all parts of plants obtained by vegetative propagation including } \\
\text { embryos; and plants produced from any of these }\end{array}$ \\
\hline Genetic diversity & Variation within a population or species that is attributable to differences in genes \\
\hline Genetic resources & $\begin{array}{l}\text { Genetic material of actual or potential value where genetic material means any material } \\
\text { containing functional units of heredity }\end{array}$ \\
\hline Girdling & $\begin{array}{l}\text { Removing a ring of the bark and cambium layer encircling the tree. The disrupt transport } \\
\text { of carbohydrates (removed phloem layer) from the assimilation organs to the roots kills a } \\
\text { tree very slowly over a longer period of time }\end{array}$ \\
\hline Interspecific & $\begin{array}{l}\text { Between different species } \\
\text { Within a species or between individuals of a single species }\end{array}$ \\
\hline
\end{tabular}




\begin{tabular}{|c|c|}
\hline Term & Explanation \\
\hline Natural selection & $\begin{array}{l}\text { One of the basic mechanisms of evolution, a process through which populations of living } \\
\text { organisms adapt and change; for natural selection to act on a population, there must } \\
\text { be variation in heritable traits (e.g. tree shape, susceptibility to disease), upon which } \\
\text { differential reproduction (some trees have a higher chance of producing offspring than } \\
\text { others) acts upon }\end{array}$ \\
\hline Necrotic lesion & A black, dead section on the bark of a stem or branch, but without callus formation \\
\hline Noble hardwood & $\begin{array}{l}\text { Tree species of the genera Juglans, Acer, Ulmus, Fraxinus, Tilia, Prunus, Sorbus, Malus and } \\
\text { Pyrus }\end{array}$ \\
\hline Population & $\begin{array}{l}\text { A group of individuals of the same species that live in a particular geographic area at } \\
\text { the same time and are capable of interbreeding. A large population can be divided into } \\
\text { several smaller groups, i.e. local populations, i.e. populations in a narrow sense, as sexual } \\
\text { reproduction only happens in such smaller groups. }\end{array}$ \\
\hline Rachis & Petiole and main vein of a leaf \\
\hline Undersowing & $\begin{array}{l}\text { Direct sowing of seeds under mature stands in order to initiate regeneration or supplement } \\
\text { the natural regeneration that is already present }\end{array}$ \\
\hline
\end{tabular}




\subsection{References by chapters}

\section{Case study: Stakeholder perspectives on riparian forest management and conservation in the Mura- Drava-Danube Biosphere Reserve}

1. Interreg Danube REFOCuS D6.1.1. (2019) Report on the overview of the national legislations of the five countries constituting Biosphere Reserve Mura-Drava-Danube and EU regulations and directives relevant for health, conservation and management of riparian forests.

2. Interreg Danube REFOCuS. WP6 Policy Interface. (2020). Report from the Online stakeholders workshop: How to harmonize forest management planning and nature conservation in riparian forests of Biosphere Reserve Mura-Drava-Danube?

3. Stevanov M, Tarjan Tobolka A, Kljajic L, Kičić M, Krott M (2021) Analysis of conflicting interests on the example of the special nature reserve in Serbia: empirically analytical approach. Šumarski list 145(3-4), 155-167. https://doi.org/10.31298/sl.145.3-4.5

\section{Importance of and threats to riparian forests}

1. Allard G, Sigaud P (2005). Alien Invasive Species: Impacts on Forests and Forestry - A Review. Forest Resources Development Service Working Paper FBS/8E Forest Resources Division FAO, Rome, Italy Forestry Department. Retrieved March 30, 2020, from hltp://www.fao.org/3/i6854e/J6854E06.htm

2. Arcanum (2017) Historical Maps of the Habsburg Empire First Military Survey 1763-1787. Österreichischen Staatsarchiv. Retrieved from http://mapire.eu/en/

3. Bastian O, Bernhardt A (1993) Anthropogenic landscape changes in Central Europe and the role of bioindication. Landscape Ecology 8(2) 139-151. https://doi.org/10.1007/BF00141593

4. Bebber DP (2015) Range-Expanding Pests and Pathogens in a Warming World. Annual Review of Phytopathology 53(1) 335356. https://doi.org/10.1146/annurev-phyto-080614-120207

5. Bonacci O, Oskorš D (2010) The changes in the lower Drava River water level, discharge and suspended sediment regime. Environmental Earth Sciences 59(8) 1661-1670. https://doi.org/10.1007/s12665-009-0148-8

6. Bonacci O, Oskoruš D (2008) The influence of three Croatian hydroelectric power plants operation on the river Drava hydrological and sediment regime. Hydrological Forecasting. Retrieved from

http://ksh.fgg.uni-li.si/bled2008/cd_2008/05_Floods, morphological processes, erosion, sediment transport and sedimentation/005_Bonacci.pdf

7. Boyd IL, Freer-Smith PH, Gilligan CA, Godfray HCJ (2013, November 15) The consequence of tree pests and diseases for ecosystem services. Science. American Association for the Advancement of Science. https://doi.org/10.1126/science.1235773

8. Charles H, Dukes JS (2007) Impacts of Invasive Species on Ecosystem Services. Biological Invasions (193) 293-310. https://doi.org/10.1007/978-3-540-36920-2

9. Dukes JS, Pontius J, Orwig D. et al. (2009) Responses of insect pests, pathogens, and invasive plant species to climate change in the forests of northeastern North America: What can we predict? This article is one of a selection of papers from NE Forests 2100: A Synthesis of Climate Change Impacts on Forests of the Northeastern US and Eastern Canada. Canadian Journal of Forest Research 39(2) 231-248. https://doi.org/10.1139/X08-171

10. Dyakov NR (2019) Testing for assembly rules along disturbance gradients in a riparian broadleaved forest. Applied Ecology \& Environmental Research 17(1) 1-13. https://doi.org/10.15666/aeer/1701

11. Dyderski MK, Paź S, Frelich LE, Jagodziński AM (2018) How much does climate change threaten European forest tree species distributions? Global Change Biology 24(3) 1150-1163. https://doi.org/10.1111/gcb.13925

12. EIONET (2020) (No Title). Retrieved January 14, 2021, from hlttps://www.eionet.europa.eu/article17/

13. European Commission. EUR-Lex - 52020DC0380 - EN - EUR-Lex (2020). Brussels. Retrieved from https://eur-lex.europa.eu/legal-content/EN/TXT/?qid=1590574123338\&uri=CELEX:52020DC0380

14. Floods and River Management - The British Geographer. (n.d.). Retrieved April 7, 2020, from http://thebritishgeographer:weebly.com/floods-and-river-management.html

15. Forest Europe (2021) About Forest Europe - Forest Europe. Retrieved January 14, 2021, from https://foresteurope.org/foresteurope/

16. FOREST EUROPE, Liaison Unit Bratislava (2019) Human Health and Sustainable Forest Management. Marušáková L' and Sallmannshofer M (ed.) FOREST EUROPE Study.

https:// foresteurope.org/new-forest-europ-publication-human-health-sustainable-forest-management/

17. Globevnik L, Kaligaric M (2005) Hydrological changes of the Mura River in Slovenia, accompanied with habitat deterioration in riverine space. RMZ - Materials and Geoenvironment 52(1) 45-49.

18. Habersack H (2016) Wasserbau, Schifffahrt und Ökologie an der Donau - Pilotprojekt Bad Deutsch-Altenburg. Osterreichische Wasser- und Abfallwirtschaft 68(5-6) 190-192. https://doi.org/10.1007/s00506-016-0316-5

19. Hansen EM (2008) Alien forest pathogens: Phytophthora species are changing world forests. Boreal Environment Research 13(SUPPL. A) 33-41. 
20. Hulme PE (2009) Trade, transport and trouble: managing invasive species pathways in an era of globalization. Journal of Applied Ecology 46(1) 10-18. https://doi.org/10.1111/j.1365-2664.2008.01600.x

21. IPCC (2019) Climate change and land. Intergovernmental Panel on Climate Change Special Report on Climate Change, Desertification, Land Degradation, Sustainable Land Management, Food Security, and Greenhouse gas fluxes in Terrestrial Ecosystems. https://www.ipcc.ch/srcel/

22. Jungwirth M, Muhar S, Schmutz S (2002) Re-establishing and assessing ecological integrity in riverine landscapes. Freshwater Biology 47(4) 867-887. https://doi.org/10.1046/j.1365-2427.2002.00914.X

23. Kautz M, Meddens AJH, Hall RJ, Arneth A (2017) Biotic disturbances in Northern Hemisphere forests - a synthesis of recent data, uncertainties and implications for forest monitoring and modelling. Global Ecology and Biogeography. Blackwell Publishing Ltd. https://doi.org/10.1111/geb.12558

24. Kevey B (2018) Floodplain forests. In Springer Geography (Vol. PartF5, pp. 299-336). https://doi.org/10.1007/978-3-319-92816-6_ 18

25. Klimo E, Hager H, Matič S, Anič I, Kulhavý J (2008) Floodplain forests of the temperate zone of Europe, Lesnická Práce 623p

26. Kwak TJ, Naiman RJ, Bilby RE (2000) Pacific Coastal River Ecology and ManagementRiver Ecology and Management: Lessons from the Pacific Coastal Ecoregion. Ecology 81(3) 882. https://doi.org/10.2307/177387

27. Leyer I, Mosner E, Lehmann B (2012) Managing floodplain-forest restoration in European river landscapes combining ecological and flood-protection issues. Ecological Applications 22(1) 240-249. https://doi.org/10.1890/11-0021.1

28. Lundström J, Öhman K, Laudon H (2018) Buffer zone alternatives in forest planning using a decision support system.

Scandinavian Journal of Forest Research 33(5) 493-501. https://doi.org/10.1080/02827581.2018.1441900

29. Meyerson LA, Mooney HA (2007) Invasive alien species in an era of globalization. Frontiers in Ecology and the Environment 5(4) 199-208. https://doi.org/10.1890/1540-9295(2007)5[199:IASIAE]2.0.CO;2

30. Millennium Ecosystem Assessment (2005) Ecosystem and human well-being: wetlands and water Synthesis. (N. D. C. Max Finlayson, Rebecca D'Cruz, Ed.). World Resources Institute.

31. Monclus R, Dreyer E, Villar M et al. (2006). Impact of drought on productivity and water use efficiency in 29 genotypes of Populus deltoides x Populus nigra. New Phytologist 169(4) 765-777. https://doi.org/10.1111/j.1469-8137.2005.01630.x

32. Mosner E, Liepelt S, Ziegenhagen B, Leyer I (2012) Floodplain willows in fragmented river landscapes: Understanding spatiotemporal genetic patterns as a basis for restoration plantings. Biological Conservation 153 211-218. https://doi.org/10.1016/j.biocon.2012.05.005

33. Nadal-Sala D, Hartig F, Gracia CA, Sabaté S (2019) Global warming likely to enhance black locust (Robinia pseudoacacia L.) growth in a Mediterranean riparian forest. Forest Ecology and Management 449 117448. https://doi.org/10.1016/j.foreco.2019.117448

34. Nagy RC, Porder S, Neill C, Brando P, Quintino RM, Do Nascimento SA (2015) Structure and composition of altered riparian forests in an agricultural Amazonian landscape. Ecological Applications 25(6) 1725-1738. https://doi.org/10.1890/14-1740.1

35. Netsvetov M, Prokopuk Y, Puchałka R, Koprowski M (2019) River Regulation Causes Rapid Changes in Relationships Between Floodplain Oak Growth and Environmental Variables 10(February) 1-11. https://doi.org/10.3389/fpls.2019.00096

36. Nilsson C, Berggren K (2000) Alterations of Riparian Ecosystems Caused by River Regulation. BioScience 50(9) 783. https://doi.org/10.1641/0006-3568(2000)050[0783:aorecb]2.0.c0;2

37. Nilsson C, Berggren K (2000) Effects of dams and regulations on riparian zones. BioScience 50(9) 783. Retrieved from https://academic.oup.com/bioscience/article-abstract/50/9/783/269505

38. Nisbet D, Kreutzweiser D, Sibley P, Scarr T (2015) Ecological risks posed by emerald ash borer to riparian forest habitats: A review and problem formulation with management implications. https://doi.org/10.1016/j.foreco.2015.08.030

39. OJEC. (1992). EUR-Lex - 31992L0043 - EN - EUR-Lex. Retrieved January 14, 2021, from https://eur-lex.europa.eu/legal-content/EN/ TXT/?uri=celex\%3A31992L0043

40. Onaindia M, Fernández de Manuel B, Madariaga I, Rodríguez-Loinaz G (2013) Co-benefits and trade-offs between biodiversity, carbon storage and water flow regulation. Forest Ecology and Management 289 1-9. https://doi.org/10.1016/j;foreco.2012.10.010

41. Planty-Tabacchi A-M, Tabacchi E, Naiman RJ, Deferrari C, Decamps H (1996) Invasibility of Species-Rich Communities in Riparian Zones. Conservation Biology 10(2) 598-607.https://doi.org/10.1046/j.1523-1739.1996.10020598.x

42. Pureswaran DS, Roques A, Battisti A (2018) Forest Insects and Climate Change. Curr Forestry Rep 4 35-50. https://doi.org/10.1007/s40725-018-0075-6

43. Ramsfield TD, Bentz BJ, Faccoli M, Jactel H, Brockerhoff EG (2016) Forest health in a changing world: effects of globalization and climate change on forest insect and pathogen impacts. https://doi.org/10.1093/forestry/cpw018

44. Regier N, Streb S, Cocozza C, Schaub M, Cherubini P, Zeeman SC, Frey B (2009) Drought tolerance of two black poplar (Populus nigra L.) clones: Contribution of carbohydrates and oxidative stress defence. Plant, Cell and Environment 32(12) 1724-1736. https://doi.org/10.1111/j.1365-3040.2009.02030.x

45. Richardson DM, Holmes PM, Esler KJ et al. (2007) Riparian vegetation: degradation, alien plant invasions, and restoration prospects. Diversity and Distributions 13(1) 126-139. https://doi.org/10.1111/j.1366-9516.2006.00314.X 
46. Roder G, Sofia G, Wu Z, Tarolli P (2017). Assessment of Social Vulnerability to floods in the floodplain of northern Italy. Weather, Climate, and Society, 9(4), 717-737. https://doi.org/10.1175/WCAS-D-16-0090.1

47. Rosenberg DM, Berkes F, Bodaly RA, Hecky RE, Kelly CA, Rudd JWM (1997) Large-scale impacts of hydroelectric development. Environmental Reviews 5(1) 27-54. https://doi.org/10.1139/er-5-1-27

48. Sanjou M, Okamoto T, Nezu I (2018) Experimental study on fluid energy reduction through a flood protection forest. Journal of Flood Risk Management 11(4) e12339. https://doi.org/10.1111/ffr3.12339

49. Schnitzler A, Hale BW, Alsum E (2005) Biodiversity of floodplain forests in Europe and eastern North America: A comparative study of the Rhine and Mississippi Valleys. Biodiversity and Conservation 14(1) 97-117 https://doi.org/10.1007/s10531-005-4056-2

50. Schnitzler A, Hale BW, Alsum EM (2007) Examining native and exotic species diversity in European riparian forests. Biological Conservation 138(1-2) 146-156. https://doi.org/10.1016/ibiocon.2007.04.010

51. Seidl R, Thom D, Kautz M et al. (2017, June 1). Forest disturbances under climate change. Nature Climate Change. Nature Publishing Group. https://doi.org/10.1038/nclimate3303

52. Sikorska D, Sikorski P, Archiciński P, Chormański J, Hopkins RJ (2019) You Can’t See the Woods for the Trees: Invasive Acer negundo L. in Urban Riparian Forests Harms Biodiversity and Limits Recreation Activity. Sustainability 11(20) 5838.

https://doi.org/10.3390/sul1205838

53. Smulders MJM, Cottrell J, Lefèvre F et al. (2008) Structure of the genetic diversity in black poplar (Populus nigra L.) populations across European river systems: Consequences for conservation and restoration. Forest Ecology and Management 255 1388-1399. https://doi.org/10.1016/j.foreco.2007.10.063

54. Spinoni J, Naumann G, Vogt JV (2017) Pan-European seasonal trends and recent changes of drought frequency and severity. Global and Planetary Change 148 113-130. https://doi.org/10.1016/.jgloplacha.2016.11.013

55. Stagge JH, Kingston DG, Tallaksen LM, Hannah DM (2017) Observed drought indices show increasing divergence across Europe. Scientific Reports 7(1) 1-10. https://doi.org/10.1038/s41598-017-14283-2

56. Sturrock RN, Frankel SJ, Brown AV et al. (2011). Climate change and forest diseases. Plant Pathology. https://doi.org/10.1111/j.1365-3059.2010.02406.X

57. Thompson I, Mackey B, McNulty S, Mosseler A (2009) Forest Resilience, Biodiversity, and Climate Change: a synthesis of the biodiversity/resilience/stability relationship in forest ecosystems. Secretariat of the Convention on Biological Diversity, Montreal. Technical Series no. 43. Secretariat of the Convention on Biological Diversity (Vol. 43)

58. Tiwari T, Lundström J, Kuglerová L, Laudon H, Öhman K, Ågren AM (2016) Cost of riparian buffer zones: A comparison of hydrologically adapted site-specific riparian buffers with traditional fixed widths. Water Resources Research 52(2) 1056-1069 https://doi.org/10.1002/2015WR018014

59. Tockner K, Stanford JA (2002) Riverine flood plains: Present state and future trends. Environmental Conservation 29(3) 308330. https://doi.org/10.1017/S037689290200022X

60. UNESCO (n.d.) Convention on Wetlands of International Importance especially as Waterfowl Habitat. 1971. Retrieved January 14, 2021, from http://portal.unesco.org/en/ev.php-URL ID=15398\&URL DO=DO TOPIC\&URL SECTION=201.html

61. van Lierop P, Lindquist E, Sathyapala S, Franceschini G (2015) Global forest area disturbance from fire, insect pests, diseases and severe weather events. Forest Ecology and Management 352 78-88. https://doi.org/10.1016/j.foreco.2015.06.010

62. Vilà M, Hulme PE (2017) Non-native Species, Ecosystem Services, and Human Well-Being. In Impact of Biological Invasions on Ecosystem Services (pp. 1-14). Springer International Publishing. https://doi.org/10.1007/978-3-319-45121-3_1

63. Von Holle B, Simberloff D (2005) Ecological resistance to biological invasion overwhelmed by propagule pressure. Ecology 86(12) 3212-3218. https://doi.org/10.1890/05-0427

64. Wraber M (1951) Gozdna vegetacijska slika in gozdnogojitveni problemi Prekmurja. Geografski vestnik, 23, 179-230

65. Zedler JB, Kercher S (2004) Causes and consequences of invasive plants in wetlands: Opportunities, opportunists, and outcomes. Critical Reviews in Plant Sciences 23(5) 431-452. https://doi.org/10.1080/07352680490514673

\section{Managing riparian forest ecosystems}

1. Bentrup G (2008) Conservation buffers: design guidelines for buffers, corridors, and greenways. Asheville. Gen. Tech. Rep. SRS109. Asheville, NC: U.S. Department of Agriculture, Forest Service, Southern Research Station. 110 p. https://www.srs.fs.usda.gov/pubs/33522

2. Connell JH (1978) Diversity in tropical rain forests and coral reefs. Science 199(4335) 1302-1310. https://doi.org/10.1126/ science.199.4335.1302

3. Dakskobler I, Kutnar L, Šilc U (2013) Poplavni, močvirni in obrežni gozdovi v Sloveniji: gozdovi vrb, jelš, dolgopecljatega bresta, velikega in ozkolistnega jesena, doba in rdečega bora ob rekah in potokih. Silva Slovenica, Gozdarski inštitut Slovenije. http://eprints.gozdis.si/id/eprint/477

4. Environment Canada (2013) How much environment is enough? Third edition. Toronto. 
5. Forman RT (1995) Land Mosaics: The Ecology of Landscapes and Regions. Cambridge University Press.

6. Forman RT, Godron M (1989) Landscape ecology. Environmental Conservation 16(1) 619. https://doi.org/10.1017/ $\underline{\text { S0376892900008766 }}$

7. Kapos V, Lysenko I (2000) Assessing forest integrity and naturalness in relation to biodiversity. Retrieved January 14, 2021, from https://www.researchgate.net/publication/242321742 Assessing forest integrity and naturalness in relation to biodiversity

8. Karr JR, Dudley DR (1981) Ecological perspective on water quality goals. Environmental Management, 5(1) 55-68. https://doi.org/10.1007/BF01866609

9. Kovač M, Ferreira A (ed) (2017) Vzorčni upravljavski načrt za gozdna območja Natura 2000 - primer poplavnih gozdov ob Muri. Ljubljana. Gozdarski inštitut Slovenije.

10. Kovač M, Kutnar L, Hladnik D (2016) Assessing biodiversity and conservation status of the Natura 2000 forest habitat types: Tools for designated forestlands stewardship. Forest Ecology and Management 359 256-267. https://doi.org/10.1016/j.foreco.2015.10.011

11. Kutnar L, Marinšek A (2016) Stanje raziskovanih gozdnih habitatnih tipov ob Muri. In: Ferreira A, Planinšek S (ed), GoForMura: upravljanje gozdnih habitatnih tipov in vrst v izbranih območjih Natura 2000 ob Muri. Silva Slovenica, Gozdarski inštitut Slovenije. https://doi.org/10.20315/sfs.149

12. Maurer BA (1993) Biological diversity, ecological integrity, and neotropical migrants: new perspectives for wildlife management. In: Finch, Deborah M.; Stangel, Peter W. (eds.). Status and management of neotropical migratory birds: September 21-25, 1992, Estes Park, Colorado. Gen. Tech. Rep. RM-229. Fort Collins, Colo.: Rocky Mountain Forest and Range Experiment Station, U.S. Dept. of Agriculture, Forest Service: 24-31 https://www.fs.usda.gov/treesearch/pubs/22884

13. Noss RF (1990) Indicators for Monitoring Biodiversity: A Hierarchical Approach. Conservation Biology. https://doi.org/10.1111/j.1523-1739.1990.tb00309.x

14. Parrish JD, Braun DP, Unnasch RS (2003) Are we conserving what we say we are? Measuring ecological integrity within protected areas. BioScience. American Institute of Biological Sciences. https://doi.org/10.1641/0006-3568 (2003)053[0851:AWCWWS]2.0.CO;2

15. Roberts MR, Gilliam FS (1995) Patterns and mechanisms of plant diversity in forested ecosystems: Implications for forest management. Ecological Applications 5(4) 969-977. https://doi.org/10.2307/2269348

16. Sallmannshofer M, Chakraborty D, Vacik H et al. (2021) Continent-Wide Tree Species Distribution Models May Mislead Regional Management Decisions: A Case Study in the Transboundary Biosphere Reserve Mura-Drava-Danube. Forests 12330. https://doi.org/10.3390/f12030330

17. Schlaepfer R (1997) Ecosystem-based management of natural resources: a step towards sustainable development. Retrieved from https://bibliotecadigitalinfor.cl/handle/20.500.12220/5660

18. Yachi S, Loreau M (1999) Biodiversity and ecosystem productivity in a fluctuating environment: The insurance hypothesis. Proceedings of the National Academy of Sciences of the United States of America 96(4) 1463-1468. https://doi.org/10.1073/pnas.96.4.1463

\section{Structure and ecology of a riverine floodplain landscape}

1. Bayley PB (1995) Understanding Large River: Floodplain Ecosystems. BioScience 45(3) 153-158. https://doi.org/10.2307/1312554

2. Čater M, Levanič T (2015) Physiological and growth response of Quercus robur in Slovenia. Dendrobiology 74 3-12. https://doi.org/10.12657/denbio.074.001

3. Dakskobler I, Kutnar L, Šilc U (2013) Poplavni, močvirni in obrežni gozdovi v Sloveniji: gozdovi vrb, jelš, dolgopecljatega bresta, velikega in ozkolistnega jesena, doba in rdečega bora ob rekah in potokih. Silva Slovenica, Gozdarski inštitut Slovenije. http://eprints.gozdis.si/id/eprint/477

4. Forman RT (1995) Land Mosaics: The Ecology of Landscapes and Regions. Cambridge University Press.

5. Hager H, Schume H, Tiefenbacher H, Buchleitner E (2007) Forest Management Systems and Regeneration. In P. Hobza (Ed.), Forest management systems and regeneration of floodplain forest sites: reviewed proceedings from the international conference (pp. 41-60). Brno: Mendel University of Agriculture and Forestry, Czech Forest Society.

6. Langhans SD, Tiegs SD, Gessner MO, Tockner K (2008) Leaf-decomposition heterogeneity across a riverine floodplain mosaic. Aquatic Sciences 70 337-346. https://doi.org/10.1007/s00027-008-8062-9

7. Tumajer J, Treml V (2016) Response of floodplain pedunculate oak (Quercus robur L.) tree-ring width and vessel anatomy to climatic trends and extreme hydroclimatic events. Forest Ecology and Management 379 185-194.

https://doi.org/10.1016/i.foreco.2016.08.013

8. Ward JV, Tockner K, Arscott DB, Claret C (2002) Riverine landscape diversity. Freshwater Biology 47(4) 517-539.

https://doi.org/10.1046/j.1365-2427.2002.00893.x 


\section{Forest habitat types}

1. Dakskobler I, Kutnar L, Šilc U (2013) Poplavni, močvirni in obrežni gozdovi v Sloveniji: gozdovi vrb, jelš, dolgopecljatega bresta, velikega in ozkolistnega jesena, doba in rdečega bora ob rekah in potokih. Silva Slovenica, Gozdarski inštitut Slovenije.

http://eprints.gozdis.si/id/eprint/477

2. Dobrovolný L (2014) Potential of natural regeneration of Quercus robur L. in floodplain forests in the southern part of the Czech Republic. Journal of Forest Science 60(12) 534-539. https://doi.org/10.17221/83/2014-jfs

3. EIONET. (2020). (No Title). Retrieved January 14, 2021, from https://www.eionet.europa.eu/article17/

4. European Commission (2013) Interpretation Manual of European Union Habitats, version EUR 28.DG Environment http://ec.europa.eu/environment/nature/legislation/habitatsdirective/docs/Int_Manual_EU28.pdf

5. Hager H, Schume H, Tiefenbacher H, Buchleitner E (2007) Forest Management Systems and Regeneration. In P. Hobza (Ed.), Forest management systems and regeneration of floodplain forest sites: reviewed proceedings from the international conference (pp. 41-60). Brno: Mendel University of Agriculture and Forestry, Czech Forest Society.

6. Marinšek A, Kutnar L (2017) Occurrence of invasive alien plant species in the floodplain forests along the Mura River in Slovenia. Periodicum Biologorum 119(4) 251-260. https://doi.org/10.18054/pb.v119i4.4933

7. Milanović Đ, Brujić J, Đug S, Muratović E, Lukić Bilela L (2015) Vodič kroz tipove staništa BiH prema Direktivi o staništima EU. Prospect C\&S, Brussels https://www.researchgate.net/publication/290770268_Vodic_kroz tipove_stanista_BiH_prema_Direktivi___stanistima_EU

8. Mölder A, Meyer P, Nagel RV (2019) Integrative management to sustain biodiversity and ecological continuity in Central European temperate oak (Quercus robur, Q. petraea) forests: An overview. Forest Ecology and Management 437 324-339. https://doi.org/10.1016/ifforeco.2019.01.006

9. Plišo Vusić I, Šapić I, Vukelić J (2019) Prepoznavanje i kartiranje šumskih staništa Natura 2000 u Hrvatskoj (I) - 91E0*, aluvijalne šume s crnom johom Alnus glutinosa i običnim jasenom Fraxinus excelsior (Alno-Padion, Alnion incanae, Salicion albae) Identification and mapping of Natura 2000 fore. Šumarski list 143(5-6) 255-263. https://doi.org/10.31298/sl.143.5-6.7

10. Plišo Vusić I, Šapić I, Vukelić J (2019) Prepoznavanje i kartiranje šumskih staništa Natura 2000 u Hrvatskoj (II) - 91F0, poplavne šume s vrstama Quercus robur, Ulmus laevis, Ulmus minor, Fraxinus angustifolia; 91L0, hrastovo-grabove šume ilirskoga područja. Šumarski list 143(9-10) 461-467. https://doi.org/10.31298/sl.143.9-10.7

11. Schütz JP, Saniga M, Diaci J, Vrška T (2016) Comparing close-to-nature silviculture with processes in pristine forests: lessons from Central Europe. Annals of Forest Science 73 911-921. https://doi.org/10.1007/s13595-016-0579-9

12. Viher, E (2011) Uspešnost saditve nižinskih dobovih sestojev v Prekmurju / Efficiency of planting lowland forest stands of Pedunculate oak in Prekmurje. Graduation thesis, University in Ljubljana https://repozitorij.uni-li.si/IzpisGradiva.php?id=16025

13. Ward JV, Tockner K, Arscott DB, Claret C (2002) Riverine landscape diversity. Freshwater Biology 47(4) 517-539. https://doi.org/10.1046/j.1365-2427.2002.00893.x

\section{Common forest management forms in riparian forests}

1. Buckley R, Castley J, Pegas F, Mossaz A, Steven R (2012) A population accounting approach to assess tourism contributions to conservation of IUCN-Redlisted mammal species. PLoS ONE, 7(9) e44134. https://doi.org/10.1371/journal.pone.0044134

2. Čater M, Kutnar L, Accetto M (2001) Slovenian lowland and floodplain forests. In Klimo E, Hager H (ed) The Floodplain forests in Europe. European Forestry Institute 233-248.

3. Fujimori $\mathrm{T}$ (2001) Silvicultural Strategies for Sustainable Forest Management. In Ecological and Silvicultural Strategies for Sustainable Forest Management. Elsevier Science

4. Johann E (2007) Traditional forest management under the influence of science and industry: The story of the alpine cultural landscapes. Forest Ecology and Management 249(1-2) 54-62. https://doi.org/10.1016/i.foreco.2007.04.049

5. KIB (1929) Privredni planovi za područje šumske uprave Dolnja Lendava za Gospodarstvene jedinice: Kobilje-Bukovnica, Dobrovnik, Crni lug, Redič-Sv. Mikluš, Murska šuma. 1929 - 1938. Direkcija šuma Križevačke imovne občine u Bjelovaru.

6. Machar I (2009) Coppice-with-standards in floodplain forests - a new subject for nature protection. J. For. Sci. 55 306-311. https://doi.org/10.17221/87/2008-jfs

7. Mosandl R, Summa J, Stimm B (2010) Coppice-With-Standards: Management Options for an Ancient Forest System. Forestry Ideas 16(1)

8. Müllerová J, Szabó P, Hédl R (2014) The rise and fall of traditional forest management in southern Moravia: A history of the past 700 years. Forest Ecology and Management 331 104-115. https://doi.org/10.1016/iforeco.2014.07.032

9. Peterken GF (1996) Natural woodland: ecology and conservation in northern temperate regions. Cambridge University Press, Cambridge

10. Piussi P (2006) Close to nature forestry criteria and coppice management. In Diaci J (ed) Nature-based forestry in central Europe: alternatives to industrial forestry and strict preservation. University of Ljubljana, Ljubljana, pp 27-37

11. Schütz J-Ph (2002) Die Plenterung und ihre unterschiedlichen Formen. Skript zu Vorlesung Waldbau II und Waldbau IV. ETH Zentrum, Zürich 
12. Vild O, Roleček J, Hédl R, Kopecký M, Utinek D (2013) Experimental restoration of coppice-with-standards: Response of understorey vegetation from the conservation perspective. Forest Ecology and Management 310 234-241.

https://doi.org/10.1016/i.foreco.2013.07.056

\section{Choosing natural or artificial regeneration}

1. Brundu G, Pauchard A, Pyšek P et al. (2020) Global guidelines for the sustainable use of non-native trees to prevent tree invasions and mitigate their negative impacts. NeoBiota 61 65-116 https://doi.org/10.3897/neobiota.61.58380

2. Medved M, Bajc M, Božič G et al. (2013) Gospodarjenje z gozdom za lastnike gozdov. Ljubljana: Kmečki glas, 2013,311 pp.

3. REFOCuS output O3.1: http://www.interreg-danube.eu/uploads/media/approved project_output/0001/38/f96aa53b7b6e761e140aceb8d49a014449ab1076.pdf

\section{Supporting adaptation of forests by selecting suitable forest reproductive material}

1. Aitken SN, Bemmels JB (2016) Time to get moving: Assisted gene flow of forest trees. Evolutionary Applications. https://doi.org/10.1111/eva.12293

2. Aitken SN, Yeaman S, Holliday JA et al. (2008) Adaptation, migration or extirpation: climate change outcomes for tree populations. Evolutionary Applications 1(1) 95-111. https://doi.org/10.1111/j.1752-4571.2007.00013.x

3. Arnell NW, Gosling SN (2016) The impacts of climate change on river flood risk at the global scale. Climatic Change 134(3) 387401. https://doi.org/10.1007/s10584-014-1084-5

4. Bebber DP (2015) Range-Expanding Pests and Pathogens in a Warming World. Annual Review of Phytopathology 53(1) 335356. https://doi.org/10.1146/annurev-phyto-080614-120207

5. Bergot M, Cloppet E, Pérarnaud V et al. (2004) Simulation of potential range expansion of oak disease caused by Phytophthora cinnamomi under climate change. Global Change Biology 10(9) 1539-1552. https://doi.org/10.1111/j.1365-2486.2004.00824.X

6. Blöschl G, Hall J, Viglione A et al. (2019, September 5) Changing climate both increases and decreases European river floods. Nature. https://doi.org/10.1038/s41586-019-1495-6

7. Dottori F, Szewczyk W, Ciscar JC et al. (2018) Increased human and economic losses from river flooding with anthropogenic warming. Nature Climate Change. https://doi.org/10.1038/s41558-018-0257-z

8. Dubrovský M, Hayes M, Duce P, Trnka M, Svoboda M, Zara P (2014) Multi-GCM projections of future drought and climate variability indicators for the Mediterranean region. Regional Environmental Change 14(5) 1907-1919 https://doi.org/10.1007/s10113-013-0562-z

9. Dyderski MK, Paź S, Frelich LE, Jagodziński AM (2018) How much does climate change threaten European forest tree species distributions? Global Change Biology 24(3) 1150-1163. https://doi.org/10.1111/gcb.13925

10. Frank A, Howe GT, Sperisen C et al. (2017) Risk of genetic maladaptation due to climate change in three major European tree species. Global Change Biology. https://doi.org/10.1111/gcb.13802

11. Hanel M, Rakovec O, Markonis Y et al. (2018) Revisiting the recent European droughts from a long-term perspective. Scientific Reports. https://doi.org/10.1038/s41598-018-27464-4

12. Jump AS, Peñuelas J (2005) Running to stand still: Adaptation and the response of plants to rapid climate change. Ecology Letters 8(9) 1010-1020. https://doi.org/10.1111/j.1461-0248.2005.00796.x

13. Kautz M, Meddens AJH, Hall RJ, Arneth A (2017) Biotic disturbances in Northern Hemisphere forests - a synthesis of recent data, uncertainties and implications for forest monitoring and modelling. Global Ecology and Biogeography.

https://doi.org/10.1111/geb.12558

14. Nadal-Sala D, Hartig F, Gracia CA, Sabaté S (2019) Global warming likely to enhance black locust (Robinia pseudoacacia L.) growth in a Mediterranean riparian forest. Forest Ecology and Management 449 117448. https://doi.org/10.1016/j.foreco.2019.117448

15. Pureswaran DS, Roques A, Battisti A (2018) Forest Insects and Climate Change. Curr Forestry Rep $435-50$. https://doi.org/10.1007/s40725-018-0075-6

16. Rehfeldt GE, Tchebakova NM, Parfenova YI et al. (2002) Intraspecific responses to climate in Pinus sylvestris. Global Change Biology. https://doi.org/10.1046/j.1365-2486.2002.00516.x

17. Schueler S, Falk W, Koskela J et al. (2014) Vulnerability of dynamic genetic conservation units of forest trees in Europe to climate change. Global Change Biology 20(5) 1498-1511. https://doi.org/10.1111/gcb.12476

18. Seidl R, Thom D, Kautz M, et al. (2017) Forest disturbances under climate change. Nature Clim Change $7395-402$ (2017) https://doi.org/10.1038/nclimate3303

19. Sperisen C, Pluess A, Arend M et al. (2016) Erhaltung genetischer Ressourcen im Schweizer Wald — heutige Situation und Handlungsbedarf angesichts des Klimawandels (pp. 367-383)

20. Spinoni J, Naumann G, Vogt JV (2017) Pan-European seasonal trends and recent changes of drought frequency and severity. Global and Planetary Change 148 113-130. https://doi.org/10.1016/j.gloplacha.2016.11.013 


\section{APPENDIX}

21. Stagge JH, Kingston DG, Tallaksen LM et al. (2017) Observed drought indices show increasing divergence across Europe. Scientific Reports 7(1) 1-10. https://doi.org/10.1038/s41598-017-14283-2

22. Sturrock RN, Frankel SJ, Brown AV et al. (2011) Climate change and forest diseases. Plant Pathology. https://doi.org/10.1111/i.1365-3059.2010.02406.x

23. Takolander A, Hickler T, Meller L, (2019) Comparing future shifts in tree species distributions across Europe projected by statistical and dynamic process-based models. Regional Environmental Change 19(1) 251-266. https://doi.org/10.1007/s10113-018-1403-x

24. Thompson I, Mackey B, McNulty S, Mosseler A (2009) Forest Resilience, Biodiversity, and Climate Change: a synthesis of the biodiversity/resilience/stability relationship in forest ecosystems. Technical Series no. 43. Secretariat of the Convention on Biological Diversity, Montreal

25. van Lierop P, Lindquist E, Sathyapala S, Franceschini G (2015) Global forest area disturbance from fire, insect pests, diseases and severe weather events. Forest Ecology and Management 352 78-88 https://doi.org/10.1016/j.foreco.2015.06.010

26. Winsemius HC, Aerts JCJH, Van Beek LPH et al. (2016) Global drivers of future river flood risk. Nature Climate Change 6(4) 381-385. https://doi.org/10.1038/nclimate2893

\section{Regeneration of pedunculate oak stands: natural and with direct sowing}

1. Bodor L (1991) Hagyomány és korszerűség az ormánsági síkvidéki kocsányos tölgyesek felújításában [Tradition and modernity in the regeneration of pedunculate oaks in the Ormánság lowlands]. Erdészeti lapok 126(2) 48-50 (in Hungarian)

2. Kovács A, Lajtos J, Sipos S, Veszeli J (2018) Az intenzíven terjedő fafajok tömeges térfoglalása a Gemenc Zrt. kezelésében lévő hullámtéren [Mass space occupation of intensively spreading tree species in the floodplain managed by Gemenc Zrt.]. Erdészeti lapok 153(6) 181-185 (in Hungarian)

3. Sipos S, Fodermayer V, Veszeli J (2016) Ártéri erdők és természetes felújítás Gemencen [Riparian forests and natural renovation in Gemenc]. Erdészeti lapok 151(6) 187-190 (in Hungarian)

\section{Supplemental enrichment, restoration and establishment of oak stands via artificial regeneration}

1. Saha S, Kuehne C, Bauhus J (2013) Tree species richness and stand productivity in low-density cluster plantings with oaks (Quercus robur L. and Q. petraea (Mattuschka) Liebl.). Forests 4:650-665

2. Saha S, Kuehne C, Kohnle U, et al. (2012) Growth and quality of young oaks (Quercus robur and Q. petraea) grown in cluster plantings in central Europe: a weighted meta-analysis. For Ecol Manag 283:106-118

\section{Biodiversity and Conservation management goals}

1. Bayrak MM, Marafa LM (2016) Ten years of REDD+: A critical review of the impact of REDD+ on forest-dependent communities. Sustainability 8(7) 620 .

2. CBD (2010) Strategic plan for biodiversity 2011-2020 and the Aichi targets. In Report of the Tenth Meeting of the Conference of the Parties to the Convention on Biological Diversity.

3. FOREST EUROPE (2015): State of Europe's Forests 2015. Status and Trends in Sustainable Forest Management in Europe.

4. Wagner M (2018) Transboundary Mura-Drava-Danube Action Plan.

\section{Literature recommendations}

1. Chirici G et al. (2012) National forest inventory contributions to forest biodiversity monitoring. For. Sci. 58:257-268

2. Coote $\mathrm{L}$ et al. (2013) Testing indicators of biodiversity for plantation forests. Ecol. Indic. 32:107-115

3. Gao T, Hedblom M, Emilsson T, Nielsen AB (2014) The role of forest stand structure as biodiversity indicator. For. Ecol. Manage. 330:82-93

4. Gao T, Nielsen AB, Hedblom $\mathrm{M}(2015)$ Reviewing the strength of evidence of biodiversity indicators for forest ecosystems in Europe. Ecol. Indic. 57:420-434

5. Marchetti M (2004) Monitoring and Indicators of Forest Biodiversity in Europe - From Ideas to Operationality

6. Oettel J, Lapin $\mathrm{K}$ (under rev. 2020) Linking forest management and biodiversity indicators to strengthen sustainable forest management in Europe. Ecol. Indic.

7. Smith GF et al. (2008) Identifying practical indicators of biodiversity for stand-level management of plantation forests. Biodivers. Conserv. 17:991-1015

8. WWF Austria (2018) coopMDD - Guidelines for a dynamic river corridor. http://www.interreg-danube.eu/uploads/media/approved project output/0001/24/c33bf56841c18e182014950ede42c8e58990d67d.pdf

9. WWF Austria (2019) LIFE14 NAT/HR/000115 - DRAVA LIFE Action A.5 Natura 2000 - Drava Management Strategy https://www.drava-life.hr/wp-content/uploads/2016/08/A.5-Drava-LIFE-Natura-2000-Drava-Management-Strategy-ENG-FINAL.pdf 
10. WWF Austria (2019) LIFE14 NAT/HR/000115 -DRAVA LIFE / Action A.7 Action plan for river birds. http://www.drava-life.hr/wp-content/uploads/2016/08/20190606_A.7_Drava_LIFE_Actionplan_riverbirds_EN_FINAL.pdf

\section{Optimization of the production of high-quality logs in hardwood stands}

1. Wilhelm GJW, Rieger H (2013) Naturnahe Waldwirtschaft mit der QD-Strategie. Ulmer Verlag, Stuttgart [in German]

\section{Challenges of climate change}

1. Alagador D, Cerdeira JO, Araújo MB (2014) Shifting protected areas: Scheduling spatial priorities under climate change. Journal of Applied Ecology 51(3) 703-713. https://doi.org/10.1111/1365-2664.12230

2. Alarcon D, Cavieres LA (2015) In the right place at the right time: Habitat representation in protected areas of South American Nothofagus-dominated plants after a dispersal constrained climate change scenario. PLoS ONE 10(3)

https://doi.org/10.1371/journal.pone.0119952

3. Araújo MB, Alagador D, Cabeza M et al. (2011) Climate change threatens European conservation areas. Ecology Letters 14(5) 484-492. https://doi.org/10.1111/i.1461-0248.2011.01610.x

4. Bolte A, Ammer C, Löf M et al. (2009) Adaptive forest management in central Europe: Climate change impacts, strategies and integrative concept. Scandinavian Journal of Forest Research. Taylor \& Francis Group. https://doi.org/10.1080/02827580903418224

5. CBD (2014) Global Biodiversity Outlook 4. A mid-term assessment of progress towards the implementation of the Strategic Plan for Biodiversity 2011-2020. CBD; PNUMA; ONU Montreal, Canada

6. Coetzee BWT, Robertson MP, Erasmus BFN et al. (2009) Ensemble models predict important bird areas in southern Africa will become less effective for conserving endemic birds under climate change. Global Ecology and Biogeography 18(6) 701-710. https://doi.org/10.1111/j.1466-8238.2009.00485.x

7. D’Amen M, Bombi P, Pearman PB et al. (2011) Will climate change reduce the efficacy of protected areas for amphibian conservation in Italy? Biological Conservation 144(3) 989-997. https://doi.org/10.1016/jibiocon.2010.11.004

8. Dudley N, Stolton S, Belokurov A et al. (2010) Natural solutions: protected areas helping people cope with climate change. Natural solutions: protected areas helping people cope with climate change.

9. Dybala KE, Matzek V, Gardali T, Seavy NE (2019) Carbon sequestration in riparian forests: A global synthesis and meta-analysis. Global change biology 25(1):57-67

10. Dyderski MK, Paź S, Frelich LE, Jagodziński AM (2018) How much does climate change threaten European forest tree species distributions? Global Change Biology 24(3) 1150-1163.https://doi.org/10.1111/gcb.13925

11. EEA (2020) Climate change. European Environment Agency

12. FOREST EUROPE (2015) State of Europe's Forests 2015. (p. 314)

13. Hannah L (2008) Protected areas and climate change. Annals of the New York Academy of Sciences. https://doi.org/10.1196/annals.1439.009

14. Hannah L, Midgley G, Andelman S et al. (2007) Protected area needs in a changing climate. Front Ecol Environ 5 131-138. https://doi.org/10.1890/1540-9295(2007)5[131:paniac]2.0.co

15. Hewitson B, Janetos AC, Carter TR et al. (2014) In: Climate Change 2014: Impacts, Adaptation, and Vulnerability. Part B: Regional Aspects. Contribution of Working Group II to the Fifth Assessment Report of the Intergovernmental Panel on Climate Change 1133-1197 Europe, 1199, 1266.

16. Hole DG, Willis SG, Pain DJ et al. (2009) Projected impacts of climate change on a continent-wide protected area network. Ecology Letters 12(5) 420-431. https://doi.org/10.1111/j.1461-0248.2009.01297.x

17. Jactel H, Desprez-Loustau M-L, Battisti A et al. (2020) Pathologists and entomologists must join forces against forest pest and pathogen invasions. NeoBiota 58107

18. Jactel H, Poeydebat C, van Halder I, Castagneyrol B (2019) Interactive Effects of Tree Mixing and Drought on a Primary Forest Pest. Frontiers in Forests and Global Change https://doi.org/10.3389/ffgc.2019.00077

19. Johnston A, Ausden M, Dodd AM et al. (2013) Observed and predicted effects of climate change on species abundance in protected areas. Nature Climate Change 3(12) 1055-1061. https://doi.org/10.1038/nclimate2035

20. Osipova E, Shadie P, Zwahlen C et al. (2017) IUCN world heritage outlook 2: a conservation assessment of all natural world heritage sites. IUCN, Gland.

21. Pureswaran DS, Roques A, Battisti A (2018) Forest Insects and Climate Change. Curr Forestry Rep 4 35-50. https://doi.org/10.1007/s40725-018-0075-6

22. Rodrigues ASL, Andelman SJ, Bakarr MI et al. (2004) Effectiveness of the global protected area network in representing species diversity. Nature 428 9-12. https://doi.org/10.1038/nature02459.1.

23. Sallmannshofer M, Chakraborty D, Vacik H et al. (2021) Continent-wide tree species distribution models may mislead regional management decisions without implementation of local site conditions. Regional Environmental Change. 
24. Seavy NE, Gardali T, Golet GH et al. (2009). Why climate change makes riparian restoration more important than ever: recommendations for practice and research. Ecological Restoration 27(3):330-338

25. Simler-Williamson AB, Rizzo DM, Cobb RC (2019) Interacting effects of global change on forest pest and pathogen dynamics. Annual Review of Ecology, Evolution, and Systematics 50:381-403

26. Sutfin NA, Wohl E (2019) Elevational differences in hydrogeomorphic disturbance regime influence sediment residence times within mountain river corridors. Nature Communications 10(1):1-14 https:// doi.org/10.1038/s41467-019-09864-W

27. Sutfin NA, Wohl EE, Dwire KA (2016) Banking carbon: a review of organic carbon storage and physical factors influencing retention in floodplains and riparian ecosystems. Earth Surface Processes and Landforms 41(1):38-60

28. Téllez-Valdés O, Dávila-Aranda P (2003) Protected areas and climate change: A case study of the cacti in the Tehuacán-Cuicatlán biosphere reserve, México. Conservation Biology 17(3) 846-853. https://doi.org/10.1046/j.1523-1739.2003.01622.X

\section{How to manage game and protect forests from damage}

1. Forstner M, Reimoser F, Lexer W et al. (2006) Sustainable Hunting Principles, Criteria and Indicators. Umweltbundesamt GmbH, Vienna, http://wildlife.reimoser.info/document/2006 Forstner $\% 20$ et $\% 20$ al. Sustainable $\% 20$ Hunting $\% 20-020$ Principles, $\% 20$ Criteria, $\% 20$ Indicators.pdf

\section{Management of non-native plants}

1. Ashton IW, Hyatt LA, Howe KM et al. (2005) Invasive species accelerate decomposition and litter nitrogen loss in a mixed deciduous forest. Ecological Applications 15(4) 1263-1272. https://doi.org/10.1890/04-0741

2. Biró M, Molnár Z, Öllerer K et al. (2020) Conservation and herding co-benefit from traditional extensive wetland grazing. Agriculture, Ecosystems and Environment 300 106983. https://doi.org/10.1016/j.agee.2020.106983

3. Brundu G, Richardson DM (2016) Planted forests and invasive alien trees in Europe: a code for managing existing and future plantings to mitigate the risk of negative impacts from invasions. NeoBiota 30 5-47. https://doi.org/10.3897/neobiota.30.7015

4. Clout MN, Williams PA (2009) Invasive species management: a handbook of principles and techniques. Oxford University Press

5. Csiszár Á, Korda M (2015) Practical experiences in invasive alien plant control. Budapest: Duna-Ipoly National Park Directorate. Rosalia Handbooks 3.

6. D'Antonio CM, Chambers JC (2006) Using ecological theory to manage or restore ecosystems affected by invasive plant species. In: Falk D, Palmer M, Zedler J (ed) Foundations of restoration ecology, Island Press, pp 260-279

7. Ducs A, Kazi A, Bilko A, Altbaecker V (2016) Milkweed control by food imprinted rabbits. Behavioural Processes $13075-80$. https://doi.org/10.1016/j.beproc.2016.07.012

8. Evans T, Kumschick S, Blackburn TM (2016) Application of the Environmental Impact Classification for Alien Taxa (EICAT) to a global assessment of alien bird impacts. Diversity and Distributions 22(9) 919-931

9. Foxcroft LC, Rouget M, Richardson DM (2007) Risk assessment of riparian plant invasions into protected areas. Conservation Biology 21(2) 412-421

10. Gaggini L, Rusterholz H-PP, Baur B (2018) The invasive plant Impatiens glandulifera affects soil fungal diversity and the bacterial community in forests. Applied Soil Ecology 124 335-343. https://doi.org/10.1016/j.apsoil.2017.11.021

11. GISD (2018) Global Invasive Species Database (GISD)

12. Hawkins CL, Bacher S, Essl F et al. (2015) Framework and guidelines for implementing the proposed IUCN Environmental Impact Classification for Alien Taxa (EICAT). Diversity and Distributions 21(11) 1360-1363

13. Heger T, Trepl L (2003). Predicting biological invasions. Biological invasions 5(4) 313-321

14. Heywood VH, Brunel S (2009) Code of conduct on horticulture and invasive alien plants. Council of Europe Publ., Strasbourg

15. Howe HF, Smallwood J (1982) Ecology of seed dispersal. Annual review of ecology and systematics 13(1) 201-228

16. Interreg Danube REFOCuS. (2021) DanubeForestHealth. Retrieved January 302021 https://danubeforesthealth.eu/

17. IUCN (2020) EICAT - Environmental Impact Classification of Alien Taxa.

18. IUCN-IAS (2020) Management of IAS.

19. Joly M, Bertrand P, Gbangou RY et al. (2011) Paving the way for invasive species: Road type and the spread of Common ragweed (Ambrosia artemisiifolia). Environmental Management 48(3) 514-522. https://doi.org/10.1007/s00267-011-9711-7

20. Knapp LB, Canham CD (2000) Invasion of an old-growth forest in New York by Ailanthus altissima: sapling growth and recruitment in canopy gaps. Journal of the Torrey Botanical Society 127(4) 307-315. https://doi.org/10.2307/3088649

21. Kowarik I (1992) Einführung und Ausbreitung nichteinheimischer Gehölzarten in Berlin und Brandenburg und ihre Folgen für Flora und Vegetation (p. 188). Verhandlungen des botanischen Vereins Berlin und Brandenburg.

22. Kumschick S, Measey GJ, Vimercati G et al. (2017) How repeatable is the Environmental Impact Classification of Alien Taxa (EICAT) ? Comparing independent global impact assessments of amphibians. Ecology and evolution 7(8) 2661-2670 
23. Langmaier M, Lapin K (2020) A Systematic Review of the Impact of Invasive Alien Plants on Forest Regeneration in European Temperate Forests. Front. Plant Sci. 11:524969. https://doi.org/10.3389/fpls.2020.524969

24. Lapin K (2017) Information on measures and related costs in relation to species included on the Union list: Asclepias syriaca. Technical note prepared by IUCN for the European Commission.

25. Lapin K, Oettel J, Steiner H et al. (2019) Invasive alien plant species in unmanaged forest reserves, Austria. NeoBiota 4871

26. Luigi Nimis P, Pittao E, Altobelli A et al. (2019) Mapping invasive plants with citizen science. A case study from Trieste (NE Italy). Plant Biosystems-An International Journal Dealing with all Aspects of Plant Biology 153(5) 700-709

27. Maschek O, Halmschlager E (2017) Natural distribution of Verticillium wilt on invasive Ailanthus altissima in eastern Austria and its potential for biocontrol. Forest Pathology 47(5) e12356.

28. Medvecká J, Jarolímek I, Hegedüšová K et al. (2018) Forest habitat invasions-Who with whom, where and why. Forest Ecology and Management 409 468-478

29. Muscolo A, Bagnato S, Sidari M, Mercurio R (2014) A review of the roles of forest canopy gaps. Journal of Forestry Research 25(4) 725-736. https://doi.org/10.1007/s11676-014-0521-7

30. Pagad S, Genovesi P, Carnevali L et al. (2015) IUCN SSC Invasive Species Specialist Group: invasive alien species information management supporting practitioners, policy makers and decision takers.

31. Petrášová M, Jarolímek I, Medvecká J (2013) Neophytes in Pannonian hardwood floodplain forests - History, present situation and trends. Forest Ecology and Management 308 31-39. https://doi.org/10.1016/j.foreco.2013.07.041

32. Potgieter LJ, Gaertner M, O’Farrell PJ, Richardson DM (2019) Perceptions of impact: Invasive alien plants in the urban environment. Journal of environmental management 229 76-87. https://doi.org/10.1016/j.jenvman.2018.05.080

33. Pötzelsberger E, Lapin K, Brundu G et al. (2020) Mapping the patchy legislative landscape of non-native tree species in Europe. Forestry 93(4) 1-21. https://doi.org/10.1093/forestry/cpaa009

34. Pysek P, Prach K (1993) Plant Invasions and the Role of Riparian Habitats: A Comparison of Four Species Alien to Central Europe. Journal of Biogeography 20 413-420. https://doi.org/10.2307/2845589

35. Pyšek P, Richardson DM, Rejmánek M et al. (2004) Alien plants in checklists and floras: towards better communication between taxonomists and ecologists. Taxon 53(1) 131-143

36. Rahmonov O (2009) The chemical composition of plant litter of black locust (Robinia pseudoacacia L.) and its ecological role in sandy ecosystems. Acta Ecologica Sinica 29(4) 237-243. https:// doi.org/10.1016/i.chnaes.2009.08.006

37. Regulation E. U. (2014). Regulation (EU) No 1143/2014 of the European Parliament and of the Council of 22 October 2014 on the prevention and management of the introduction and spread of invasive alien species. Official Journal of the European Union 57(317) 35

38. Richardson DM, Holmes PM, Esler KJ et al. (2007) Riparian vegetation: degradation, alien plant invasions, and restoration prospects. Diversity and Distributions 13(1) 126-139 https://doi.org/10.1111/j.1366-9516.2006.00314.x

39. Richardson DM, Pyšek P, Rejmánek M et al. (2000) Naturalization and invasion of alien plants: concepts and definitions. Diversity and distributions 6(2) 93-107

40. Rivers M, Beech E, Bazos I et al. (2019) European Red List of Trees. International Union for Conservation of Nature and Natural Resources (IUCN).

41. Roy H, Groom Q, Adriaens T et al. (2018) Increasing understanding of alien species through citizen science (Alien-CSI). Research Ideas and Outcomes 4 e31412

42. Roy HE, Bacher S, Essl F et al. (2019) Developing a list of invasive alien species likely to threaten biodiversity and ecosystems in the European Union. Global change biology 25(3) 1032-1048. https://doi.org/10.1111/gcb.14527

43. Roy HE, Rabitsch W, Scalera R et al. (2018) Developing a framework of minimum standards for the risk assessment of alien species. Journal of applied ecology 55(2) 526-538

44. Rusterholz H-P, Schneuwly J, Baur B (2018) Invasion of the alien shrub Prunus laurocerasus in suburban deciduous forests: Effects on native vegetation and soil properties. Acta Oecologica 92 44-51. https://doi.org/10.1016/j.actao.2018.08.004

45. Schmiedel D, Huth F, Wagner S (2013) Using data from seed-dispersal modelling to manage invasive tree species: The example of Fraxinus pennsylvanica Marshall in Europe. Environmental Management 52(4) 851-860. https://doi.org/10.1007/s00267-013-0135-4

46. Seebens H, Blackburn TM, Dyer EE et al. (2017) No saturation in the accumulation of alien species worldwide. Nature communications 8(1) 1-9

47. Shackleton RT, Biggs R, Richardson DM, Larson BMH (2018) Social-ecological drivers and impacts of invasion-related regime shifts: consequences for ecosystem services and human wellbeing. Environmental science \& policy 89 300-314 https://doi.org/10.1016/i.envsci.2018.08.005

48. Sitzia T, Campagnaro T, Kowarik I, Trentanovi G (2016) Using forest management to control invasive alien species: helping implement the new European regulation on invasive alien species. Biological invasions 18(1) 1-7

49. Szitár K, Török K (2008) Short-term effects of herbicide treatment on the vegetation of semiarid sandy oldfields invaded by Asclepias syriaca. L. In Extended abstract in the Proceedings of the 6th European Conference on Ecological Restoration 8-12 
50. Tanner R (2017) Information on measures and related costs in relation to species included on the Union list: Impatiens glandulifera. Technical note prepared by IUCN for the European Commission.

51. Thomsen PF, Willerslev E (2015) Environmental DNA-An emerging tool in conservation for monitoring past and present biodiversity. Biological conservation 183 4-18

52. Vilà M, Espinar JL, Hejda M et al. (2011) Ecological impacts of invasive alien plants: a meta-analysis of their effects on species, communities and ecosystems. Ecology letters 14(7) 702-708

53. Villamagna AM, Murphy BR (2010) Ecological and socio-economic impacts of invasive water hyacinth (Eichhornia crassipes): a review. Freshwater biology 55(2) 282-298 https://doi.org/10.1111/j.1365-2427.2009.02294.x

54. Woziwoda B, Krzyżanowska A, Dyderski MK et al. (2018) Propagule pressure, presence of roads, and microsite variability influence dispersal of introduced Quercus rubra in temperate Pinus sylvestris forest. Forest ecology and management $42835-45$. https://doi.org/10.1016/j.foreco.2018.06.033

\section{Integration of deadwood portions into regular management}

1. BAFU (2015) Maßnahmenbereich 2: Förderung von Alt- und Totholz. In Biodiversität im Wald: Ziele und Maßnahmen 57-74

2. Bayerische Staatsforsten. Naturschutzkonzept der Bayerischen Staatsforsten. (2009).

3. Bouget C, Larrieu L, Brin A (2014) Key features for saproxylic beetle diversity derived from rapid habitat assessment in temperate forests. Ecol. Indic. 36 656-664

4. Bouget C, Larrieu L, Nusillard B, Parmain G (2013) In search of the best local habitat drivers for saproxylic beetle diversity in temperate deciduous forests. Biodivers. Conserv. 22 2111-2130

5. Brassard BW, Chen HYH (2008) Effects of forest type and disturbance on diversity of coarse woody debris in boreal forest. Ecosystems 11 1078-1090

6. Bütler R, Lachat T (2009) Wälder ohne Bewirtschaftung: eine Chance für die saproxylische Biodiversität | Forests without harvesting: an opportunity for the saproxylic biodiversity. Schweizerische Zeitschrift fur Forstwes. 160 324-333

7. Cálix M et al. (2018) European Red List of Saproxylic Beetles. IUCN. https://portals.iucn.org/library/node/47296. Accessed 11 August 2020

8. Christensen M et al. (2005) Dead wood in European beech (Fagus sylvatica) forest reserves. For. Ecol. Manage. 210 267-282

9. Della Rocca F, Stefanelli S, Pasquaretta C et al. (2014) Effect of deadwood management on saproxylic beetle richness in the floodplain forests of northern Italy: Some measures for deadwood sustainable use. J. Insect Conserv. 18 121-136

10. Dittrich S, Jacob M, Bade C et al. (2014) The significance of deadwood for total bryophyte, lichen, and vascular plant diversity in an old-growth spruce forest. Plant Ecol. 215 1123-1137

11. Doerfler I, Müller J, Gossner MM et al. (2017) Success of a deadwood enrichment strategy in production forests depends on stand type and management intensity. For. Ecol. Manage. 400, 607-620

12. FOREST EUROPE (2015) State of Europe's Forests 2015.

13. ForstBW (Hrsg.). (2010) Alt- und Totholzkonzept Landesbetrieb ForstBW, Stuttgart

14. Franklin JF, Shugart HH, Harmon ME (2006) Tree Death as an Ecological Process. Bioscience $37550-556$

15. Fridman J, Walheim M (2000) Amount, structure, and dynamics of dead wood on managed forestland in Sweden. For. Ecol. Manage. $13123-36$

16. FSC (2018) International Generic Indicators

17. Gao T, Nielsen AB, Hedblom M (2015) Reviewing the strength of evidence of biodiversity indicators for forest ecosystems in Europe. Ecol. Indic. 57 420-434

18. Harmon ME. et al. (1986) Ecology of Coarse Woody Debris in Temperate Ecosystems. Adv. Ecol. Res. 15 133-263

19. Heinze B (2019) Progressive mortality of Fraxinus species in Austria caused by Ash-dieback, in the context of Europe. In BFW Praxisinfo 43 7-12

20. Helfenstein J, Kienast F (2014) Ecosystem service state and trends at the regional to national level: A rapid assessment. Ecol. Indic. $3611-18$

21. HorákJ, Kout J, Vodka Š, Donato DC (2016) Dead wood dependent organisms in one of the oldest protected forests of Europe: Investigating the contrasting effects of within-stand variation in a highly diversified environment. For. Ecol. Manage. $363229-236$

22. Humphrey J, Bailey S (2012) Managing deadwood in forests and woodlands. Forestry Commission Practice Guide

23. Humphrey JW et al. (2004) Deadwood as an Indicator of Biodiversity in European Forests: From Theory to Operational Guidance. In: Marchetti M (ed) Monitoring and Indicators of Forest Biodiversity in Europe - From Ideas to Operationality. EFI Proceedings 51 193-206

24. Kunttu P, Junninen K, Kouki J (2015) Dead wood as an indicator of forest naturalness: A comparison of methods. For. Ecol. Manage. 353 30-40

25. Lassauce A, Paillet Y, Jactel H, Bouget C (2011) Deadwood as a surrogate for forest biodiversity: Meta-analysis of correlations between deadwood volume and species richness of saproxylic organisms. Ecol. Indic. 11 1027-1039. 
26. Lindenmayer DB, Margules CR, Botkin DB (2000) Indicators of biodiversity for ecologically sustainable forest management. Conserv. Biol. 14 941-950

27. Lombardi F et al. (2010) Deadwood in Forest Stands Close To Old-Growthness Under Mediterranean Conditions in the Italian Peninsula. L'Italia For. e Mont. 65(5) 481 - 504 https://doi.org/10.4129/ifm.2010.5.02

28. Maser C, Trappe JM (1984) The Seen and Unseen World of the Fallen Tree the Seen and Unseen World of the Fallen Tree. General Technical Report PNW-164

29. Meyer P, Schmidt M (2011) Accumulation of dead wood in abandoned beech (Fagus sylvatica L.) forests in northwestern Germany. For. Ecol. Manage. $261342-352$

30. Miler AT, Dobroczyński M (2019) Results of floodplain forests protection in the Uroczysko Warta, the Wielkopolska region, Poland. Infrastruct. Ecol. Rural Areas II 7-24

31. Morrissey RC, Jenkins MA, Saunders MR (2014) Accumulation and connectivity of coarse woody debris in partial harvest and unmanaged relict forests. PLoS One 9

32. Müller J, Bütler R (2010) A review of habitat thresholds for dead wood: A baseline for management recommendations in European forests. Eur. J. For. Res. 129 981-992

33. Nagel TA et al. (2017) Evaluating the influence of integrative forest management on old-growth habitat structures in a temperate forest region. Biol. Conserv. 216 101-107

34. Oettel J et al. (2020) Patterns and drivers of deadwood volume and composition in different forest types of the Austrian natural forest reserves. For. Ecol. Manage. 463

35. Parisi F et al. (2015) Spatial patterns of saproxylic beetles in a relic silver fir forest (Central Italy), relationships with forest structure and biodiversity indicators. For. Ecol. Manage. 381 217-234

36. PEFC (2018) Sustainable forest management - Requirements. Sustainable forest management

37. Rimle A, Heiri C, Bugmann H (2017) Deadwood in Norway spruce dominated mountain forest reserves is characterized by large dimensions and advanced decomposition stages. For. Ecol. Manage. 404 174-183

38. Schuck A, Meyer P, Menke N et al. (2004) Forest Biodiversity Indicator: Dead Wood - A Proposed Approach towards Operationalising the MCPFE Indicator. In: Marchetti M (ed) Monitoring and Indicators of Forest Biodiversity in Europe - From Ideas to Operationality, pp 49-78

39. Seibold $S$ et al. (2015) Association of extinction risk of saproxylic beetles with ecological degradation of forests in Europe. Conserv. Biol. $29382-390$

40. Seibold S. et al. (2015) Experimental studies of dead-wood biodiversity - A review identifying global gaps in knowledge. Biol. Conserv. 191 139-149

41. Shorohova E, Kapitsa E (2015) Stand and landscape scale variability in the amount and diversity of coarse woody debris in primeval European boreal forests. For. Ecol. Manage. 356

42. Siitonen J (2001) Forest management, coarse woody debris and saproxylic organisms: Fennoscandian boreal forests as example. Ecol. Bull. 49 11-41

43. Siitonen J, Martikainen P, Punttila P, Rauh J (2000) Coarse woody debris and stand characteristics in mature managed and oldgrowth boreal mesic forests in southern Finland. For. Ecol. Manage. 128 211-225

44. Stürzenbaum K (2013) Potential effects of box elder control measures and vertical stratification of xylobiontic beetles in floodplain forests of the Donau-Auen National Park, Lower Austria. Diploma thesis. University Vienna https://doi.org/10.25365/ thesis.30147

45. Vandekerkhove K, De Keersmaeker L, Menke N et al. (2009) When nature takes over from man: Dead wood accumulation in previously managed oak and beech woodlands in North-western and Central Europe. For. Ecol. Manage. 258 425-435

46. Winter S (2012) Forest naturalness assessment as a component of biodiversity monitoring and conservation management. Forestry 85 291-304

47. Zielonka T (2006) Quantity and decay stages of coarse woody debris in old-growth subalpine spruce forests of the western Carpathians, Poland. Can. J. For. Res. 36 2614-2622

\section{Forest pests and diseases in a changing world: the importance of early detection}

1. Faccoli M (2015) European Bark and Ambrosia Beetles: Types, Characteristics and Identification of Mating Systems. WBA Handbooks 5, Verona

2. Kunca A, Zúbrik M, Csóka G (ed) (2013). Insects and Diseases Damaging Trees and Shrubs of Europe: A Colour Atlas. N. A. P.

3. Roques A, Cleary M, Matsiakh I, Eschen R (2017) Field guide for the identification of damage on woody sentinel plants. CABI Book. https://doi.org/10.1079/9781786394415.0000 


\section{Diseases of poplars and their hybrids with an emphasis on disease management recommendations}

1. Cellerino GP (1999) Review of fungal diseases in poplar. Food and Agriculture Organization of the United Nations. Rome AC492/E

2. Guzina V, Herpka I, Marinković P et al. (ed) (1986) Poplars and willows in Yugoslavia. Poplar Research Institute, Novi Sad, Yugoslavia.

3. Tóth T, Lakatos T, Koltay A (2013) Lonsdalea quercina subsp. populi subsp. nov., isolated from bark canker of poplar trees. Int. J. Syst. Evol. Microbiol. 63 2309-2313

4. Zlatković M, Tenorio-Baigorria I, Lakatos T et al. (2020) Bacterial canker disease of Populus $\times$ euramericana caused by Lonsdalea populi in Serbia. Forests 11(10) 1080. https://doi.org/10.3390/f11101080

\section{Oak decline - an example for a disease phenomenon characterized by various interacting causal agents}

1. Denman S, Brown N, Kirk S et al. (2014) A description of the symptoms of Acute Oak Decline in Britain and a comparative review on causes of similar disorders on oak in Europe. Forestry. Oxford University Press. https://doi.org/10.1093/forestry/cpu010

2. Denman S, Brown N, Kirk S et al. (2014). A description of the symptoms of Acute Oak Decline in Britain and a comparative review on causes of similar disorders on oak in Europe. Forestry 87 535-551. http://dx.doi.org/10.1093/forestry/cpu010

3. Forest Research UK (s. a.) Oak Decline. Tools and resources, Pest and disease resources, https://www.forestresearch.gov.uk/tools-and-resources/pest-and-disease-resources/oak-decline/Accessed 16 Oct. 2020

\section{Ash dieback as a major threat to riparian forest biodiversity}

1. Bartha B, Mayer A, Lenz HD (n.d.). Acceleration of Ash Petiole Decomposition to Reduce Hymenoscyphus fraxineus Apothecia Growth-a Feasible Method for the Deprivation of Fungal Substrate.

2. Enderle R, Bußkamp J, Metzler B (2017) Growth performance of dense natural regeneration of Fraxinus excelsior under attack of the ash dieback agent Hymenoscyphus fraxineus. Baltic Forestry, 23(1) 218-228

3. Grosdidier M, Scordia T, Ioos R, Marçais B (2020) Landscape epidemiology of ash dieback. Journal of Ecology 108(5) 17891799. https://doi.org/10.1111/1365-2745.13383

4. Havrdová L, Zahradník D, Romportl D et al. (2017) Environmental and Silvicultural Characteristics Influencing the Extent of Ash Dieback in Forest Stands. Baltic Forestry (Vol. 23).

5. Skovsgaard JP, Wilhelm GJ, Thomsen IM et al. (2017) Silvicultural strategies for Fraxinus excelsior in response to dieback caused by Hymenoscyphus fraxineus. Forestry: An International Journal of Forest Research 90(4) 455-472. https://doi.org/10.1093/forestry/cpx012

6. Timmermann V, Nagy NE, Hietala AM et al. (2017) Progression of ash dieback in Norway related to tree age, disease history and regional aspects. Baltic Forestry 23(1) 150-158

\section{Measures against the spread of Phytophthora in riparian forests}

1. Dalio RJD, Fleischmann F, Humez M, Osswald W (2014) Phosphite Protects Fagus sylvatica Seedlings towards Phytophthora plurivora via Local Toxicity, Priming and Facilitation of Pathogen Recognition. PLoS ONE 9(1) e87860.

https://doi.org/10.1371/journal.pone.0087860

2. Jung T, Blaschke M (2004) Phytophthora root and collar rot of alders in Bavaria: Distribution, modes of spread and possible management strategies. Plant Pathology 53(2) 197-208. https://doi.org/10.1111/j.0032-0862.2004.00957.x

3. Jung T, Orlikowski L, Henricot B et al. (2016) Widespread Phytophthora infestations in European nurseries put forest, seminatural and horticultural ecosystems at high risk of Phytophthora diseases. Forest Pathology 46(2) 134-163. https://doi.org/10.1111/ efp.12239

\section{Tree species portraits}

1. Barsig, M. (2004) Literaturrecherche. Vergleichende Untersuchungen zur ökologischen Wertigkeit von Hybrid- und Schwarzpappeln. Literarturstudie TU Berlin. 32 S, http://www.tu-berlin.de/fileadmin/f12/Downloads/kubus/30_Pappelvgl_Endfassung___.pdfaccessed 17.08.2020

2. Beck, P., Caudullo, G., Tinner, W., de Rigo, D. (2016) Fraxinus excelsior in Europa: Verbreitung, Lebensraum, Nutzung und Bedrohungen. In: San-Miguel-Ayanz, J., de Rigo, D., Caudullo, G., Houston Durrant, T., Mauri, A. (Eds.), European Atlas of Forest Tree Species. Publ. Off. EU, Luxemburg, pp. e0181c0+

3. BFW (2019) Österreichs Baumarten Fächer für unterwegs. Bundesforschungs- und Ausbildungszentrum für Wald, Naturgefahren und Landschaft Österreich (BFW), Wien. 
4. Binder, F. \& Hofmann, M. (2015) Hybridpappel (Populus x canadensis Mönch; Syn. Populus x euramericana Guinier). In: Vor, T.; Spellmann, H.; Bolte, A.; Ammer, C. (Hrsg.): Potenziale und Risiken eingeführter Baumarten. Baumartenportraits mit naturschutzfachlicher Bewertung. Göttinger Forstwissenschaften, Band 7, 155-166

5. Bohn, U., et al. (2000/2003) Karte der natürlichen Vegetation Europas / Map of the Natural Vegetation of Europe. Maßstab / Scale 1 : 2500 000. Münster (Landwirtschaftsverlag)

6. CAB International (2020) Robinia pseudoacacia (Schwarzheuschrecke). Datasheet. Invasive Species Compendium. https://www.cabi.org/isc/datasheet/47698, Zugriff am 06.08.2020

7. Carl, Christin (2018): Kurzportrait Robinie (Robinia pseudoacacia). https://www.waldwissen.net/waldwirtschaft/waldbau/wuh_robinie/index_DE, Zugriff am 11.08.2020

8. Caudullo, G. Houston Durrant, T. (2016) Fraxinus angustifolia in Europe: distribution, habitat, usage and threats. In: San-MiguelAyanz, J. de Rigo, D., Caudullo, G., Houston Durrant, T., Mauri, A. (Eds.), European Atlas of Forest Tree Species. Publ. Off. EU, Luxemburg, pp. e0101d2+

9. Caudullo, G., de Rigo, D. (2016) Ulmus - Ulmen in Europa: Verbreitung, Lebensraum, Nutzung und Bedrohungen. In: SanMiguel-Ayanz, J., de Rigo, D., Caudullo, G., Houston Durrant, T., Mauri, A. (Eds.), European Atlas of Forest Tree Species. Publ. Off. EU, Luxemburg, pp. e01bd40+

10. Caudullo, G., de Rigo, D. (2016) Populus alba in Europa: Verbreitung, Lebensraum, Nutzung und Bedrohungen. In: San-MiguelAyanz, J., de Rigo, D., Caudullo, G., Houston Durrant, T., Mauri, A. (Eds.), European Atlas of Forest Tree Species. Publ. Off. EU, Luxemburg, pp. e010368+

11. Collin, E. (2003) EUFORGEN Technical Guidelines for genetic conservation and use for European white elm (Ulmus laevis). International Plant Genetic Resources Institute, Rome, Italy. 6 pages

12. Cronk Q. Ruzzier E., Belyaeva I., Percy D. (2015) Salix transect of Europe: latitudinal patterns in willow diversity from Greece to arctic Norway. Biodiversity Data Journal 3: e6258. doi: 10.3897/BDJ.3.e6258

13. de Rigo, D., Enescu, C. M., Houston Durrant, T.,Caudullo, G. (2016) Populus nigra in Europe: distribution, habitat, use and threats. In: San-Miguel-Ayanz, J., de Rigo, D., Caudullo, G., Houston Durrant, T., Mauri, A. (Eds.), European Atlas of Forest Tree Species. Publ. Off. EU, Luxemburg, pp. e0182a4+

14. Duke, J. (1983) Handbook of Energy Crops. https://www.hort.purdue.edu/newcrop/duke energy/Alnus glutinosa.html, Zugriff am 12.08.2020

15. Enescu, C. M., Houston Durrant, T., de Rigo, D., Caudullo, G. (2016) Salix caprea in Europe: distribution, habitat, use and threats. In: San-Miguel-Ayanz, J., de Rigo, D., Caudullo, G., Houston Durrant, T., Mauri, A. (Eds.), European Atlas of Forest Tree Species. Publ. Off. EU, Luxemburg, pp. e01322d+

16. FRAXIGEN. 2005. Eschenarten in Europa: biologische Merkmale und praktische Richtlinien für eine nachhaltige Nutzung. Oxford Forestry Institute, University of Oxford, UK. 128 pp

17. Glenz, C; chlaepfer, R; Iorgulescu, I; Kienast, F. (2006) Flooding tolerance of Central European tree and shrub species, Forest Ecology and Management, Volume 235, Issues 1-3, Pages 1-13, ISSN 0378-1127, https://doi.org/10.1016/j.forec0.2006.05.065.

18. Global Invasive Species Database http://issg.org/database/species/ecology.asp?si=1669\&fr=1\&sts=\&lang=EN) - Zugriff am 20.07.2020

19. Heinze, B. (2016) Wasser.Wald: Auwaldbewirtschaftung zwischen Holzproduktion, neuen Schädlingen und Krankheiten sowie Naturschutz. BFW-Praxisinformation 40: 6-8,

https://www.waldwissen.net/wald/naturschutz/gewaesser/bfw_auwaldbewirtschaftung/index_DE/printerfriendly? accessed 17.08.2020

20. Houston Durrant, T., de Rigo, D., Caudullo, G. (2016) Salix alba in Europe: distribution, habitat, usage and threats. In: SanMiguel-Ayanz, J., de Rigo, D., Caudullo, G., Houston Durrant, T., Mauri, A. (Eds.), European Atlas of Forest Tree Species. Publ. Off. EU, Luxemburg, pp. e01153e+

21. 21. Houston Durrant, T., de Rigo, D., Caudullo, G., (2016) Alnus glutinosa in Europe: distribution, habitat, use and threats. In: San-Miguel-Ayanz, J., de Rigo, D., Caudullo, G., Houston Durrant, T., Mauri, A. (Eds.), European Atlas of Forest Tree Species. Publ. Off. EU, Luxemburg, pp. e01f3c0+

22. http://www.energiewald.org/?Daten_\%26amp\%3B_Fakten:Standort_und_Baumartenwahl, Zugriff 17.08.2020

23. Jaeger, C. (2008) Ökophysiologische Untersuchungen zur Hochwassertoleranz der Gemeine Esche (Fraxinus excelsiorL.) - Einfluss der Wurzelzonenhypoxie auf zentrale Parameter des C-Stoffwechsels. Fakultät für Forst- und Umweltwissenschaften,Albert-Ludwigs-Universit at Freiburg im Breisgau, Deutschland

24. Jaeger, C. (2009) Unterschiede im C-Stoffwechsel von Eschenarten und -provenienzen als Folge von Wurzelsauerstoffentzug durch Staunässe. Journal of Experimental Botany, Vol. 60, No. 15, pp. 4335-4345, 2009 doi:10.1093/jxb/erp268

25. Kajba D. und J. Gračan. (2003) EUFORGEN technical guidelines for genetic conservation and use for black alder (Alnus glutinosa). International Plant Genetic Resources Institute, Rome, Italy. 4 pages

26. Konrad, H. (Hrsg.) (2020) Esche in Not. http://www.esche-in-not.at/index.php/problematik, 10.07.2020

27. Kremer, D. et al. (2008) Distribution and management of black walnut (Juglans nigra L.) in Croatia. Periodicum Biologorum. VOL. 110, Nr. 4, 317-321 
28. Markus-Michalczyk, H. et al. (2014) Salt intrusion in tidal wetlands: Salt intrusion in tidal wetlands: European willow species tolerate oligohaline conditions. Estuarine, Coastal and Shelf Science, Band 136, S. 35-42. doi 10.1016/j.ecss.2013.11.008

29. Mühlethaler, U. (2010): Eine Baumart gibt zu diskutieren. Mit Robinie in die Zukunft - oder den Neophyten bekämpfen? Wald Holz 91, 6: 35-38. https://www.waldwissen.net/waldwirtschaft/waldbau/wsl robinie/index DE, accessed 11.08.2020

30. Nicolescu, V., Rédei, K., Vor, T. et al. (2020) A review of black walnut (Juglans nigra L.) ecology and management in Europe. Trees. https://doi.org/10.1007/s00468-020-01988-7

31. Palancean, I., Alba, N., Sabatti, M. und de Vries, S.M.G. (2018) EUFORGEN technical guidelines for genetic conservation and use for white poplar (Populus alba), European Forest Institute. 6 pages.

32. Pliûra, A.; Heuertz, M. (2003) EUFORGEN technical guidelines for genetic conservation and use for common ash (Fraxinus excelsior), International Plant Genetic Resources Institute, Rome, Italy. 6 pages.

33. Rédei, K.; Keserü, ZS.; Csiha, I.; Rásó, J.; Honfy, V. (2017) Plantagen-Waldbau von Robinie (Robinia pseudoacacia L.) Kultivaren in Ungarn - Eine Übersicht. South-east Eur for 8 (2): 151-156. DOI: https://doi.org/10.15177/seefor:17-11

34. Rédei, K.; Takács, M.; Kiss, T. \& Keserü, Z. (2019) Ecology and Management of Black Walnut (Juglans nigra L.) in Hungary. South-east Eur for 10 (2): 187-191. DOI: https://doi.org/10.15177/seefor.19-12

35. Russell, K. (2003) EUFORGEN technical Guidelines for genetic conservation and use for wild cherry (Prunus avium). International Plant Genetic Resources Institute, Rome, Italy. 6 pages.

36. Schütt, P., Weisgerber, H., Lang, U. M., Roloff, A., Stimm, B. (2006) Enzyklopädie der Holzgewächse - Handbuch und Atlas der Dendrologie. ecomed Medizin, Verlagsgruppe Hüthig Jehle Rehm GmbH, Landsberg am Lech.

37. Sitzia, T., Cierjacks, A., de Rigo, D., Caudullo, G. (2016) Robinia pseudoacacia in Europa: Verbreitung, Lebensraum, Nutzung und Bedrohungen. In: San-Miguel-Ayanz, J., de Rigo, D., Caudullo, G., Houston Durrant, T., Mauri, A. (Eds.), European Atlas of Forest Tree Species. Publ. Off. EU, Luxemburg, pp. e014e79+

38. Starfinger, U. \& Kowarik, I. (2011) Populus x canadensis. In: Arten-Handbuch - Portraits wichtiger invasiver und potenziell invasiver Pflanzen- und Tierarten. Bundesamt für Naturschutz. Neobiota.de. https://neobiota.bfn.de/handbuch/gefaesspflanzen/populus-x-canadensis.html Accessed 17.08.2020

39. Valenta, V., Moser, D., Kapeller, S. \& Essl, F. (2016) Ein neuer Forstschädling in Europa: A review of Emerald ash borer (Agrilus planipennis) invasion. Journal of Applied Entomology. 10.1111/jen.12369.

40. Vanden Broeck, A. (2003) EUFORGEN technical guidelines for genetic conservation and use for European black poplar (Populus nigra). International Plant Genetic Resources Institute, Rome, Italy. 6 pages.

41. Vítková, M. et al. (2016) Black locust (Robinia pseudoacacia) beloved and despised: A story of an invasive tree in Central Europe. Forest Ecology and Management. 384 (2017) 287-302. http://dx.doi.org/10.1016/i.foreco.2016.10.057

42. Walentowski H., Falk W., Mette T., Kunz J., Bräuning A., Meinardus C., Zang Ch., Sutcliffe L., Leuschner Ch., (2017) Assessing future suitability of tree species under climate change by multiple methods: a case study in southern Germany. Ann. For. Res. 60(1): 101-126.

43. Ward, J.V. et al. (2002) Riverine landscape diversity. Freshwater Biology, Band 47, 4th edition. https://doi.org/10.1046/j.1365-2427.2002.00893.x

44. Welk, E., de Rigo, D., Caudullo, G. (2016) Prunus avium in Europe: distribution, habitat, usage and threats. In: San-MiguelAyanz, J., de Rigo, D., Caudullo, G., Houston Durrant, T., Mauri, A. (Eds.), European Atlas of Forest Tree Species. Publ. Off. EU, Luxemburg, pp. e01491d+

45. Williams, R.D. () Juglans nigra L. - Black Walnut. U.S. Department of Agriculture, Forest Service. https://www.srs.fs.usda.gov/pubs/misc/ag_654/volume_2/juglans/nigra.htm, Zugriff am 06.08.2020

46. Ziemiańska, M. \& Kalbarczyk, R. (2018) Biometrics of tree-ring widths of (Populus X canadensis Moench) and their dependence on precipitation and air temperature in south-western Poland. In: Holzforschung 63(1):2018(1)

\section{Glossary}

1. Finkeldey R (1993) Die Bedeutung allelischer Profile für die Konservierung genetischer Ressourcen bei Waldbäumen. Goett. Forstgenet. Bericht 14:176p.

2. FRAXIGEN (2005) Ash species in Europe: biological characteristics and practical guidelines for sustainable use. Oxford Forestry Institute, University of Oxford, UK

3. Rohmeder E (1972) Das Saatgut in der Forstwirtschaft. Parey Verlag, Berlin

4. Vidaković M (n.d.). Četinjače - morfologija i varijabilnost. Biblioteka znanstvenih radova, JAZU, Sveučilišna naklada Liber, Zagreb. 




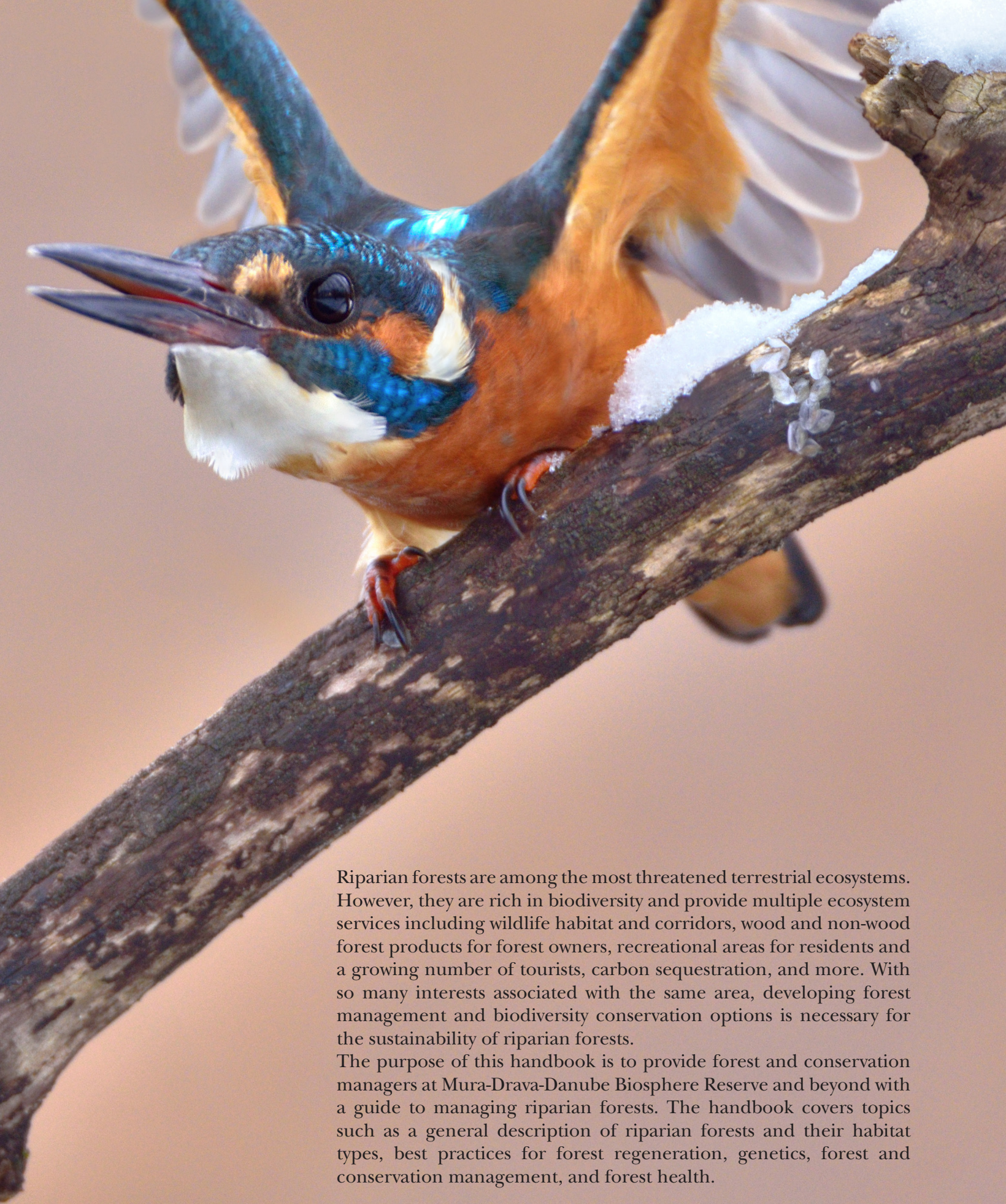

